\title{
Amino acids, ammonia and exercise in man
}

Citation for published version (APA):

van Hall, G. (1996). Amino acids, ammonia and exercise in man. [Doctoral Thesis, Maastricht University]. Universiteit Maastricht. https://doi.org/10.26481/dis.19960913gh

Document status and date:

Published: 01/01/1996

DOI:

10.26481/dis.19960913gh

Document Version:

Publisher's PDF, also known as Version of record

\section{Please check the document version of this publication:}

- A submitted manuscript is the version of the article upon submission and before peer-review. There can be important differences between the submitted version and the official published version of record.

People interested in the research are advised to contact the author for the final version of the publication, or visit the DOI to the publisher's website.

- The final author version and the galley proof are versions of the publication after peer review.

- The final published version features the final layout of the paper including the volume, issue and page numbers.

Link to publication

\footnotetext{
General rights rights.

- You may freely distribute the URL identifying the publication in the public portal. please follow below link for the End User Agreement:

www.umlib.nl/taverne-license

Take down policy

If you believe that this document breaches copyright please contact us at:

repository@maastrichtuniversity.nl

providing details and we will investigate your claim.
}

Copyright and moral rights for the publications made accessible in the public portal are retained by the authors and/or other copyright owners and it is a condition of accessing publications that users recognise and abide by the legal requirements associated with these

- Users may download and print one copy of any publication from the public portal for the purpose of private study or research.

- You may not further distribute the material or use it for any profit-making activity or commercial gain

If the publication is distributed under the terms of Article $25 \mathrm{fa}$ of the Dutch Copyright Act, indicated by the "Taverne" license above, 
Amino acids, ammonia and exercise in man 
. 


\title{
Amino acids, ammonia and exercise in man
}

\author{
PROEFSCHRIFT \\ ter verkrijging van de graad van doctor \\ aan de Rijksuniversiteit Limburg te Maastricht, \\ op gezag van de Rector Magnificus, Prof. mr. Cohen, \\ volgens het besluit van het college van Dekanen, \\ in het openbaar te verdedigen \\ op vrijdag 13 september 1996 om 16.00 uur
}

door

Gerrit van Hall

geboren op 3 maart 1964 te Doetinchem 
Promotores:

Prof. dr. ir. W.H.M. Saris

Prof. dr. B. Saltin (University of Copenhagen)

Co-promotor:

Dr. A.J.M. Wagenmakers

Beoordelingscommissie: Prof. dr. G.J. van der Vusse, voorzitter Prof. R.L. Terjung (State University of New York)

Prof. dr. H. Kuipers

Dr. H.A. Keizer

Dr A. de Haan (Universiteit van Amsterdam)

Part of the research presented in this thesis was supported by a Isostar Research Grant from Sandoz Nutrition, Bem, Switzerland and the Wallenberg Foundation, Sweden. 
Aan mijn ouders 


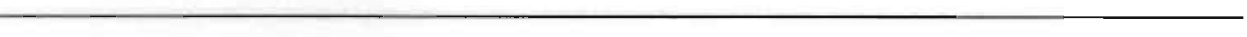




\section{Contents}

Page

Chapter 1 General introduction 9

1.1 Amino acid metabolism in skeletal muscle 10

1.2 The relation between ammonia production and amino acid metabolism during exercise 13

1.3 Interaction of BCAA metabolism and the tricarboxylic acid cycle 15

1.4 Potential role of BCAA in central fatigue 16

1.5 Potential effect of glutamine on glycogen synthesis in liver and muscle

$\begin{array}{ll}1.6 & \text { One legged exercise model } \\ 18\end{array}$

$\begin{array}{ll}1.7 \text { Outline and aims of the thesis } & 19\end{array}$

Chapter 2 Deamination of amino acids as a source for ammonia production in human skeletal muscle during prolonged exercise

Chapter 3 Mechanisms of activation of muscle branched-chain $\alpha$-keto acid dehydrogenase during exercise in man

Chapter 4 Muscle glycogen content, glycogenolytic rate and $\mathrm{K}^{+}$exchange during prolonged dynamic exercise

Chapter 5 Ingestion of banched-chain amino acids and tryptophan during sustained exercise - Failure to affect performance

Chapter 6 Effect of carbohydrate supplementation on plasma glutamine during prolonged exercise and recovery

Chapter 7 The effect of glutamine and peptide ingestion on the rate of muscle glycogen resynthesis in man

Chapter 8 Muscle protein degradation during prolonged on leg cycle exercise in man

Chapter 9 General discussion

9.1 Muscle ammonia production during prolonged exercise 118

9.2 Carbohydrate availability and amino acid and ammonia metabolism during prolonged exercise

9.3 Interaction of amino acids and the TCA-cycle 122

9.4 Directions for future research 


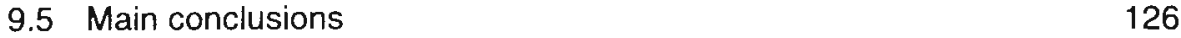

$\begin{array}{lr}\text { Summary } & 129\end{array}$

$\begin{array}{lr}\text { Samenvatting } & 133\end{array}$

$\begin{array}{lr}\text { Abbreviations } & 137\end{array}$

$\begin{array}{lr}\text { Dankwoord } & 139\end{array}$

$\begin{array}{ll}\text { Curriculum vitea } & 141\end{array}$ 


\section{Chapter}

\section{General introduction}

Skeletal muscle accounts for 40 to $50 \%$ of total body mass of a lean $70 \mathrm{~kg}$ subject. At rest energy expenditure is low as skeletal muscle needs less energy compared to organs such as liver, gut and kidney. However, exercise causes a dramatic increase in muscle energy expenditure. ATP the universal energy donor is then not only required to maintain normal cell function but there is a tremendous ATP demand for contraction. The energy for the increased rate of ATP resynthesis can be derived from carbohydrates, fat and protein. In the 1840 s the German physiologist von Liebig proposed that protein was the major fuel used during physical exercise. He suggested that industrial workers had to ingest large amounts of protein to replenish protein lost during muscular work. However, in the 1800's and early 1900's more and more studies indicated that carbohydrates and fat were the major fuels during exercise and that nitrogen losses in the urine did not substantially increase during and after moderate intensity exercise. Although it now is generally accepted that amino acids are not important as a fuel during exercise, they deserve attention as they might have an important regulatory role in skeletal muscle metabolism both at rest and during exercise. In this first chapter an overview will be given of the general knowledge of muscle amino acid metabolism and its regulatory roles in muscle and whole body metabolism in man (section $1.1-1.5$ ). One leg exercise is used in several of the investigations in this thesis. In section 1.6 the advantages and limitations of the one leg knee-extensor exercise model for studies of muscle metabolism will be summarized. In section 1.7 the outline of this thesis and the aims of the individual investigations will be presented. 


\subsection{Amino acid metabolism in skeletal muscle}

The major pool of nitrogen is in the form of amino acids in various proteins in the body (about $12 \mathrm{~kg}$ in a $70 \mathrm{~kg}$ man). The pool second in size is the intracellular free amino acid pool (about $200 \mathrm{~g}$ ) while less than $5 \mathrm{~g}$ of free amino acids are present in the blood. Quantitatively, muscle constitutes the largest reservoir of protein and of amino acids present in the free form. In the postabsorptive state in man amino acids are released from muscle, particularly glutamine and alanine (Marliss, Aoki, Pozefsky, Most \& Cahill, 1971; Felig \& Wahren, 1971; Felig, 1975; Wahren, Felig \& Hagenfeldt, 1976). Glutamine and alanine together account for $60-80 \%$ of the amino acids released by muscle, while their occurrence in muscle protein is approximately $24 \%$ (Clowes, Randall \& Cha, 1980. This implies that there is de novo synthesis of these amino acids in muscle. Carbon skeletons for glutamine production have been shown to be derived from other amino acids that are metabolized in muscle specifically the branched-chain amino acids (BCAA), glutamate and aspartate (Chang \& Goldberg, 1978; Wagenmakers, Salden \& Veerkamp, 1985; Lee \& Davis, 1986; Yoshida, Lanza-Jacobs \& Stein, 1991), while Krebs (1975) suggested that glucose and muscle glycogen also contributed part of the carbon skeletons for glutamine production. The carbon skeletons for alanine production have been shown to be primarily derived from blood born glucose and muscle glycogen (Odessey, Khairallah \& Goldberg, 1974; Spydevold, 1976; Chang \& Goldberg, 1978). The $\alpha-$ amino groups for glutamine and alanine synthesis were suggested to be derived from the BCAA, glutamate and aspartate. Studies with [ $\left.{ }^{15} \mathrm{~N}\right]$-leucine have shown that the amino group of the BCAA is indeed incorporated in humans in vivo in the $\alpha$-amino group of glutamine (Darmaun \& Déchelotte, 1991) and alanine (Galim, Hruska, Bier, Matthews \& Haymond, 1980; Haymond \& Miles, 1982). The source of the [5-15N] amide group is not known.

Ingestion of a large steak by overnight fasted and rested men causes a large uptake of BCAA across the forearm and a doubling of the release of glutamine (Elia \& Livesey, 1983), while alanine output was reduced to $10 \%$ of the postabsorptive value. Similar data, though with less suppression of alanine output, were obtained after oral ingestion of leucine (Aoki, Brennan, Fitzpatrick \& Knight, 1981), intravenous infusion of leucine in humans (Elia \& Livesey, 1983; Abumrad, Robinson, Gooch \& Lacey, 1982) and ingestion of a mixed meal (Elia, Schlatmann, Goran \& Austin, 1989). These data suggest that glutamine, not alanine, is the major nitrogen carrier leaving the human limb after consumption of a protein containing meal.

During exercise an increase has been observed in the release of alanine (Ahlborg, Felig, Hagenfeldt, Hendler \& Wahren, 1974; Eriksson et al, 1985; Sahlin, Katz \& Broberg, 1990) and glutamine (Eriksson et al, 1985) (Fig. 1). For this increase in alanine and glutamine synthesis more $\alpha$-amino groups are needed. During prolonged exercise an increase of the splanchnic release of BCAA was observed and an increased BCAA uptake by the active muscle (Ahlborg et al, 1974). Furthermore, the activity of the branched-chain $\alpha$-keto acid dehydrogenase (BCKADH), the enzyme catalyzing the rate limiting step in BCAA oxidation, was increased several fold in man during sustained moderate intensity exercise (Wagenmakers, Brookes, 
Coakley, Reilly \& Edwards, 1989). This could imply that during prolonged exercise the increased oxidation of the BCAA might provide the nitrogen for the augmented glutamine and alanine synthesis. The source of the increased glutamine and alanine output during brief incremental exercise is not known.

The increase in muscle alanine production in the postabsorptive state and during exercise led to the formulation of the glucose-alanine cycle (Felig, Pozefsky, Marliss \& Cahill, 1970). In this cycle, which is analogous to the Cori cycle for lactate, alanine is
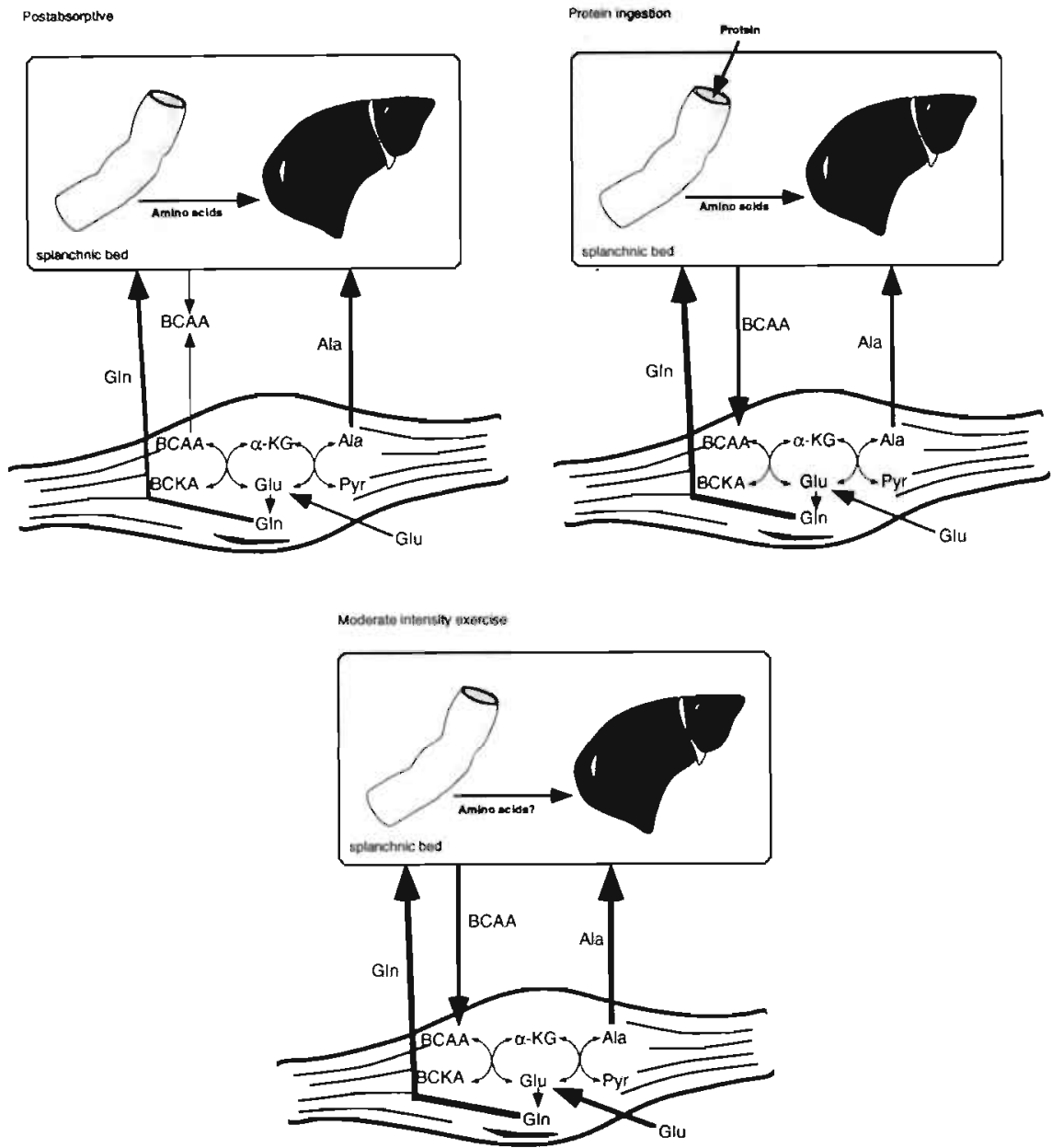

Figure 1. Amino acid exchange between the splanchnic bed and skeletal muscle. Based on data from Ahlborg et al, 1974; Wahren et al, 1976; Eriksson et al, 1985; Elia et al, 1989 and Sahlin et al, 1990. 
synthesized in muscle by transamination of glucose derived pyruvate and released into the bloodstream and taken up by the liver. In the liver the carbon skeleton of alanine is reconverted to glucose and released into the bloodstream where it is available for uptake by muscle and synthesis of alanine. Thus, in circumstances in which glycogen stores are depleted such as starvation and during prolonged exercise towards exhaustion, glucose output is dependent on gluconeogenesis and, therefore, alanine availability has been suggested to be important for the maintenance of blood glucose (Felig et al, 1970).

The gluiamine concentration in skeletal muscle is very high $( \pm 20 \mathrm{mM}$, about $60 \%$ of the free amino acid pool in muscle) and skeletal muscle contains most of the glutamine stored in the human body. Furthermore, skeletal muscle is thought to be the most important tissue in glutamine production (Golden, Jahoor \& Jackson, 1982). In tracer studies it has been suggested that 70-90 gram of glutamine is transported from muscle to central tissues every $24 \mathrm{~h}$ (Darmaun, Matthews \& Bier, 1986). Estimates of leg arterio-venous differences across the leg amount to 10-30 gram of glutamine being released from muscle each day (Wahren, Felig \& Hagenfeldt, 1976; Eriksson, Broberg, Björkman \& Wahren, 1985). This very high rate of glutamine transport between tissues indicates that glutamine plays an important role in human metabolism. Sir Hans Krebs in 1975 already speculated: "Maybe the significance of glutamine synthesis is to be sought in the role of glutamine in other organs, as a precursor of urinary ammonia and as a participant in the biosynthesis of purines, $\mathrm{NAD}^{+}$, amino sugars and proteins. Glutamine is an important blood constituent, present in higher concentrations than any other amino acid, presumably to serve these various functions. Muscle may play a role in maintaining the high plasma concentration of glutamine". Glutamine has been shown to be an important fuel for cells of the immune system (Newsholme, Newsholme \& Curi, 1987; Newsholme \& Parry-Billings, 1990) and for mucosal cells of the intestine (Windmueller \& Spaeth, 1980; Souba, 1991). it, furthermore, is a potential regulator of protein (MacLennan, Smith, Weryk, Watt \& Rennie, 1987), nucleotide (Newsholme \& Parry-Billings, 1990) and glycogen synthesis in muscle (Scislowski, Niblock, Lindsay, Weryk, Watt \& Rennie, 1989). A relative shortage of glutamine may lead to a derangement of intermediary metabolism and loss of organ functions especially in patients with trauma and sepsis (Rennie, Hundal, Babij, MacLennan, Taylor, Watt et al, 1986; Wilmore, Smith, O'Dwyer, Jacobs, Ziegler \& Wand, 1988).

Changes in muscle glutamine, glutamate and alanine concentration during exercise have been observed in several studies. Bergström, Fürst \& Hultman (1985) described a $25 \%$ increase in glutamine and a $60 \%$ increase in alanine during $10-20$ min of exercise at $70 \% \mathrm{VO}_{2 \max }$ whereas glutamate decreased with $65 \%$. At similar exercise intensity Sahlin et al (1990) observed a 10\% decrease in muscle glutamine and a 2 -fold increase in alanine and a $70 \%$ decrease in glutamate. Exhaustive exercise for 4 min at maximal oxygen uptake (Katz, Broberg, Sahlin \& Wahren, 1986) did not cause any change in glutamine but the decrease in glutamate and increase in alanine were identical as in the study of Sahlin et al (1990). Glutamate uptake by the muscle did not change with exercise (Sahlin et al, 1990), while others observed a 2or 3-fold increase (Eriksson et al, 1985; Katz et al, 1986). Leg alanine release 
increased during exercise 3-fold (Eriksson et al, 1985), 2.5-fold (Sahlin et al, 1990) and 6-fold (Katz et al, 1986). One aim of this thesis was to investigate the mechanisms leading to these changes in muscle amino acid concentrations and amino acid exchange.

\subsection{The relation between ammonia production and amino acid metabolism during exercise}

At rest ammonia is taken up by skeletal muscle. Voluntary short high intensity exercise or high frequency electrical stimulation leads to a considerable increase in muscle ammonia production. Under these conditions ammonia increases stoichiometrically with muscle IMP formation (Goodman \& Lowenstein, 1977). In 1991 it was generally accepted that during high intensity exercise ammonia is exclusively or mainly produced by deamination of AMP by the action of AMPdeaminase. The AMP-deaminase reaction is thought to be important to limit the increase in AMP concentration within the contracting muscle. This contributes to shift the myokinase reaction (2ADP <---> AMP + ATP) to the right, thereby maintaining a high muscle ATP content and a favorable muscle energy status. AMP, ADP and $\mathrm{H}^{+}$ have all been suggested to activate AMP-deaminase in contracting muscle (Wheeler \& Lowenstein, 1979). The AMP-deaminase reaction appears to be important as patients with inherited or acquired AMP-deaminase deficiency show exercise intolerance (Fishbein, 1985).

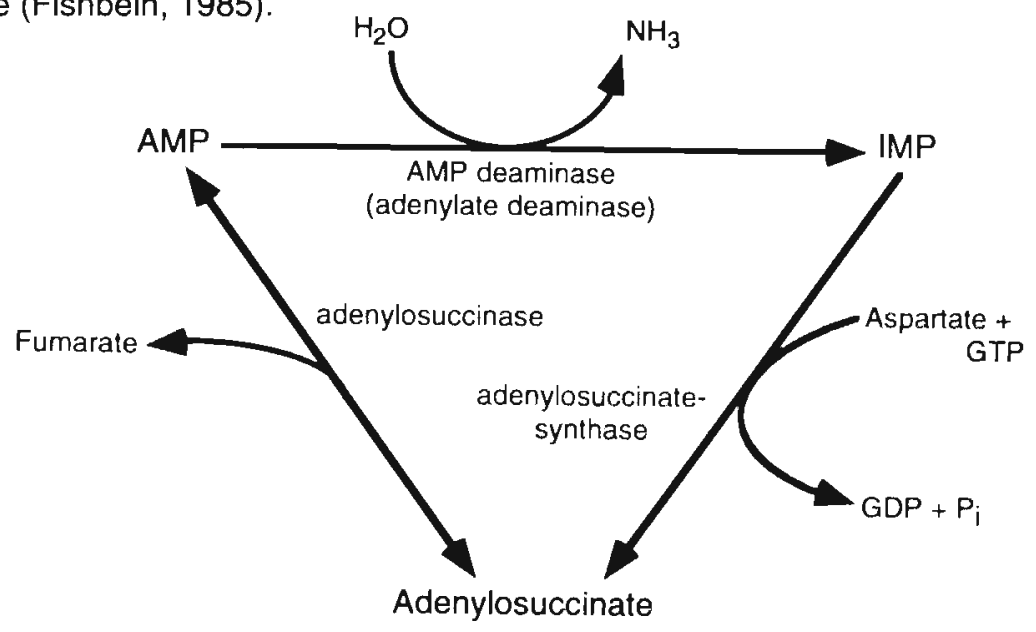

Figure 2. Schematic presentation of the purine nucleotide cycle.

Sustained dynamic moderate intensity exercise will cause no - or only a marginal increase in IMP formation whereas plasma ammonia is increased progressively with exercise duration (Norman, Sollevi, Kaiser \& Jansson, 1987; Wagenmakers, Beckers, Brouns, Kuipers, Soeters, Van der Vusse \& Saris, 1991). Furthermore, total 
muscle adenine nucleotide concentration remains nearly constant during prolonged exercise at moderate exercise intensity. This suggests that another source than net ATP breakdown is then responsible for ammonia production. It has been proposed that AMP-deaminase is active during prolonged exercise, with AMP being resynthesized in the purine nucleotide cycle (PN-cycle) (Broberg \& Sahlin, 1989) and, therefore, no net increase in muscle IMP concentration. One complete turn of the cycle results in the deamination of aspartate and the formation of ammonia and fumarate (Fig. 2). Via linked transaminase reactions the PN-cycle may also be used to deaminate other amino acids such as BCAA and glutamate (Goodman \& Lowenstein, 1977). Whether the PN-cycle is active during exercise was under debate in 1991. Meyer \& Terjung (1980) subjected rat gastrocnemius muscle to mild and intense electrical stimulation in the presence of hadacidin, an inhibitor of adenylosuccinate synthase. Hadacidin did not increase the muscle IMP concentration during mild and intense electrical stimulation. From this experiment they concluded that reamination of IMP only occurred following and not during exercise. This suggests that the IMP reamination arm of the PN-cycle is not an important pathway in the working rat muscle. However, it cannot be excluded that the PN-cycle is active during some forms of exercise in human muscle and is used for the net deamination of aspartate and other amino acids (Goodman \& Lowenstein, 1977). Other mechanisms that may be involved in net deamination of amino acids and ammonia

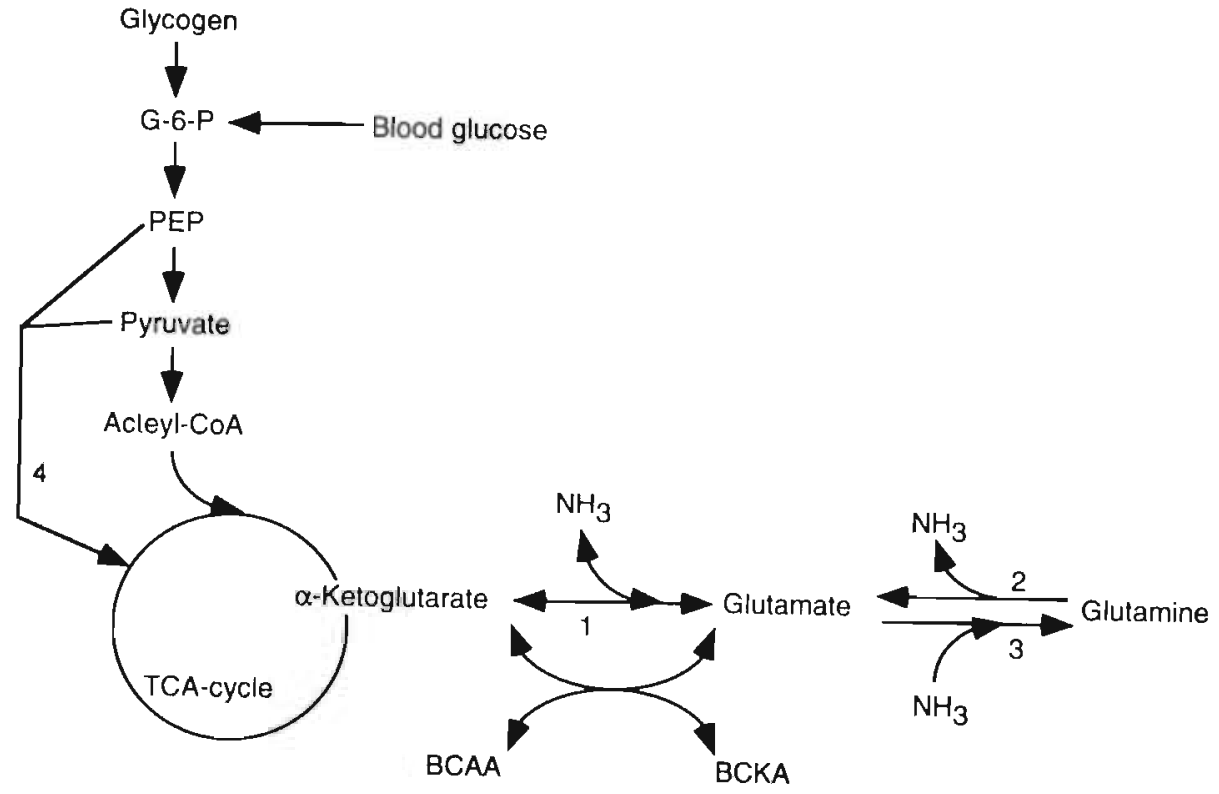

Figure 3. Reactions that may produced ammonia and lead to the synthesis of tricarboxylic acid cycle intermediates and glutamine.

1. glutamate dehydrogenase; 2 . glutaminase; 3 . glutamine synthetase; 4 . pyruvate carboxylase, phosphoenol pyruvate carboxykinase or NADP-specific malic enzyme. 
production are the glutamate dehydrogenase and glutaminase reaction. Glutamate dehydrogenase catalyses an equilibrium reaction and can function in ammonia production and fixation depending on the concentration of its substrates (Fig. 3). Furthermore, glutamate dehydrogenase can potentially be used to deaminate other amino acids as most transaminase reactions lead to glutamate production. Glutaminase activity is present in muscle homogenates but it is not clear whether it originates from muscle fibres, infiltrating inflammatory (Kelso, Shear \& Max, 1989) or endothelial cells (Leighton, Curi, Hussein \& Newsholme, 1987). Another aim of the studies in this thesis is to evaluate whether ammonia production during prolonged exercise originates from net deamination of amino acids or from ATP breakdown.

\subsection{I.teraction of BCAA metabolism and the tricarboxylic acid cycle}

The degradation routes of the BCAA imply that the metabolism of BCAA may have an impact on the level of tricarboxylic acid cycle, intermediates (TCAI) in muscle (Fig. 4). The activity of the branched-chain $\alpha$-keto acid dehydrogenase, the rate limiting enzyme in BCAA degradation, is increased during exercise (Wagenmakers et al, 1989, 1991). Valine and isoleucine, may form succinyl CoA. These amino acids, therefore, have been suggested to be potentially beneficial in supporting the function of the tricarboxylic acid cycle (TCA-cycle) during high rates of substrate oxidation in contracting muscle (Aragón, Tornheim, Goodman \& Lowenstein, 1974; Kasperek, Dohm \& Snider, 1985; Lee \& Davis, 1986). However, Wagenmakers and colleagues (1990) instead argued that BCAA degradation will not cause an increase in TCAl but cause a net drain on the TCA-cycle. The first step in BCAA degradation, the branched-chain amino acid aminotransferase reaction, uses $\alpha$-ketoglutarate as amino group acceptor and, therefore, may put a carbon drain on the TCA-cycle. Valine and isoleucine are metabolized to succinyl CoA, so that the level of intermediates would be maintained, if complete degradation of these amino acids takes place in muscle itself. On the other hand, if branched-chain $\alpha$-keto acids, branched-chain fatty acids and hydroxylated branched-chain fatty acids are released by muscle for further metabolism in liver and kidney as previously suggested (Wagenmakers et al, 1985; Lee \& Davis, 1986), then the net result would be a net drain on the TCA-cycle pool. Leucine metabolism is always coupled to net removal of TCAl, since its degradation only gives acetyl CoA and does not lead to synthesis of TCAI (Fig. 4). Therefore, the net result of an acceleration of the metabolism of the three BCAA must be a drain on the TCA-cycle, which must be compensated by other reactions to maintain the oxidative capacity of the muscle. Indirect evidence for a net draining effect of the BCAA aminotransferase reaction on the TCA-cycle has been obtained from a study with exercising patients with McArdle's disease (Wagenmakers et al, 1990). These patients are not able to use muscle glycogen as an energy source. In these patients a very rapid activation of the BCKADH was observed during exercise and supplementation of BCAA reduced exercise tolerance, whereas oral ingestion of branched-chain $\alpha$-keto acids (BCKA) had a positive effect on performance. Wagenmakers et al $(1990,1991)$, therefore, suggested that the 
increased oxidation of BCAA in glycogen depleted muscles limited the TCA-cycle activity and the maximal rates of fatty acid oxidation and played a role in fatigue mechanisms during prolonged exercise leading to glycogen depletion at intensities $\geq$ $60 \% W_{\max }$.

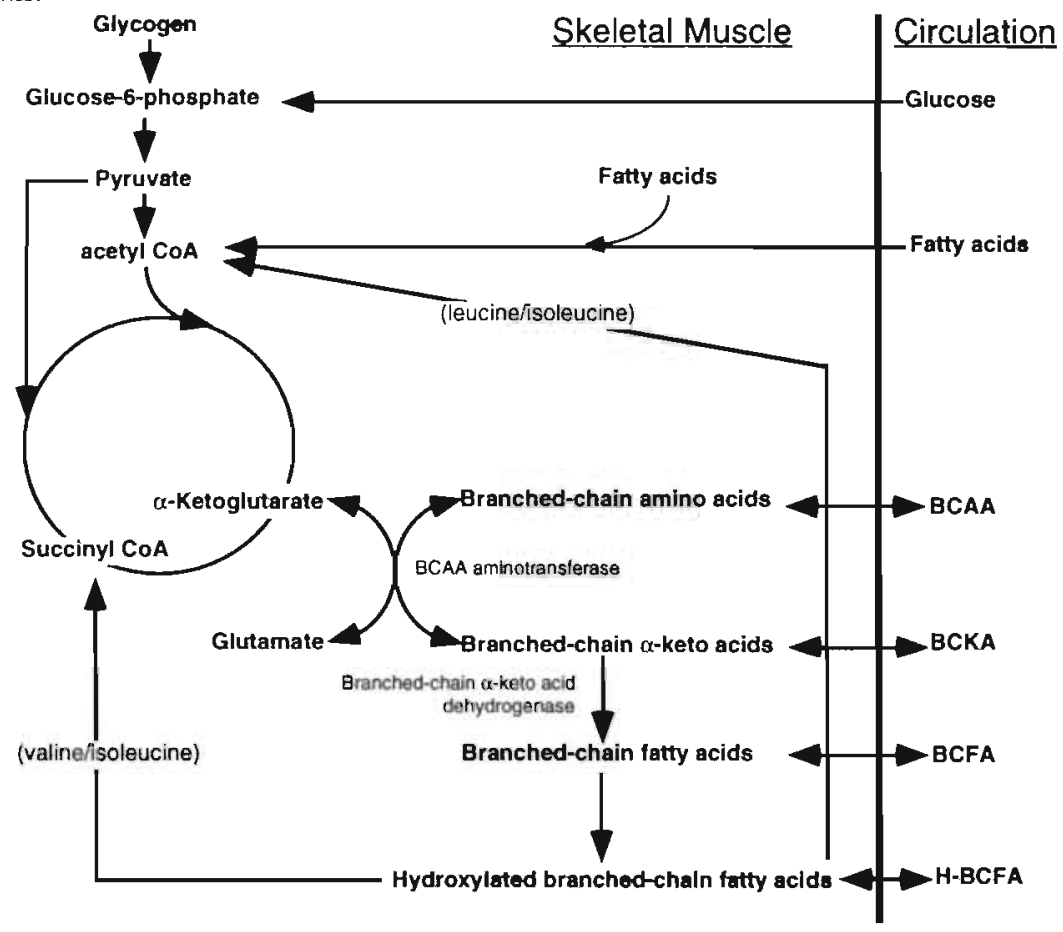

Figure 4. BCAA metabolism in the regulation of the level of tricarboxylic acid cycle intermediates in skeletal muscle. (Adapted from Wagenmakers \& Van Hall, 1996).

\subsection{Potential role of BCAA in central fatigue mechanisms}

Increased oxidation rates of BCAA during exercise (Kasperek, Dohm \& Snider, 1984; Wagenmakers et al, 1989; Wagenmakerset al, 1991) may lead to a decrease of the plasma BCAA concentration. In the 'central fatigue' hypothesis (Newsholme, Acworth \& Blomstrand, 1987) it is suggested that this decrease in plasma BCAA and the displacement of tryptophan from albumin by the increasing fatty acid concentration (Davis, Bailey, Woods, Galiano, Hamilton \& Bartoli, 1992) leads to an increase of the tryptophan/BCAA ratio. The increase in this ratio would lead to an increased tryptophan transport across the blood-brain barrier, since BCAA and tryptophan compete for entry by the large neutral amino acid transporter. Once taken up tryptophan conversion to 5-hydroxytryptamine would occur and lead to a local increase of this neurotransmitter (Knott \& Curzon, 1972; Chaouloff, Laude, 
Guezennec \& Elghozi, 1986) (Fig. 5). That this increase occurs during exercise in certain brain areas has been established in rat (Chaouloff et al, 1986), but not in man. The increase in serotoninergic activity would subsequently lead to 'central fatigue', forcing athletes to stop exercise or reduce pace or workload. One of the implications of the 'central fatigue' hypothesis is that ingestion of BCAA could reduce the exercise induced increase of brain tryptophan uptake and thus delay fatigue by giving athletes the ability to push on when peripheral fatigue mechanisms come into operation. This indeed has been suggested to be the case in a field study with marathon runners (Blomstrand, Hassmén, Ekblom \& Newsholme, 1991).

This implies that two contrasting hypothesis were put forward on the potential effect of BCAA supplements during exercise. One of these predicted that ingestion of BCAA during exercise would improve performance via a 'central' effect, while the other predicted that ingestion of BCAA would lead to premature muscle fatigue via a reduction of the activity of the TCA-cycle (Wagenmakers et al, 1990). Therefore, a third aim of these investigations was to investigate whether BCAA ingestion during prolonged exercise influences time to exhaustion.

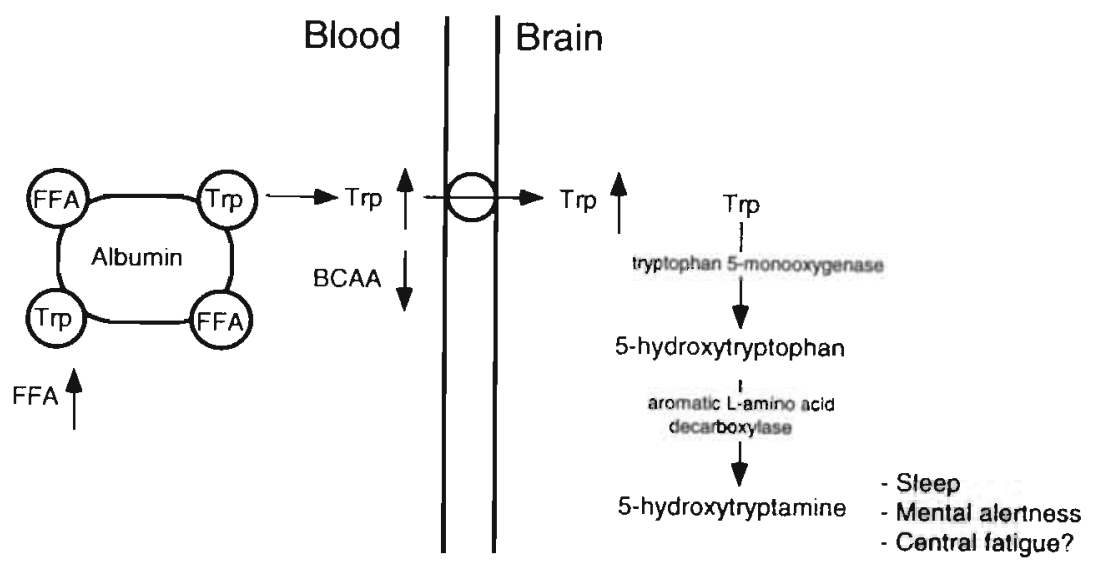

Figure 5. Schematic presentation of the central fatigue hypothesis during prolonged exercise.

\subsection{Potential effect of glutamine on glycogen synthesis in liver and muscle}

Glycogen is the most important stored energy source for skeletal muscle during moderate to high intensity exercise. The maintenance of muscle and liver glycogen stores during exercise and a high rate of glycogen resynthesis after exercise is very important for optimal performance. Glutamine was suggested to have a positive effect on glycogen synthesis in isolated rat EDL muscles via a stimulation of glycogen synthase (Scislowski, Niblock, Lindsay, Weryk, Watt \& Rennie, 1989). In isolated hepatocytes glutamine has also been shown to stimulate glycogen synthesis 
(Lavoinne, Baquet \& Hue, 1987) due to an activation of glycogen synthase, which in turn seemed to result from a stimulation of synthase phosphatase (Lavoinne et al, 1987). A fourth aim of these investigations was to evaluate whether glutamine ingestion following exercise may accelerate glycogen resynthesis in skeletal human muscle in vivo.

\subsection{One legged exercise model}

The one leg knee-extensor model has several advantages above cycle ergometer exercise or treadmill running for the quantitative measurement of metabolite consumption or production (Fig. 6). For such measurements the muscle mass involved in exercise, arterial and venous metabolite concentration, the blood flow and the changes in muscle metabolite concentrations should be known. It is easier to make measurements during exercise with the one leg knee-extensor than during two legged exercise (Andersen \& Saltin, 1985). The active muscle involved in one leg knee-extensor exercise is restricted to the quadriceps femoris. Very little or no electromyogram (EMG) activity was observed in other leg muscles (Andersen, Adams, Sjøgaard, Thorboe \& Saltin, 1985). The EMG activity in the quadriceps femoris increased linear with exercise intensity. Furthermore, when a cuff below the knee was inflated no reduction in exercise $\mathrm{O}_{2}$ uptake was observed and flow obstruction could be tolerated for many minutes, even during maximal power output. This indicates that the lower leg was only used as lever arm (Andersen et al,1985). The quadriceps femoris muscle mass involved in the exercise can be calculated accurately from thigh length, leg circumferences and leg skin folds (Andersen \& Saltin, 1985). Femoral arterio-venous blood samples and muscle biopsies are easy to obtain during one leg knee-extensor exercise compared to whole body exercise. During one leg knee-extensor exercise in the upright or supine position the subjects do not move their hips. Therefore, the catheters in the femoral artery and vein will hardly move, thereby, reducing the discomfort for the subjects and making it easy to take blood samples and to flush the catheters. Muscle biopsies can be taken without the necessity to let the subjects dismount the exercise device.

Using the one leg knee-extensor exercise model it is possible to selectively deplete muscle glycogen in one leg (see chapter 2 for details). Selective depletion of muscle glycogen leads to smaller changes in blood hormones than glycogen depletion during two legged exercise (Richter, Kiens, Saltin, Christensen \& Savard, 1988), while a comparison between metabolism in the normal and low glycogen leg can be made in the same hormonal milieu. During two legged exercise the hormonal milieu of the glycogen depleted state is different from the normal glycogen state. Therefore, the advantage of the one legged exercise model is that the effect of glycogen lowering on muscle amino acid and ammonia metabolism can be studied more independently of changes in hormonal milieu.

Maximal heart rate is around 140 during exercise with the one leg knee-extensor compared to 190 beats. in $^{-1}$ with whole body exercise. Maximal oxygen consumption of the approximately $3 \mathrm{~kg}$ of muscle involved in one leg knee-extensor 
exercise is about $800 \mathrm{ml}$ per min implying that maximal $\mathrm{O}_{2}$ consumption per $\mathrm{kg}$ of muscle per $\min$ is 2 - to 3 -fold higher than for whole body exercise (Welch \& Stainsby, 1967). This also implies that the metabolic rate of the active muscle during one leg knee-extensor exercise is higher than during whole body exercise and that changes in amino acid and ammonia metabolism per $\mathrm{kg}$ of muscle may be higher and easier to quantify.

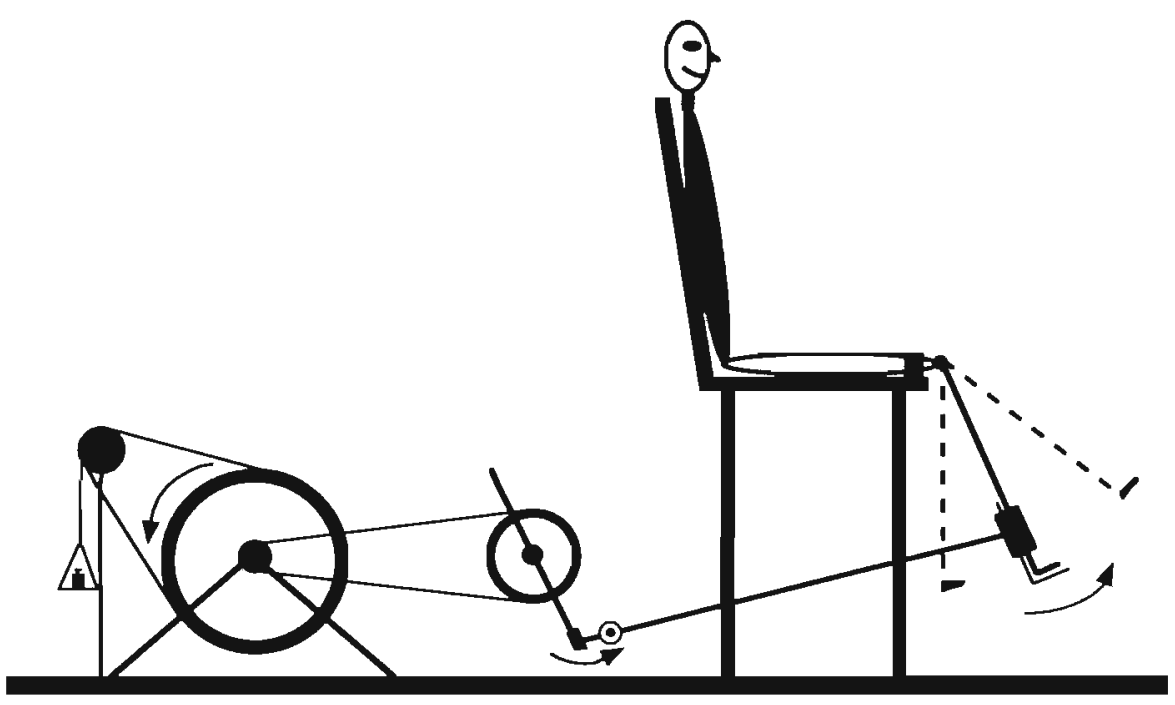

Figure 6. Schematic drawing of the one leg kneextensor ergometer.

The subject is kept in place by straps around the hip-joint and distal part of the upper leg. A rod attached to the ankle of the subject and to the crank of the cycle ergometer is used to transfer the movement of the lower leg to the wheel. Fly-wheel momentum returns the relaxed leg (Andersen \& Saltin, 1985).

\subsection{Outline and aims of the thesis}

All investigations in this thesis are performed on human subjects. In chapter 2 we investigate whether the ammonia production during prolonged one leg knee-extensor exercise can be attributed to net adenine nucleotide breakdown to IMP or to deamination of amino acids. Since it has been reported that ammonia production is increased when exercise is performed with low glycogen stores (Broberg \& Sahlin, 1989) we measure ammonia production during exercise with a normal and low glycogen content leg.

Our understanding of the regulation of the rate of BCAA degradation in human skeletal muscle at rest and during exercise is limited. In chapter 3 we investigate the effect of oral ingestion of BCAA and of a low and normal muscle glycogen 
concentration on the muscle exchange of BCAA and on the activation of the $\mathrm{BCKADH}$, the rate limiting enzyme in the degradation of the BCAA at rest and during exercise.

In chapter $\mathbf{4}$ we investigate whether the rate of glycogen breakdown in muscle is regulated by the same mechanisms during prolonged moderate intensity exercise than previously reported during high intensity exercise. We specifically investigate the time course of lactate and pyruvate release and whether positive correlations are seen between changes in muscle adenine nucleotides and ammonia concentrations as well as plasma catecholamine levels and the rate of glycogen breakdown during sustained exercise with a normal and a low muscle glycogen content.

One of the implications of the 'central fatigue' hypothesis of Newsholme and colleagues is that BCAA ingestion will improve performance. Another implication is that tryptophan ingestion will decrease performance. In chapter 5 we, therefore, measure performance during prolonged cycle exercise with oral ingestion of BCAA and tryptophan present in carbohydrate containing drinks in amounts that grossly increase the plasma concentration of these amino acids.

Glutamine is produced in skeletal muscle in considerable amounts at rest and during exercise. Muscle glycogen and blood glucose have been suggested to be carbon-chain precursors for glutamine production (Krebs, 1975) (Fig. 3). During prolonged exercise, however, muscle glycogen stores are diminished and glucose availability is reduced. We, therefore, investigate whether carbohydrate supplementation better maintains plasma glutamine concentration during intense prolonged exercise and recovery (Chapter 6 ).

Scislowski, Niblock, Lindsay, Weryk, Watt \& Rennie (1989) observed an increase in the rate of skeletal muscle glycogen synthesis and a higher glycogen synthase activity when isolated rat EDL muscles were incubated with glutamine. In chapter 7 the effect of glutamine supplementation on the in vivo rate of muscle glycogen resynthesis is investigated in the presence of glucose as a substrate for glycogen synthesis during recovery from prolonged exercise leading to glycogen depletion.

Net muscle protein degradation during exercise may provide extra BCAA for glutamine, alanine and ammonia production and may increase the potential carbon drain of the BCAA aminotransferase reaction on the TCA-cycle. In chapter 8 we, therefore, estimate protein degradation rates during prolonged exercise from the arterio-venous amino acid differences across the exercising leg and the blood flow.

In chapter 9 issues that could not be discussed in detail in chapter 2-8 will be fully elaborated or integrated making use of recent literature.

\section{References}

Abumrad, N.N., Robinson, R.P., Gooch, B.R. \& Lacey, W.W. (1982). The effect of leucine infusion on substrate flux across the human forearm. Journal of Surgical Research 32: 453-463.

Ahlborg, G., Felig, P., Hagenfeldt, L., Hendler, R. \& Wahren, J. (1974). Substrate turnover during prolonged exercise in man - Splanchnic and leg metabolism of glucose, free fatty acids, and amino acids -. Journal of Clinical Investigation 53: 1080-1090. 
Andersen, P., Adams, R.P., Sjøgaard, G., Thorboe, A. \& Saltin, B. (1985). Dynamic knee extension as a model for study of isolated exercising muscle in humans. Journal of Applied Physiology 59: $1647-1653$.

Andersen, P. \& Saltin, B. (1985). Maximal perfusion of skeletal muscle in man. Journal of Physiology 366: 233-249.

Aoki, T.T., Brennan, M.F., Fitzpatrick, G.F. \& Knight, D.C. (1981). Leucine meal increases glutamine and total nitrogen release from forearm muscle. Journal of Clinical Investigation 68: 1522-1528.

Aragón, J.J., Tornheim, K., Goodman, M.N. \& Lowenstein, J.M. (1981). Replenishment of citric acid cycle intermediates by the purine nucleotide cycle in rat skeletal muscle. Current Topics in Cellular Regulation 18: 131-149.

Baquet, A.L., Hue, L., Meyer, A.J., Van Woerkom, G.M. \& Plomp, P.J.A.M. (1990). Swelling of rat hepatocytes stimulates glycogen synthesis. Journal of Biological Chemistry 265: 955-959.

Bergström, J., Fürst, P. \& Hultman, E. (1985). Free amino acids in muscle tissue and plasma during exercise in man. Clinical Physiology 5: 155-160.

Blomstrand, E., Perret, D., Parry-Billings, M. \& Newsholme, E.A. (1989). Effect of sustained exercise on plasma amino acid concentrations and on 5-hydroxytryptamine metabolism in six different regions of the brain in the rat. Acta Physiologica Scandinavica 136: 473-481.

Blomstrand, E., Hassmén, P., Ekblom, B. \& Newsholme, E.A. (1991). Administration of branched chain amino acids during sustained exercise - effects on performance and on plasma concentration of some amino acids. European Journal of Applied Physiology 63: 83-88.

Broberg, S. \& Sahlin, K. (1989). Adenine nucleotide degradation in human skeletal muscle during prolonged exercise. Journal of Applied Physiology 67: 116-122.

Chang, T.W. \& Goldberg, A.L. (1978). The metabolic fates of amino acids and the formation of glutamine in skeletal muscle. Journal of Biological Chemistry 253: 3685-3695.

Chang, T.W. \& Goldberg, A.L. (1978). The origin of alanine produced in skeletal muscle. Journal of Biological Chemistry 253: 3677-3684.

Chaouloff, F., Laude, D., Guezennec, Y. \& Elghozi, J.L. (1986). Motor activity increases tryptophan, 5 hydroxyindoleacetic acid, and homovanillic acid in ventricular cerebrospinal fluid of the conscious rat. Journal of Neurochemistry 46:1313-1316.

Clowes, G.H.A., Randall, H.T. \& Cha, C.-J. (1980). Amino acid and energy metabolism in septic and traumatized patients. Journal of Parenteral and Enteral Nutrition 4: 195-205.

Darmaun, D., Matthews, D.E. \& Bier, D.M. (1986). Glutamine and glutamate kinetics in humans. American Journal of Physiology 251: E117-E126.

Darmaun, D. \& Déchelotte, P. (1991). Role of leucine as a precursor of glutamine $\alpha$-amino nitrogen in vivo in humans. American Journal of Physiology 260: E326-E329.

Davis, J.M., Bailey, S.P., Woods, J.A., Galiano, F.J., Hamilton, M.T. \& Bartoli, W.P. (1992). Effects of carbohydrate feedings on plasma free tryptophan and branched-chain amino acids during prolonged cycling. European Journal of Applied Physiology 65: 513-519.

Elia, M. \& Livesey, G. (1983). Effects of ingested steak and infused leucine on forearm metabolism in man and the fate of amino acids in healthy subjects. Clinical Science 64: 517-526.

Elia, M., Schiatmann, A., Goren, A. \& Austin, S. (1989). Amino acid metabolism in muscle and in the whole body of man before and after ingestion of a single mixed meal. American Joumal of Clinical Nutrition 49: 1203-1210.

Eriksson, L.S., Broberg, S., Björkman, O. \& Wahren, J. (1985). Ammonia metabolism during exercise in man. Clinical Physiology 5: 325-336.

Felig, P. \& Wahren, J. (1971). Amino acid metabolism in exercising man. Journal of Clinical Investigation 50: 2703-2714.

Felig, P., Pozeisky, T., Marliss, E. \& Cahill, G.F. (1970). Alanine: key role in gluconeogenesis. Science 167: 1003-1004.

Felig, P. (1975). Amino acid metabolism in man. Annual Reviews of Biochemistry 44: 933-955.

Fishbein, W.N. (1985). Myoadenylate deaminase deficiency: inherited and acquired forms. Biochemical Medicine 33: 158-169. 
Galim, E.B., Hruska, K., Bier, D.M., Matthews, D.E. \& Haymond, M.W. (1980). Branched-chain amino acid nitrogen transfer to alanine in vivo in dogs. Joumal of Clinical Investigation 66: 1295-1304.

Goldberg, A.L. \& Chang, T.W. (1978). Regulation and significance of amino acid metabolism in skeletal muscle. Federation Proceedings 37: 2301-2307.

Golden, M.H.N., Jahoor, P. \& Jackson, A.A. (1982). Glutamine production rate and its contribution to urinary ammonia in nomal man. Clinical Science 62: 299-305.

Goodman, T.E. \& Lowenstein, J.M. (1977). The purine nucleotide cycle. Studies of ammonia production by skeletal muscle in situ and in perfused preparations. Journal of Biological Chemistry 252: 5054-5060.

Haymond, M.W. \& Mile, J.M. (1982). Branched-chain amino acids as a major source of alanine nitrogen in man. Diabetes 31: 86-91.

Kasperek, G.J., Dohm, G.L. \& Snider, R.D. (1985). Activation of branched-chain keto acid dehydrogenase by exercise. American Journal of Physiology 248: R166-R171.

Katz, A., Broberg, S., Sahlin, K. \& Wahren, J. (1986). Muscle ammonia and amino acid metabolism during dynamic exercise in man. Clinical Physiology 6 : 365-379.

Knott, P.J. \& Curzon, G. (1972). Free tryptophan in plasma and brain tryptophan metabolism. Nature 239: 452-453.

Kelso, T.B., Shear, C.R. \& Max, S.R. (1989). Enzymes of glutamine metabolism in inflammation associated with skeletal muscle hypertrophy. American Journal of Physiology 257: E885-E894.

Krebs, H.A. (1975). The role of chemical equilibria in organ function. Advances in Enzyme Regulation 15: $449 \cdot 472$.

Lacey, J.M. \& Wilmore, D.W. (1990). Is glutamine a conditionally essential amino acid? Nutrition Reviews 48: 297-309.

Lavoinne, A., Baquet, A. \& Hue, L. (1987). Stimulation of glycogen synthesis and lipogenesis by glutamine in isolated rat hepatocytes. Biochemical Journal 248: 429-437.

Lee, S.-H. \& Davis, E.J. (1986). Carboxylation and decarboxylation reactions. Anaplerotic flux and removal of citrate cycle intermediates in skeletal muscle. Journal of Biological Chemistry 254: 420430.

Leighton, B., Curi, R., Hussein, A. \& Newsholme, E.A. (1987). Maximum activities of some key enzymes of glycolysis, glutaminolysis, Krebs cycle and fatty acid utilization in bovine pulmonary endothelial cells. FEBS Letters 225: 93-96.

MacLennan, P.A., Smith, K., Weryck, B., Watt, P.W. \& Rennie, M.J. (1987). Inhibition of protein breakdown by glutamine in perfused rat skeletal muscle. FEBS letters 237: 133-136.

Marliss, E.B., Aoki, T.T., Pozefsky, T., Most, A.S. \& Cahill, G.F. (1971). Muscle and splanchnic glutamine and glutamate metabolism in postabsorptive and starved man. Journal of Clinical Investigation 50: 814-817.

Meyer, R.A. \& Terjung, R.L. (1980). AMP deamination and IMP reamination in working skeletal muscle. American Journal of Physiology 239: C32-C38.

Newsholme, E.A., Acworth, I.N. \& Blomstrand, E. (1987). Amino acids, brain neurotransmitters and a functional link between muscle and brain that is important in sustained exercise. In Advances in myochemistry, ed. Benzi G., pp. 127-138. John Libbey Eurotext, London.

Newsholme, E.A. \& Parry-Billings, M. (1990). Properties of glutamine release from muscle and its importance for the immune system. Journal of Parenteral and Enteral Nutrition 14: 63S-67S.

Norman, B., Sollevi, A., Kaijser, L. \& Jansson, E. (1987). ATP breakdown products in human skeletal muscle during prolonged exercise to exhaustion. Clinical Physiology 7: 503-509.

Odessey, A., Khairallah, E.A. \& Goldberg, A.L. (1974). Origin and possible significance of alanine production by skeletal muscle. Journal of Biological Chemistry 249: 7623-7623.

Rennie, M.J., Edwards, R.H.T., Krywawych, S., Davies, C.T.M., Halliday, D., Waterlow, J.C. \& Millward, D.J. (1981). Effect of exercise on protein turnover in man. Clinical Science 61: 627-639.

Rennie, M.J., Hundal, H.S., Babij, P., MacLennan, P., Taylor, P.M., Watt, P.W., Jepson, M.M. \& Millward, D.J. (1986). Characteristics of a glutamine carrier in skeletal muscle have important consequences for nitrogen loss in injury, infection, and chronic disease. Lancet 11: 1008-1011. 
Richter, E.A., Kiens, B., Saltin, B., Christensen N.J. \& Savard, G. (1988). Skeletal muscle glucose uptake during dynamic exercise in humans: role of muscle mass. American Journal of Physiology 254: E555-E561.

Sahlin, K., Katz, A. \& Broberg, S. (1990). Tricarboxylic acid cycle intermediates in human muscle during prolonged exercise. American Journal of Physiology 259: C834-C841.

Scislowski, P.W.D., Niblock, A., Lindsay, Y., Weryk, B., Watt, P.W. \& Rennie, M.J. (1989). Glutamine simulates glycogen synthesis in skeletal muscle. Clinical Nutrition (Suppl) 8: 97.

Spydevold, $\oslash$ (1976). Sources of carbon skeletons of alanine released from skeletal muscle Acta Physiologica Scandinavica 97: 273-280.

Souba, W.W. (1991). Glutamine; a key substrate for the splanchnic bed. Annual Reviews of Nutrition 11: $285-308$.

Wagenmakers, A.J.M., Salden, H.J.M. \& Veerkamp, J.H. (1985). The metabolic fate of branched-chain amino acids and 2-oxo acids in rat muscle homogenates and diaphragms. International Journal of Biochemistry 17: 957-962.

Wagenmakers, A.J.M., Brooks, J.H., Coakley, J.H., Reilly, T. \& Edwards, R.H.T. (1989). Exercise induced activation of branched-chain 2-oxo acid dehydrogenase in human muscle. European Journal of Applied Physiology 59: 159-167.

Wagenmakers, A.J.M., Coakley, J.H. \& Edwards, R.H.T. (1990). Metabolism of branched-chain amino acids and ammonia during exercise: clues from McArdle's disease. International Journal of Sports Medicine 11: S101-S113.

Wagenmakers, A.J.M., Beckers, E.J., Brouns, F., Kuipers, H., Soeters, P.B., Van der Vusse, G.J. \& Saris, W.H.M. (1991). Carbohydrate supplementation, glycogen depletion, and amino acid metabolism during exercise. American Journal of Physiology 260: E883-E890.

Wagenmakers, A.J.M. \& Van Hall, G. (1996). Branched-chain amino acids - Nutrition and metabolism in exercise. In Biochemistry of exercise IX conference proceedings, ed. Maughan, R.J., in press, Human Kinetics

Wahren, J., Felig, P. \& Hagenfeldt, L. (1976). Effect of protein ingestion on splanchnic and leg metabolism in normal man and patients with Diabetes Mellitus. Journal of Clinical Investigation 57: 987-999.

Welch, H.G. \& Stainsby, W.N. (1967). Oxygen debt in contracting dog skeletal muscle in situ. Respiratory Physiology 3: 229-242.

Wheeler, T.J. \& Lowenstein, J.M. (1979). Adenylate deaminase from muscle. Regulation by purine nucleotides and orthophosphate in the presence of $150 \mathrm{mM} \mathrm{KCl}$. Journal of Biological Chemistry 254: 8894-8899.

Wilmore, D.W., Smith, R.J., O'Dwyer, S.T., Jacobs, D.O., Ziegler, T.R. \& Wang, X-D. (1988). The gut: A central organ after surgical stress. Surgeny 104: 917-923.

Windmueller, H.G. \& Spaeth, A.E. (1980). Respiratory fuels and nitrogen metabolism in vivo in small intestine of fed rats. Quantitative importance of glutamine, glutamate and aspartate. Journal of Biological Chemistry 255: 107-112. 


\title{
Chapter 2
}

\section{Deamination of amino acids as a source for ammonia production in human skeletal muscle during prolonged exercise}

\author{
G. van Hall, B. Saltin*, G.J. van der Vusse, K. Söderlund\$, A.J.M. Wagenmakers \\ University of Limburg, Maastricht, The Netherlands; "CMRC, Copenhagen, Denmark; \$Karolinska \\ Institute, Stockholm, Sweden.
}

Journal of Physiology 489: 251-261, 1995.

\begin{abstract}
1. The influence of pre-exercise muscle glycogen content on ammonia production, adenine nucleotide breakdown and amino acid metabolism was investigated during prolonged exercise in six subjects having one leg with a normal and one leg with a low muscle glycogen content. One leg knee-extensor exercise was performed for $90 \mathrm{~min}$ at a workload of $60-65 \%$ of the maximal power output first with one leg and then with the other leg.

2. During exercise ammonia was released in gradually increasing amounts and plateaued after $1 \mathrm{~h}$ exercise at a rate of approximately $80 \mu \mathrm{mol} \cdot \mathrm{min}^{-1}$. The total ammonia production is was $9.1 \pm 0.4$ and $9.5 \pm 1.4 \mathrm{mmol} \mathrm{kg}^{-1}$ dry muscle in the normal and low glycogen content leg, respectively.

3. Levels of muscle phosphocreatine (PC), total adenine nucleotides and inosine monophosphate (IMP) were similar at rest and after $90 \mathrm{~min}$ of exercise.

4. Only minor differences were observed between rest and exercise and between legs for the muscle concentration of glutamine, alanine and the branched-chain amino acids. Muscle glutamate concentration decreased by $60-70 \%$ within the first 10 min of exercise. Glutamate consumption over 90 min quantitatively equaled ammonia production. Most of the glutamate was consumed within the first $10 \mathrm{~min}$ of exercise, while ammonia production gradually increased during exercise. Therefore deamination of glutamate cannot be the main source of ammonia production during the later stage of exercise.

5. It is concluded that during prolonged one leg exercise at moderate intensity: a) ammonia production is not affected by pre-exercise muscle glycogen content; b) ammonia production exceeds by far the breakdown of adenine nucleotides to IMP and therefore has to be derived from alternative sources; c) deamination of amino acids is a likely source of ammonia production during prolonged exercise.
\end{abstract}




\section{INTRODUCTION}

Ammonia is produced by skeletal muscle during short intense and prolonged sub maximal exercise. Ammonia production during brief intense exercise has been suggested to be caused primarily or solely by the net breakdown of adenine nucleotides to IMP in the AMP-deaminase reaction (Meyer \& Terjung, 1979; Meyer, Dudley \& Terjung, 1980; Katz, Broberg, Sahlin \& Wahren, 1986a; Katz, Sahlin \& Henriksson, 1986b). Under these conditions the rate of ATP hydrolysis exceeds the rate of ADP rephosphorylation. Removal of AMP by deamination then functions to stabilize the relative ratios of ATP to ADP and AMP by favoring ATP production in the myokinase reaction (2ADP <---> AMP + ATP). Net ammonia and IMP production have been reported to be stoichiometric to the decrease in muscle adenine nucleotides during brief intense exercise (Meyer \& Terjung, 1979; Meyer et al, 1980; Katz et al, 1986a) suggesting that the contribution of other sources is insignificant. A different situation may exist during prolonged exercise at moderate intensity $(50-75 \%$ $\left.\mathrm{VO}_{2 \max }\right)$. The decrease in muscle total adenine nucleotides and increase in IMP is much smaller than during high intensity exercise (Norman, Sollevi, Kaijser \& Jansson, 1987; Wagenmakers, Beckers, Brouns, Kuipers, Soeters, Van der Vusse et al, 1991; MacLean, Spriet, Hultman \& Graham, 1991) while gradual increases were seen in plasma concentrations of ammonia (Graham, Pedersen \& Saltin, 1987; Graham, Kiens, Hargreaves \& Richter, 1991; Wagenmakers et al, 1991; MacLean et al, 1991) and muscle ammonia release (Broberg \& Sahlin, 1989; Graham et al, 1991). Furthermore, ammonia production in patients with McArdle's disease (myophosphorylase deficiency; a glycogen breakdown defect in muscle) exceeded by far the estimates of total adenine nucleotide breakdown (Wagenmakers, Coakley \& Edwards, 1990). It was suggested that another source, that is deamination of amino acids, contributes to ammonia production during prolonged exercise (Graham et al, 1987; Wagenmakers et al, 1990; Wagenmakers et al, 1991; MacLean et al, 1991).

Suggestions have been made that a reduction of the muscle glycogen content increases the muscle ammonia production during prolonged exercise. Broberg \& Sahlin (1989) observed an increased production rate of ammonia when a previous exercise bout had lowered the muscle glycogen stores. Wagenmakers et al (1991) observed a more rapid increase in plasma ammonia concentration when subjects were studied during exercise at $70 \%$ of $W_{\max }$ after glycogen depletion than during carbohydrate ingestion. Two explanations have been given for an increase of ammonia production in glycogen depleted muscles. Broberg \& Sahlin (1989) suggested that the reduced availability of glycogen promotes net breakdown of adenine nucleotides to IMP. Wagenmakers et al $(1990,1991)$ hypothesized that the carbon atoms of glycogen are converted to TCA-cycle intermediates, glutamate and than glutamine. In the last reaction ammonia is fixed to glutamate via the glutamine synthase reaction. Glycogen depletion may reduce the availability of carbon precursors for glutamine synthesis and result in an increased net ammonia production.

The present study was, therefore, undertaken to investigate whether ammonia production can be explained by adenine nucleotide breakdown during prolonged 
exercise with normal and low muscle glycogen stores in healthy human subjects. To this event subjects were submitted to a glycogen depletion protocol in one leg the night before the experiment, such that they had one normal and one low glycogen leg on the day of the experiment. Ammonia and amino acid exchange were measured during 90 min of one leg knee-extensor exercise at moderate intensity, starting at random with the normal and low glycogen leg. Concentrations of ammonia, amino acids and adenine nucleotides in muscle were measured before and after 10 and 90 min of exercise.

\section{METHODS}

\section{Subjects}

Six healthy male volunteers participated in the study. Their mean age, weight, height, and maximal one leg power output were $25 \pm 2 \mathrm{yr}, 77 \pm 4 \mathrm{~kg}, 1.80 \pm 0.04 \mathrm{~m}$ and $64 \pm$ 5 Watt. All subjects were healthy and physically active and participated regularly in leisure sport. The subjects were informed about possible risks and discomfort involved in this experiment before giving their voluntary consent to participate. The study was approved by the Ethical Committee of the Karolinska Institute.

\section{Protocol}

Subjects performed one leg exercise in the upright position on an ergometer that permits the exercise to be confined to the quadriceps femoralis muscle group (Andersen \& Saltin, 1985). Three days before the actual experiment subjects performed a graded exercise test to determine their maximal one leg power output $\left(W_{\max }\right)$. The exercise protocol consisted of $90 \mathrm{~min}$ one leg knee-extensor exercise at a workload of $60-65 \% W_{\max }$. After the $90 \mathrm{~min}$ of exercise the subjects were not completely exhausted, but experienced moderate to intense exertion localized in the exercised leg. The subjects were studied under two experimental conditions, with a normal and a low glycogen content of the quadriceps femoralis muscle. The two tests were performed on one day. In the morning subjects started at random with the normal or low glycogen content leg and in the afternoon with the other leg after a resting period of $2 \mathrm{~h}$. In order to obtain one normal and one low glycogen content leg the subjects had to undergo a glycogen depletion protocol on the evening before the actual test. On the experimental day subjects reported to the laboratory in the morning. Catheters for blood sampling were placed in the femoral artery and vein in the inguinal region of the leg to be exercised and advanced with the tip placed 5-6 $\mathrm{cm}$ proximal to the inguinal ligament. A thermistor was inserted through the venous catheter for blood flow measurements by the constant infusion thermodilution technique (Andersen \& Saltin, 1985). After placement of the catheters the subjects rested for $\mathbf{3 0} \mathrm{min}$ in the supine position. During the resting period between the two tests a femoral venous catheter was placed in the leg to be exercised in the afternoon. Local anesthesia was applied to the skin and percutaneous incisions were made before exercise for subsequent muscle biopsies with the needle biopsy technique (Bergström, 1962). Muscle biopsies were taken from the lateral part of the 
quadriceps femoralis muscle prior to exercise, and after 10 and 90 min of exercise. Arterial and venous blood was sampled simultaneously before exercise and after 10 , 30,60 , and $90 \mathrm{~min}$ of exercise. Blood flow was measured just before the blood samples were taken in the morning exercise bout. In the afternoon blood flow was not measured since previous studies had shown that no measurable differences occurred between the normal and low glycogen leg while performing exercise at the same workload (Savard, Kiens \& Saltin, 1987).

\section{Glycogen depletion protocol}

In order to obtain one normal and one low glycogen content leg subjects had to undergo a combination of upper-body exercise and one leg knee-extensor exercise on the night before the experiment. Muscle glycogen had returned to normal again when the glycogen depletion protocol was limited to one leg knee-extensor exercise (not shown). The glycogen depletion protocol consisted of $1 \mathrm{~h}$ arm cranking (Monark, Rehab trainer) and $1 \mathrm{~h}$ one leg knee-extensor exercise, both for $40 \mathrm{~min}$ at $60-70 \%$ $W_{\max }$ followed by 5 exercise bouts of $3 \mathrm{~min}$ at maximal power output. After the glycogen depletion protocol subjects were instructed only to eat a boiled egg as an evening snack. From the evening until the end of the experiment on the next day subjects did not ingest food and as fluid only water ad libitum.

\section{Blood flow}

Femoral venous blood flow was measured by the thermodilution technique (Andersen \& Saltin, 1985). Briefly, ice-cold saline is infused at a constant rate into the femoral vein for $10-15 \mathrm{sec}$ to achieve a drop in femoral venous blood temperature of $0.5-1{ }^{\circ} \mathrm{C}$. At rest blood flow is low and measured by a $3 \mathrm{ml}$ bolus injection of ice-cold saline (Gaffney, Sjøgaard \& Saltin, 1990).

\section{Muscle analysis}

Biopsies were divided and quickly frozen in liquid nitrogen. Five to $10 \mathrm{mg}$ of muscle tissue was extracted with $150 \mu \mathrm{l}$ of $3 \mathrm{M}$ perchloric acid (PCA) for 20 min and slowly neutralized with $250 \mu \mathrm{l}$ of $2 \mathrm{M}$ potassium bicarbonate $\left(\mathrm{KHCO}_{3}\right)$ and analyzed fluorometrically for ammonia by the method of Kun \& Kearney (1974). The remainder of the biopsy was freeze-dried and freed from adhesent blood and connective tissue. The water content of the biopsies was calculated from the weight differences before and after freeze drying and used for conversion from wet to dry weight. The muscle specimens were powdered and extracted with PCA for determination of adenine nucleotides, inosine monophosphate (IMP), inosine and hypoxanthine by HPLC (Van der Vusse, Janssen, Coumans, Kuipers, Does \& Ten Hoor, 1989). An aliquot of the dried biopsy was used for glycogen determination by a fluorometric enzymatic method (Van der Vusse et al, 1989). Phosphocreatine (PC) was determined with an enzymatic method on a COBAS BIO analyzer (Roche, The Netherlands) (Harris, Hultman \& Nordesjö, 1974). For amino acid analysis 2-5 mg dried muscle was extracted with $5 \%$ sulfosalicylic acid under vigorously vortex-mixing and analyzed by HPLC (Van Eijk, Rooyakkers \& Deutz, 1993). 


\section{Blood analysis}

Blood was sampled with heparinized syringes and immediately centrifuged to obtain plasma and directly frozen in liquid nitrogen. Plasma was deproteinized with $0.3 \mathrm{M}$ PCA and analyzed fluorometrically for ammonia with glutamate dehydrogenase. Plasma for amino acid analysis was deproteinized with sulfosalicylic acid $(6 \mathrm{mg} .100$ $\mu^{-1}$ plasma) vortex mixed and frozen in liquid nitrogen and analyzed by HPLC (Van Eijk et al, 1993).

\section{Muscle mass}

Thigh volume [V] was calculated using the thigh length, 3 circumferences and 3 skin fold measurements (Jones \& Pearson, 1969). The active muscle mass (M) was calculated as $\mathrm{M}=0.307 \times \mathrm{V}+0.353$ (Bangsbo, Gollnick, Graham, Juel, Kiens, Mizuno et al, 1990). This anthropometric method gave similar values compared to multiple CAT scans (Saltin, 1985).

\section{Calculations}

Ammonia fluxes across the muscle were calculated from the product of the difference in concentration in femoral arterial and venous plasma (a-v) and blood flow since it has been shown that plasma and whole blood ammonia concentrations are comparable (Janssen, Van Berlo, Van Leeuwen, Soeters, 1988). For the calculation of amino acid fluxes plasma flow was used (plasma flow is derived from the blood flow using the hematocrit). The total net exchange between 10-90 min of exercise was determined as the area under the curve. The efflux rates of two consecutive time points were averaged and multiplied by the time span and summing these for the whole exercise period. Net ammonia and amino acid production/consumption was calculated as the sum of total net exchange and the change in muscle pool size between $10 \mathrm{~min}$ and $90 \mathrm{~min}$ exercise expressed per kilogram dry muscle mass. The net production or consumption in the first 10 min was calculated from the flux measurements at $10 \mathrm{~min}$ and change in muscle pool between rest and $10 \mathrm{~min}$. The muscle wet : dry ratio was used for recalculation of muscle ammonia and for the concentration of total active muscle mass from wet to dry weight.

\section{Statistical analysis}

All data are means \pm SEM. Statistical analysis of the data was done using one way repeated measures analysis of variance (ANOVA). Differences between rest and exercise were checked for statistical significance using the Fisher's protected least significant difference test. The non parametric Wilcoxon signed-rank test was used to determine differences between data obtained in the low and normal glycogen leg test and for determining whether ammonia and amino acids fluxes were different from zero. Statistical significance was set at $\mathrm{P}<0.05$.

\section{RESULTS}

Muscle glycogen content 


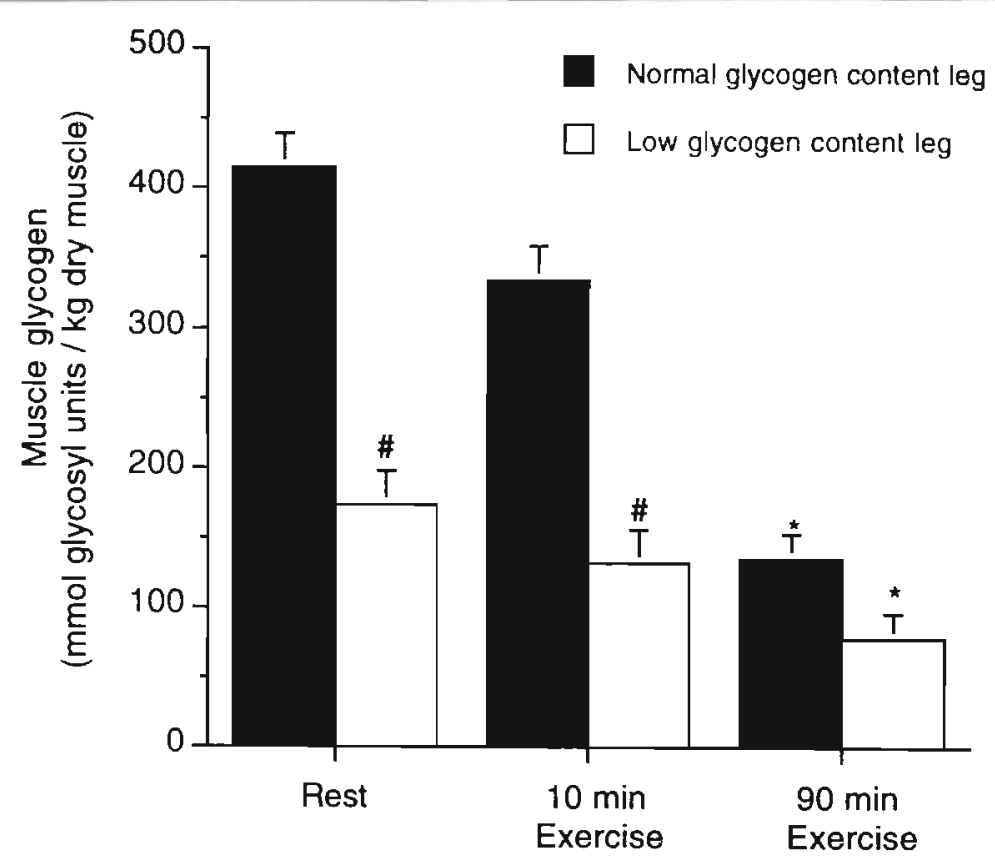

Figure 1. Muscle glycogen concentration in the normal and low glycogen content leg. Values are means \pm SEM of 6 subjects; "significant differences from rest $(P<0.05)$; "significant differences from the normal glycogen leg $(P<0.05)$.

The muscle glycogen depletion protocol with a combination of upper body- and one leg exercise the night before the experiment resulted in a significantly lower resting glycogen content in the leg that underwent the depletion protocol, that is $174 \pm 24$ versus $415 \pm 22 \mathrm{mmol}$ glycosyl units. $\mathrm{kg}^{-1} \mathrm{dry}$ muscle. No significant difference in glycogen content was found after 90 min of exercise between the legs (Fig. 1). Glycogen breakdown is substantially higher in the normal glycogen muscle $(280 \pm 29$ mmol. $\mathrm{kg}^{-1} \mathrm{dry}$ muscle) than in the low glycogen muscle ( $96 \pm 36 \mu \mathrm{mol}^{-1} \mathrm{~g}^{-1} \mathrm{dry}$ muscle). Since one leg knee-extensor exercise is confined to the quadriceps femoris muscle the active muscle mass was calculated as $2.84 \pm 0.19 \mathrm{~kg}$ wet muscle corresponding to $0.66 \pm 0.07 \mathrm{~kg}$ dry muscle calculated from the individual wet/dry weight muscie ratio of $4.3 \pm 0.1$.

\section{Energy rich phosphates in muscle}

The low glycogen content muscle had a significantly lower rest ATP concentration than the normal glycogen content leg. Prolonged exercise for $90 \mathrm{~min}$ did not lead to changes in muscle concentration of adenine nucleotides, IMP, NAD ${ }^{+}$and PC in both legs (Table 1). Muscle hypoxanthine concentration was below the level of detection (0.1 mmol. $\mathrm{kg}^{-1} \mathrm{dry}$ muscle).

\section{Ammonia}

The arterial plasma ammonia concentration increased continuously with exercise and was doubled compared to the rest value after $90 \mathrm{~min}$ of exercise in both legs (Table 
Table 1. High energy phosphate compounds and $\mathrm{NAD}^{+}$during exercise in muscle with a normal and low glycogen content.

\begin{tabular}{|c|c|c|c|}
\hline \multirow[b]{2}{*}{ Compound } & \multirow[b]{2}{*}{ Muscle } & \multicolumn{2}{|c|}{ Muscle content (mmol. $\mathrm{kg}^{-1} \mathrm{dry}$ muscle) } \\
\hline & & Rest & $90 \mathrm{~min}$ \\
\hline $\mathrm{PC}$ & $\begin{array}{l}\text { normal glycogen } \\
\text { low glycogen }\end{array}$ & $\begin{array}{l}87 \pm 5 \\
86 \pm 10\end{array}$ & $\begin{array}{l}78 \pm 5 \\
83 \pm 5\end{array}$ \\
\hline ATP & $\begin{array}{l}\text { normal glycogen } \\
\text { low glycogen }\end{array}$ & $\begin{array}{l}27.1 \pm 0.8 \\
24.6 \pm 0.3^{*}\end{array}$ & $\begin{array}{l}26.9 \pm 0.6 \\
24.4 \pm 1.2^{\prime \prime}\end{array}$ \\
\hline ADP & $\begin{array}{l}\text { normal glycogen } \\
\text { low glycogen }\end{array}$ & $\begin{array}{l}3.3 \pm 0.1 \\
3.3 \pm 0.1\end{array}$ & $\begin{array}{l}3.4 \pm 0.1 \\
3.6 \pm 0.2\end{array}$ \\
\hline AMP & $\begin{array}{l}\text { normal glycogen } \\
\text { low glycogen }\end{array}$ & $\begin{array}{l}0.12 \pm 0.01 \\
0.10 \pm 0.01\end{array}$ & $\begin{array}{l}0.12 \pm 0.01 \\
0.14 \pm 0.01\end{array}$ \\
\hline IMP & $\begin{array}{l}\text { normal glycogen } \\
\text { low glycogen }\end{array}$ & $\begin{array}{l}0.3 \pm 0.1 \\
0.3 \pm 0.1\end{array}$ & $\begin{array}{l}0.5 \pm 0.2 \\
0.3 \pm 0.1\end{array}$ \\
\hline $\mathrm{NAD}^{+}$ & $\begin{array}{l}\text { normal glycogen } \\
\text { low glycogen }\end{array}$ & $\begin{array}{l}2.0 \pm 0.3 \\
2.0 \pm 0.3\end{array}$ & $\begin{array}{l}2.0 \pm 0.3 \\
2.1 \pm 0.4\end{array}$ \\
\hline
\end{tabular}

Values are means \pm SEM of 6 subjects. "Significant differences from normal glycogen muscle leg $(P<0.05)$.

2). Ammonia was taken up by both legs at rest at a rate of $1.6 \pm 0.5$ and $1.4 \pm 0.6$ $\mu \mathrm{mol} . \mathrm{min}^{-1}$ for the normal and low glycogen content leg, respectively. During exercise ammonia was released by muscle in continuously increasing amounts during the first hour (Fig. 2). Ammonia release plateaued after one hour at a rate of approximately $80 \mu \mathrm{mol} . \mathrm{min}^{-1}$ in both legs. Muscle ammonia concentration increased 2- to 3 -fold with exercise in both legs (Fig. 3). Total ammonia production during $90 \mathrm{~min}$ of exercise was $9.1 \pm 0.4$ and $9.5 \pm 1.4 \mathrm{mmol} \mathrm{kg}^{-1} \mathrm{dry}$ muscle in the normal and low glycogen content leg, respectively.

\section{Arterial amino acid concentration and amino acid flux}

Only minor changes were observed in arterial plasma amino acid concentrations during exercise in both legs (Table 2). Alanine concentration was increased after 10 and $30 \mathrm{~min}$ of exercise. The arterial BCAA concentration decreased while exercising the normal glycogen content leg and did not change while exercising the low glycogen content leg. Glutamate was the only amino acid that was taken up both at rest and during exercise in both legs (Fig. 2). Significant BCAA uptake was observed after $90 \mathrm{~min}$ for both legs. Glutamine and alanine were released in significant amounts both at rest and during exercise (Fig. 3). Differences existed between the normal and low glycogen leg in glutamine and alanine release. In the normal glycogen leg glutamine and alanine release increased in the first half hour of exercise 
등응 옹 ชั 㳕它 0 吕 들 을을 ज ह ह ह ज - 艺 ᄃ (1) 品 은 0 䒘 동다

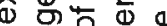
○ 89 ᄃ 궁을 ह 잉 ○ E क 등

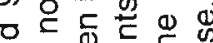
ᄃ ¿ $0 . \geq \frac{\pi}{\square}$ ᄂ을 $53 \frac{0}{5}$ 《은 는

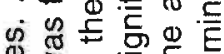
$\Phi 3 \leqq \frac{5}{\omega} . \frac{5}{\sigma}$ त $>$ 向 凹 워

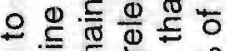
든 Ф ए 든 긍 0 을 苛

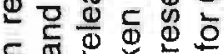
ᄃ

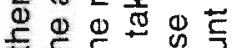

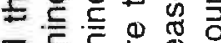

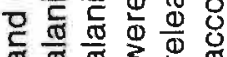

Table 2. Arterial plasma ammonla and amino acids at rest and durlng one leg exercise.

\begin{tabular}{|c|c|c|c|c|c|c|c|c|c|c|}
\hline \multicolumn{6}{|c|}{ Normal ghycogen } & \multicolumn{5}{|c|}{ Low glycogen } \\
\hline umols & res! & $10 \mathrm{~min}$ & $30 \mathrm{~min}$ & $60 \mathrm{~min}$ & $90 \mathrm{~min}$ & rest & $10 \mathrm{~min}$ & $30 \mathrm{~min}$ & $60 \mathrm{~min}$ & $90 \mathrm{~min}$ \\
\hline Anmonia & $24.6 \pm 3.1$ & $31.1 \pm 6.6^{\circ}$ & $35.9 \pm 6.1^{\circ}$ & $42.3 \pm 6.9^{\circ}$ & $45.4 \pm 6.9^{\circ}$ & $28.8 \div 4.2$ & $41.0 \pm 5.5^{\circ}$ & $44.9 \pm 8.3$ & $49.5 \pm 7.0^{\circ}$ & $51.8 \pm 7.0^{\circ}$ \\
\hline Giv & $76.7 \pm 18.6$ & $61.7 \pm 10.5$ & $99.5 \pm 21.5$ & $71.2 \pm 11.8$ & $113.0 \pm 290$ & $85.5 \pm 190$ & $112.4 \pm 30.5$ & $76.2 \pm 10.9$ & $86.8 \pm 23.8$ & $72.0 \pm 11.2$ \\
\hline Asn & $41.9 \pm 6.0$ & $40.1 \pm 3.8^{\circ}$ & $40.6 \pm 2.9$ & $37.2 \pm 3.4^{\circ}$ & $36.3 \pm 2.7$ & $42.9 \pm 2.9$ & $42.6 \pm 2.9$ & $39.9 \pm 2.5$ & $37 . \pm 2.5^{\circ}$ & $35.0 \pm 27$ \\
\hline Ser & $106.5 \pm 13.9$ & $95.6 \pm 11.6$ & $97.9 \pm 8.2$ & $90.0 \pm 10.1$ & $97.2 \pm 8.6$ & $108.8 \pm 7.2$ & $104.0 \pm 7.0$ & $97.2 \pm 6.0^{\circ}$ & $91.8 \pm 6.7$ & $86.8 \pm 7.2^{\circ}$ \\
\hline Gin & $507.0 \pm 22.4$ & $504.2 \pm 15.6$ & $519.8 \pm 17.7$ & $507.8 \pm 25.4$ & $514.8 \pm 22.3$ & $597.5 \pm 5.6$ & $532.4 \pm 14.0$ & $527.4 \pm 8.8$ & $511.1 \pm 20.9$ & $484.0 \pm 25.1 \%$ \\
\hline Gy & $181.1 \pm 12.8$ & $170.6 \pm 12.1$ & $169.6 \pm 9.6$ & $158.2 \pm 11.2^{\circ}$ & $159.0 \pm 8.7^{*}$ & $184: \pm 106$ & $983.0 \pm 8.2$ & $173.1 \pm 9.9$ & $166.0 \pm 8.8^{\circ}$ & $157.3 \pm 9.3^{\circ}$ \\
\hline Thr & $104.8 \pm 10.8$ & $95.6 \pm 9.1 \%$ & $98.3 \pm 6.8$ & $88.7 \pm 8.3^{\circ}$ & $87.6 \pm 7.3$ & $105.0 \pm 7.7$ & $108.8=7.3$ & $96.2 \pm 6.3$ & ว1. $3 \pm 6.2^{\circ}$ & $84.8 \pm 8.5^{\circ}$ \\
\hline Hig & $81.9 \pm 4.2$ & $78.7 \pm 2.9$ & $78.2 \pm 2.6$ & $74.5 \pm 2.8$ & $76.6 \pm 33^{\circ}$ & $81.8=3.3$ & $822 \pm 3.6$ & $30.6 \pm 3.3$ & $78.5 \pm 4.2$ & $75.7 \pm 4.3$ \\
\hline $\mathrm{CH}$ & $27.5 \pm 20$ & $29.4 \pm 1.9$ & $28.9 \pm 2.8$ & $29.6 \pm 1.8$ & $31.2 \div 1.5^{\circ}$ & $33.1 \pm 3.2$ & $32.9 \pm 3.1$ & $33.0 \pm 3.3$ & $31.7 \pm 3.7$ & $33.1 \pm 3.3$ \\
\hline Alo & $213.3 \pm 17.7$ & $256.1 \pm 27.4^{\circ}$ & $276.2 \pm 32.7^{*}$ & $240.4 \pm 29.5$ & $208.4 \star 232$ & $1893 \pm 20.7$ & $238.9 \pm 23.9^{\circ}$ & $228.5=19.0^{\circ}$ & $193.5 \pm 13.0$ & $169.6 \pm 13.7$ \\
\hline Arg & $60.6 \pm 5.8$ & $57.2 \div 5.8$ & $60.3 \neq 4.1$ & $543 \pm 3.5$ & $55.4 \div 42$ & $57.6 \div 60$ & $59.8 \pm 5.6$ & $5.9 \pm 4.6$ & $536 \pm 2.7$ & $50.7 \pm 3.5$ \\
\hline $\mathbf{A A B}$ & $47.1 \pm 6.0$ & $43.7 \pm 5.6$ & $44.4 \pm 4.1$ & $39.5 \pm 4.8$ & $38.4 \pm 4.6$ & $436 \pm 40$ & $42.4 \pm 36$ & $40.6+3.8$ & $39.3 \pm 4.4$ & $39.2 \div 4.7$ \\
\hline Tyr & $49.7 * 4.6$ & $46.1 \pm 4.0$ & $45.6 \pm 3.8$ & $41.7 \pm 28$ & $41.3 \neq 3.0$ & $49.9 \pm 6.1$ & $49.0 \geq 5.8$ & $472 \approx 4.4$ & $45.8=40$ & $44.3 \neq 3.0$ \\
\hline Val & $331.3 \pm 21.1$ & $321.2 \pm 27.7$ & $3176 \pm 26$ & $291.6 \pm 236^{\circ}$ & $2900=24 \mathrm{~g}^{\circ}$ & $304.9 \pm 26.6$ & $3054: 24.0$ & $295.9 \pm 22.4$ & $293.1 \pm 23.7$ & $300.8 \pm 23.4$ \\
\hline Mat & $25.9 \pm 6.0$ & $23.0 \pm 2.6$ & $24.0 \pm 2.3$ & $20.2 \pm 2.7$ & $19.2 \pm 2.1^{\circ}$ & $23.1 \leq 2.3$ & $23.3 \pm 20$ & $23.2 \pm 1.9$ & $20.9 \pm 1.6$ & $19 z=20$ \\
\hline lie & $111.9 \pm 40$ & $106.0 \pm 9.1$ & $99.9 \pm 8.5^{\circ}$ & Ba $3 \pm 74^{\circ}$ & $87.7 \pm 7.7^{\circ}$ & $96.7 \pm 6.7$ & $96.5 \pm 7.1$ & $914: 7.3$ & $91.5 \pm 7.0$ & $96.4 \pm 6.7$ \\
\hline Pho & $51.7 \pm 4.4$ & $48.3 \pm 3.0$ & $49.3 \pm 3.3$ & $447 \div 28^{\circ}$ & $45.3 \neq 29^{\circ}$ & $47.5 \pm 4.8$ & $47.7 \div 4.7$ & $46 . a \pm 4.5$ & $44.7 \pm 38$ & $43.4=3.3$ \\
\hline $\operatorname{Trp}$ & $33.9=2.8$ & $301 \pm 3.8$ & $30.1 \pm 2.7$ & $24.3 \pm 1.7$ & $21.5 \pm 1.6^{*}$ & $33.7 \pm 4.4$ & 323236 & $27.5 \div 3.8^{\circ}$ & $23.4 \pm 2.8^{\circ}$ & $21.5 \pm 2.4$ \\
\hline Leu & $193.2 \pm 3.6$ & $188.7 \pm 15.2$ & $178.4 \pm 15.4^{*}$ & $155.9=124^{*}$ & $1546 \pm 14,4^{*}$ & $171.1=10.2$ & $171.3 \pm 12.2$ & $165.0 \pm 11.9$ & $165.0 \pm 11.0$ & $172.5 \pm 11.2$ \\
\hline Lys & $145.8=16.3$ & $143.4 \pm 15.7$ & $144.2 \pm 12.2$ & $133.9 \pm 12.8$ & $128.4 \pm 9.9$ & $1446 \geq 11.3$ & $1487 \pm 112$ & $1370=71$ & $130.7 \neq 57$ & $124.0=0.5$ \\
\hline$B C M$ & $641 \pm 36$ & $616 \pm 51$ & $594 \pm 49^{\circ}$ & $536 \pm 42^{\circ}$ & $532=46^{*}$ & $573=48$ & $573 \pm 42$ & $552 \div 40$ & $550 \pm 41$ & $570 \pm 40$ \\
\hline Tot M & $2421 \pm 10 ?$ & $2356 \pm 89$ & $2411 \pm 91$ & $2205 \div 81$ & $2209 \pm 75$ & $2344=118$ & $2428 \pm 10 \%$ & $2303 \pm 73$ & $2215 \pm 88$ & $2131 \pm 72$ \\
\hline
\end{tabular}


Flux

( $\mu$ mol.min $\left.^{-1}\right)$

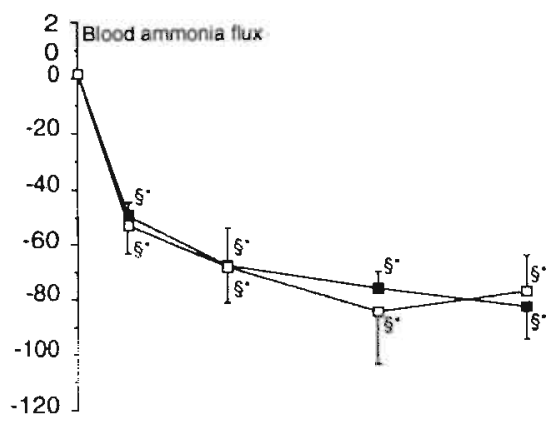

Muscle concentration

(mmol. $\mathrm{kg}^{-3}$ dry muscle)
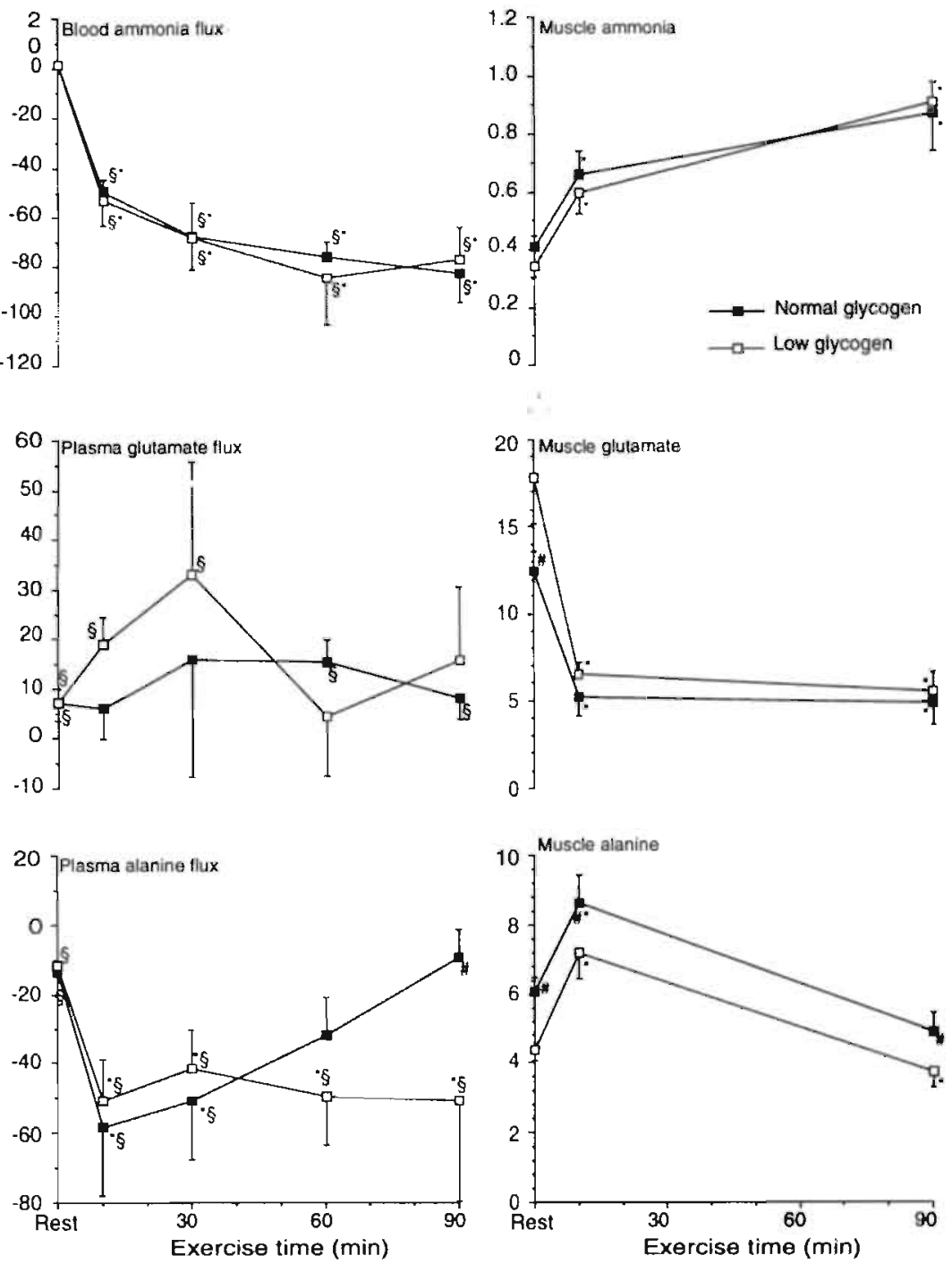

Figure 2. Fluxes and muscle ammonia, glutamate and alanine during one leg exercise.

Values are means \pm SEM of 6 subjects. Fluxe rate and muscle concentration are expressed in $\mu \mathrm{mol} . \mathrm{min}^{-1}$ and $\mathrm{mmol} . \mathrm{kg}^{-1} \mathrm{dry}$ muscle respectively. A negative value for flux rates indicate a net release. "Significant differences from rest $(P<0.05)$; "significant differences from low glycogen $(P<0.05)$. SSignificant differences from zero flux rates. 


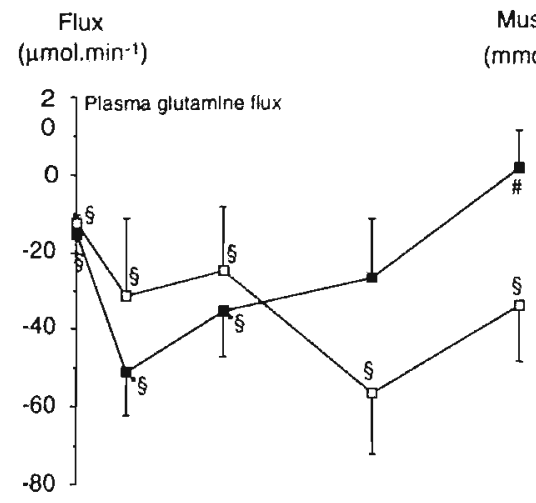

Muscle concentration

(mmol.kg-1 dry muscle)
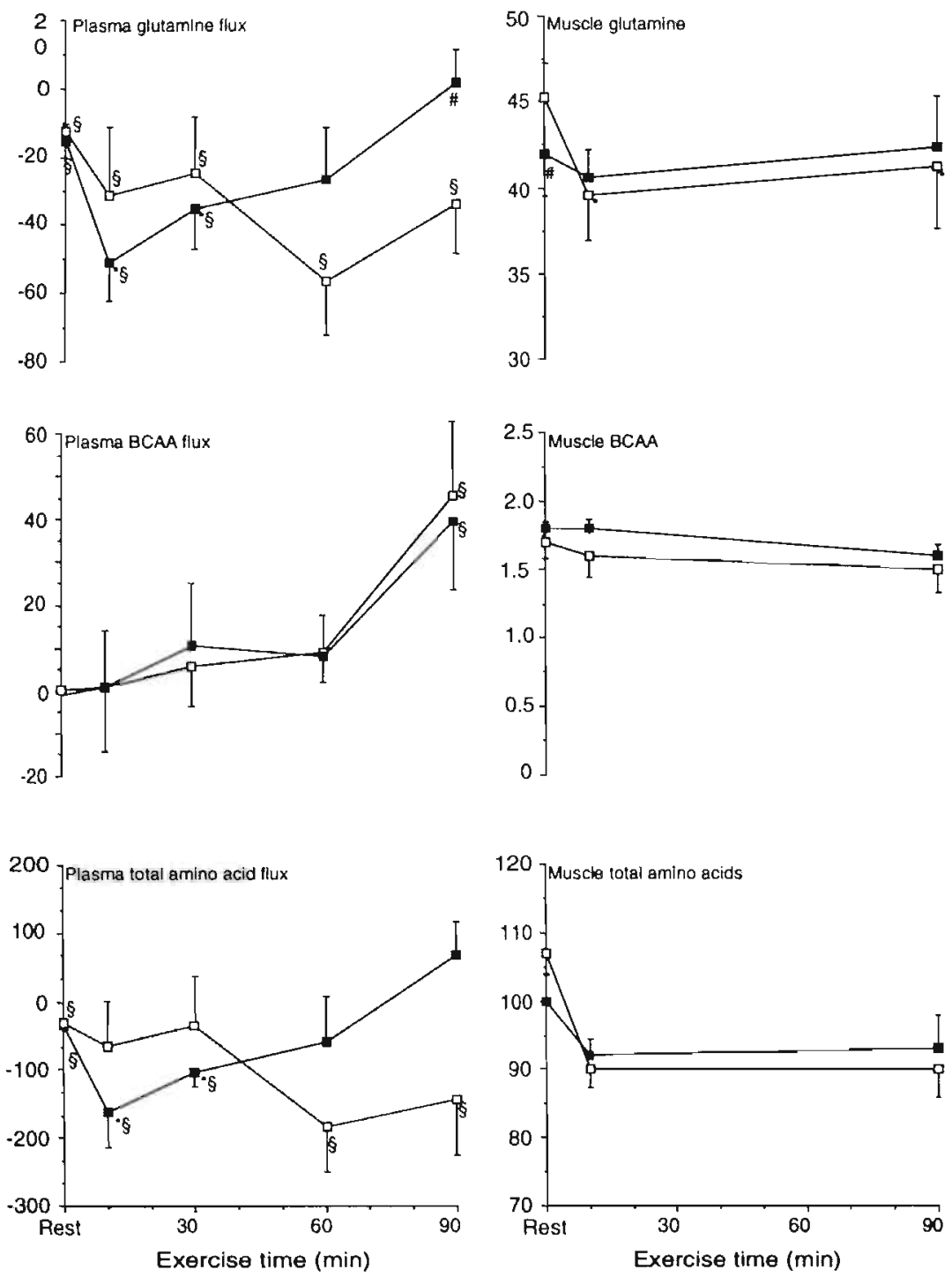

Figure 3. Fluxes and muscle glutamine, BCAA and total amino acids during one leg exercise. Further details are given in legend to Fig. 2 . 
Muscle amino acids (Fig. 2, 3)

The muscle glutamate pool decreased by $60 \%$ within $10 \mathrm{~min}$ of exercise. No further decrease in muscle glutamate was observed in the 90 min biopsy. Muscle alanine increased over the first 10 min compared to rest but in the 90 min biopsy alanine

Table 3. Rate of ammonia and amino acid production or consumption at rest and during exercise.

\begin{tabular}{|c|c|c|c|c|}
\hline \multirow[b]{2}{*}{ Compound } & \multirow[b]{2}{*}{ Leg } & \multicolumn{3}{|c|}{ Production/consumption ( $\mu$ mol. $\mathrm{kg}^{-1} \mathrm{dry}$ muscle.min ${ }^{-1}$ ) } \\
\hline & & Rest & $\begin{array}{l}\text { Exercise } \\
\text { (first } 10 \mathrm{~min} \text { ) }\end{array}$ & $\begin{array}{c}\text { Exercise } \\
(10-90 \mathrm{~min})\end{array}$ \\
\hline Ammonia & $\begin{array}{l}\text { normal glycogen } \\
\text { low glycogen }\end{array}$ & $\begin{array}{l}1.5 \pm 0.5 \\
1.4 \pm 0.6\end{array}$ & $\begin{array}{l}-50 \pm 12^{*} \\
-63 \pm 15^{*}\end{array}$ & $\begin{array}{l}-107 \pm 5^{* 5} \\
-111 \pm 17^{\star \xi}\end{array}$ \\
\hline Glutamate & $\begin{array}{l}\text { normal glycogen } \\
\text { low glycogen }\end{array}$ & $\begin{array}{l}10 \pm 4 \\
11 \pm 6\end{array}$ & $\begin{array}{c}751 \pm 152^{*} \\
1183 \pm 251^{*}\end{array}$ & $\begin{array}{l}26 \pm 3^{* \S} \\
43 \pm 4^{* \S}\end{array}$ \\
\hline Alanine & $\begin{array}{l}\text { normal glycogen } \\
\text { low glycogen }\end{array}$ & $\begin{array}{l}-19 \pm 4 \\
-19 \pm 6\end{array}$ & $\begin{array}{l}-306 \pm 103^{\star} \\
-343 \pm 43^{*}\end{array}$ & $\begin{array}{c}-8 \pm 23^{\S} \\
-35 \pm 37^{\S}\end{array}$ \\
\hline Glutamine & $\begin{array}{l}\text { normal glycogen } \\
\text { low glycogen }\end{array}$ & $\begin{array}{l}-23 \pm 3 \\
-19 \pm 3\end{array}$ & $\begin{array}{l}-44 \pm 128 \\
449 \pm 104^{* \prime}\end{array}$ & $\begin{array}{l}-75 \pm 42 \\
-83 \pm 21^{*}\end{array}$ \\
\hline BCAA & $\begin{array}{l}\text { normal glycogen } \\
\text { low glycogen }\end{array}$ & $\begin{array}{r}0.3 \pm 0.9 \\
-1.2 \pm 1.3\end{array}$ & $\begin{array}{l}12 \pm 17 \\
15 \pm 17\end{array}$ & $\begin{array}{l}16 \pm 12 \\
13 \pm 13\end{array}$ \\
\hline Total AA & $\begin{array}{l}\text { normal glycogen } \\
\text { low glycogen }\end{array}$ & $\begin{array}{l}-54 \pm 9 \\
-45 \pm 8\end{array}$ & $\begin{array}{r}478 \pm 581 \\
1670 \pm 540\end{array}$ & $\begin{array}{l}-149 \pm 115 \\
-213 \pm 65\end{array}$ \\
\hline
\end{tabular}

Net ammonia and amino acid production or consumption at rest and exercise. A negative value signifies a net production. Net production or consumption is calculated from the flux and change in muscle concentration normalized with the estimated dry quadriceps weight involved in exercise. Values are means \pm SEM of 6 subjects; "significant differences from rest $(P<0.05)$; ${ }^{5}$ significant differences from $10 \mathrm{~min}(P<0.05)$; "significant differences from the nomal glycogen leg $(P<0.05)$.

concentration had returned to or slightly below the resting concentration. The muscle BCAA pool did not change during exercise in both legs. Differences in muscle free amino acid concentration between the normal and low glycogen leg were found at rest for glutamate, glutamine and alanine. Resting muscle concentration of glutamate and glutamine were significantly higher in the low glycogen leg, whereas alanine concentration was lower. Although rest concentrations of glutamine were higher in the low glycogen muscle, no differences were observed between the legs after 10 and 90 min of exercise. The muscle glutamine content decreased below the resting value with exercise in the low glycogen leg. The decrease of muscle total amino acid pool during exercise is primarily caused by the decrease in the muscle glutamate pool. 
Rate of production or consumption of amino acids (Table 3)

The rate of glutamate consumption by the active muscle was several fold higher during the first 10 min compared to the $10-90$ min period in both legs. The rate of glutamate consumption during exercise was increased in both legs and significantly higher in the low glycogen than in the normal glycogen leg. Alanine production rate was 10-15 times higher during the first $10 \mathrm{~min}$ than at rest or between 10-90 min of exercise in both legs. Glutamine production rate was not significantly changed in the normal glycogen leg. In the low glycogen leg, however, the first $10 \mathrm{~min}$ a net consumption of glutamine was observed mainly caused by the decrease in the glutamine muscle pool. Glutamine production rate was increased during the 10-90 min exercise period compared to rest in the low glycogen leg.

\section{DISCUSSION}

Considerable amounts of ammonia were produced during the 90 min of exercise in both legs. Enzymatic reactions that could lead to ammonia production in muscle are AMP-deaminase, glutamate dehydrogenase, and glutaminase. It is generally accepted that ammonia production during brief intense exercise is predominantly caused by action of AMP-deaminase which results in the net breakdown of ATP via AMP to IMP (Katz et al, 1986a, b; Tullson \& Terjung, 1990; Fig. 4A). During prolonged one leg exercise the contribution of this reaction appears to be insignificant since the subjects in this study did not produce IMP. This has also been found previously during $120 \mathrm{~min}$ whole body exercise at $50-70 \% W_{\max }$ (Wagenmakers et al, 1991). Other studies have reported small increases in IMP concentration during prolonged exercise continued until exhaustion (Norman, Sollevi \& Jansson, 1988; Broberg \& Sahlin, 1989; Spencer, Yan \& Katz, 1992).

Once AMP is converted to IMP reamination of IMP to AMP may occur in the purine nucleotide cycle (PN-cycle) (Fig. 4B). IMP accumulation, therefore, may only be observed when the other reactions of the $\mathrm{PN}$-cycle do not match the rate of IMP production. In the reamination reaction of IMP to AMP in the PN-cycle the amino groups are derived from aspartate. The muscle aspartate pool is small $\left( \pm 1 \mathrm{mmol} . \mathrm{kg}^{-1}\right.$ dry weight, [Spencer, Yan \& Katz, 1991; MacLean et al, 1991]) but aspartate can be synthesized from other amino acids via aminotransferase reactions (Gorski, Hood, Brown \& Terjung, 1985). This means that several amino acids may be deaminated in muscle via the PN-cycle (Lowenstein \& Goodman, 1978).

Ammonia may also be produced by the action of glutamate dehydrogenase. Ammonia production in our study was approximately 10 mmol. $\mathrm{kg}^{-1}$ dry muscle in 90 min which is equivalent to $0.027 \mu \mathrm{mol}^{-1} \mathrm{~g}^{-1}$ wet muscle. $\mathrm{min}^{-1}$. Glutamate dehydrogenase activities in human skeletal muscle have been reported to range from 1.03 in sedentary controls to $1.78 \mu \mathrm{mol} . \mathrm{g}^{-1}$ wet muscle. $\mathrm{min}^{-1}$ in highly trained subjects (Wibom \& Hultman, 1990). This is sufficiently high to account for the ammonia production observed. Whether the enzyme is fully active in skeletal muscle in vivo is not known. It is also not known whether the activity present in muscle homogenates originates from myocytes or from endothelial cells of the vascular system (Leighton, 
Curi, Hussein \& Newsholme, 1987). These reflections also hold for the glutaminase activity that is present in muscle homogenates. It cannot be excluded that glutaminase plays a role in ammonia production, although measurement of arterial venous differences across the human leg and forearm have suggested that the role of skeletal muscle is glutamine synthesis rather than glutamine degradation (Elia, 1993).

The relative contribution of the $\mathrm{PN}$-cycle, glutamate dehydrogenase or glutaminase reactions to ammonia production remains unclear. However, the net

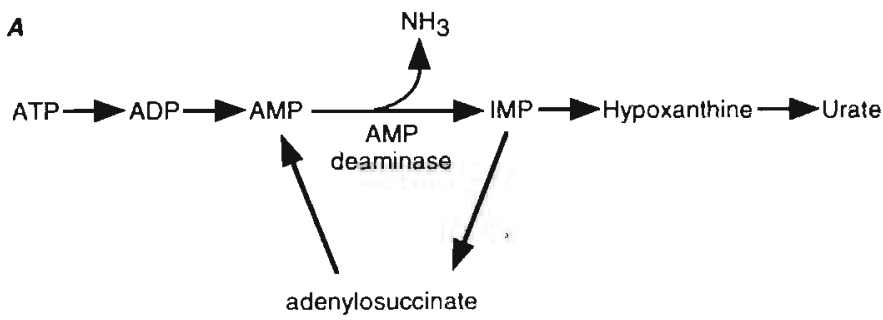

$B$

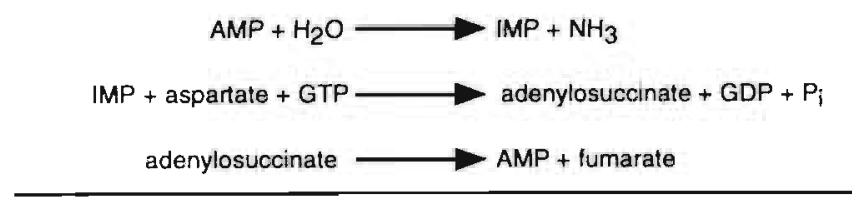

Net: aspartate $+\mathrm{GTP}+\mathrm{H}_{2} \mathrm{O} \longrightarrow$ fumarate $+\mathrm{GDP}+\mathrm{P}_{\mathrm{i}}+\mathrm{NH}_{3}$

Figure 4. Schematic presentation of the production of ammonia in the skeletal muscle by net breakdown of ATP $(A)$ or by deamination of aspartate in the purine nucleotide cycle (B).

result is deamination of amino acids independent of the reaction. It is therefore concluded that deamination of amino acids is a more likely source of ammonia production in this study than net adenine nucleotide breakdown.

Glutamate is the only amino acid taken up in substantial quantities from the circulation and disappearing out of the muscle pool in large amounts during exercise. Total glutamate consumption during the $90 \mathrm{~min}$ of exercise can easily account for the net ammonia production. However, the large net consumption of glutamate observed within the first $10 \mathrm{~min}$ of exercise does not coincide with the gradual increase in ammonia production during exercise. The early alanine production observed here and by others (Henriksson, 1991; Sahlin et al, 1990) indicates that the alanine aminotransferase reaction (pyruvate + glutamate $<------>$ alanine $+\alpha$-ketoglutarate) is very active in the beginning of exercise. This reaction provides a mechanism for an acute increase of tricarboxylic acid cycle intermediates (TCAI) and may be needed to 
meet the increased energy demands of exercise (Sahlin et al, 1990). Therefore, the net consumption of glutamate in the early phase of exercise appears to be required for replenishment of TCAl by means of the alanine aminotransferase reaction rather than for production of ammonia.

Significant amounts of ammonia, alanine and glutamine are released between 10 and 90 min of exercise. In that period the uptake of glutamate by the muscle and the further decrease of the muscle glutamate pool is small in comparison to the first 10 min of exercise. This implies that other amino acids should provide the amino groups for the formation of the ammonia, alanine and glutamine. The branched-chain amino acids (BCAA), aspartate and asparagine may deliver amino groups in muscle for the synthesis of alanine and glutamine (Chang \& Goldberg, 1978) and potentially may also contribute to the ammonia production between 10 and 90 min of exercise via one of the indicated deamination reactions. Exercise activates BCAA oxidation in muscle (Wagenmakers, Brooks, Coakley, Reilly \& Edwards, 1989; Wagenmakers et al, 1991). Both BCAA taken up from the circulation (Table 2; Ahlborg, Felig, Hagenfeldt, Hendler \& Wahren, 1974) and originating from net protein breakdown may provide amino groups. Net protein breakdown also may directly provide alanine, glutamine, glutamate, aspartate and asparagine for production of ammonia, alanine and glutamine. The larger release of alanine and glutamine and of total amino acids in the low glycogen leg than in the normal glycogen leg at $90 \mathrm{~min}$ of exercise seems to suggest that protein breakdown is higher in the low glycogen leg.

in this study no differences are observed in ammonia flux between the normal and low glycogen content muscle and no differences between the legs in net adenine nucleotide breakdown and IMP production. Our data, therefore, are different from those of Broberg \& Sahlin (1989). However, we have to take into consideration that two major differences exist in experimental design of the studies. Broberg \& Sahlin (1989) continued exercise until exhaustion while we did not. Another difference is that Broberg \& Sahlin (1989) induced glycogen depletion by a previous exercise bout $75 \mathrm{~min}$ before the test, while we lowered muscle glycogen $14 \mathrm{~h}$ before the test.

The data do not support the hypothesis of Wagenmakers et al $(1990,1991)$ that glycogen is a carbon-chain precursor for the synthesis of glutamine and that glycogen depletion, therefore, would lead to reduced glutamine production and increased ammonia production as a result of decreased ammonia removal in the glutamine synthase reaction. No significant difference was found in either the rate of ammonia or glutamine production between the normal and low glycogen leg during the first 60 min of exercise. The increased glutamine release from the low glycogen leg after $90 \mathrm{~min}$ of exercise is most probably due to an increased rate of protein breakdown in the low glycogen leg.

One of the unexplained observations in this study is the fact that significant amounts of muscle amino acids disappear from the low glycogen muscle during the first 10 min of exercise and that the amino groups are not recovered in any of the likely products. Between rest and $10 \mathrm{~min}$ of exercise $5 \mathrm{mmol}$ of glutamate is consumed in the normal glycogen leg; $2 \mathrm{mmol}$ of alanine, $0.3 \mathrm{mmol}$ of glutamine and $0.3 \mathrm{mmol}$ of ammonia is simultaneously produced. This implies that about $2 \mathrm{mmol}$ of amino groups are not recovered in alanine, glutamine or ammonia. Part of the amino 
groups may temporarily have been converted to aspartate and aspargine, though previous studies suggest that the increase is very small early on during exercise (Bergström, Fürst, \& Hultman, 1985; Graham et al, 1991). However, when applying the same calculation to the low glycogen muscle then $11 \mathrm{mmol}$ of amino groups have disappeared. This implies that in the low glycogen leg a major part of the amino groups are disappearing in the first $10 \mathrm{~min}$ of exercise and that either an unknown product is formed or that the amount of products released from muscle in the first 10 min of exercise is grossly underestimated. More frequent sampling in future studies in the early exercise period may shed some light on this puzzling amino group imbalance.

In conclusion, this study shows that during prolonged one leg exercise ammonia production is not derived from adenine nucleotide breakdown to IMP. No net IMP formation is observed in this study implying that ammonia production has to be derived from another source, most likely deamination of amino acids. Pre-exercise glycogen stores did not influence ammonia production in one leg knee-extensor exercise at $60-65 \% W_{\max }$. Further research is needed to identify the reaction(s) responsible for deamination of amino acids during prolonged exercise.

\section{References}

Ahlborg, G., Felig, P., Hagenfeldt, L., Hendler, R. \& Wahren, J. (1974). Substrate tumover during prolonged exercise in man - Splanchnic and leg metabolism of glucose, free fatty acids, and amino acids *. Journal of Clinical Investigation 53: 1080-1090.

Andersen, P. \& Saltin, B. (1985). Maximal perfusion of skeletal muscle in man. Journal of Physiology 366: 233-249.

Bangsbo, J., Gollnick, P.D., Graham, T.E., Juel, C., Kiens, B., Mizuno, M. \& Saltin, B. (1990). Anaerobic energy production and $\mathrm{O}_{2}$ deficit-debt relationship during exhaustive exercise in humans. Journal of Physiology 422: 530-559.

Bergström, J. (1962). Muscle electrolytes in man. Determination by neutron activation analysis on needle biopsy specimens. A study on normal subjects, kidney patients, and patients with chronic diarrhea. Scandinavian Journal of Clinical \& Laboratory investigations Suppl. 68: 7-110.

Bergström, J., Fürst P. \& Hultman, E. (1985). Free amino acids in muscle tissue and plasma during exercise in man. Clinical Physiology 5: 155-160.

Broberg, S. \& Sahlin, K. (1989). Adenine nucleotide degradation in human skeletal muscle during prolonged exercise. Journal of Applied Physiology 67: 116-122.

Chang, T.W. \& Goldberg, A.L. (1978). The metabolic fates of amino acids and the formation of glutamine in skeletal muscle. Journal of Biological Chemistry 253: 3685-3695.

Elia, M. (1993). Glutamine metabolism in human adipose tissue in vivo. Clinical Nutrition 12: 51-53.

Gaffney, K.N., Sjøgaard, G. \& Saltin, B. (1990). Cardiovascular and metabolic responses to static contraction in man. Acta Physiologica Scandinavica 138: 249-259.

Gorski, J., Hood, D.A., Brown, O.M. \& Terjung, R.L. (1985). Incorporation of ${ }^{15} \mathrm{~N}$-leucine amine into ATP of fast-twitch muscle following stimulation. Biochemical and Biophysical Research Communications 128: 1254-1260.

Graham, T.E., Pedersen, P.K. \& Saltin, B. (1987). Muscle and blood ammonia and lactate responses to prolonged exercise with hyperoxia. Journal of Applied Physiology 63: 1457-1462.

Graham, T.E., Kiens, B., Hargreaves, M. \& Richter, E.A. (1991). Influence of fatty acids on ammonia and amino acid flux from active human muscle. American Joumal of Physiology 261: E168-E176. 
Harris, R.C., Hultman, E. \& Nordesjö, L.O. (1974). Glycogen, glycolytic intermediates and high-energy phosphates determined in biopsy samples of musculus quadriceps femoris of man at rest. Methods and variance of values. Scandinavian Journal of Clinical \& Laboratory Investigations 33: 109-120.

Henriksson, J. (1991). Effect of exercise on amino acid concentrations in skeletal muscle and plasma. Journal of Experimental Biology 160: 149-165.

Janssen, M.A., Van Berlo, C.L.H., Van Leeuwen, P.A.M. \& Soeters, P.B. (1988). The determination of ammonia in plasma and whole blood. In Advances in ammonia metabolism and hepatic encephalopathy ed. Soeters, P.B., Wilson, J.H.P., Meijer, A.J. \& Holm, R. pp 587-592. Elsevier Science Publishers B.V., Amsterdam.

Jones, P.R.M. \& Pearson, J. (1969). Anthropometric determination of leg fat and muscle plus bone volumes in young male and female adults. Journal of Physiology 204: 63P-66P.

Kasperek, G.J., Dohm, G.L. \& Snider, R.D. (1985). Activation of branched-chain keto acid dehydrogenase by exercise. American Journal of Physiology 248: R166-R171.

Katz, A., Broberg, S., Sahlin, K. \& Wahren, J. (1986a). Muscle ammonia and amino acid metabolism during dynamic exercise in man. Clinical Physiology 6: 365-379.

Katz, A., Sahlin, K. \& Henriksson, J. (1986b). Muscle ammonia metabolism during isometric contraction in humans. American Joumal of Physiology 250: C834-C840.

Kun, E. \& Kearney, E.B. (1974). Ammonia. In Methods of enzymatic analysis. ed. Bergmeyer, H.U. pp 1802-1805. Acadamic Press, New York.

Leighton, B., Curi, R., Hussein, A. \& Newsholme, E.A. (1987). Maximum activities of some key enzymes of glycolysis, glutaminolysis, krebs cycle and fatty acid utilization in bovine pulmonary endothelial cells. FEBS Letters 225: 93-96.

Lowenstein, J.M. \& Goodman, M.N. (1978). The purine nucleotide cycle in skeletal muscle. Federation Proceedings 37: 2308-2312.

MacLean, D.E., Spriet, L.L., Hultman, E. \& Graham, T.E. (1991). Plasma and muscle amino acid and ammonia responses during prolonged exercise in humans. Journal of Applied Physiology 70: 20952103.

Meyer, R.A., Dudley, G.A. \& Terjung, R.L. (1980). Ammonia and IMP in different skeletal muscle fibers atter exercise in rats. Journal of Applied Physiology 49: 1037-1041.

Meyer, R.A. \& Terjung, R.L. (1979). Differences in ammonia and adenylate metabolism in contracting fast and slow muscle. American Journal of Physiology 6: C111-C118.

Norman, B., Sollevi, A. \& Jansson, E. (1988). Increased IMP content in glycogen depleted muscle fibres during sub maximal exercise in man. Acta Physiologica Scandinavica 133: 97-100.

Norman, B., Sollevi, A., Kaijser, L. \& Jansson, E. (1987). ATP breakdown products in human skeletal muscle during prolonged exercise to exhaustion. Clinical Physiology 7: 503-509.

Sahlin, K., Katz, A. \& Broberg, S. (1990). Tricarboxylic acid cycle intermediates in human muscle during prolonged exercise. American Journal of Physiology 259: C834-C841.

Saltin, B. (1985). Hemodynamic adaptations to exercise. American Joumal of Cardiology 55: 42-47.

Savard, G.K., Kiens, B. \& Saltin, B. (1987). Limb blood flow in prolonged exercise; magnitude and implication for cardiovascular control during muscular work in man. Canadian Journal of Applied Sports Sciences 12: S89-S101.

Spencer, M.K., Yan, Z. \& Katz, A. (1991). Carbohydrate supplementation attenuates IMP accumulation in human muscle during prolonged exercise. American Journal of Physiology 261: C71-C76.

Spencer, M.K., Yan, Z. \& Katz, A. (1992). Effect of low glycogen on carbohydrate and energy metabolism in human muscle during exercise. American Journal of Physiology 262: C975-C979.

Tullson, P.C. \& Terjung, R.L. (1990). Adenine nucleotide degradation in straited muscle. International Joumal of Sports Medicine 11: S47-S55.

Van der Vusse, G.J., Janssen, G.M.E., Coumans, W.A., Kuipers, H., Does, R.J.M.M. \& Ten Hoor, F. (1989). Eflect of training and 15-, 25-, and 42-km contests on the skeletal muscle content of adenine and guanine nucleotides, creatine phosphate, and glycogen. International Journal of Sports Medicine 10: S146-S152. 
Van Eijk, H.M.H., Rooyakkers, D.R. \& Deutz, N.E.P. (1993). Rapid routine determinalion of amino acids in plasma by high-performance liquid chromatography with a 2-3 $\mu \mathrm{m}$ Spherisorb ODS II column. Journal of Chromatography 620: 143-148.

Wagenmakers, A.J.M., Schepens, J.T.G. \& Veerkamp, J.H. (1984). Effect of starvation and exercise on actual and total activity of the branched-chain 2-oxo acid dehydrogenase complex in rat lissues. Biochemical Journal 223: 815-821.

Wagenmakers, A.J.M., Brooks, J.H., Coakley, J.H., Reilly, T. \& Edwards, R.H.T. (1989). Exercise induced activation of branched-chain 2-oxo acid dehydrogenase in human muscle. European Journal of Applied Physiology 59: 159-167.

Wagenmakers, A.J.M., Coakley, J.H. \& Edwards, R.H.T. (1990). Metabolism of branched-chain amino acids and ammonia during exercise: clues from McArdle's disease. International Journal of Sports Medicine 11: S101-S113.

Wagenmakers, A.J.M., Beckers, E.J., Brouns, F., Kuipers, H., Soeters, P.B., Van der Vusse, G.J. \& Saris, W.H.M. (1991). Carbohydrate supplementation, glycogen depletion, and amino acid metabolism during exercise. American Journal of Physiology 260: E883-E890.

Wibom, R. \& Hultman, E. (1990). ATP production rate in mitochondria isolated from micro samples of human muscle. American Journal of Physiology 259: E204-E209. 


\title{
Chapter 3
}

\section{Mechanisms of activation of muscle branched-chain $\alpha$-keto acid dehydrogenase during exercise in man}

G. van Hall, D.A. MacLean*, B. Saltin*, A.J.M. Wagenmakers

University of Limburg, Maastricht, The Netherlands; "CMRC, Copenhagen, Denmark.

Journal of Physiology in press.

\begin{abstract}
1. Exercise leads to activation (dephosphorylation) of the BCKADH. Here we investigate the effect of low pre-exercise muscle glycogen content and of branched-chain amino acid (BCAA) ingestion on the activaty of BCKADH at rest and after $90 \mathrm{~min}$ of one leg knee-extensor exercise at $65 \% \mathrm{~W}_{\max }$ in 5 subjects.

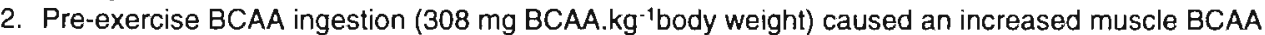
uptake, a higher intra-muscular BCAA concentration and activation of BCKADH both at rest $9 \pm 1$ and $25 \pm 5 \%$ (for the control and BCAA test, respectively) and after exercise $27 \pm 4$ versus $54 \pm$ $7 \%$.

3. At rest the percentage active $\mathrm{BCKADH}$ was not different, $6 \pm 2 \%$ versus $5 \pm 1 \%$, in the normal and low glycogen content leg (392 \pm 21 and $147 \pm 34 \mu \mathrm{mol}$ glycosyl units..$^{-1} \mathrm{dry}$ muscle, respectively). The post-exercise BCKADH activity was higher in the low (46 $\pm 2 \%$ ) than in the normal glycogen content leg $(26 \pm 2 \%)$.

4. It is concluded that: 1 . The mechanism of activation by BCAA ingestion probably involves an increase of the muscle BCAA concentration; 2. BCKADH activation caused by exercise and BCAA ingestion are additive; 3 . Low pre-exercise muscle glycogen content augments the exercise induced BCKADH activation without an increase in muscle BCAA concentration. 4. The mechanism of BCKADH activation via BCAA ingestion and low muscle glycogen content are different.
\end{abstract}




\section{INTRODUCTION}

The branched-chain amino acids (BCAA) - leucine, valine and isoleucine - are three of the nine essential amino acids in mammals. After ingestion of a protein containing meal most of the essential amino acids are degraded by the liver. The BCAA, however, largely escape from hepatic uptake and are primarily degraded in peripheral tissues. Skeletal muscle is able to degrade BCAA and it has been suggested that the BCAA are the third fuel for skeletal muscle (Goldberg \& Chang, 1978; Shinnick \& Harper, 1976). The first step in BCAA degradation is a reversible $B C A A$ aminotransferase reaction in which the BCAA are converted to their respective branched-chain $\alpha$-keto acids (BCKA) and the amino group acceptor $\alpha$-ketoglutarate is converted to glutamate. BCAA also have been suggested to play a role in fatigue mechanisms in muscle, supposedly by a carbon-draining effect of this BCAA aminotansferase reaction on the TCA-cycle (Wagenmakers, Coakley \& Edwards, 1990). The BCKA are further degraded in an irreversible oxidative decarboxylation reaction by the branched-chain $\alpha$-keto acid dehydrogenase complex (BCKADH). This reaction is the rate limiting step in BCAA degradation in most tissues and the activity of the BCKADH decides whether the carbon skeletons of the BCAA remain available for protein synthesis or are broken down in the oxidative pathway.

The BCKADH is regulated by a phosphorylation/dephosphorylation cycle with dephosphorylation causing activation. At rest $2-10 \%$ of the enzyme is active in rat (Wagenmakers, Schepens \& Veerkamp, 1984; Aftring, Miller \& Buse, 1988) and human skeletal muscle (Wagenmakers, Brookes, Coakley, Reilly \& Edwards, 1989). Prolonged exercise at $50-70 \% \mathrm{~W}_{\max }$ in the overnight fasted state is known to lead to a 2- to 5-fold increase of the percentage active BCKADH in rat (Kasperek \& Snider, 1987; Fujii, Shimomura, Tokuyama \& Suzuki, 1994) and human skeletal muscle (Wagenmakers et al, 1989; Wagenmakers, Beckers, Brouns, Kuipers, Soeters, Van der Vusse et al, 1991). The nutritional status appears to influence the activation of the BCKADH by exercise. Carbohydrate loading and carbohydrate ingestion during exercise prevented the exercise induced activation whereas low resting muscle glycogen without carbohydrate supplementation caused a 3.6 fold activation (Wagenmakers et al, 1991). Furthermore, an increased circulating leucine concentration achieved by ingestion of BCAA activated the BCKADH in rat muscle (Aftring, Block \& Buse, 1986). BCKADH activity in rat muscle also was increased $3 \mathrm{~h}$ after feeding of a high amount of protein that increased BCAA concentration in both plasma and muscle (Block, Aftring, Mehard \& Buse, 1987).

Here we investigated the effect of low pre-exercise muscle glycogen content on the activation of the BCKADH and whether BCAA ingestion, causing an increase in muscle BCAA uptake (MacLean, Graham \& Saltin, 1995), is related to activation of BCKADH during 90 min of one leg knee-extensor exercise in man.

\section{METHODS}


Ten healthy male volunteers participated in the study. Five subjects were studied during one leg knee-extensor exercise with a normal and low muscle glycogen content leg. The other five subjects were studied during exercise with and without pre-exercise BCAA ingestion. Mean age, weight, height, and maximal one leg power output was $27 \pm 3 \mathrm{yr}, 72 \pm 3 \mathrm{~kg}, 1.79 \pm 0.05 \mathrm{~cm}$ and $63 \pm 4$ Watt. All subjects were healthy and physically active and participated regularly in leisure sport. The subjects were informed about possible risks and discomfort involved in this experiment before giving their voluntary consent to participate. The study was performed according to the 'Declaration of Helsinki' and was approved by the Ethical Committee of the Karolinska Institute, Stockholm and of the Copenhagen-Fredrikberg, committee.

\section{Protocol}

Subjects performed one legged exercise in the upright position on an ergometer that permits the exercise to be confined to the quadriceps femoralis muscle group (Andersen \& Saltin, 1985). Three days before the actual experiment subjects performed a graded exercise test to determine their maximal one leg power output $\left(W_{\max }\right)$. The exercise protocol consisted of $90 \mathrm{~min}$ one leg knee-extensor exercise at a workload of $60-65 \% \mathrm{~W}_{\max }$. After the $90 \mathrm{~min}$ of exercise the subjects were not completely exhausted, but experienced moderate to quite intense exertion localized in the exercised leg. The subjects that participated in the study with a normal and low glycogen content quadriceps femoralis muscle performed the two tests on one day. In the morning subjects started at random with the normal or low glycogen content leg and in the afternoon with the other leg after a resting period of $1 \mathrm{~h}$. In order to obtain one normal and one low glycogen content leg the subjects underwent a glycogen depletion protocol on the evening before the actual test (Van Hall, Saltin, Van der Vusse, Söderlund \& Wagenmakers, 1995). The five subjects that were studied with or without BCAA ingestion performed the control test during the morning and after $1 \mathrm{~h}$ of rest the other leg was exercised after BCAA ingestion. The BCAA were provided as three boluses 45 and $20 \mathrm{~min}$ before the start of exercise and the last bolus was provided $5 \mathrm{~min}$ after the start of the exercise bout. The first bolus that was provided contained $154 \mathrm{mg} \cdot \mathrm{kg}^{-1}$ body weight BCAA and the second and third bolus contained $77 \mathrm{mg} \cdot \mathrm{kg}^{-1}$ body weight BCAA with a composition of $1.7: 1.15: 1$ of $\mathrm{L}$-leucine, $\mathrm{L}$-valine and $\mathrm{L}$-isoleucine, respectively.

On the experimental day subjects reported to the laboratory in the morning after an overnight fast. The subjects were fasted throughout the day. Catheters for blood sampling were placed in the femoral artery and vein in the inguinal region of the leg to be exercised and advanced with the tip placed $5-6 \mathrm{~cm}$ proximal to the inguinal ligament. $A$ thermistor was inserted through the venous catheter for blood flow measurements by the constant infusion thermodilution technique (Andersen \& Saltin, 1985). After placement of the catheters the subjects rested for $60 \mathrm{~min}$ in the supine position. During the resting period between the two tests a femoral venous catheter was placed in the leg to be exercised in the afternoon. Arterial and venous blood was sampled simultaneously before exercise and after 30,60 , and $90 \mathrm{~min}$ of exercise. Femoral venous blood flow was measured by the thermodilution technique (Andersen \& Saltin, 1985) just before the blood samples were taken. Muscle biopsies 
were taken at rest, just before the exercise started and exactly after $90 \mathrm{~min}$ of exercise for analysis of the BCKADH, amino acids and glycogen.

\section{Plasma analysis}

Blood was sampled with heparinized syringes and analyzed for hemoglobin and hematocrit, the remainder was immediately centrifuged to obtain plasma. Part of the plasma was deproteinized with sulfosalicylic acid (6 mg.100 $\mathrm{ll}^{-1}$ plasma) vortex-mixed and frozen in liquid nitrogen and analyzed for amino acids by HPLC (Van Eijk, Fooyakkers \& Deutz, 1993).

\section{Muscle analysis}

Muscle biopsies were obtained within $10 \mathrm{~s}$ after termination of the exercise bout. 10$30 \mathrm{mg}$ of fresh muscle tissue was directly weighed and transferred in $700 \mu \mathrm{l}$ ice-cold SET buffer ( $250 \mathrm{mM}$ sucrose, $2 \mathrm{mM}$ EDTA, $10 \mathrm{mM}$ TRIS/HCl pH 7.4) the remainder of muscle tissue was immediately frozen in liquid nitrogen for amino acid and glycogen analysis. Homogenates for BCKADH measurements were prepared with a Teflon-glass Potter-Elvehjem homogenizer. The actual activity and total activity were measured as described previously (Wagenmakers et al, 1984) from the ${ }^{14} \mathrm{CO}_{2}$ production from $\left[1-{ }^{14} \mathrm{C}\right]-\alpha$-ketoisocaproic acid. The incubation time in this study was $20 \mathrm{~min}$ and the specific activity of the $\alpha$-ketoisocaproic acid was $10.000 \mathrm{dpm} . \mathrm{nmol}^{-1}$.

Muscle tissue for amino acid and glycogen analysis was freeze dried and blood and connective tissue was removed. For amino acid analysis 2-5 mg dried muscle

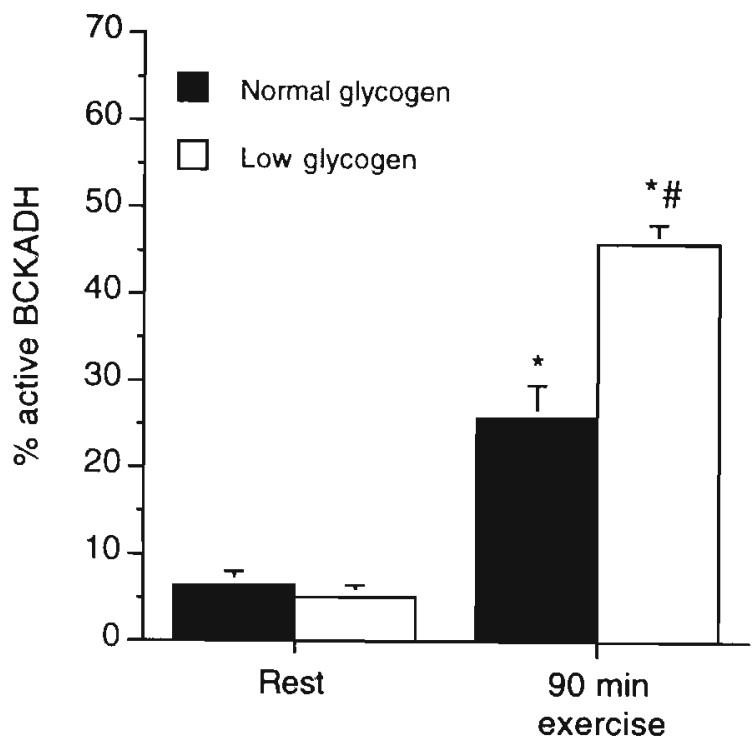

Figure 1. Percentage active branched-chain $\alpha$-keto acid dehydrogenase in skeletal muscle at rest and after $90 \mathrm{~m} / \mathrm{n}$ of exercise with a normal and low muscle glycogen content leg.

"Significant different from rest, "versus the nomal glycogen content muscle $(P<0.05)$. 
was extracted with $5 \%$ sulfosalicylic acid while vortex-mixed vigorously and analyzed by HPLC (Van Eijk et al, 1993). The remainder was powdered and extracted with PCA for determination of muscle glycogen determined by a fluorometric enzymatic method (Van der Vusse, Janssen, Coumans, Kuipers, Does \& Ten Hoor, 1989).

\section{Statistical analysis}

All data are means \pm SEM. Statistical analysis of the data was done using the non parametric Wilcoxon signed-rank test to determine differences between data obtained in the low and normal glycogen leg test. Statistical significance was set at $\mathrm{P}<0.05$.

\section{RESULTS}

\section{Muscle glycogen}

The glycogen depletion protocol the evening before the normal/low muscle glycogen content test caused a considerable lower muscle glycogen concentration in the depleted leg, $147 \pm 34 \mathrm{mmol}$ glycosyl units. $\mathrm{kg}^{-1} \mathrm{dry}$ muscle for the low glycogen leg and $392 \pm 21 \mathrm{mmol}$ glycosyl units. $\mathrm{kg}^{-1} \mathrm{dry}$ muscle for the normal glycogen leg. During the 90 min of exercise muscle glycogen concentration was decreased considerably in both legs. Glycogen usage during the $90 \mathrm{~min}$ of exercise was higher when exercise was performed with normal muscle glycogen stores. Muscle glycogen content was different in both legs although not significant, $160 \pm 45$ and $91 \pm 19 \mathrm{mmol}$ glycosyl units. $\mathrm{kg}^{-1} \mathrm{dry}$ muscle for the normal and low glycogen content leg, respectively.

\section{$B C K A D H$ activity}

Pre-exercise muscle glycogen content did not affect the percentage active BCKADH at rest (Fig. 1). However, the exercise induced activation of BCKADH was considerably higher after pre-exercise muscle glycogen lowering. The exercise induced increase in the percentage active BCKADH is 4-fold whereas exercise with low glycogen stores caused a 9-fold increase of the percentage active BCKADH (Fig. 1).

$B C A A$ ingestion caused a nearly 3 -fold increase in the resting BCKADH activity (Fig. 2). The exercise induced increase in BCKADH activity after BCAA supplementation had nearly the same magnitude as the exercise induced increase without BCAA supplementation implying that the effects of BCAA ingestion and exercise are additive.

The total BCKADH activity was similar in both experiments and the resting actual activity was the same except when BCAA were ingested. In that case the actual activity increased approximately 3 -fold (Table 1 ).

\section{BCAA fluxes and muscle concentration}

At rest and during exercise with the leg with a normal and low muscle glycogen content there was no significant exchange of BCAA across the exercising leg (Fig. 3). However, after 90 min of exercise an uptake of BCAA amino acids was found. 
Significance $(P<0.04)$ was only reached in the leg with normal muscle glycogen content. The BCAA concentration in muscle was not different between the legs at rest and after $90 \mathrm{~min}$ of exercise and did not change from the resting value during exercise (Fig. 3).

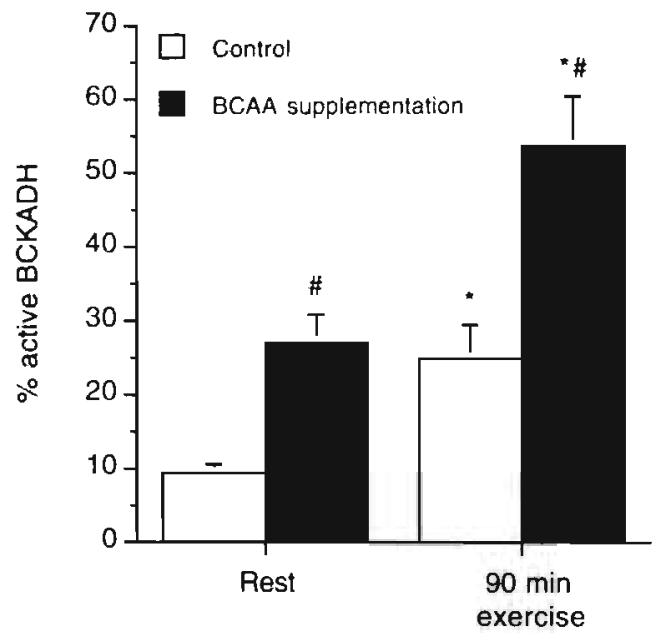

Figure 2. Percentage active branched-chain $\alpha$-keto acid dehydrogenase in skeletal muscle at rest and after 90 min of exercise without (control) and with oral pre-exercise BCAA ingestion (BCAA supplementation).

"Significant different from rest, "versus the control $(P<0.05)$.
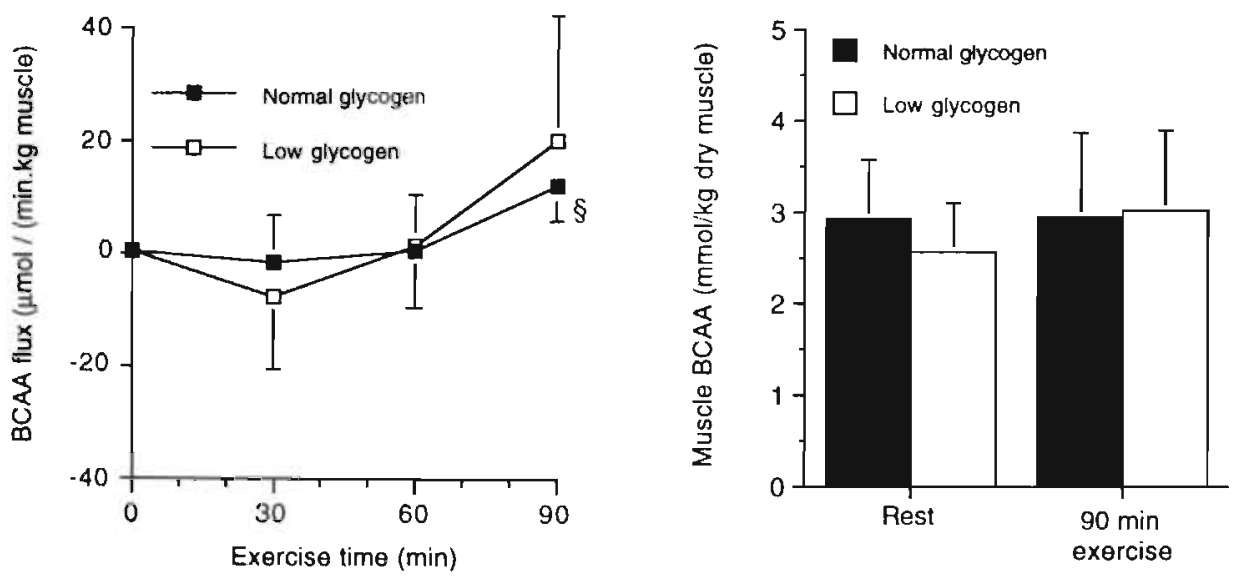

Figure 3. BCAA flux over the leg and muscle BCAA content at rest and after 90 min of exercise with a normal and low glycogen content leg.

$\$$ Significant uptake of the BCAA by the muscle $(P<0.05)$. 

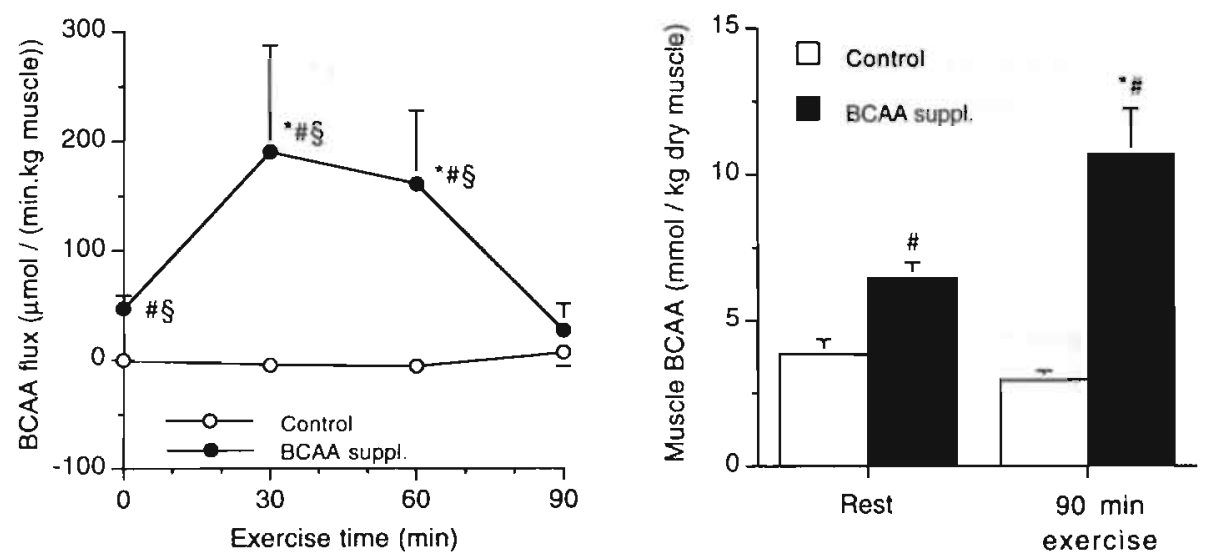

Figure 4. BCAA flux over the active leg and muscle BCAA content at rest and after 90 min of exercise without (control) or with pre-exercise BCAA ingestion (BCAA suppl.).

3 out of 5 subjects BCAA fluxes have been published before (MacLean et al, 1996). "Significant differences from rest, "versus the control, §significant uptake of the BCAA by the muscle $(P<0.05)$.

$B C A A$ ingestion prior to exercise caused a substantial uptake of BCAA in the muscle at rest and after 30 and 60 min of exercise (Fig. 4). No exchange of BCAA was observed in the control test without $B C A A$ ingestion. BCAA ingestion caused an increase in the BCAA concentration in the muscle both at rest and after $90 \mathrm{~min}$ of exercise in comparison to the control test (Fig. 4).

\section{DISCUSSION}

This study clearly demonstrates that the exercise-induced activation of the BCKADH is larger in a muscle with a low glycogen content than in a muscle with a normal glycogen content. Muscle glycogen was lower during exercise with the low glycogen content leg, albeit not significantly anymore after $90 \mathrm{~min}$. Previously, Wagenmakers et al (1991) observed an inverse relationship between the post-exercise muscle glycogen content and the activity of the BCKADH during prolonged two legged cycle exercise. Furthermore, a rapid activation of the BCKADH (from $17 \%$ at rest to $53 \%$ at exhaustion) also was observed in a patient with McArdle's disease a glycogen breakdown defect in muscle (Wagenmakers et al, 1990). All these studies seem to indicate that the BCKADH is activated more during exercise when the glycogen availability or rate of glycolysis in muscle is lower.

ADP and ATP have been implicated in the activation of the BCKADH during exercise. ADP is an inhibitor of the kinase of the BCKADH (Lau, Fatania \& Randle, 1982 ) and a rise in its concentration due to a decrease in the muscle energy state 
could, therefore, activate the BCKADH. A direct effect of ATP on BCKADH activity was proposed in rat muscle during exercise as a negative correlation was found between BCKADH activity and the muscle ATP concentration (Kasperek, 1989). However, the exercise protocol used in this study does not lead to a change of the muscle ATP and ADP concentration compared to the resting value (Van Hall et al, 1995) while the BCKADH is substantially activated. Furthermore, no difference was observed in the muscle ATP and ADP concentration of the normal and low glycogen leg, while more activation occurred in the low glycogen leg. Others have also observed activation of BCKADH during exercise without changes in muscle ADP and ATP concentration (Wagenmakers et al, 1991; Shimomura, Suzuki, Saitoh, Tasaki, Harris \& Suzuki,1990; Shimomura, Fujii, Suzuki, Fujitsuka, Naoi, Sugiyama et al, 1993). In these studies only total tissue ATP and ADP have been measured. However, it is possible that the free (not bound to myosin) cytosolic or more likely the mitochondrial ADP pool is involved in activation of the BCKADH kinase. Such changes may have occurred and may have been larger in the glycogen depleted leg. Excessive rise in free ADP concentration were also estimated to occur during exercise in patients with McArdle's disease, a condition in which glycogen cannot be broken down and which also leads to rapid activation of the BCKADH (Radda, 1986). Only small changes in free ADP and AMP are required for the control of mitochondrial respiration (Dudley, Tullson \& Terjung, 1987), this could also apply for activation of the BCKADH. A major problem in investigating the role of the cytosolic or mitochondrial free ADP concentration in the regulation of metabolism is that methods to directly estimate these at present are lacking.

Suggestions have also been made that an increase of the BCKA concentration in rat muscle during exercise leads to activation of BCKADH (Harris, Paxton, Powell,

Table 1. The total- and actual activity of skeletal muscle branched-chain $\alpha$-ketoacid dehydrogenase at rest and after 90 min of exercise with a normal and low muscle glycogen content and with and without pre-exercise BCAA supplementation.

Normal glycogen

Total activity Actual activity

$4.3 \pm 1.0$

$3.9 \pm 0.8$

$0.2 \pm 0.03$

$1.0 \pm 0.2^{*}$

Control

Total activity

Actual activity

$3.5 \pm 0.9$

$0.4 \pm 0.2$

$4.2 \pm 1.2$

$1.2 \pm 0.5^{*}$
Low glycogen

Total activity

Actual activity

$5.6 \pm 1.2$

$0.2 \pm 0.02$

$5.2 \pm 1.1$

Rest

$90 \mathrm{~min}$ exercise

BCAA supplementation

Values are means \pm SEM from 5 subjects in $\mathrm{nmol}^{\mathrm{min}} \mathrm{m}^{-1} \cdot \mathrm{g}^{-1}$ wet weight muscle. Statistically significance, $\mathrm{P}<0.05$, are expressed as, "versus rest, "versus normal glycogen in the glycogen effect test or versus control in the BCAA supplementation test. 
Goodwin, Kuntz \& Han, 1986). The BCKA have an inhibitory effect on the BCKADH kinase (Lau, Fatania \& Randle, 1982; Harris et al, 1986). Kasperek (1989) did not find increases in muscle BCAA and BCKA concentrations during exercise and suggested that the BCKA are not the primary physiological regulators for activation of the BCKADH during exercise. Here no changes occur in the muscle BCAA concentration during exercise under control conditions. As a large $(>60 \%)$ fall occurs in the muscle glutamate concentration during exercise (Van Hall et al, 1995) the expectation is, however, that the BCAA aminotransferase reaction will shift in the direction of BCKA formation during exercise. This shift is potentially larger in the low glycogen leg (leading to more BCKADH activation) as the fall in muscle glutamate was larger in the low than in the normal glycogen muscle. Increases in the BCKA concentration have been reported during high intensity exercise in human muscle (Fielding, Evans, Hughes, Moldawer \& Bistrain, 1986).

A new finding of this study is that BCAA ingestion leads to activation of the $B C K A D H$ under resting conditions and to a further increase of the BCKADH activity during exercise. As the BCAA concentrations in muscle increased following BCAA ingestion, this will probably lead to higher $B C K A$ concentrations due to a further shift of the BCAA aminotransferase reaction in the direction of BCKA formation. Activation of the BCKADH will then occur via inhibition of the BCKADH kinase. Aftring et al (1986) observed that the intravenous administration of leucine to rats increased the circulating leucine concentration and rapidly the BCKADH activity at rest. Ingestion of a meal with a high protein content also led to a parallel increase of the plasma and muscle BCAA concentrations and of the muscle BCKADH activity for several hours following meal ingestion (Block et al, 1987). All these effects have been suggested to be mediated via increases of the muscle BCKA concentration and the inhibitor effect on the BCKADH kinase.

In conclusion this study clearly shows that the activation of the BCKADH is larger during exercise in muscle with a low as opposed to a normal glycogen content leg. It is also shown that oral ingestion of BCAA leads to activation of the BCKADH and that the effects of exercise and BCAA ingestion are additive. The mechanism of activation by $B C A A$ ingestion probably involves inhibition of the BCKADH kinase as a consequence of an increase of the BCAA and BCKA concentration in muscle. The mechanism of the activation during exercise remains unclear. On the basis of the existing literature it is suggested that increases in the cytosolic or mitochondrial $\mathrm{BCKA}$ and or ADP concentration may both play a role.

\section{References}

Andersen, P. \& Saltin, B. (1985). Maximal perfusion of skeletal muscle in man. Journal of Physiology 366: $233-249$.

Aftring, R.P., Block, K.P. \& Buse, M.G. (1986). Leucine and isoleucine activate skeletal muscle branched-chain $\alpha$-keto acid dehydrogenase in vivo. American Journal of Physiology 250: E599E604. 
Aftring, R.P., Miller, W.J. \& Buse, M.G. (1988). Effects of diabetes and starvation on skeletal muscle branched-chain $\alpha$-keto acid dehydrogenase activity. American Journal of Physiology 254: E292E296.

Block, K.P., Aftring, R.P., Mehard, W.B. \& Buse, M.G. (1987). Modulation of rat skeletal muscle branched-chain $\alpha$-keto acid dehydrogenase in vivo. Journal of Clinical Investigation 79: 1349-1358.

Dudley, G.A., Tullson, P.C. \& Terjung, R.L. (1987). Influence of mitochondrial content on the sensitivity of respiratory control. Journal of Biological Chemistry 262: 9109-9114.

Fielding, R.A., Evans, W.J., Hughes, V.A., Moldawer, L.L. \& Bistrain, B.R. (1986). The effects of high intensity exercise on muscle and plasma levels of alpha-ketoisocaproic acid. European Journal of Applied Physiology 55: 482-485.

Fujii, H., Shimomura, Y., Tokuyama, K. \& Suzuki, M. (1994). Modulation of branched-chain 2-oxo acid dehydrogenase complex activity in rat skeletal muscle by endurance training. Biochimica et Biophysica Acta 1199: 130-136.

Harris, R.A., Paxton, R., Powell, S.M., Goodwin, G.W., Kuntz, M.J. \& Han, A.C. (1986). Regulation of branched-chain $\alpha$-keto acid dehydrogenase complex by covalent modification. Advances in Enzyme Regulation 25: 219-226.

Goldberg, A.L. \& Chang, T.W. (1987). Regulation and significance of amino acid metabolism in skeletal muscle. Federation Proceedings 37: 2301-2307.

Kasperek, G.J. \& Snider, A.D. (1987). Effect of exercise intensity and starvation on activation of branched-chain keto acid dehydrogenase by exercise. American Journal of Physiology 252: E33E37.

Kasperek, G.J. (1989). Regulation of branched-chain 2-oxo acid dehydrogenase activity during exercise. American Journal of Physiology 256: E186-E190.

Lau, K.S., Fatania, H.R. \& Randle, P.J. (1982). Regulation of the branched-chain 2-oxoacid dehydrogenase kinase reaction. FEBS Letters 144: 57-62.

MacLean, D.A., Graham, T.E. \& Saltin, B. (1996). Stimulation of muscle ammonia production during exercise following branched-chain amino acid supplementation in humans. Journal of Physiology submitted.

Shimomura, Y., Suzuki, T., Saitoh, S., Tasaki, Y., Harris, R.A. \& Suzuki, M. (1990). Activation of branched-chain $\alpha$-keto acid dehydrogenase complex by exercise: effect of high-fat diet intake. Joumal of Applied Physiology 68: 161-165.

Shimomura, Y., Fujii, H., Suzuki, M., Fujitsuka, N., Naoi, M., Sugiyama, S. \& Harris, R. A. (1993). Branched-chain 2-oxo acid dehydrogenase complex activation by tetanic contractions in rat skeletal muscle. Biochimica et Biophysica Acta 1157: 290-296.

Shinnick, F.L. \& Harper, A.E. (1976). Branched-chain amino acid oxidation by isolated rat tissue preparations. Biochimica et Biophysica Acta 437: 477-477.

Van der Vusse, G.J., Janssen, G.M.E., Coumans, W.A., Kuipers, H., Does, R.J.M.M. \& Ten Hoor, F. (1989). Effect of training and 15-, 25-, and $42-\mathrm{km}$ contests on the skeletal muscle content of adenine and guanine nucleotides, creatine phosphate, and glycogen. International Journal of Sports Medicine 10: S146-S152.

Van Eijk, H.M.H., Rooyakkers, D.R. \& Deutz, N.E.P. (1993). Rapid routine determination of amino acids in plasma by high-performance liquid chromatography with a 2-3 $\mu \mathrm{m}$ Spherisorb ODS II column. Journal of Chromatography 620: 143-148.

Van Hall. G., Saltin, B., Van der Vusse, G.J., Söderlund, K. \& Wagenmakers, A.J.M. (1995). Deamination of amino acids as a source for ammonia production in human skeletal muscle during prolonged exercise. Journal of Physiology 489: 251-261.

Wagenmakers, A.J.M., Schepens, J.T.G. \& Veerkamp, J.H. (1984). Effect of starvation and exercise on the actual and total activity of the branched-chain 2-oxo acid dehydrogenase complex in rat tissues. Biochemical Jouma/233: 815-821.

Wagenmakers, A.J.M., Brookes, J.H., Coakley, J.H., Reilly, T. \& Edwards, R.H.T. (1989). Exerciseinduced activation of the branched-chain 2-oxo acid dehydrogenase in human skeletal muscle. European Journal of Applied Physiology 59: 159-167. 
Wagenmakers, A.J.M., Coakley, J.H. \& Edwards, R.H.T. (1990). Metabolism of branched-chain amino acids and ammonia during exercise: clues from McArdle's disease. International Joumal of Sports Medicine 11: S101-S113.

Wagenmakers, A.J.M., Beckers, E.J., Brouns, F., Kuipers, H., Soeters, P.B., Van der Vusse, G.J. \& Saris, W.H.M. (1991). Carbohydrate supplementation, glycogen depletion and amino acid metabolism during exercise. American Journal of Physiology 260: E883-E890. 


\title{
Chapter 4
}

\section{Muscle glycogen content, glycogenolytic rate and $\mathrm{K}^{+}$exchange during prolonged dynamic exercise}

G. van Hall, A.J.M. Wagenmakers, B. Saltin*

University of Limburg, Maastricht, The Netherlands; "CMRC, Copenhagen, Denmark.

Plügers Archiv submitted.

\begin{abstract}
1. Most of our knowledge on factors that regulate muscle glycogen breakdown originates from studies using high intensity exercise. Here we examine whether the same factors regulate glycogen breakdown during prolonged exercise. Six subjects performed dynamic one leg knee-extensor exercise for 90 min at a workload of $60-65 \%$ of their maximal one leg power output. In the morning exercise was performed starting at random with the normal or low glycogen leg and in the afternoon with the other leg.

2. Pre-exercise muscle glycogen content was $415 \pm 22$ and $174 \pm 24 \mu \mathrm{mol} . \mathrm{g}^{-1} \mathrm{dry}$ weight in the normal and low glycogen content muscle, respectively. Glycogen breakdown was 3 -fold higher in the normal glycogen leg than in the low glycogen leg suggesting that glycogen as a substrate enhances its own breakdown. Glucose uptake increased continuously with exercise duration but no differences were observed between the legs. During the initial phase of exercise blood lactate and pyruvate release was substantial in both legs but returned to pre-exercise levels after 30-60 min of exercise. Lactate as well as pyruvate release was significantly higher in the normal glycogen leg during the first half hour of exercise. The peak lactate release coincided with a temporary decrease in muscle PC. No relation was observed between blood ammonia concentration or release or adrenaline concentration and the rate of glycogen breakdown.

3. $\mathrm{K}^{+}$was continuously released during exercise at a rate $2-$ to 3 -fold higher than at rest. No difference between the legs was observed.

4. In contrast to high intensity exercise adrenaline and ammonia do not appear to be involved in the regulation of the rate of glycogen breakdown. The glycogen concentration in muscle and increase in $\mathrm{P}_{\mathrm{i}}$ (due to $\mathrm{PC}$ breakdown) appear to play a role both at high and moderate exercise intensity exercise.
\end{abstract}




\section{INTRODUCTION}

During high intensity exercise the rate of glycogen breakdown increases several thousand fold within seconds. This high glycogenolytic rate results in a massive lactate production and is achieved by activation of the key enzymes glycogen phosphorylase and phosphofructokinase. The following mechanisms for activation of glycogen phosphorylase do apply. During contraction $\mathrm{Ca}^{2+}$ is released from the endoplasmatic reticulum and activates phosphorylase $b$ kinase. This leads to a transformation of phosphorylase $b$ to its more active $a$ form. Phosphorylase $b$ kinase is also activated by the c-AMP dependent cascade of reactions initiated by binding of adrenaline to the muscle receptor. Muscle glycogen as a substrate itself may also be important for its own breakdown as intense exercise with reduced glycogen stores was reported to lead to a reduced rate of glycogen breakdown and an elevated muscle glycogen content enhanced glycogenolysis (Gollnick, Pernow, Essén, Jansson \& Saltin, 1981). Furthermore, allosteric activation of glycogen phosphorylase by AMP, IMP and inorganic phosphate occurs during intense exercise.

The regulation of phosphofructokinase is complex and some uncertainty exists regarding to its control. Phosphofructokinase activity is thought to be influenced by several intracellular factors including the energy charge, and concentrations of AMP, fructose-bisphosphate, ammonia and $\mathrm{pH}$. Moreover, in several studies a strong correlation has been observed between blood ammonia concentration and blood lactate concentration during graded incremental exercise (Babij, Matthews \& Rennie, 1983; Buono, Clancy \& Cook, 1984). Others have suggested that adrenaline is the main activator of phosphofructokinase and of the rate of glycogen breakdown (Brooks, 1991; Brooks, Butterfield, Wolfe, Groves, Mazzeo, Sutton et al, 1991) as a positive correlation was observed between adrenaline and lactate concentration in blood at rest and during graded exercise under hypoxic conditions.

Most of the above mentioned studies investigating the effect of potential regulators of glycogen breakdown used high intensity exercise. The present study was undertaken to investigate whether the rate of glycogen breakdown is regulated by the same mechanisms during prolonged moderate intensity exercise. We specifically investigated the time course of lactate and pyruvate release and whether positive correlations are seen between changes in muscle adenine nucleotides, PC and ammonia concentrations as well as plasma catecholamine levels and lactate release and the rate of glycogen breakdown during dynamic one leg exercise with a normal and a low glycogen content leg. We finally investigated whether $\mathrm{K}^{+}$is continuously released from the muscle during prolonged exercise as previously observed during high intensity exercise (Sjøgaard, Adams \& Saltin, 1985) and whether a difference exist in the $\mathrm{K}^{+}$release from the leg with the normal and low glycogen content.

\section{METHODS}




\section{Subjects}

Six healthy male volunteers participated in the study. Their mean age, weight, height, and maximal one leg power output was $25 \pm 2 \mathrm{yr}, 77 \pm 4 \mathrm{~kg}, 1.80 \pm 0.04 \mathrm{~m}$ and $64+$ 5 Watt. All subjects were healthy and physically active and participated regularly in leisure sport. The subjects were informed about possible risks and discomfort involved in this experiment before giving their voluntary consent to participate. The study was approved by the Ethical Committee of the Karolinska Institute.

\section{Protocol}

Subjects performed one legged exercise in the upright position on an ergometer that permits the exercise to be confined to the quadriceps muscle group (Andersen \& Saltin, 1985). Three days before the actual experiment subjects performed a graded exercise test to determine their maximal one leg power output $\left(W_{\max }\right)$. The exercise protocol consisted of 90 min one leg knee-extensor exercise at a workload of $60-65 \%$ $\mathrm{W}_{\max }$. After the 90 min of exercise the subjects were not completely exhausted, but experienced moderate to intense exertion localized in the exercised leg. The subjects were studied under two experimental conditions, with a normal and a low glycogen content of the quadriceps muscle. The two tests were performed on one day. In the morning subjects started at random with the normal or low glycogen content leg and in the afternoon with the other leg after a resting period of $2 \mathrm{~h}$. In order to obtain one normal and one low glycogen content leg the subjects had to undergo a glycogen depletion protocol on the evening before the actual test (Van Hall, Saltin, Van der Vusse, Söderlund \& Wagenmakers, 1995). On the experimental day subjects reported to the laboratory in the morning. Catheters for blood sampling were placed in the femoral artery and vein in the inguinal region of the leg to be exercised and advanced with the tip placed $5-6 \mathrm{~cm}$ proximal to the inguinal ligament. A thermistor was inserted through the venous catheter for blood flow measurements by the constant infusion thermodilution technique (Andersen \& Saltin, 1985). After placement of the catheters the subjects rested for $30 \mathrm{~min}$ in the supine position. During the resting period between the two tests a femoral venous catheter was placed in the leg to be exercised in the afternoon. Arterial and venous blood was sampled simultaneously before exercise and after 10,30,60, and 90 min of exercise. Femoral venous blood flow was measured by the thermodilution technique (Andersen \& Saltin, 1985) just before the blood samples were taken in the morning exercise bout.

\section{Analysis}

Blood was sampled anaerobically with heparinized syringes and analyzed for blood gasses, hemoglobin and hematocrit. Plasma was deproteinized with $0.3 \mathrm{M}$ perchloric acid (PCA) and analyzed fluorometrically for ammonia with glutamate dehydrogenase. Lactate and pyruvate were determined in whole blood that was deproteinized with $1.2 \mathrm{M}$ perchloric acid $(1: 1)$ and stored immediately in liquid nitrogen. Just before the determination of lactate and pyruvate the samples were neutralized with $2.3 \mathrm{M}$ potassium bicarbonate $\left(\mathrm{KHCO}_{3}\right)$. Blood lactate, pyruvate and plasma glucose were determined in duplicate with enzymatic methods on a COBAS 
$\mathrm{BIO}$ analyzer. Plasma $\mathrm{K}^{+}$concentration was measured using an ion-selective electrode (radiometer KNA1 Sodium-Potassium Analyzer). Plasma catecholamines were measured by HPLC (Pharmacia, The Netherlands). Plasma insulin concentrations were determined by a commercially available radio immunoassay kit (Pharmacia, The Netherlands).

Biopsies were divided and quickly frozen in liquid nitrogen. 5-10 mg of muscle tissue was extracted with $150 \mu \mathrm{l}$ of $3 \mathrm{M} \mathrm{PCA}$ for $20 \mathrm{~min}$ and slowly neutralized with $250 \mu$ of $2 \mathrm{M} \mathrm{KHCO}_{3}$ and analyzed fluorometrically for ammonia by the method of Kun \& Kearney (1974). The remainder of the muscle specimens were freeze dried and blood and connective tissue was removed. Since one leg knee-extensor exercise is confined to the quadriceps femoris muscle the active muscle mass is calculated as $2.84 \pm 0.46 \mathrm{~kg}$ wet weight corresponding to $0.66 \pm 0.16 \mathrm{~g}$ dry weight calculated from the individual dry/wet weight muscle ratio with a mean of $4.3 \pm 0.1$. The freeze dried muscle was powdered and extracted with PCA for determination of adenine nucleotides, inosine monophosphate (IMP), inosine and hypoxanthine by HPLC (Van der Vusse, Janssen, Coumans, Kuipers, Does \& Ten Hoor, 1989). Muscle glycogen was determined by a fluorometric enzymatic method (Van der Vusse et al, 1989). PC was determined with an enzymatic method (Harris, Hultman \& Nordesjö, 1974) on a COBAS BIO analyzer (Roche, The Netherlands).

\section{Calculations}

Lactate, pyruvate, glucose, ammonia and $\mathrm{K}+$ fluxes across the thigh were calculated from the difference in concentration in femoral arterial and venous blood (a-fv) and blood flow. The total net exchange of glucose, lactate and pyruvate during the $90 \mathrm{~min}$ of exercise was determined as the area under the curve. The flux rates of two consecutive time points were averaged and multiplied by the time span and summing these for the whole exercise period.

\section{Statistical analysis}

All data are means \pm SEM. Statistical analysis of the data was done using the non parametric Wilcoxon signed-rank test to determine differences between data obtained in the low and normal glycogen leg test. Statistical significance was set at $\mathrm{P}<0.05$.

\section{RESULTS}

\section{Muscle glycogen breakdown}

On the experimental day muscle glycogen content was $174 \pm 24$ versus $415 \pm 23$ mmol glycosyl units. $\mathrm{kg}^{-1} \mathrm{dry}$ weight muscle in the low and normal glycogen content leg, respectively $(P<0.003)$. During the $90 \mathrm{~min}$ of exercise muscle glycogen decreased with 280 and 96 mmol glycosyl units. $\mathrm{kg}^{-1}$ dry muscle in the normal and low glycogen muscle, respectively, representing a glycogen breakdown of $184 \mathrm{mmol}$ (normal) and $64 \mathrm{mmol}$ (low) glycosyl units in the respective legs. 

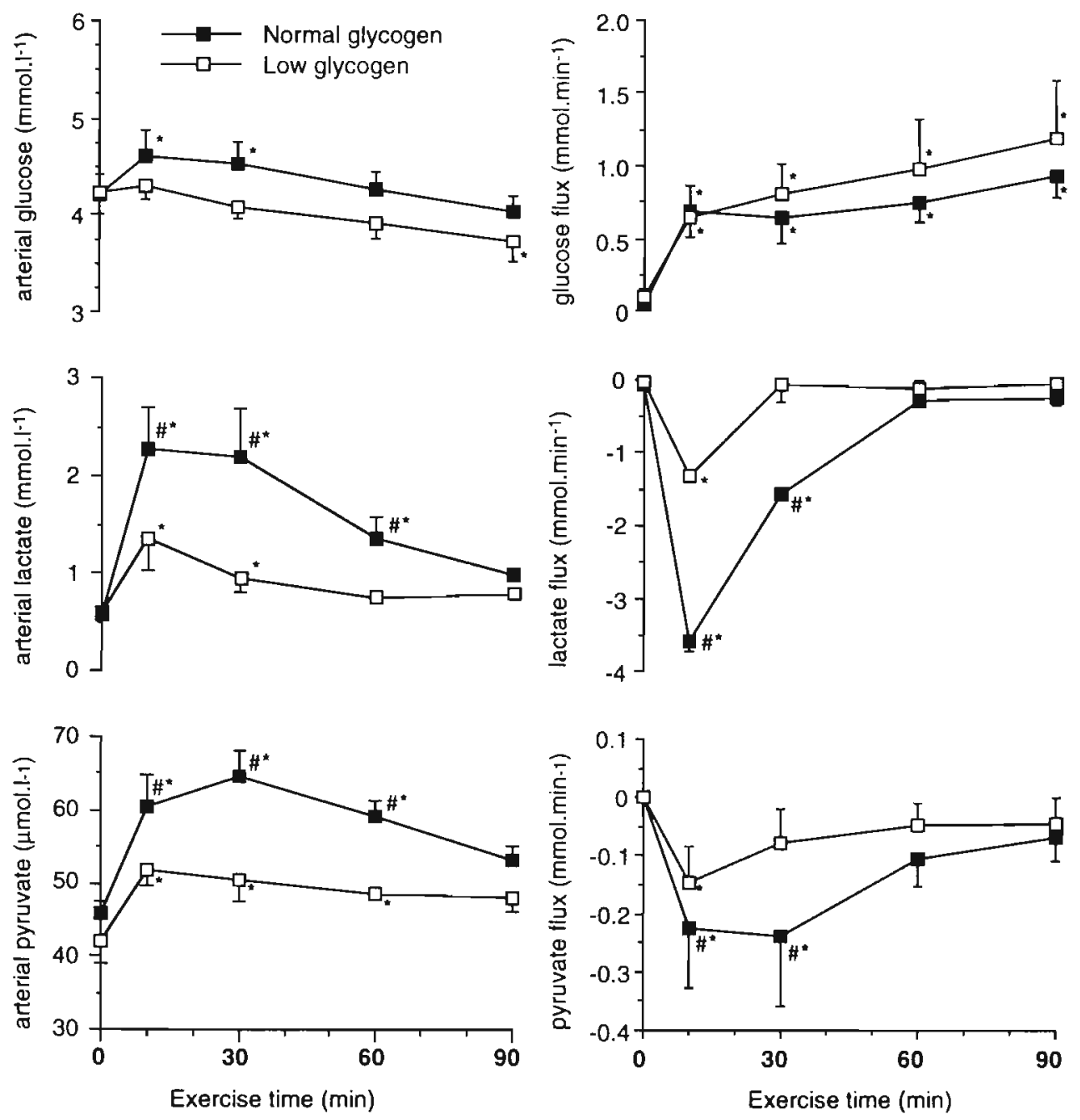

Figure 1. Femoral arterial concentrations and fluxes of glucose, lactate and pyruvate at rest and during one leg knee-extensor exercise with a normal and low glycogen content leg.

Values are means \pm SEM of 6 subjects. "Significant different from rest $(P<0.05)$, "significant different from the low glycogen leg $(P<0.05)$.

Muscle oxygen consumption and blood $\mathrm{pH}$

Muscle oxygen consumption was not different between the legs during the whole exercise period (Table 1). Blood $\mathrm{pH}$ was higher in the low glycogen leg after 10 $(\mathrm{P}<0.01)$ and $30 \mathrm{~min}(\mathrm{P}<0.04)$ of exercise. After $90 \mathrm{~min}$ of exercise blood $\mathrm{pH}$ was not different between the legs. 
Table 1. Blood parameters at rest and during exercise

\begin{tabular}{|c|c|c|c|c|c|}
\hline & & Rest & $10 \mathrm{~min}$ & $30 \mathrm{~min}$ & $90 \mathrm{~min}$ \\
\hline $\begin{array}{l}\mathrm{pO}_{2} \text { venous } \\
(\mathrm{Pa})\end{array}$ & $\begin{array}{l}\text { NG } \\
\text { LG }\end{array}$ & $\begin{array}{l}6.0 \pm 0.4 \\
6.2 \pm 0.2^{F}\end{array}$ & $\begin{array}{l}4.2 \pm 0.2^{*} \\
3.8 \pm 0.2^{*}\end{array}$ & $\begin{array}{l}4.0 \pm 0.2^{*} \\
3.9 \pm 0.1^{*}\end{array}$ & $\begin{array}{l}4.2 \pm 0.3^{*} \\
4.1 \pm 0.2^{*}\end{array}$ \\
\hline a-fv $\underset{\text { (mil. } \mathrm{O}_{2} \text { blood) }}{ }$ & $\begin{array}{l}N G \\
L G\end{array}$ & $\begin{array}{l}62 \pm 7 \\
44 \pm 6^{\prime \prime}\end{array}$ & $\begin{array}{l}133 \pm 2^{*} \\
137 \pm 5^{*}\end{array}$ & $\begin{array}{l}139 \pm 2^{*} \\
135 \pm 5^{*}\end{array}$ & $\begin{array}{l}129 \pm 5^{*} \\
132 \pm 6^{*}\end{array}$ \\
\hline Venous blood pH & $\begin{array}{l}N G \\
L G\end{array}$ & $\begin{array}{l}7.36 \pm 0.02 \\
7.35 \pm 0.01\end{array}$ & $\begin{array}{l}7.23 \pm 0.02^{*} \\
7.29 \pm 0.01^{* *}\end{array}$ & $\begin{array}{l}7.27 \pm 0.02^{*} \\
7.30 \pm 0.01^{* *}\end{array}$ & $\begin{array}{l}7.32 \pm 0.01 \\
7.31 \pm 0.01\end{array}$ \\
\hline
\end{tabular}

Values are means \pm SEM from 6 subjects. NG is normal glycogen leg; LG is low glycogen leg; a-fv, arterial minus femoral venous. "Significant different from rest and "significant different from normal glycogen.

\section{Glucose, lactate and pyruvate fluxes}

Glucose uptake increased during the whole exercise period (Fig. 1). No differences in glucose uptake was observed between the normal- and low glycogen muscle, although a trend existed to higher glucose uptake in the low glycogen muscle despite lower arterial glucose concentration (Fig. 1). Lactate release increased during the initial period of exercise and declined to rest values after $30 \mathrm{~min}$. Pyruvate release was elevated during the whole exercise period but as with lactate peak pyruvate release was observed within the first $30 \mathrm{~min}$ of exercise. Both, lactate and pyruvate release were significantly higher in the leg with normal muscle glycogen content during the initial period of exercise (Fig. 1). Total lactate and pyruvate release during the exercise period for the two legs was higher in the normal glycogen leg, mean values being $36 \pm 3$ versus $19 \pm 2$ and pyruvate release was $14 \pm 2$ versus $6 \pm 3$ mmol.90 $\mathrm{min}^{-1}$ for the normal and low glycogen content leg, respectively.

\section{Energy rich phosphates and ammonia in muscle}

Prolonged exercise for $90 \mathrm{~min}$ did not lead to changes in muscle concentration of ATP, IMP and PC in the two legs (Fig. 2). PC was decreased in both legs after 10 min of exercise and returned to pre-exercise concentration after $90 \mathrm{~min}$ of exercise (Fig. 2). Muscle hypoxanthine concentration was below the level of detection at rest and during exercise $\left(0.1 \mathrm{mmol} . \mathrm{kg}^{-1} \mathrm{dry}\right.$ muscle). Muscle ammonia concentration increased gradually to similar values during exercise in the two legs (Van Hall et al, 1995).

\section{Ammonia exchange}

Ammonia was taken up by the muscle at rest. During exercise ammonia was released from the active muscle and appeared to reach a plateau after $60 \mathrm{~min}$ of exercise. No differences were observed between the normal and low glycogen leg (Van Hall et al, 1995). No relation was found between lactate and ammonia release during the 90 min of sustained one leg knee-extensor exercise (Fig. 3). 


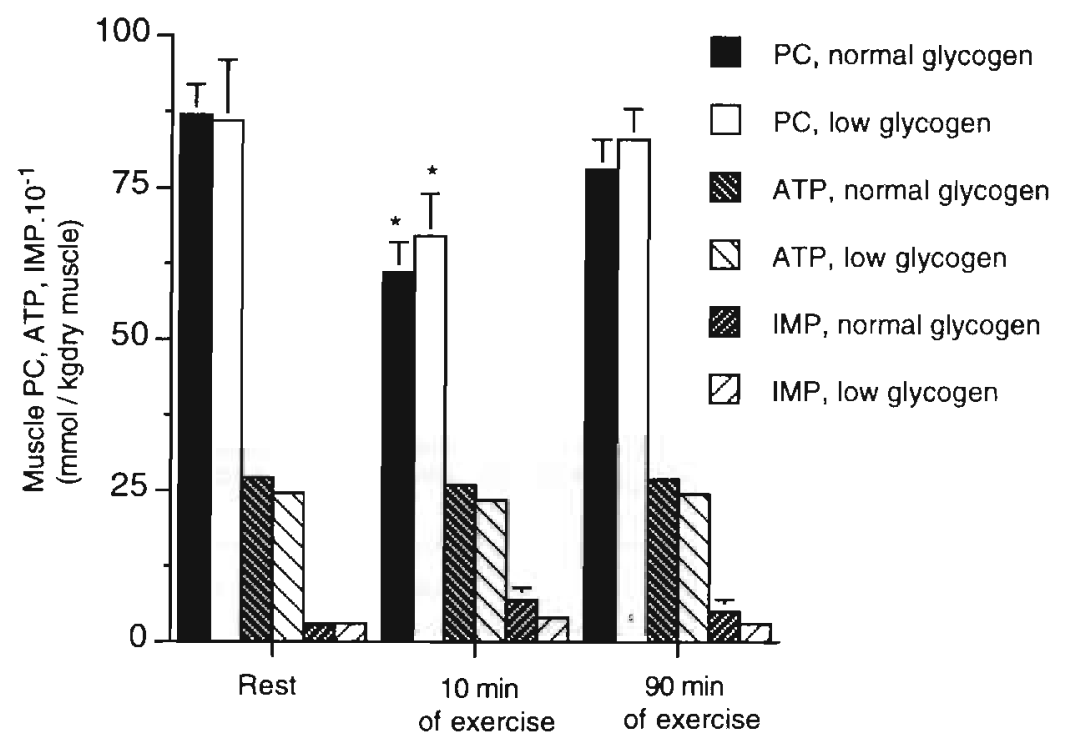

Figure 2. Muscle PC, ATP and IMP at rest and during exercise with a normal and low glycogen content leg.

Values are means \pm SEM of 6 subjects. "Significant different from rest $(P<0.05)$. Part of the data have previously reported (Van Hall et al, 1995).

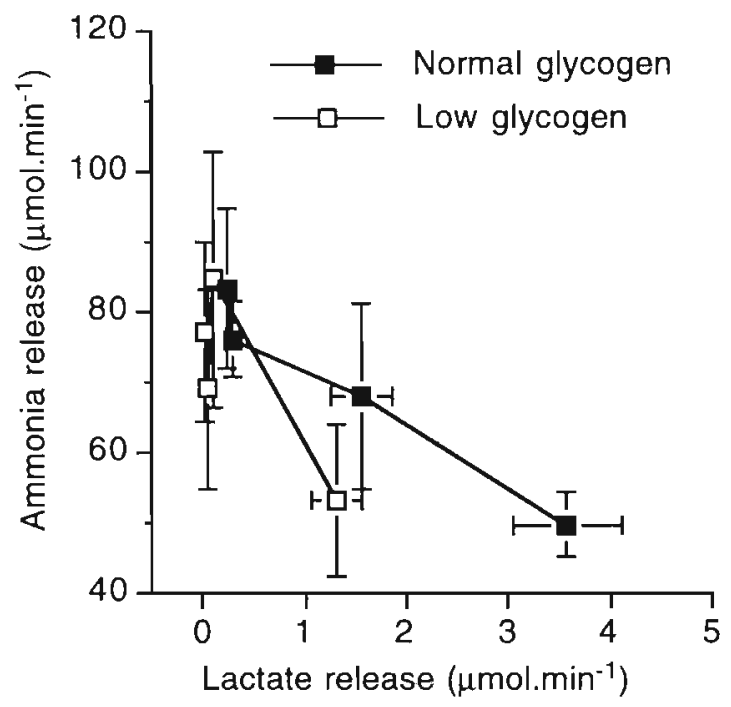

Figure 3. The relation between ammonia and lactate release during prolonged exercise with a normal and low glycogen leg.

Values are means \pm SEM of 6 subjects. 
Plasma catecholamine and insulin

Arterial adrenaline and noradrenaline concentrations increased 3- to 4-fold during exercise and were significantly higher after $90 \mathrm{~min}$ of exercise compared to $30 \mathrm{~min}$ of exercise (Table 2). The arterial adrenaline concentration was significantly lower after 30 and 90 min of exercise when the normal glycogen leg was exercised than when the low glycogen leg was exercised implying that the highest rate of glycogen breakdown was observed when arterial adrenaline was lower. During exercise with the normal and low glycogen leg arterial noradrenaline concentrations were not different and only small changes were seen in the arterial insulin concentration (Table 2).

Table 2. Arterial plasma concentration of adrenaline, noradrenaline and insulin at rest and during prolonged exercise with a normal and low glycogen content leg.

\begin{tabular}{|c|c|c|c|c|}
\hline & & Rest & $30 \mathrm{~min}$ & $90 \mathrm{~min}$ \\
\hline $\begin{array}{l}\text { Adrenaline } \\
\text { (ng. } \mathrm{ml}^{-1} \text { ) }\end{array}$ & $\begin{array}{l}\text { NG } \\
\text { LG }\end{array}$ & $\begin{array}{l}0.20 \pm 0.02 \\
0.21 \pm 0.04\end{array}$ & $\begin{array}{l}0.59 \pm 0.05^{*} \\
0.74 \pm 0.05^{\star *}\end{array}$ & $\begin{array}{l}0.76 \pm 0.06^{* \S} \\
0.91 \pm 0.02^{* \# \S}\end{array}$ \\
\hline $\begin{array}{l}\text { Noradrenaline } \\
\left(\mathrm{ng} \cdot \mathrm{ml}^{-1}\right)\end{array}$ & $\begin{array}{l}\text { NG } \\
\mathrm{LG}\end{array}$ & $\begin{array}{l}0.75 \pm 0.05 \\
0.66 \pm 0.04\end{array}$ & $\begin{array}{l}2.24 \pm 0.19 \\
2.38 \pm 0.27^{\star}\end{array}$ & $\begin{array}{l}2.98 \pm 0.21 \S \\
3.32 \pm 0.19^{\star \S}\end{array}$ \\
\hline $\begin{array}{l}\text { Insulin } \\
\left(\mu U . \mathrm{ml}^{-1}\right)\end{array}$ & $\begin{array}{l}\text { NG } \\
\text { LG }\end{array}$ & $\begin{array}{l}5.4 \pm 0.5 \\
4.9 \pm 0.7\end{array}$ & $\begin{array}{l}5.1 \pm 0.5^{\star} \\
5.7 \pm 0.9^{*}\end{array}$ & $\begin{array}{l}4.7 \pm 0.4^{\star \S} \\
4.9 \pm 0.5^{\S}\end{array}$ \\
\hline
\end{tabular}

\footnotetext{
Values are means \pm SEM from 6 subjects. NG is normal glycogen leg; LG is low glycogen leg. "Significant different from rest, "significant different from normal glycogen, \$significant different from $30 \mathrm{~min}$.
}

\section{Plasma $K^{+}$and $K^{+}$release}

During exercise the arterial and venous femoral (not shown) $\mathrm{K}^{+}$concentration increased and peak $\mathrm{K}^{+}$concentration was observed after $10 \mathrm{~min}$ of exercise (Fig. 4). After 30 and 90 min of exercise the arterial $\mathrm{K}^{+}$concentration was similar during exercise with the respective legs. $K^{+}$release was higher during exercise than at rest. Again no differences were observed in the potassium release from the normal and low glycogen leg.

\section{DISCUSSION}

The new finding of this study is that during prolonged exercise at constant power output and with a constant oxygen uptake there is a marked lower lactate release from a leg with a low glycogen content. Furthermore, in this study no positive relation was observed between the rate of glycogenolysis and the arterial concentrations of adrenaline and ammonia and the release of ammonia from muscle. There also was no positive relation between $\mathrm{K}^{+}$release and arterial concentration of adrenaline and lactate release. 
Huckabee (1958) showed in a series of experiments in human subjects that lactate accumulation was not a result of muscle hypoxia but primarily a result of its tendency to maintain equilibrium with the amount pyruvate produced in the muscle. Therefore, the observed lactate and pyruvate release that occurs during exercise most likely is caused by a transient imbalance between the rate of pyruvate production by glycogenolysis / glycolysis and the rate of pyruvate oxidation in the mitochondria. Later during the exercise bout the rate of glycolysis and oxidation of pyruvate will be in balance and lactate formation is retarded when pyruvate release is
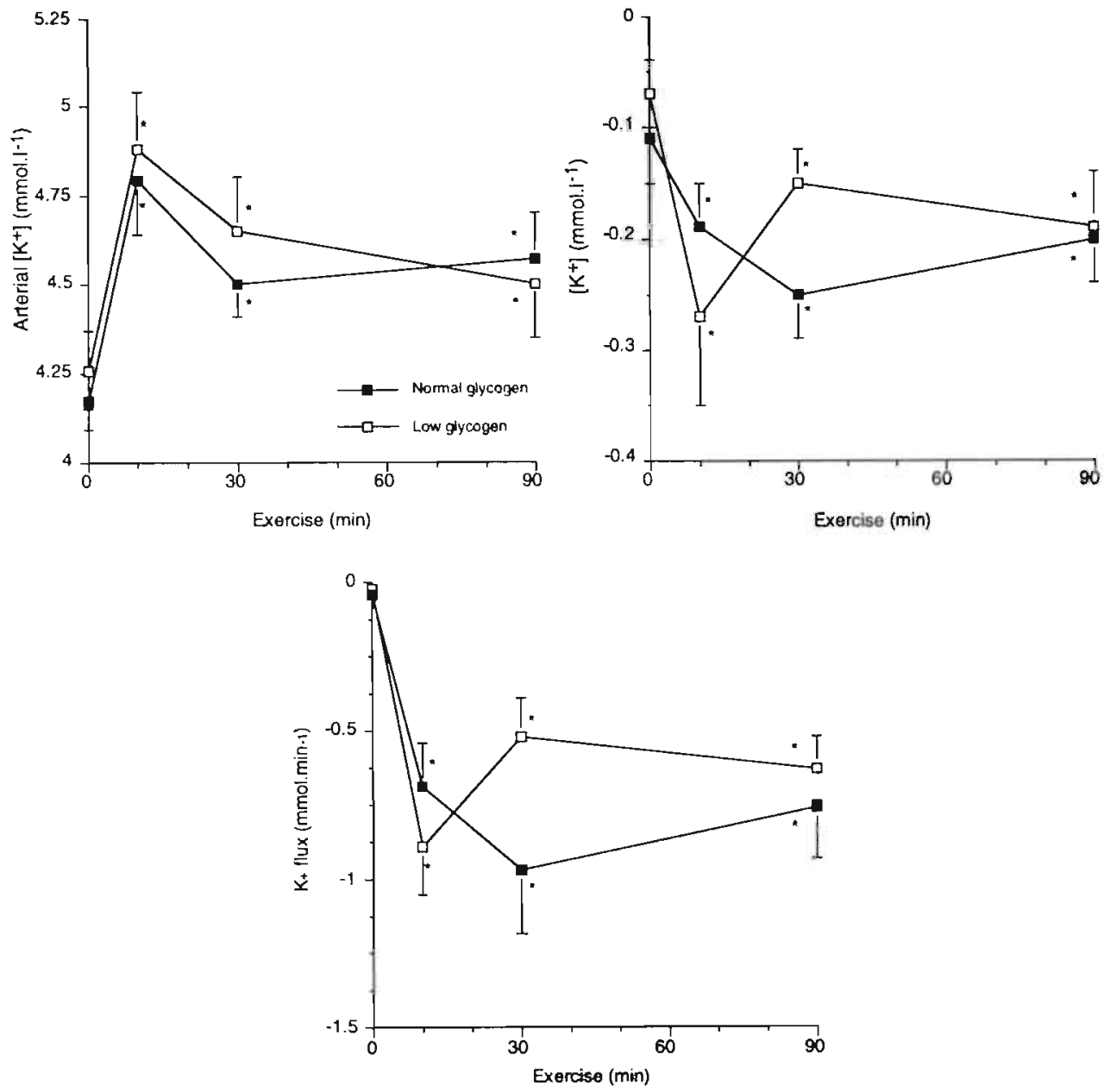

Figure 4. Femoral arterial $K^{+}$concentration, arterio-femoral venous $K^{+}$concentratlon and $K^{+}$ flux at rest and during exercise with a normal and low glycogen content leg.

Values are means \pm SEM of 6 subjects. "Significant different from rest. 
reduced. This implies that the tricarboxylic acid cycle (TCA-cycle) or pyruvate dehydrogenase is not optimally active early in exercise or that the rate of pyruvate formation is higher than needed for energy provision. It has been suggested that the flux through the TCA-cycle has to increase several times to meet the energy demand of exercise (Sahlin, Katz \& Broberg, 1990). An increased flux through the TCA-cycle can be established by increased spinning of the cycle and/or an increased concentration of tricarboxylic acid cycle intermediates (TCAI). This latter option seems to be applicable since TCAl increased within minutes after the start of exercise in rat (Aragon \& Lowenstein, 1980) and man (Sahlin et al, 1990). The time needed to achieve the increase in TCAI may give a delay in the optimal oxidation of pyruvate in the TCA-cycle and will subsequently cause pyruvate accumulation and lead to lactate formation. Pyruvate accumulation per se also seems to play an active role in the expansion of the TCAl as increases in pyruvate force the alanine aminotransferase reaction to production of alanine and TCAl (pyruvate + glutamate <--> alanine $+\alpha$-ketoglutarate). We and others previously reported that the muscle glutamate pool is reduced in size by approximately $60 \%$ within 10 min of exercise at moderate intensity (Sahlin et al, 1990; Van Hall et al, 1995).

Adrenaline has been proposed to regulate and enhance muscle glycogenolysis during high intensity exercise (Richter, Kiens, Saltin, Christensen \& Savard, 1988). A strong correlation has been found between plasma lactate and adrenaline concentration during graded exercise (Mazzeo, Brooks, Schoeler \& Budinger, 1989) and during exercise at altitude (Brooks, 1991; Brooks et al, 1991). In addition, Kaiser, Tesch, Thorssen, Karlsson \& Kaijser (1985) observed a reduced lactate concentration with $B$-adrenoceptor blockade. These studies support the idea that Badrenergic stimulation accelerates muscle glycogenolysis and leads to lactate formation. However, in this study at moderate intensity exercise circulating adrenaline concentrations did not correlate with the rate of glycogen breakdown. The adrenaline concentration was higher when the leg with the low glycogen content was exercised. Chesley, Hultman \& Spriet (1995) were unable to find an effect on muscle lactate and glycogen breakdown when plasma adrenaline concentration was increased within the physiological range by infusion during exercise. Furthermore, Jensen-Ursted, Ahlborg \& Sahlin (1993) found that B-adrenoceptor blockade during prolonged exercise had no effect on lactate release. The increased adrenaline response observed in this study during exercise with a low glycogen leg may lead to increased lipolysis and hepatic glucose production to provide free fatty acids and glucose to compensate for the low muscle glycogen. However, the lack of a difference between the legs in concentrations of adenine nucleotides and ammonia seems to indicate that both legs had access to sufficient fuel to meet energy demand. Blood noradrenaline concentration followed adrenaline concentration.

In this study no relation has been found between lactate and ammonia release during prolonged moderate intensity exercise. Such relations have previously been described during graded incremental and high intensity exercise (Babij et al, 1983; Buono et al, 1984). Therefore, the relation between lactate and ammonia production during short intense exercise appears to be a coincidence of an accelerated rate of glycogenolysis and AMP deamination. The absence of such a correlation at 
moderate intensity exercise seems to indicate that the muscle ammonia concentration is not a main regulator of the rate of glycogen breakdown and glycolysis.

This study clearly shows that the pre-exercise muscle glycogen content has a major effect on the rate of glycogenolysis during moderate intensity exercise. It has been demonstrated in vitro that glycogen phosphorylase has a $K_{m}$ of about 1-2 mM (Newsholme \& Leech, 1983). This implies that the enzyme is nearly always saturated with glycogen and hence glycogen breakdown is not expected to be influenced by glycogen concentration. However, glycogen is not homogeneously distributed in the cell and in vivo saturation kinetics for phosphorylase may not be applicable. Other explanations which cannot be excluded are that 1. an allosteric regulator not recognized sofar reduces the glycogen breakdown rate in the low glycogen leg or 2. that different fibres with a greater reduction in glycogen content are used in the low glycogen leg.

The temporary decrease in $\mathrm{PC}$ after 10 min of exercise implies that $\mathrm{P}_{\mathrm{i}}$ (not measured here) is also increased at that point in time. This temporary increase in $P_{i}$ may be one of the causal factors leading to the high rate of glycogen breakdown observed in the beginning of exercise, as $\mathrm{P}_{\mathrm{i}}$ is an allosteric regulator of glycogen phosphorylase. $P_{i}$ has been shown to enhance the conversion of phosphorylase $b$ to its more active a form. The concentration of adenine nucleotides and IMP did not change from resting values and, therefore, does not seem to play a role in the regulation of the rate of glycogen breakdown.

A net release of $\mathrm{K}^{+}$is found when muscles are made to contract by electric stimulation (Fenn, 1938), and is also observed in exercising muscle (Hnik, Holas, Kerkule, Kriz, Mejsnar, Sniesko et al, 1976) especially when an isolated muscle group is made to contract (Sjøgaard et al, 1985). The magnitude of the $\mathrm{K}^{+}$release can be large and cause an imbalance in $\mathrm{K}^{+}$homeostasis of the muscle cell (Sjøgaard et al, 1985). The mechanism behind the net outflow of $\mathrm{K}^{+}$from muscle during exercise is debated and has been related to the opening of ATP sensitive $\mathrm{K}^{+}$ channels as well as the lactate release. In the present study neither explanation appears to be plausible. Muscle ATP was barely affected during exercise. The highest femoral venous $\mathrm{K}^{+}$concentrations were observed after $10 \mathrm{~min}$ of exercise when $\mathrm{PC}$ was temporarily decreased and $\mathrm{P}_{\mathrm{i}}$ increased indicating that the $\mathrm{K}^{+}$release nevertheless seems to depend on the energy status of the muscle. The $\mathrm{K}^{+}$release was similar from both legs indicating that there was no coupling between lactate and $\mathrm{K}^{+}$release as previously observed during high intensity exercise (Sjøgaard, 1990). Our finding of a continuous $\mathrm{K}^{+}$release support the notion that there is an imbalance between the $\mathrm{K}^{+}$efflux which occurs each action potential and the rate by which the $\mathrm{Na}^{+} / \mathrm{K}^{+}$pump operates (Juel, 1986). This imbalance is power output dependent and rather insensitive to the metabolism of the muscle or hormonal changes, although it is well documented that both adrenaline and insulin can affect the activity of the $\mathrm{Na}^{+} / \mathrm{K}+$ pumps (Clausen, 1986).

In conclusion during moderate intensity prolonged dynamic exercise, which could be sustained for at least $90 \mathrm{~min}$, there is during the first half hour of exercise an imbalance between the rate of pyruvate production and pyruvate oxidation resulting 
in lactate production. The lactate production is positively related to the glycogen content of the contracting muscle, suggesting that glycogen as a substrate enhances its own utilization. Adrenaline and ammonia do not appear to be involved in the regulation of the rate of glycogen breakdown during prolonged dynamic exercise. $\mathrm{K}^{+}$ is continuously released from the muscle during prolonged dynamic exercise; the greatest release occurs in the first 30 min simultaneously with a temporary reduction of muscle PC. There is no relation between $\mathrm{K}^{+}$release and arterial adrenaline concentration and lactate release and the $\mathrm{K}^{+}$release is not influenced by the muscle glycogen content.

\section{References}

Andersen, P. \& Saltin, B. (1985). Maximal perfusion of skeletal muscle in man. Joumal of Physiology 366: $1080-1090$.

Aragón, J.J. \& Lowenstein, J.M. (1980). The purine-nucleotide cycle. Comparison of the levels of citric acid cycle intermediates with the operation of the purine nucleotide cycle in rat skeletal muscle during exercise and recovery from exercise. European Journal of Biochemistry 110: 371-377.

Babij, P. Matthews, S.M. \& Rennie, M.J. (1983). Changes in blood ammonia, lactate and amino acids in relation to workload during bicycle ergometer exercise in man. European Journal of Applied Physiology 50: 405-411.

Brooks, G.A. (1991). Current concepts in lactate exchange. Medicine and Science in Sports and Exercise 23: 895-906.

Brooks, G.A., Butterfield, G.E., Wolfe, R.R., Groves, B.M., Mazzeo, R.S., Sutton, J.R., Wolfe, E.E. \& Reeves, J.T. (1991). Decreased reliance on lactate during exercise after acclimatization to 4,300 m. Journal of Applied Physiology 71: 333-341.

Buono, M.J., Clancy, T.R. \& Cook, J.R. (1984). Blood lactate and ammonia ion accumulation during graded exercise in humans. Journal of Applied Physiology 57: 135-139.

Chesley, A., Hultman, E. \& Spriet, L.L. (1995). Effects of epinephrine infusion on muscle glycogenolysis during intense aerobic exercise. American Journal of Physiology 268: E127-E134.

Clausen, T. (1986). Regulation of active $\mathrm{Na}^{+}, \mathrm{K}^{+}-$transport in skeletal muscle. Physiological Reviews 66: $542-580$.

Fenn, W.O. (1938). Factors affecting the loss of potassium from stimulated muscle. American Journal of Physiology 124: 213-229.

Gollnick, P.D., Pernow, B., Essén, B., Jansson, E. \& Saltin, B. (1981). Availability of glycogen and plasma FFA for substrate utilization in leg muscle of man during exercise. Clinical Physiology 1: 27-42.

Harris, R.C., Hultman, E. \& Nordesjö, L.O. (1974). Glycogen, glycolytic intermediates and high energy phosphates determined in biopsy samples of muscular quadriceps femor of man at rest. Methods and variances of values. Scandinavian Journal of Clinical \& Laboratory Investigations 33: 109-120.

Hnik, P., Holas, M., Krekule, I., Kriz, N., Mejsnar, J., Smiesko, V., Ujec, E. \& Vyskocil, F. (1976). Work-induced potassium changes in skeletal muscle and effluent venous blood assessed by liquid ion-exchanger micro electrodes. Pflügers Archiv 362: 85-94.

Huckabee, W.E. (1958). Relationships of pyruvate and laclate during anaerobic metabolism. I-III, Journal of Clinical Investigation 37: 244-271.

Jensen-Urstad, M., Ahlborg, G. \& Sahlin, K. (1993). High lactate and $\mathrm{NH}_{3}$ release during arm vs. leg exercise is not due to B-adrenoceptor stimulation. Journal of Applied Physiology 74: 2860-2867.

Juel, C. (1986). Potassium and sodium shifts during in vitro isometric muscle contraction, and the time course of the ion-gradient recovery. Pfluggers Archiv 406: 458-463. 
Kaiser, P., Tesch, P.A., Thorssen, A., Karlsson, J. \& Kaijser, L. (1985). Skeletal muscle glycolysis during sub-maximal exercise foltowing acute B-adrenergic blockade in man. Acta Physiologica Scandinavica 123: 285-291.

Kun, E. \& Kearny, E.B. (1974). Ammonia. In Methods of enzymatic analysis. ed Bergmeyer, H. U. pp 1802-1805. Acadamic Press, New York.

Mazzeo, R.S., Brooks, G.A., Schoeler, D.A. \& Budinger, T.F. (1989). Influence of plasma catecholamines on lactate threshold during graded exercise. Journal of Applied Physiology 67: 232-241.

Newsholme, E.A. \& Leech, A.R. (1983). The reactions of glycolysis. In Biochemistry for the medical sciences. pp 178-192. John Wiley \& Sons, Chichester.

Richter, E.A., Kiens, B., Saltin, B., Christensen, N.J. \& Savard, G. (1988). Skeletal muscle glucose uptake during dynamic exercise in humans: role of muscle mass. American Journal of Physiology 254: E555-E561.

Sahlin, K., Katz, A. \& Broberg, S. (1990). Tricarboxylic acid cycle intermediates in human muscle during prolonged exercise. American Journal of Physiology 259: C834-C841.

Sjøgaard, G., Adams, R.P. \& Saltin, B. (1985). Water and ion shifts in skeletal muscle of humans with intense dynamic exercise. American Journal of Physiology 248: R190-R196.

Sjøgaard, G. (1990). Exercise-induced muscle fatigue: the significance of potassium. Acta Physiologica Scandinavica 140 (Suppl 593): 1-63.

Van der Vusse, G.J., Janssen, G.M.E., Coumans, W.A., Kuipers, H., Does, R.J.M.M. \& Ten Hoor, F. (1989). Effect of training and 15-, 25-, and 42-km contests on the skeletal muscle content of adenine and guanine nucleotides, creatine phosphate, and glycogen. International Journal of Sports Medicine 10: S146-S152.

Van Hall, G., Saltin, B., Van der Vusse, G.J., Söderlund, K. \& Wagenmakers, A.J.M. (1995). Deamination of amino acids as a source of ammonia production during prolonged exercise. Joumal of Physiology 489: 251-261. 


\title{
Chapter 5
}

\section{Ingestion of branched-chain amino acids and tryptophan during sustained exercise - Failure to affect performance}

\author{
G. van Hall, J.S.H. Raaymakers, W.H.M Saris, A.J.M. Wagenmakers \\ University of Limburg, Maastricht, The Netherlands.
}

Journal of Physiology 486: 789-794, 1995.

\begin{abstract}
1. An increased uptake of tryptophan in the brain may increase serotoninergic activity and recently has been suggested to be a cause of fatigue during prolonged exercise. The present study, therefore, investigates whether ingestion of tryptophan or the competing branched-chain amino acids (BCAA) affects performance. Ten male endurance trained athletes were studied during cycle exercise at $70-75 \% W_{\max }$, while ingesting at random and double blind drinks that contained $6 \%$ sucrose (control) or $6 \%$ sucrose supplemented with 1) tryptophan ( $\left.3 \mathrm{g.l}^{-1}\right) ; 2$ ) a low dose of BCAA (6 $\left.\mathrm{g.}^{-1}\right)$ and 3 ) a high dose of BCAA $\left(18 \mathrm{g. \textrm {l } ^ { - 1 }}\right)$.

2. These treatments greatly increased the plasma concentration of the respective amino acids. Using kirietic parameters of transport of human brain capillaries, BCAA supplements were estimated to reduce brain tryptophan uptake at exhaustion by $8-12 \%$, while tryptophan ingestion caused a $7-$ to 20 -fold increase. Exercise time to exhaustion was not different between treatments (122 $\pm 3 \mathrm{~min})$.

3. The data suggest that manipulation of tryptophan supply to the brain either has no additional effect upon serotoninergic activity during prolonged exhaustive exercise or that manipulation of serotoninergic activity functionally does not contribute to mechanisms of fatigue.
\end{abstract}




\section{INTRODUCTION}

Prolonged exercise inevitably leads to fatigue. Traditionally fatigue mechanisms have focused on events in skeletal muscle leading to loss of contractility. Glycogen depletion (Hermansen, Hultman \& Saltin, 1967), a decrease of the resting membrane potential as a consequence of potassium losses (Sjøgaard, 1990), failure of the calcium pump in the sarcoplasmatic reticulum, an increase in the free ADP concentration and failure of the neuromuscular transmission (Edwards, 1981) have all been associated with fatigue during sustained exercise. Newsholme and colleagues (Newsholme, Acworth \& Blomstrand, 1987) more recently have proposed that fatigue during prolonged exercise may be caused by increased serotoninergic activity in the central nervous system.

In the 'central fatigue' hypothesis it is suggested that during prolonged exercise the increased oxidation of BCAA (Kasperek, Dohm \& Snider, 1984; Wagenmakers, Beckers, Brouns, Kuipers, Soeters, Van der Vusse et al, 1991) and the displacement of tryptophan from albumin by the increasing fatty acid concentration (Davis, Bailey, Woods, Galiano, Hamilton \& Bartoli, 1992) leads to an increase of the tryptophan / BCAA ratio. The increase in this ratio would lead to an increased tryptophan transport across the blood-brain barrier, since BCAA and tryptophan compete for entry by the large neutral amino acid (LNAA) transporter. Once taken up tryptophan conversion to 5-hydroxytryptamine would occur and lead to a local increase of this neurotransmitter (Knott \& Curzon, 1972; Chaouloff, Laude, Guezennec \& Elghozi, 1986a). That this increase occurs during exercise in certain brain areas has been established in rat (Chaouloff et al, 1986a), but not in man. The increase in serotoninergic activity would subsequently lead to 'central fatigue', forcing athletes to stop exercise or reduce pace or workload. One of the implications of the 'central fatigue' hypothesis is that ingestion of BCAA could reduce the exercise induced increase of brain tryptophan uptake and thus delay fatigue by giving athletes the ability to push on when peripheral fatigue mechanisms come into operation. This indeed has been suggested to be the case in a field study with marathon runners (Blomstrand, Hassmén, Ekblom \& Newsholme, 1991). Another implication is that ingestion of tryptophan would reduce time to exhaustion.

The present study, therefore, was undertaken to investigate whether oral ingestion of BCAA or tryptophan has an effect predicted by the 'central fatigue' hypothesis on time to exhaustion during prolonged exercise in a controlled laboratory study. The amino acids were given in doses that greatly influence the circulating levels to values well outside the normal physiological ranges. It was chosen to add the amino acids to a carbohydrate solution for two reasons: 1 . In order to obtain similar experimental conditions as in the field study of Blomstrand et al (1991), where BCAA supplementation indeed was claimed to improve performance when given in combination with carbohydrates and 2. to avoid a potential interfering effect of BCAA supplementation on muscle fatigue in conditions of low carbohydrate availability. BCAA supplementation previously has been reported to have a negative effect on performance in patients with a glycogen breakdown defect in muscle (McArdle's disease, muscle phosphorylase deficiency) supposedly by a further reduction of the 
activity of the tricarboxylic acid cycle in conditions of depleted glycogen stores and low carbohydrate availability (Wagenmakers, Coakley \& Edwards, 1990).

\section{METHODS}

\section{Subjects:}

Ten healthy and endurance trained male athletes participated in this study after they had been informed about possible risks involved and had given their voluntary consent to participate. Their age, weight, and maximal workload (mean \pm SD) were $23.3 \pm 4.4 \mathrm{yr}, 70.6 \pm 4.9 \mathrm{~kg}, 373.1 \pm 25.3 \mathrm{Watt}$. The study was approved by the Medical Ethical Committee of the University of Limburg.

\section{Procedures:}

The subjects were studied while exercising on an electro-magnetically braked cycle ergometer (Lode, The Netherlands). The maximal power output $\left(W_{\max }\right)$ of each subject was measured as described previously (Kuipers, Keizer Brouns \& Saris, 1987). Within 2-3 weeks of assessment of $W_{\max }$ the subjects performed a pre-test, to get familiar with the protocol, and four experimental tests until exhaustion at 70-75\% $W_{\max }$ at a freely chosen power output independent pedaling rate (60-120 revolutions. $\left.\min ^{-1}\right)$. During these four experimental tests they received at random and double blind different drinks. The experimental drinks contained $6 \%$ sucrose without additives (control) and with one of the following amino acids: $3 \mathrm{~g} . \mathrm{I}^{-1}$ of tryptophan; 2 g..$^{-1}$ each of valine, isoleucine and leucine (low BCAA); $6 \mathrm{~g} . \mathrm{l}^{-1}$ each of valine, isoleucine and leucine (high BCAA). The low BCAA dose is comparable to the amount given by Blomstrand et al (1991) in their field study. The control, tryptophan and low BCAA drink were flavored with small amounts of quinine sulfate to simulate the bitter taste of the high BCAA drink.

Subjects were instructed to avoid intense exercise on the day prior to each test. At $7.30 \mathrm{~h}$ a.m. subjects had to eat a standardized breakfast that consisted of three slices of whole grain bread with low fat margarine and honey or marmalade, and tea. The actual performance test started at $9.00 \mathrm{~h}$ a.m. with a warming up period of $10 \mathrm{~min}$ at 100 Watt. After the warming up the workload was increased to $70-75 \% W_{\max }$ and subjects had to cycle until exhaustion, defined as the inability to maintain a pedaling rate of 60 revolutions. min $^{-1}$ despite encouragement to push on. The test drinks were provided after 5 min of warming up as a bolus of $4 \mathrm{ml}^{.} \mathrm{kg}^{-1}$ body weight and then every $15 \mathrm{~min}$ as a bolus of $2 \mathrm{ml} . \mathrm{kg}^{-1}$ body weight. During the exercise bout the subjects were additionally allowed to drink water ad libitum $(0-200 \mathrm{ml})$. During the exercise bout the subjects received on average $1.3 \mathrm{I}$ water and 7.8 and $23.4 \mathrm{~g}$ of BCAAs for the low and high BCAA dose respectively and $3.9 \mathrm{~g}$ tryptophan during the tryptophan trial.

\section{Blood analysis:}

Blood was sampled with heparinized syringes from a forearm vein using a catheter, patency was realized by flushing the catheter with saline. Blood samples were taken just before the start of the performance test and at the moment of exhaustion. Blood 
was immediately centrifuged to obtain plasma. An aliquot was directly frozen in liquid nitrogen for enzymatic determination of ammonia using a modification of the enzymatic determination with glutamate dehydrogenase performed on a COBAS BIO analyzer (Janssen, Van Berlo, Van Leeuwen \& Soeters, 1988). Plasma for amino acids analysis was deproteinized with sulfosalicylic acid (6 mg. $100 \mu^{-1}$ plasma) stored at $-80^{\circ} \mathrm{C}$ and analyzed by HPLC (Van Eijk, Van der Heijden, Van Berlo \& Soeters, 1988).

Rates of unidirectional tryptophan transport across the blood-brain barrier:

The rate of unidirectional influx $(v)$ of circulating plasma tryptophan to the brain may be estimated from the Michaelis-Menten equation:

$$
v=\left\{V_{\max }[T r p] /\left(K_{m}(a p p)^{T r}+[T r p]\right)\right\} * K_{d}[T r p]
$$

where [Trp] is the plasma tryptophan concentration; $\mathrm{K}_{\mathrm{d}}$ is the nonsaturable transport constant; $V_{\text {max }}$ is the maximal transport rate of tryptophan; $K_{m}(a p p)^{\text {trp }}$ is the apparent $K_{m}$ of tryptophan in the presence of competing amino acids; $K_{m}$ trp is the absolute $K_{m}$ in the absence of competing amino acids and $\mathrm{K}_{\mathrm{m}}{ }^{\mathrm{AA}}$ is the absolute $\mathrm{K}_{\mathrm{m}}$ of each competing amino acid. $K_{m}(a p p)^{\text {trp }}$ is calculated from the formula (Pardridge, 1977):

$$
K_{m}(a p p)^{\operatorname{trp}}=K_{m}^{\text {trp }}\left\{1+\sum\left([A A] / K_{m}^{A A}\right)\right\}
$$

For the calculations of the rate of tryptophan influx the $K_{m}, V_{\max }$ and $K_{d}$ were used reported by Hargreaves \& Pardridge (1988) for human brain capillaries studied in vitro. Rates of tryptophan transport were calculated from these formulas (Table 2) both using the plasma total tryptophan concentration assuming that all tryptophan is available for transport (Pardridge, 1983) or the estimated plasma free tryptophan concentration assuming that only free tryptophan is available for transport (Chaouloff, Kennett, Serrurrier, Merino \& Curzon, 1986b; Newsholme et al, 1987). It is assumed that about $10 \%$ of the total tryptophan is free (not bound to albumin) at rest and $30 \%$ is free tryptophan at exhaustion (Blomstrand, Celsing \& Newsholme, 1988).

\section{Statistics:}

All data are means $\pm S D$. Differences among the four tests were tested for significance with one way repeated measures analysis of variance (ANOVA), location of significance was determined with the Fisher's protected least significant difference post hoc test. Two tail Students $t$-test was used to determine differences between rest and exhaustion for the different tests. Statistical significance was set at $P<0.05$.

\section{RESULTS}

Performance: 
Time to exhaustion (Fig. 1) and heart rates (not shown) did not differ between the four tests. The individual times to exhaustion are shown in Fig. 2. Fig. 2 shows that most of the variation in Fig. 1 was caused by the inter subject difference in performance time and not by a large intra subject variation between treatments. The data implies that administration of tryptophan or BCAA had neither a positive nor a negative effect on performance during prolonged cycle ergometer exercise.

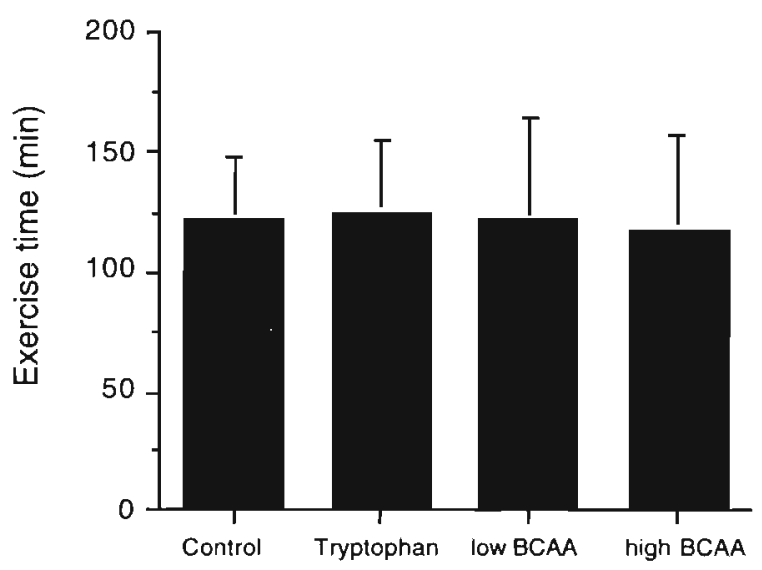

Figure 1. Time to exhaustion

Values are means \pm SD of 10 endurance trained subjects. Subjects ingested one of four drinks which were given double-blind and in random order $\left(4 \mathrm{ml} . \mathrm{kg}^{-1}\right.$ body weight during the warming up and then $2 \mathrm{ml} . \mathrm{kg}^{-1}$ body weight every $15 \mathrm{~min}$ during exercise). Drinks

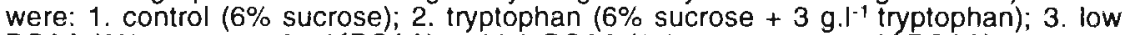
BCAA $\left(6 \%\right.$ sucrose $\left.+6 \mathrm{~g}^{-1}{ }^{-1} \mathrm{BCAA}\right) ; 4$. high BCAA $\left(6 \%\right.$ sucrose $\left.+18 \mathrm{~g} . \mathrm{l}^{-1} \mathrm{BCAA}\right)$.

Amino acids and ammonia:

Ingestion of a mixture of BCAAs or tryptophan during exercise caused an increased plasma concentration of those amino acids at the moment of exhaustion (Table 1). The 3-fold higher BCAA dose in the high BCAA test significantly increased plasma BCAA concentration at the moment of exhaustion compared to the low BCAA test $(\mathrm{P}<0.0001)$. The plasma BCAA concentration in the control and tryptophan test decreased with exercise. Tryptophan concentration decreased with exercise when $B C A A$ were ingested whereas in the control test the concentration remained constant. Plasma ammonia was increased at exhaustion in all four tests. The BCAA supplement, however, amplified the exercise induced increase in ammonia concentration at the moment of exhaustion (Table 1).

\section{Unidirectional tryptophan transport across the blood-brain barrier}

We calculated the rate of unidirectional tryptophan transport across the blood-brain barrier (into the brain) from the concentrations of tryptophan and competing amino acids in the different treatments using kinetic parameters of transport of human brain capillaries measured in vitro (Hargreaves \& Pardridge, 1988). Calculations were 


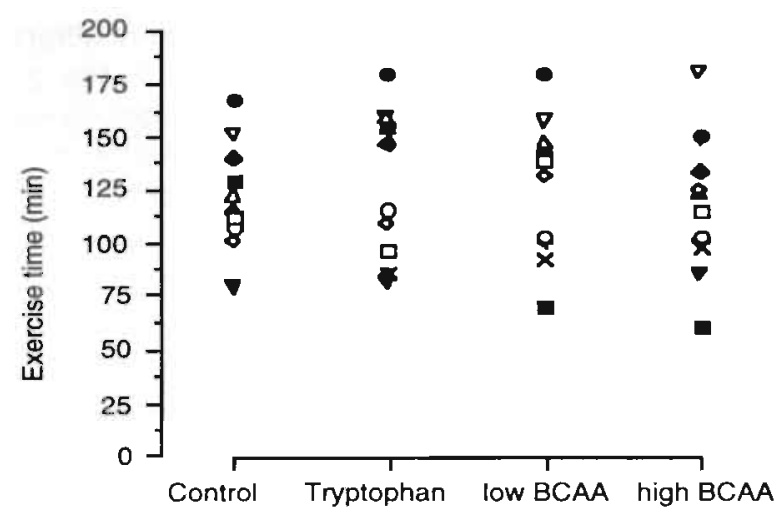

Figure 2. Individual cycling times until exhaustion. of the ten subjects See Fig. 1 for further details.

made under two ultimate assumptions. In the first case it is assumed that total tryptophan is available for transport as suggested by Pardridge (1983); in the second case it is assumed that only free tryptophan is available as suggested by Chaouloff et al (1986b) and Newsholme ef al (1987). In the first case the rate of inward transport does not change when going from rest to exercise in the control treatment, while a $12-15 \%$ reduction occurs at exhaustion in the BCAA treatments and a 6.5 fold increase in the tryptophan treatment. In the second case the rate of inward transport is increased 2.9-fold when going from rest to exhaustion, while a 2.5 - 2.7-fold increase occurs in the BCAA treatments and a 20-fold increase in the tryptophan treatment.

Table 2. $K m(a p p)^{\text {rp }}$ and tryptophan influx rate to the brain at rest and exhaustion.

\begin{tabular}{|c|c|c|c|c|c|}
\hline & & \multicolumn{4}{|c|}{ Supplementation } \\
\hline & & Control & Tryptophan & Low BCAA & High BCAA \\
\hline$K_{m}(a p p)^{t r p}$ & pre & 1008 & 1073 & 1087 & 1003 \\
\hline$\left(\mu \mathrm{mol} . \mathrm{I}^{1-1}\right)$ & exh & 935 & 862 & 1286 & 1286 \\
\hline$v$ (influx) total Trp & pre & 26 & 27 & 26 & 26 \\
\hline (nmol.min $\left.{ }^{-1} \cdot \mathrm{mg}^{-1}\right)$ & exh & 25 & 177 & 23 & 22 \\
\hline$v$ (influx) free Trp & pre & 2.6 & 2.7 & 2.6 & 2.6 \\
\hline (nmol.min $\left.{ }^{-1} \cdot \mathrm{mg}^{-1}\right)$ & exh & 7.6 & 54.0 & 7.0 & 6.6 \\
\hline
\end{tabular}

For calculation of $\mathrm{K}_{\mathrm{m}}(\mathrm{app})$ and $\mathrm{v}$ (rate of tryptophan influx) for total and free tryptophan concentration see methods. 
Table 1. Ammonia and amino acids concentration at rest and at the moment of exhaustion.

\begin{tabular}{|c|c|c|c|c|c|}
\hline \multirow[b]{2}{*}{ Metabolite } & & \multicolumn{4}{|c|}{ Supplementation } \\
\hline & & Control & Tryptophan & Low BCAA & High BCAA \\
\hline Ammonia & $\begin{array}{l}\text { pre } \\
\text { exh }\end{array}$ & $\begin{array}{c}49 \pm 18 \\
105 \pm 55^{\S}\end{array}$ & $\begin{array}{l}43 \pm 23 \\
93 \pm 55^{\S}\end{array}$ & $\begin{array}{c}46 \pm 25 \\
157+65^{\star \S}\end{array}$ & $\begin{array}{c}58 \pm 27 \\
180 \pm 59^{* \S}\end{array}$ \\
\hline Tryptophan & $\begin{array}{l}\text { pre } \\
\text { exh }\end{array}$ & $\begin{array}{l}44 \pm 7 \\
43 \pm 7\end{array}$ & $\begin{array}{c}47 \pm 6 \\
304 \pm 61 * \S\end{array}$ & $\begin{array}{l}44 \pm 5 \\
40 \pm 6 \S\end{array}$ & $\begin{array}{l}45 \pm 10 \\
38 \pm 7^{\prime} \delta\end{array}$ \\
\hline Leucine & $\begin{array}{l}\text { pre } \\
\text { exh }\end{array}$ & $\begin{array}{l}136 \pm 29 \\
115 \pm 13\end{array}$ & $\begin{array}{l}145 \pm 16 \\
108 \pm 6^{\S}\end{array}$ & $\begin{array}{l}155 \pm 42 \\
252 \pm 49^{\star \S}\end{array}$ & $\begin{array}{l}135 \pm 22 \\
636 \pm 133.56\end{array}$ \\
\hline Isoleucine & $\begin{array}{l}\text { pre } \\
\text { exh }\end{array}$ & $\begin{array}{l}62 \pm 13 \\
51 \pm 8\end{array}$ & $\begin{array}{l}68 \pm 7 \\
48 \pm 4^{\S}\end{array}$ & $\begin{array}{c}80 \pm 38 \\
192 \pm 58^{\star \S}\end{array}$ & $\begin{array}{c}63 \pm 13 \\
561 \pm 137^{* \S}\end{array}$ \\
\hline Valine & $\begin{array}{l}\text { pre } \\
\text { exh }\end{array}$ & $\begin{array}{l}244 \pm 42 \\
214 \pm 24 \S\end{array}$ & $\begin{array}{l}259 \pm 15 \\
216 \pm 14 \S\end{array}$ & $\begin{array}{l}287 \pm 81 \\
503 \pm 85^{\star \S}\end{array}$ & $\begin{array}{c}252+25 \\
1200 \pm 221 * 5\end{array}$ \\
\hline BCAA & $\begin{array}{l}\text { pre } \\
\text { exh }\end{array}$ & $\begin{array}{l}443 \pm 92 \\
380 \pm 42^{\S}\end{array}$ & $\begin{array}{l}471 \pm 35 \\
372 \pm 225\end{array}$ & $\begin{array}{l}521 \pm 160 \\
947 \pm 186^{* \S}\end{array}$ & $\begin{array}{c}450 \pm 54 \\
2397 \pm 483^{* 5}\end{array}$ \\
\hline Tyrosine & $\begin{array}{l}\text { pre } \\
\text { exh }\end{array}$ & $\begin{array}{l}65 \pm 10 \\
65 \pm 10\end{array}$ & $\begin{array}{l}71 \pm 14 \\
63 \pm 11\end{array}$ & $\begin{array}{l}68 \pm 8 \\
61 \pm 9 \S\end{array}$ & $\begin{array}{l}66 \pm 11 \\
56 \pm 11^{* \S}\end{array}$ \\
\hline Phenylalanine & $\begin{array}{l}\text { pre } \\
\text { exh }\end{array}$ & $\begin{array}{l}57 \pm 8 \\
54 \pm 5\end{array}$ & $\begin{array}{l}60 \pm 6 \\
48 \pm 4^{\star \S}\end{array}$ & $\begin{array}{l}59 \pm 8 \\
52 \pm 6^{\S}\end{array}$ & $\begin{array}{l}56 \pm 8 \\
51 \pm 6\end{array}$ \\
\hline Methionine & $\begin{array}{l}\text { pre } \\
\text { exh }\end{array}$ & $\begin{array}{l}16 \pm 3 \\
14 \pm 2\end{array}$ & $\begin{array}{l}19 \pm 4 \\
15 \pm 3\end{array}$ & $\begin{array}{l}17 \pm 4 \\
15 \pm 6\end{array}$ & $\begin{array}{l}17 \pm 4 \\
12 \pm 2\end{array}$ \\
\hline
\end{tabular}

Values are means \pm SD from 10 subjects in $\mu$ mol. $I^{-1}$. Statistically significance, $P<0.05$, are expressed as, "versus control at rest, "versus control at the moment of exhaustion, §res! versus exhaustion and - high BCAA versus low BCAA dose.

\section{DISCUSSION}

In 1987 Newsholme and colleagues (Newsholme et al, 1987) proposed the 'central fatigue' hypothesis (for details see introduction). One of the implications of this hypothesis is that oral ingestion of BCAA would reduce 'central fatigue' and would enable athletes to maintain a higher pace during prolonged competitive exercise. Physical performance has previously been investigated in a field test by Blomstrand et al (1991). They studied 193 male subjects running a marathon race. Subjects were randomly divided into an experimental group receiving 16 gram of BCAA in plain water during the race and the placebo group receiving flavored water. The subjects additionally had ad libitum access to carbohydrate containing drinks and other drinks. No difference was observed in the marathon time of the group receiving BCAA and 
those receiving placebo. However, when subjects were divided in fast and slower runners, then a small significant reduction in marathon time was observed in the slower runners only. Three main criticisms can be raised against the design of the study of Blomstrand et al (1991): 1. in a performance test investigating a potentially ergogenic effect subjects in the two groups should have been matched for previous performance; 2. carbohydrate intake and nutritional status should have been controlled; 3 . division of subjects in a group of fast and slower runners, taking an arbitrary marathon time as selection criterion, is not in accordance with accepted statistical methods. Each of these points may have biased the data obtained by Blomstrand et al (1991).

Here we fail to find an effect of oral ingestion of two doses of BCAA in a $6 \%$ sucrose solution on time to exhaustion in a controlled laboratory setting. The rate of ingestion of the low dose of BCAA is similar to that used in the study of Blomstrand et a) (1991). The rate of ingestion of the high dose of BCAA is three-fold higher. In accordance with our data Verger, Aymard, Cynobert, Anton \& Luigi (1994) also failed to find an effect of intragastric BCAA supplementation on time to exhaustion in rats running on a treadmill in comparison with a water control.

Another implication of the 'central fatigue' hypothesis is that oral ingestion of tryptophan could lead to premature fatigue. Here, however, we also fail to find an effect on time to exhaustion of an oral dose of tryptophan.

Controversy exists in literature whether total plasma tryptophan or free tryptophan (not bound to albumin) is available for transport across the blood-brain barrier. A correlation between plasma free tryptophan and brain tryptophan concentration made Chaouloff and colleagues $(1985,1986 \mathrm{~b})$ suggest that plasma free tryptophan rather than total tryptophan is the determinant of increased brain tryptophan transport during exercise. However, it has also been proposed that binding of tryptophan to albumin appears to be of little importance for the uptake of tryptophan into the brain (Madras, Cohen, Messing, Munro \& Wurtman, 1974; Yuwiler, Oldendorf, Geller \& Braun, 1977; Pardridge \& Fierer, 1990; Fernstrom \& Fernstrom, 1993). Pardridge (1983) presented evidence suggesting that during the course of plasma flowing through the capillary, albumin bound tryptophan molecules instantaneously dissociate into the free intermediate state and become available for reassociation with either albumin or the carrier-binding site. In the calculations of the inward transport rate of tryptophan across the blood-brain barrier (Table 2) we used the concentration of total and free tryptophan. When total plasma tryptophan is available for transport across the bloodbrain barrier than no increase in the rate of tryptophan transport is observed when going from rest to exhaustion (Table 2). However, if the free plasma tryptophan is only available for transport than a 3 -fold increase in the rate of tryptophan influx is observed at the moment of exhaustion. The effect of BCAA and tryptophan ingestion seems to be independent of whether total or free tryptophan is considered to be available for transport. In both cases BCAA ingestion reduced tryptophan uptake only minimally, while tryptophan ingestion greatly increased tryptophan uptake (Table 2).

The 6- to 20-fold (in the case of free tryptophan) increase in tryptophan transport does not seem to affect performance. This may imply that increased tryptophan influx across the blood-brain barrier does not increase the brain 5-hydroxytryptamine 
concentration in the human subjects. This could be due to a proportional increase of tryptophan efflux from the brain and/or a simultaneous increase of the activity of intraneuronal monoamine oxidase leading to an acceleration of the degradation of 5hydroxytryptamine. In agreement with the latter possibility Grahame-Smith (1971) found that tryptophan administration only resulted in functional behavioral effects in the rat when monoamine oxidase activity was inhibited. In another study tryptophan administration only increased 5-hydroxytryptamine concentration in the brain after inhibition of monoamine oxidase activity (Marsden, Conti, Strope, Curzon \& Adams, 1979). Another possibility is that brain 5-hydroxytryptamine concentration is increased after tryptophan ingestion, but that the increase in serotoninergic activity does not functionally contribute to fatigue and exhaustion.

A few studies with pharmacological agents seem to contradict the latter explanation. 5-Hydroxytryptamine agonists were reported to lead to premature fatigue during prolonged exercise in rat (Bailey, Davis \& Ahlborn, 1993). A 5hydroxytryptamine re-uptake inhibitor also was reported to hasten fatigue during prolonged exercise in man (Wilson \& Maughan, 1992). Quite obvious more research is required in this area.

Both the low and high dose BCAA treatment increased plasma ammonia concentration at exhaustion as previously reported in healthy controls (MacLean \& Graham, 1993) and in patients with McArdle's disease, a glycogen breakdown defect in muscle (Wagenmakers et al, 1990). In the patients oral ingestion of BCAA (doses equivalent to the high dose used in this study) not only increased the ammonia production by the exercising muscle, but also caused premature fatigue during incremental exercise. The mechanistic explanation given for this observation was that increased oxidation of BCAA in muscle may put a carbon-drain on the tricarboxylic acid cycle as the BCAA aminotransferase reaction uses $\alpha$-ketoglutarate as an amino group acceptor. The possibility, therefore, should be considered that the large dose of BCAA may have a negative effect on muscle performance in conditions of a limited glycogen availability. Here, however we have chosen to give BCAA in combination with carbohydrates as we aimed at improving performance via the potential inhibition of BCAA on brain uptake of tryptophan. Carbohydrate ingestion on its own also may reduce brain uptake of tryptophan as ingestion of carbohydrates reduces the increase of free fatty acids during prolonged exercise (Davis et al, 1992) and, therefore, may reduce the proportion of tryptophan present in the free form.

In conclusion we fail to show an effect of oral ingestion of BCAA or tryptophan in a carbohydrate containing solution on time to exhaustion in a controlled laboratory study. This implies that oral ingestion of these amino acids either does not change the 5-hydroxytryptamine concentration in relevant local areas in the brain or that a change in serotoninergic activity during prolonged exercise contributes little to mechanisms of fatigue and exhaustion.

\section{References}

Bailey, S.P., Davis, J. M. \& Ahlborn, E.N. (1993). Serotonergic agonists and antagonists affect endurance performance in the rat. International Joumal of Sports Medicine 14: 330-333. 
Blomstrand, E., Hassmén, P., Ekblom, B. \& Newshoime, E.A. (1991). Administration of branched-chain amino acids during sustained exercise - effects on performance and on plasma concentration of some amino acids. European Journal of Applied Physiology 63: 83-88.

Blomstrand, E., Celsing, F. \& Newsholme, E.A. (1988). Changes in plasma concentrations of aromatic and branched-chain amino acids during sustained exercise in man and their possible role in fatigue. Acta Physiologica Scandinavica 113: 115-121.

Chaouloff, F., Elghozi, J.L., Guezennec, Y. \& Laude, D. (1985). Effect of conditioned running on plasma, liver and brain tryptophan and on brain 5-hydroxytryptamine metabolism of the rat. British Journal of Pharmacology 86: 33-41.

Chaouloff, F., Laude, D., Guezennec, Y. \& Elghozi, J.L. (1986a). Motor activity increases tryptophan, 5-hydroxyindoleacetic acid, and homovanillic acid in ventricular cerebrospinal fluid of the concious rat. Journal of Neurochemistry 46: 1313-1316.

Chaouloft, F., Kennett, G.A., Serrurrier, B., Merino, D. \& Curzon, G (1986b). Amino acid analysis demonstrates that increased plasma free tryptophan causes the increase of brain tryptophan during exercise in the rat. Journal of Neurochemistry 46: 1647-1650.

Davis, J.M., Bailey, S.P., Woods, J.A., Galiano, F.J., Hamilton, M.T. \& Bartoli, W.P. (1992). Effects of carbohydrate feedings on plasma free tryptophan and branched-chain amino acids during prolonged cycling. European Journal of Applied Physiology 65: 513-519.

Edwards, R.H.T. (1981). Human muscle function and fatigue. In Human muscle fatigue: physiological mechanisms, ed. pp. 1-18. Pitman Medical, London.

Fernstrom, M.H. \& Fernstrom, J.D. (1993). Large changes in serum free tryptophan levels do not alter brain tryptophan levels: studies in streptozotocin-diabetic rats. Life Sciences 52: 907-916.

Grahame-Smith, D.G. (1971). Studies in vivo on the relationship between brain tryptophan, brain 5HT synthesis and hyperactivity in rats treated with a monoamine oxidase inhibitor and L-tryptophan. Journal of Neurochemistry 18: 1053-1066.

Hargreaves, K.M. \& Pardridge, W.M. (1988). Neutral amino acid transport at the human blood-brain barrier. Journal of Biological Chemistry 263: 19392-19397.

Hermansen, L., Hultman, E. \& Saltin, B. (1967). Muscle glycogen during prolonged severe exercise. Acta Physiologica Scandinavica 71: 129-139.

Janssen, M.A., Van Berlo, C.L.H., Van Leeuwen, P.A.M. \& Soeters, P.B. (1988). The determination of ammonia in plasma and whole blood. In Advances in ammonia metabolism and hepatic encephalopathy, ed. Soeters, P.B., Wilson, J.H.P., Meijer, A.J., Holm, E., pp. 587-592. Excerpta Medica, Amsterdam.

Kasperek, G.J., Dohm, G.L. \& Snider, R.D. (1984). Activation of branched-chain keto acid dehydrogenase by exercise. American Journal of Physiology 248: R166-R171.

Knott, P.J. \& Curzon, G. (1972). Free tryptophan in plasma and brain tryptophan metabolism. Nature 239: 452-453.

Kuipers, H., Keizer, H.A., Brouns, F. \& Saris, W.H.M. (1987). Carbohydrate feeding and glycogen synthesis during exercise in man. Pflügers Archiv 410:652-656.

MacLean, D.A. \& Graham, T.E. (1993). Branched-chain amino acid supplementation augments plasma ammonia responses during exercise in humans. Journal of Applied Physiology 74: 2711-2717.

Madras, B.K., Cohen, E.L., Messing, R., Munro, H.N. \& Wurtman, R.J. (1974). Relevance of free tryptophan in serum to tissue tryptophan concentrations. Metabolism 23: 1107-1116.

Marsden, C.A., Conti, J., Strope, E.D., Curzon, G. \& Adams, R.N. (1979). Monotoring 5hydroxytryptamine release in the brain of freely moving unaneasthetised rats using in vivo voltammetry. Brain Research 171: 85-99.

Newsholme, E.A., Acworth, I.N. \& Blomstrand, E. (1987). Amino acids, brain neurotransmitters and a functional link between muscle and brain that is important in sustained exercise. In Advances in myochemistry, ed. Benzi G., pp. 127-138. John Libbey Eurotext, London.

Pardridge, W.M. (1977). Kinetics of competitive inhibition of neutral amino acid transport across the blood-brain barner. Journal of Neurochemistry 28: 103-108.

Pardridge, W.M. (1983). Brain metabolism: A perspective from the blood-brain barrier. Physiological Reviews 63:1481-1535. 
Sjøgaard, G. (1990). Exercise-induced muscle fatigue: The significance of potassium. Acta. Physiological Scandinavica 140, suppl. 593: 3-39.

Van Eijk, H.M.H., Van der Heijden, M.A.H., Van Berlo, C.L.H. \& Soeters, P.B. (1988). Fully automated liquid-chromatographic determination of amino acids. Clinical Chemistry 34: 2510-2513.

Verger, PH., Aymard, P., Cynobert, L., Anton, G. \& Luigi, R. (1994). Effects of administration of branched-chain amino acids vs. glucose during acute exercise in the rat. Physiology \& Behavior 55: 523-526.

Wagenmakers, A.J.M., Coakley, J.H. \& Edwards, R.H.T. (1990). Metabolism of branched-chain amino acids and ammonia during exercise: clues from McArdle's disease. International Journal of Sports Medicine 11: S101-S113.

Wagenmakers, A.J.M., Beckers, E.J., Brouns, F., Kuipers, H., Soeters, P.B., Van der Vusse, G.J. \& Saris, W.H.M. (1991). Carbohydrate supplementation, glycogen depletion, and amino acid metabolism during exercise. American Journal of Physiology 260: E883-E890.

Wilson, W.M. \& Maughan, R.J. (1992). Evidence for a possible role of 5-hydroxytryptamine in the genesis of fatigue in man: administration of paroxetine, a 5-HT re-uptake inhibitor, reduces the capacity to perform prolonged exercise. Experimental Physiology 77: 921-924.

Yuwiler, A., Oldendorf, W.H., Geller, E. \& Braun, L. (1977). Effect of albumin binding and amino acid competition on tryptophan uptake into the brain. Journal of Neurochemistry 28: 1015-1023. 


\title{
Chapter 6
}

\section{Effect of carbohydrate supplementation on plasma glutamine during prolonged exercise and recovery}

\author{
G. van Hall, W.H.M. Saris, A.J.M. Wagenmakers
}

University of Limburg, Maastricht, The Netherlands

Journal of Applied Physiology submitted.

\begin{abstract}
1. Muscle glycogen and glucose have been suggested to be carbon-chain precursors for glutamine synthesis in skeletal muscle. Therefore, the aim of the present study is to investigate whether carbohydrate supplementation affects plasma glutamine concentration during exercise and recovery.

2. Eight well-trained subjects cycled at an alternating workload of 50 and $80 \% W_{\text {max }}$ until exhaustion ( 59 to $140 \mathrm{~min}$ ). During the exercise bout the subjects received either water (control) or a carbohydrate drink ( $83 \mathrm{~g} \mathrm{CHO} \cdot 1^{-1}, 2 \mathrm{ml}^{\mathrm{kg}}{ }^{-1}$ body weight every $15 \mathrm{~min}$ ). Blood samples were taken during exercise and 7 hours of recovery for measurement of glucose, laclate, ammonia and amino acids.

3. During exercise and recovery no effect was seen of carbohydrate ingestion on the plasma concentration of glucose, lactate and ammonia. Ammonia concentration increased continuously until exhaustion whereas lactate increased the first $30 \mathrm{~min}$ and remained constant during the latter stage of the exercise period. Ammonia and lactate returned to pre-exercise values within 40 minutes of recovery.

4. Plasma alanine and glutamine increased during exercise in both tests. During the recovery period the concentration of alanine, glutamine and total amino acids decreased below the pre-exercise level. Plasma glutamine returned to pre-exercise concentration after 7 hours of recovery but alanine and the total amino acid concentration was still suppressed after 7 hours.

5. In conclusion, carbohydrate supplementation had neither an effect during exercise nor during recovery on the concentration of plasma glutamine or other amino acids. Plasma glutamine decreased during recovery from prolonged intense exercise. The lowest plasma concentration was reached after $2-3$ hours and was $78 \%$ of the concentration reached at the end of exercise.
\end{abstract}




\section{INTRODUCTION}

Glutamine is the most abundant amino acid in human plasma and muscle. In muscle glutamine accounts for $60 \%$ of the total intracellular muscle free amino acid pool (excluding the non-protein amino acid taurine; Bergstrom, Fürst, Noree \& Vinnars, 1974). In the postabsorptive state glutamine $(48 \%)$ and alanine $(32 \%)$ together account for $80 \%$ of the amino acids released from skeletal muscle (Marliss, Aoki, Pozefsky, Most \& Cahill, 1971), implying that glutamine with two $\mathrm{N}$-atoms per molecule is dominant for the amino acid $\mathrm{N}$-release from muscle. In the 4 hour period after the ingestion of a mixed meal the dominance of glutamine in carrying $\mathrm{N}$ out of skeletal muscle is even greater. Glutamine then accounts for $71 \%$ of the amino acid release and $82 \%$ of the $\mathrm{N}$ release from muscle (Elia, Schlatmann, Goren \& Austin, 1989 ). As the relative occurrence of glutamine in muscle protein is only $10-15 \%$ this indicates that the glutamine de novo synthesis in muscle is substantial 24 hours per day. Tracer studies in man (Darmaun, Matthews \& Bier, 1986; Nurjhan, Bucci, Perriello, Dailey, Bier, Toft et al, 1995) also indicate that production rates of glutamine are higher than of any other amino acid and that glutamine is more important than alanine as a vehicle for transporting amino acid carbon and nitrogen from muscle through the plasma to the sites of oxidation. Recent tracer studies also suggest that glutamine is more important than alanine and as a gluconeogenic precursor in postabsorptive humans (Nurjhan et al, 1995).

The biochemical pathways in muscle that contribute to glutamine production in skeletal muscle are only partly known. In the postabsorptive state the uptake of glutamate from the circulation accounts for $18-65 \%$ of the glutamine production (mean value of 5 studies is $40 \%$; Marliss et al, 1971; Eriksson, Broberg, Björkman \& Wahren 1985; Elia et al, 1989; Nurjhan et al, 1995; Van Hall, Saltin, Van der Vusse, Söderlund \& Wagenmakers, 1995). Part of the glutamine production in the postabsorptive state also results from the net breakdown of muscle protein (Nurjhan et al, 1995). Protein degradation not only produces glutamine directly, but also leads to the production of branched-chain amino acids, glutamate, aspartate and asparagine. The carbon skeleton of these amino acids have all been shown to be used for de novo synthesis of glutamine in incubated rat muscles (Chang \& Goldberg, 1978; Wagenmakers, Salden \& Veerkamp, 1985). Sir Hans Krebs (1975) suggested that the carbon skeletons of muscle glycogen and blood glucose are also used for synthesis of tricarboxylic acid cycle intermediates (TCAI) and glutamine. The reaction used for conversion of glycolytic 3-carbon molecules to TCAl either is reversal of the phosphoenolcarboxykinase reaction (Krebs, 1975) or pyruvate carboxylase (Davis, Spydevold \& Bremer, 1980). Exercise leads to an increase in glutamine release from muscle (Eriksson et al, 1985; Sahlin, Katz \& Broberg, 1990; Van Hall et al, 1995). However, this increase was only temporary during $90 \mathrm{~min}$ of one leg exercise at $60-65 \% W_{\max }$ (Van Hall et al, 1995). A decrease in plasma glutamine was observed during and following 4 hours of treadmill running at $40 \%$ $\mathrm{VO}_{2 \max }$ leading to glycogen depletion in untrained subjects (Rennie, Edwards, Krywawych, Davies, Halliday, Waterlow \& Millward, 1981). Such decreases in plasma glutamine may be important as it has been suggested to be associated with 
immune system impairment in overtrained athletes (Parry-Billings, Budgett, Koutedakis, Blomstrand, Brooks, Williams, Calder, Pilling, Baigrie, \& Newsholme, 1992). Here we investigated whether decreases in plasma glutamine and other amino acids were also observed during and following prolonged high intensity exercise with elite cyclists and whether glucose ingestion could prevent such decreases in line with the suggestion that glucose is a carbon-chain precursor for glutamine synthesis.

\section{METHODS}

\section{Subjects}

Eight healthy and highly trained male cyclists, competing at national and international level participated in the study. The subjects were informed about procedures and possible risks involved before giving their voluntary consent to participate. Their age, weight, and length (mean $\pm \mathrm{SD}$ ) were $20.9 \pm 2.4 \mathrm{yr}, 73.3 \pm 4.6 \mathrm{~kg}$, and $1.82 \pm 0.04 \mathrm{~m}$, respectively.

\section{Protocol}

The subjects were studied while exercising on an electromagnetically braked cycle ergometers (Lode, The Netherlands) at a freely chosen, power output independent pedaling rate (60-120 revolutions. $\min ^{-1}$ ). Before the experiment (on a separate day) each subject performed a maximal workload test to determine their maximal work output $\left(W_{\max }\right)$ as described previously (Kuipers, Keizer, Brouns \& Saris, 1987). The subjects were studied during exercise until exhaustion and 7 hours of recovery on two separate occasions with carbohydrate supplementation during the exercise bout and a control test when only water was ingested. Both tests were performed within 2 weeks of assessment of $W_{\max }(407 \pm 20$ Watt). During the test days the subjects reported to the laboratory at 7.30 hour after an overnight fast. They were allowed to eat a standardized breakfast that consisted of two sandwiches with marmalade and water or tea. The exercise bout started at 8.45 with a warming up period of $5 \mathrm{~min}$ at $100 \mathrm{~W}$ followed by $5 \mathrm{~min}$ at $50 \% \mathrm{~W}_{\max }$. The subjects then cycled at an alternating exercise intensities in blocks of $6 \mathrm{~min}$ at $80 \% \mathrm{~W}_{\max }$ and $3 \mathrm{~min}$ at $50 \% \mathrm{~W}_{\max }$ until exhaustion was reached. Exhaustion was defined as the inability to maintain a pedaling rate above the 60 revolutions. $\min ^{-1}$ despite encouragement. During the control test the subjects had to drink $4 \mathrm{ml}^{.} \mathrm{kg}^{-1}$ body weight water in the warming up period and then every $15 \mathrm{~min} 2 \mathrm{ml}^{\mathrm{kg}}{ }^{-1}$ body weight of water. After the exercise bout they were allowed to drink water or tea without sugar. The test with carbohydrate ingestion was performed at least 3 days after the control test. The standardized breakfast at 7.30 hour was supplemented with 0.5 liter of a carbohydrate drink ( $166 \mathrm{~g}$ $\mathrm{CHO}^{-1}-1$, Perform ${ }^{\circledR}$, Wander Ltd, Bern, Switzerland) replacing water or tea. The exercise bout started at 8.45 hour and was performed as described for the control test. During the warming up period the subjects had to drink $4 \mathrm{ml} . \mathrm{kg}^{-1} \mathrm{body}$ weight of the carbohydrate drink ( $83 \mathrm{~g} \mathrm{CHO}^{-1}$ ) and then every $15 \mathrm{~min} 2 \mathrm{ml} . \mathrm{kg}^{-1}$ body weight of the same $\mathrm{CHO}$-drink, water was provided ad libitum during the whole test. Exercise 
was terminated for each subject at the exact moment that exhaustion was reached in the control test.
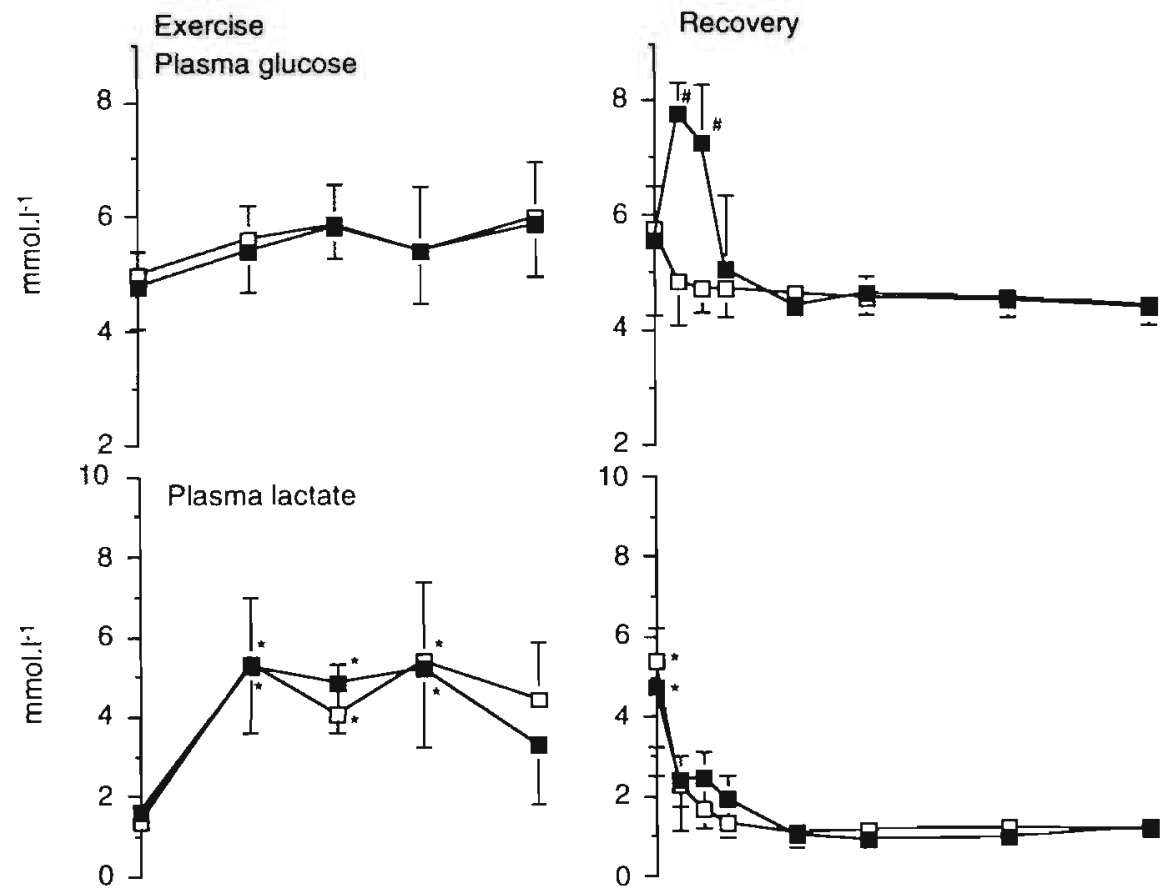

10
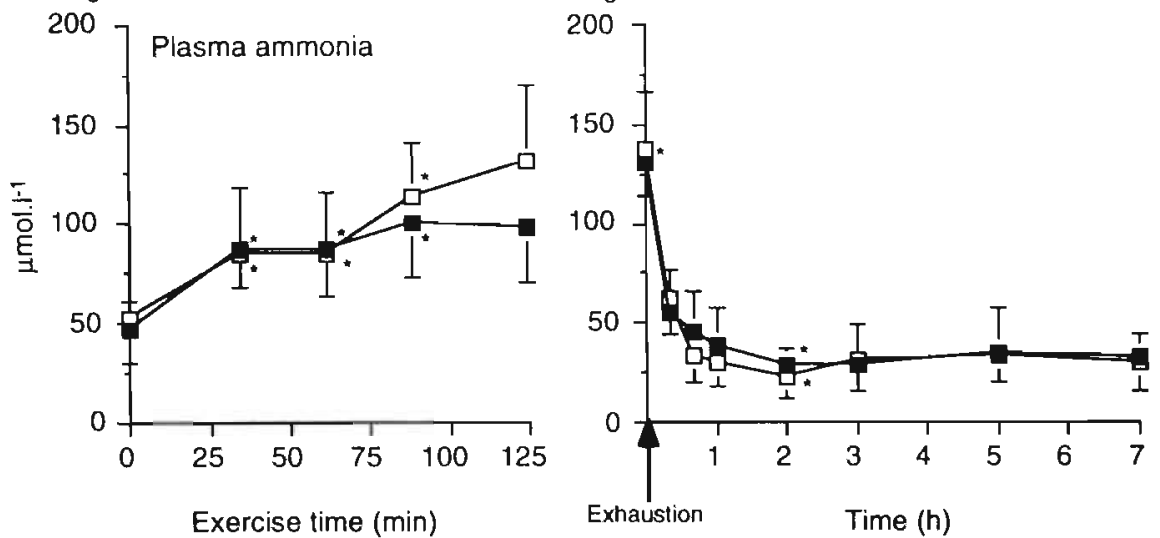

Figure 1. Plasma glucose, lactate and ammonia in 8 highly trained subjects during exercise and recovery.

Values are means \pm SD obtained in the carbohydrate supplementation test (closed squares) and the control test (open squares). Values during exercise are of 8 subjects at $34 \mathrm{~min}$, of 7 subjects at $61 \mathrm{~min}$, of 5 subjects at $88 \mathrm{~min}$ and of 2 subjects at $124 \mathrm{~min}$. - Significant differences from the pre-exercise concentration during exercise as well as recovery, "significant differences between the carbohydrate- and control test. 


\section{Analysis}

Blood was sampled during the exercise bout and 7 hours of recovery from a forearm vein using a catheter kept patent by flushing with saline. Samples were obtained just before the warming up and at the end of the $80 \% \mathrm{~W}_{\max }$ blocks at $34,61,88,124 \mathrm{~min}$, and at the moment of exhaustion. During the recovery period blood samples were obtained after $20,40,60,120,180,300$, and 420 min of recovery. Heparinized blood was centrifuged immediately to obtain plasma; aliquots of plasma were frozen for analysis of glucose, lactate, and ammonia. Plasma for the analysis of amino acids was deproteinized with sulfosalicylic acid (6 mg.100 $\mu^{-1}$ plasma) and analyzed by HPLC (Parmacia, The Netherlands) (Van Eijk, Van der Heijden, Van Berlo, \& Soeters, 1988) and stored at $-80^{\circ} \mathrm{C}$. Ammonia was measured using a modification of the enzymatic determination with glutamate dehydrogenase (Janssen, Van Berlo, Van Leeuwen \& Soeters, 1988) performed on a COBAS BIO analyzer (Roche, The Netherlands). Plasma lactate and glucose were analyzed with standard enzymatic techniques on a COBAS BIO analyzer.

\section{Statistics}

All data are means \pm SD. Significant differences were determined between related samples of the same subject in the two tests and differences of the same subject at different times during exercise and recovery with one way repeated measures analysis of variance (ANOVA), location of significance was determined with the Fisher protected least significant difference test. Statistical significance was set at $\mathrm{P}<0.05$.

\section{RESULTS}

\section{Performance}

Exercise time to exhaustion with the alternating workload protocol of $3 \mathrm{~min}$ at $50 \%$ $\mathrm{W}_{\max }$ and $6 \mathrm{~min}$ at $80 \% \mathrm{~W}_{\max }$ varied from 59 to $140 \mathrm{~min}$. Plasma lactate concentrations were higher in the subjects with the relatively short exercise times. Seven of the eight subjects were able to continue exercise with carbohydrate ingestion for the same period of time as they had reached in the control test.

\section{Plasma metabolites}

Plasma glucose concentration during the exercise bout was similar for both tests. During the recovery period, however, plasma glucose concentration increased the first $40 \mathrm{~min}$ in the test with carbohydrate ingestion whereas the plasma glucose concentration decreased to pre-exercise concentrations in the control test (Fig. 1). No significant differences were observed between the test with carbohydrate supplementation and control test for plasma ammonia and lactate concentration during exercise and recovery (Fig. 1). Plasma ammonia gradually increased with exercise duration. Plasma lactate increased fourfold compared to resting level during the first 30 min of exercise but then remained constant until exhaustion (Fig. 1). During the first hour of recovery a sharp fall was observed in plasma ammonia and 
lactate concentration and within 40 min of recovery their concentrations returned to pre-exercise values. Plasma glutamine concentration increased significantly during exercise in the control test and alanine increased in both tests (Fig. 2). The concentration of plasma glutamine and alanine declined rapidly during the initial phase of recovery and reached the lowest concentration after 2 hours. Both glutamine and alanine concentrations decreased below pre-exercise concentrations but glutamine returned to pre-exercise concentrations after 5 to 7 hours of recovery whereas alanine remained low even after 7 hours of recovery (Fig. 2). Plasma

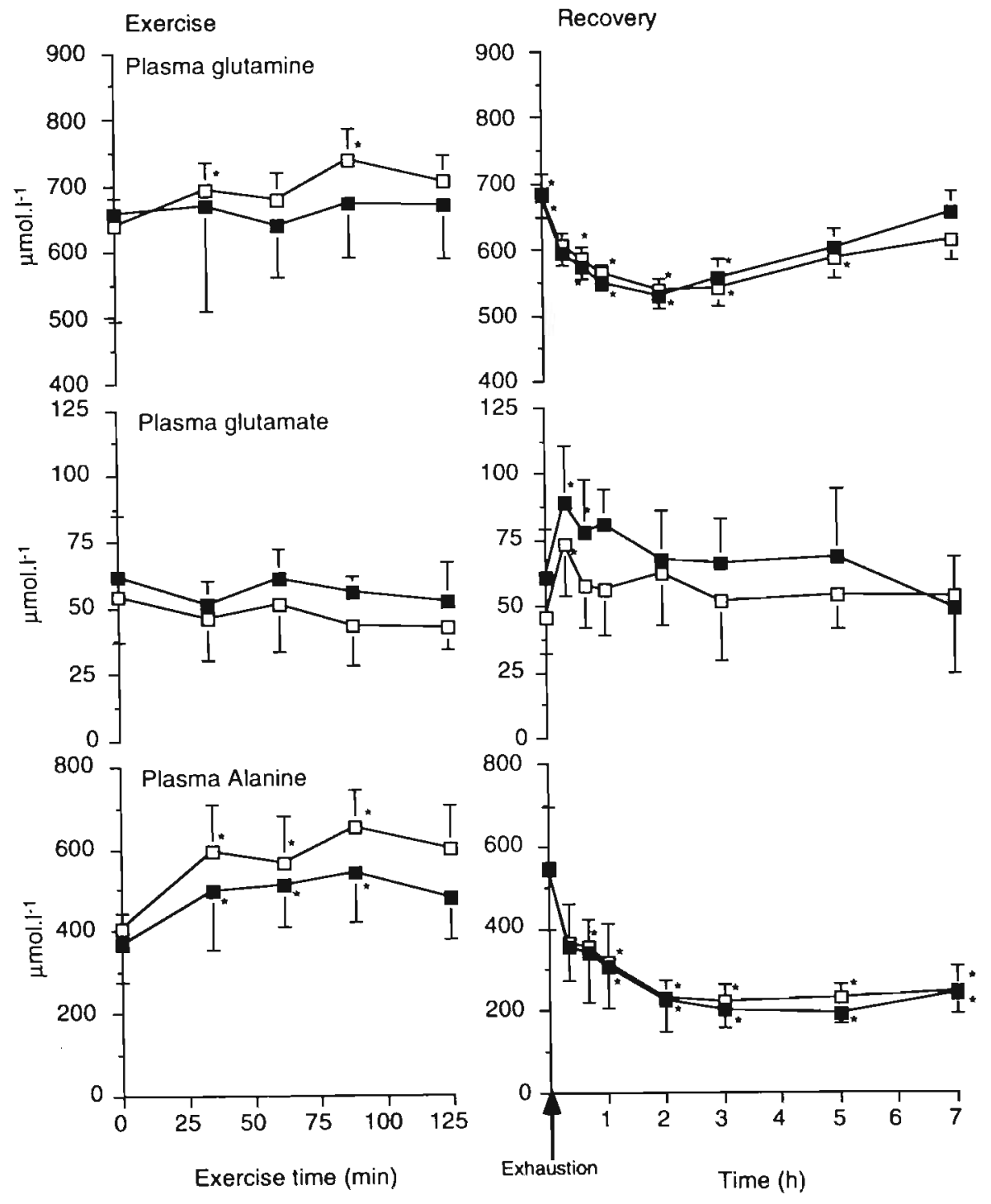



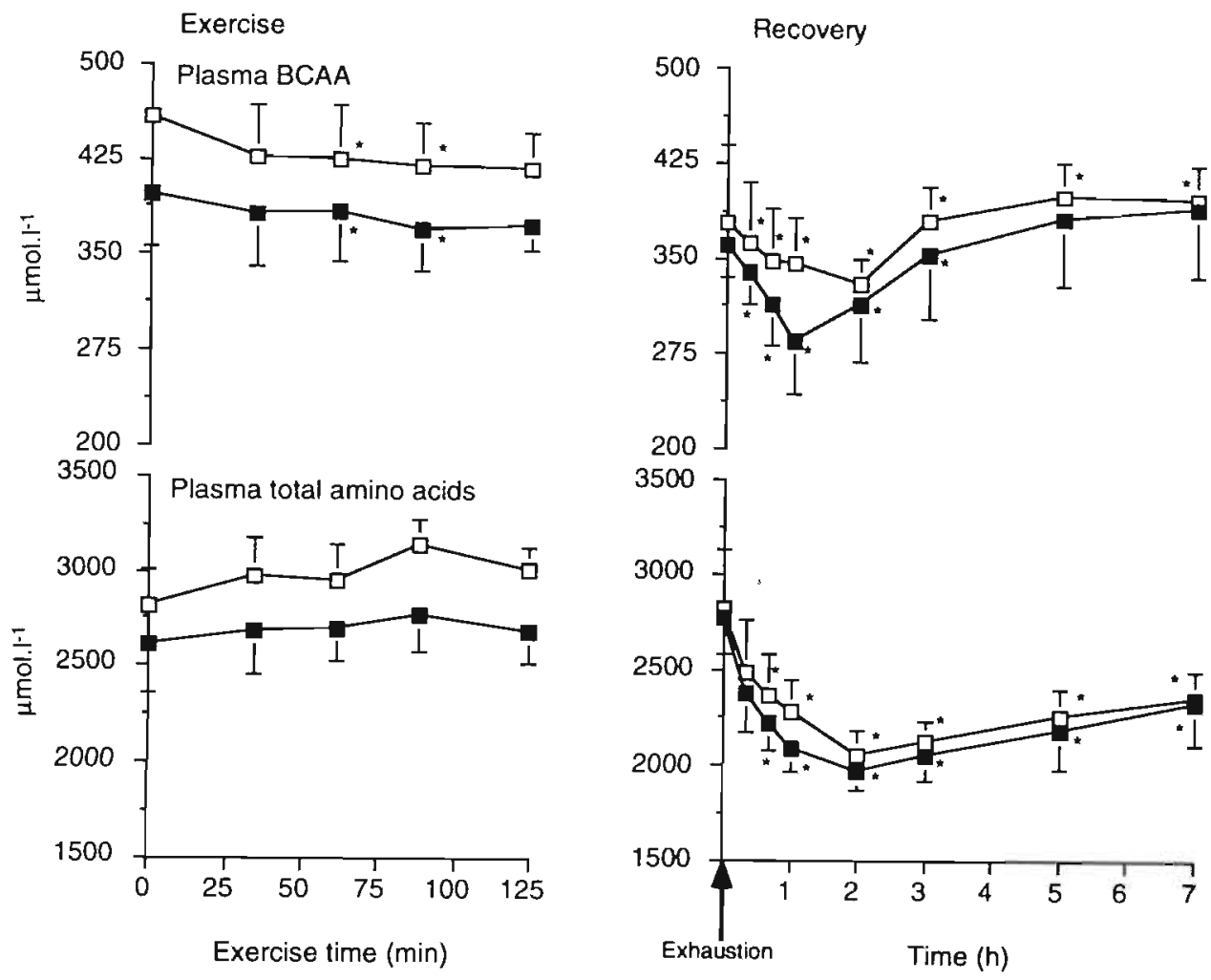

Figure 2. Plasma amino acid concentration during exercise and recovery. Details are given in legend to Fig. 1.

glutamate increased during the first 20 to $40 \mathrm{~min}$ of recovery. The pre-exercise BCAA concentration in the control test was significantly higher than in the carbohydrate supplementation test. The BCAA decreased with exercise and during the first hour of recovery. Plasma BCAA concentration in the control test remained below the preexercise concentration but in the carbohydrate supplementation test plasma BCAA concentration returned to pre-exercise concentration within 5 hours. The absolute BCAA concentration during recovery was equal for both tests (Fig. 2).

\section{DISCUSSION}

The new finding in this study is that the concentration of most plasma amino acids shows a remarkable (10-25\%) decrease after moderate to high intensity exercise performed in blocks alternating at $80 \%$ and $50 \% \mathrm{~W}_{\max }$ simulating intense cycling competition of relatively short duration (1-2 hours). The mechanism behind the post- 
exercise decrease in the plasma amino acid concentration is not clear. One possibility is a temporary increase of muscle protein synthesis rates and net muscle protein deposition as has been observed during recovery from 4 hours of cycling exercise at $40 \% \mathrm{VO}_{2 \max }$ (Carraro, Stuart, Hartl, Rosenblatt \& Wolfe, 1990) and during recovery from resistance exercise (Chesley, MacDougall, Tarnopolsky, Atkinson \& Smith, 1992). It also cannot be excluded that an increased clearance of plasma amino acids by other tissues (e.g. gut, liver) contributes to the reduction of plasma amino acid concentrations.

The post-exercise reduction of the plasma concentration is also seen for alanine and glutamine. These amino acids are special as they are rapidly synthesized $d e$ novo in human skeletal muscle at rest from branched-chain amino acids (BCAA) and carbon-chain precursors as pyruvate and $\alpha$-ketoglutarate both after consumption of a protein containing meal and in the postabsorptive state (Felig, 1975; Goldberg \& Chang, 1978; Elia et al, 1989; Nurjhan et al, 1995). In the BCAA aminotransferase reaction the amino group is donated to $\alpha$-ketoglutarate (BCAA $+\alpha$-ketoglutarate <--> $\mathrm{BC} \alpha$-keto acids + glutamate). In the reaction catalyzed by glutamine synthase, glutamate may then react with ammonia to give glutamine the main non-toxic amino group carrier released by human skeletal muscle 24 hours a day. Alternatively, glutamate may donate the amino group to pyruvate to form alanine, a reaction catalyzed by alanine aminotransferase (glutamate + pyruvate $<---->$ alanine $+\alpha$ ketoglutarate). Exercise leads to significant changes in the rate at which alanine and glutamine are released by skeletal muscle (Felig, 1975; Ahlborg, Felig, Hagenfeldt, Hendler \& Wahren, 1974; Eriksson et al, 1985; Katz, Broberg, Sahlin \& Wahren, 1986; Van Hall et al, 1995). Felig (1975) was the first to report that the alanine output increased greatly with and in proportion to the exercise intensity and the rate of glycolysis and pyruvate accumulation. During prolonged exercise at moderate work load the release of both alanine and glutamine increased during the first $30 \mathrm{~min}$ and then gradually returned to resting values when exercise was continued for 90 min (Van Hall et al, 1995). This may indicate that the rate of alanine and glutamine production is reduced when the glycogen concentration in muscle is decreased towards exhaustion of prolonged exercise and maybe also following exercise.

The other major finding of this study is that oral ingestion of carbohydrates prior to and during exercise has no effect on the concentration of plasma glutamine, alanine and ammonia during exercise and cannot prevent the post-exercise decrease in plasma glutamine and other amino acids. This may imply that blood glucose is relatively unimportant as a precursor for muscle glutamine production during and following prolonged intense exercise in contrast to the original suggestion of Sir Hans Krebs (1975).

After prolonged intense exercise the number of lymphocytes in the blood is reduced, and the function of natural killer cells is suppressed; furthermore, secretory immunity is impaired (Pedersen \& Ullum, 1994). During this time of immune suppression, referred to as 'open window', the host may be more susceptible to micro-organisms bypassing the first line of defense (Pedersen \& Ullum, 1994). This is of interest to top athletes who perform severe exercise frequently. Newsholme and colleagues have linked decreases in plasma glutamine to a weakened immune 
response in heavily training and overtrained athletes (Newsholme, Newsholme \& Curi, 1987; Newsholme and Parry-Billings, 1990; Parry-Billings, Budgett, Koutedakis, Blomstrand, Brooks, Williams et al ; 1992), although experimental evidence for the existence of such a link is lacking. The practical message of this study is that similar decreases in plasma glutamine as observed in overtrained athletes also are seen in the 7 hour period following prolonged intense exercise in elite athletes. Further research is needed to investigate whether this decrease is related to the 'open window' and whether nutritional means can be used to prevent the decrease in plasma glutamine and the 'open window' in parallel. This study finally shows that carbohydrate ingestion during exercise does not prevent the post-exercise decrease in plasma glutamine.

\section{References}

Alhborg, G., Felig, P., Hagenfeldt, L., Hendler, R. \& Wahren, J. (1974). Substrate turnover during prolonged exercise in man. Joumal of Clinical Investigation 53: 1080-1090.

Bergstróm, J., Fürst, P. \& Hultman, E. (1985). Free amino acids in muscle tissue and plasma during exercise in man. Clinical Physiology 5: 155-160.

Broberg, S. \& Sahlin, K. (1989). Adenine nucleotide degradation in human skeletal muscle during prolonged exercise. Journal of Applied Physiology 67: 116-122.

Chang. T.W. \& Goldberg, A.L. (1978). The metabolic fates of amino acids and the formation of glutamine in skeletal muscle. Journal of Biological Chemistry 253: 3685-3695.

Carraro, F., Stuart, C.A., Hart, W.H., Rosenblatt, J. \& Wolfe, R.R. (1990). Effect of exercise and recovery on muscle protein synthesis in human subjects. American Journal of Physiology 259: E470-E476.

Chesley, A., MacDougall, J.D., Tarnopolsky, M.A., Atkinson, S.A. \& Smith, K. (1992). Changes in human muscle protein synthesis after resistance exercise. Journal of Applied Physiology 73: 13831388.

Darmaun, D., Matthews, D. \& Bier, D. (1986). Glutamine and glutamate kinetics in humans. American Joumal of Physiology 251: E117-E126.

Davis, E.J., Spydevold, Ø. \& Bremer, J. (1980). Pyruvate carboxylase and propionyl CoA carboxylase as anaplerotic enzymes in skeletal muscle mitochondria. European Journal of Biochemistry 110: 255-262.

Elia, M., Schlatmann, A., Goren, A. \& Austin, S. (1989). Amino acid metabolism in muscle and in the whole body of man before and after ingestion of a single mixed meal. American Joumal of Clinical Nutrition 49: 1203-1210.

Eriksson, L.S., Broberg, S., Björkman, O. \& Wahren, J. (1985). Ammonia metabolism during exercise in man. Clinical Physiology 5: 325-336.

Felig, P. (1975). Amino acid metabolism in man. Annual Reviews of Biochemistry 44: 933-955.

Goldberg, A.L. \& Chang, T.W. (1978). Regulation and significance of amino acid metabolism in skeletal muscle. Federation Proceedings 37: 2301-2307.

Golden, M.H.N., Jahoor, P. \& Jackson, A.A. (1982). Glutamine production rate and its contribution to urinary ammonia in normal man. Clinical Science 62: 29-305.

Janssen, M.A., Van Berlo, C.L.H., Van Leeuwen, P.A.M. \& Soeters, P.B. (1988). The determination of ammonia in plasma and whole blood. In: Advances in ammonia metabolism and hepatic encephalopathy, edited by Soeters, P.B., Wilson, J.H.P., A.J. Meijer, A.J. \& Holm, E. Amsterdam: Excerpta Medica, 587-592.

Katz, A., Broberg, S., Sahlin, K. \& Wahren, J. (1987). Muscle ammonia and amino acid metabolism during dynamic exercise in man. Clinical Physiology 6: 365-379. 
Krebs, H.A. (1975). The role of chemical equilibrium in organ function. Advances in Enzyme Regulation 15: 449-472.

Kuipers, H., Keizer, H.A., Brouns, F. \& Saris, W.H.M. (1987). Carbohydrate feeding and glycogen synthesis in exercise in man. Pflügers Archiv 410: 652-656.

Marliss, E.B., Aoki, T.T., Pozefsky, T., Most, A.S. \& Cahill, G.F. (1971). Muscle and splanchnic glutamine and glutamate metabolism in postabsorptive and starved man. Journal of Clinical Investigation 50: 814-817.

Newsholme, E.A., Newsholme, P. \& Curi, R. (1987). The role of the citric acid cycle in cells of the immune system and its importance in sepsis, trauma and burns. Biochem. Soc. Sympos. 54: 145161.

Newsholme, E.A., \& Parry-Billings, M. (1990). Properties of glutamine release from muscle and its importance for the immune system. Joumal of Parenteral and Enteral Nutrition 14: 63S-67S.

Nurjhan, N., Bucci, A., Perriello, G., Stumvoll, M., Dailey, G., Bier, D.M., Toft, I., Jenssen, T.G. \& Gerich, J.E. (1995). Glutamine: A major gluconeogenic precursor and vehicle for interorgan carbon transport in man. Journal of Clinical Investigation 95: 272-277.

Pedersen, B.K. \& Ullum, H. (1994). NK cell response to physical activity: possible mechanisms of action. Medicine Science in Sports and Exercise 26: 140-146.

Parry-Billings, M., Budgett, R., Koutedakis, Y., Blomstrand, E., Brooks, S., Williams, C., Calder, P.C., Pilling, S., Baigrie, R. \& Newsholme, E.A. (1992). Plasma amino acid concentrations in the overtraining syndrome: possible effects on the immune system. Medicine and Science in Sports and Exercise 24: 1353-1358.

Rennie, M.J., Edwards, R.H.T., Krywawych, S., Davies, C.T.M., Halliday, D., Waterlow, J.C. \& Millward, D.J. (1981). Effect of exercise on protein turnover in man. Clinical Science 61: 627-639.

Sahlin, K., Katz, A. \& Broberg, S. (1990). Tricarboxylic acid cycle intermediates in human muscle during prolonged exercise. American Journal of Physiology 259: C834-C841.

Van Eijck, H.M.H., Van der Heijden, M.A.H., Van Berlo, C.M.H. \& Soeters, P.B. (1988). Fully automated liquid chromatographic determination of amino acids. Clinical Chemistry 34: 2510-2513.

Van Hall, G., Saltin, B., Van der Vusse, G.J., Söderlund, K. \& Wagenmakers, A.J.M. (1995). Deamination of amino acids as a source for ammonia production during prolonged exercise. Joumal of Physiology 489: 251-261.

Wagenmakers, A.J.M., Salden, H.J.M. \& Veerkamp, J.H. (1985). The metabolic fate of branchedchain amino acids and 2-oxo acids in rat muscle homogenates and diaphragms. International Joumal of Biochemistry 17: 957-962. 


\title{
Chapter 7
}

\section{The effect of glutamine and peptide ingestion on the rate of muscle glycogen resynthesis in man}

\author{
G. van Hall, W.H.M. Saris, P.A.I. van de Schoor, A.J.M. Wagenmakers \\ University of Limburg, Maastricht, The Netherlands
}

American Journal of Physiology submitted.

\begin{abstract}
1. The present study investigates whether oral ingestion of the amino acid glutamine and of two protein hydrolysates increases the rate of glycogen synthesis following intense glycogen lowering exercise. Eight trained subjects were studied during $3 \mathrm{~h}$ of recovery while consuming one of four drinks in random order. Drinks were ingested in three $500 \mathrm{ml}$ boluses, the first immediately after exercise and then after 1 and $2 \mathrm{~h}$ of recovery. Each bolus of the control drink conlained $0.8 \mathrm{~g} \cdot \mathrm{kg}^{-1}$ body weight of glucose. The other drinks contained the same amount of glucose and per $500 \mathrm{ml}$ bolus $0.3 \mathrm{~g} . \mathrm{kg}^{-1}$ body weight of 1 . the amino acid glutamine, of 2 . a wheat hydrolysate $(26 \%$ glutamine) and of 3 . a whey hydrolysate ( $6.6 \%$ glutamine).

2. Plasma glutamine decreased with approximately $20 \%$ during recovery while ingesting the control drink whereas ingestion of both protein hydrolysates prevented the post-exercise decrease of plasma glutamine. Ingestion of the glutamine containing drink caused a two-fold increase in plasma glutamine concentration.

3. The rate of glycogen synthesis was not significantly different in the four tests: $0.46 \pm 0.09,0.38 \pm$ $0.12,0.64 \pm 0.11$ and $0.55 \pm 0.07 \mu \mathrm{mol}$ glycosyl units. $\mathrm{g}^{-1}$ wet weight muscle. $\mathrm{min}^{-1}$ for the control drink and the drinks containing glutamine, the hydrolysate with a high glutamine content and the control hydrolysate, respectively. Glycogen synthase activity was similar immediately after exercise compared to after $3 \mathrm{~h}$ of recovery and between treatments. Plasma insulin concentrations during recovery were significantly higher after ingestion of the protein hydrolysates but not at the $3 \mathrm{~h}$ recovery time point when glycogen synthase activity was measured.

4. It is concluded that ingestion of the amino acid glutamine does not affect the rate of glycogen synthesis in the presence of an excess of glucose as a substrate. Glycogen synthesis rates tended to be higher after ingestion of both protein hydrolysates, though not significantly. This increase is probably mediated by an increase plasma insulin concentration. Both protein hydrolysates prevented the exercise induced decrease in plasma glutamine concentration but the hydrolysate with the high glutamine content did not further increase the plasma glutamine concentration.
\end{abstract}




\section{INTRODUCTION}

Carbohydrate is the most important energy substrate during exercise for an athlete because it is the only fuel that can provide the energy to maintain a prolonged high exercise intensity ( $>60 \% \vee \mathrm{O}_{2 \max }$ ). The carbohydrate stores within the body, in the form of glycogen, are relatively small $(500 \mathrm{~g}$ in sedentary- to $1000 \mathrm{~g}$ in trained individuals). After prolonged moderate intensity exercise the muscle glycogen stores are nearly depleted. Restoration of the muscle glycogen store after training and competition is an important factor determining the time needed to recover. When an adequate amount of carbohydrates is consumed immediately after exercise and at regular intervals muscle glycogen resynthesis will proceed quite rapidly for the first 6to $8 \mathrm{~h}$ (Bergström \& Hultman, 1967; Ivy, Lee, Brozinick \& Reed, 1988; Reed, Brozinick, Lee \& Ivy, 1989).

Glutamine is known to stimulate glycogen synthesis in isolated hepatocytes (Lavoinne, Baquet \& Hue, 1987). It was suggested that this stimulation depended mainly on the activation of glycogen synthase, which in turn seemed to result from a stimulation of synthase phosphatase rather than an inhibition of synthase kinase (Lavoinne et al, 1987). This effect is potentially related to an increase in cell volume resulting from glutamine uptake (Baquet, Hue, Meijer, Woerkom \& Plomp, 1990). Cell swelling recently has been suggested to act as a universal anabolic signal also causing an increased rate of glycogen synthesis (Häussinger, Lang \& Gerok, 1994). Scislowski, Niblock, Lindsay, Weryk, Watt \& Rennie (1989) observed an increase in the rate of skeletal muscle glycogen synthesis and a higher glycogen synthase activity when isolated EDL muscles were incubated with glutamine. Recently, it has been reported that intravenous glutamine infusion stimulates sub maximal muscle glycogen synthesis rates in humans who were not ingesting glucose (Vamier, Leese, Thompson \& Rennie, 1995). Zawadzki, Yaspelkis \& Ivy (1993) have shown that postexercise muscle glycogen deposition can be enhanced with ingestion of a carbohydrate-protein mixture in comparison to only carbohydrate ingestion. These authors suggested that protein ingestion leads to an increased insulin response which in itself will activate glycogen synthesis via activation of glycogen synthase and an increase of the rate of glucose uptake by the myocytes (Ivy \& Holloszy, 1981; James, Jenkins \& Kreagen, 1985).

The present study was designed to investigate whether an increased glutamine availability increases the rate of muscle glycogen synthesis after intense exercise and whether the increased glycogen synthesis rate following ingestion of a carbohydrate-protein mixture is due to a direct effect of glutamine on muscle or can be attributed to a general insulin tropic effect of amino acid or protein ingestion. Several amino acids have been shown to stimulate insulin release in vitro by pancreatic B-cells (Hutton, Sener \& Malaisse, 1980; Sener, Hutton \& Malaisse, 1981), while ingestion of a protein-carbohydrate mixture in vivo also increased the plasma concentration to a much higher value then ingestion of only carbohydrates (Rabinowitz, Merimee, Maffezzoli \& Burgess, 1966). Glutamine, furthermore, has been shown to enhance the in vitro insulin tropic effect of other amino acids (Sener \& Malaisse, 1980). Therefore, subjects were studied during $3 \mathrm{~h}$ of recovery from 
intermittent high intensity exercise, causing muscle glycogen depletion, while ingesting at regular intervals drinks containing 1 . glucose only; 2 . glucose and glutamine; 3. glucose and a protein hydrolysate with a high glutamine content; 4 . glucose and a protein hydrolysate with a normal glutamine content.

\section{METHODS}

\section{Subjects}

Eight well trained male cyclists participated in this study. Their mean age, weight, height, and maximal power output were $25 \pm 3 \mathrm{yr}, 72 \pm 3 \mathrm{~kg}, 1.83 \pm 0.03 \mathrm{~m}$ and $5.0 \pm$ 0.2 Watt. $\mathrm{kg}^{-1}$ body weight. All subjects were healthy trained cyclists. The subjects were informed about possible risks and discomfort involved in this experiment before giving their consent to participate. The study was approved by the Ethical Committee of the University of Limburg.

\section{Experimental Protocol}

Each subject underwent four randomized experimental treatments separated by at least 7 days. Three days before the actual experiment started subjects had to perform a graded exercise test in order to determine their maximal power output $\left(W_{\max }\right)$. At the experimental days subjects report to the laboratory at 8.30 after an overnight fast. Muscle glycogen depletion was established before the treatment by intense cycle ergometer exercise. The glycogen depletion protocol was as described previously by Kuipers, Keizer, Brouns \& Saris (1987), after a warming up period of 10 min at $50 \%$ of their $W_{\max }$ the subjects had to cycle blocks of 2 min in length at an alternating workload of $90 \%$ and $50 \%$ of their respective $W_{\max }$. This was continued until they were not able to complete the $2 \mathrm{~min}$ at $90 \% \mathrm{~W}_{\max }$. That moment was defined as the inability to maintain a cycling speed of 60 revolutions per min. The high intensity block was then reduced to $80 \% \mathrm{~W}_{\max }$. Again the subjects had to cycle until they were unable to complete the $2 \mathrm{~min}$ at $80 \% \mathrm{~W}_{\max }$ and the intensity was reduced to $70 \% \mathrm{~W}_{\max }$. When the $70 \% \mathrm{~W}_{\max }$ could not be completed subjects were allowed to stop. During the glycogen depletion cycle exercise the subjects were cooled with standing floor fans in a room with a constant temperature of $20^{\circ} \mathrm{C}$. Water was provided ad libitum before during and after the tests.

After cessation of the glycogen depletion exercise bout the subjects were allowed to take a shower and a catheter was inserted in an anticubital vein. Approximately 15 min after the end of the exercise period the pre-treatment blood sample and muscle biopsy was taken and the first bolus of the test drink was immediately provided. Another bolus was given after 1 - and $2 \mathrm{~h}$ of recovery. Each bolus of the control drink contained $0.8 \mathrm{~g} . \mathrm{kg}^{-1}$ body weight glucose (Amylum, The Netherlands); the same amount of glucose and 1) $0.3 \mathrm{~g} . \mathrm{kg}^{-1}$ body weight glutamine (Degussa, The Netherlands 2) $0.3 \mathrm{~g}^{\mathrm{kg}} \mathrm{kg}^{-1}$ body weight of a wheat protein hydrolysate with a high glutamine content (Quest International, The Netherlands) and 3) $0.3 \mathrm{~g} . \mathrm{kg}^{-1}$ body weight of a whey protein hydrolysate with a normal glutamine content (Quest International, The Netherlands). The protein hydrolysate with the high glutamine 
content was a polypeptide derived from wheat protein with a mean chain length of 11 amino acids and a glutamine content of $26 \%$. The whey protein hydrolysate had a mean chain length of 5.5 and a glutamine content of $6.6 \%$. All supplements were dissolved in water to a volume of $500 \mathrm{ml}$.

\section{Tissue collection and blood sampling}

Muscle biopsies from the quadriceps muscle were taken 15 min after the glycogen depletion protocol and $3 \mathrm{~h}$ thereafter from the contra lateral leg. Muscle specimens were analyzed for glycogen concentration and glycogen synthase activity (active and total). Blood samples $(3 \mathrm{ml})$ were drawn before the first bolus of the test drinks and then every $30 \mathrm{~min}$. Venous blood was centrifuged to obtain plasma and immediately frozen in liquid nitrogen and analyzed for glucose, glutamine and insulin.

\section{Analysis}

Glucose and glutamine (Lund, 1990) were measured enzymatically on a COBAS BIO analyzer (Roche, The Netherlands). Insulin was measured with a commercially available radio immunoassay kit (Pharmacia, Sweden).

For glycogen determination $\pm 50 \mathrm{mg}$ of wet weight muscle was heated for 3 hours

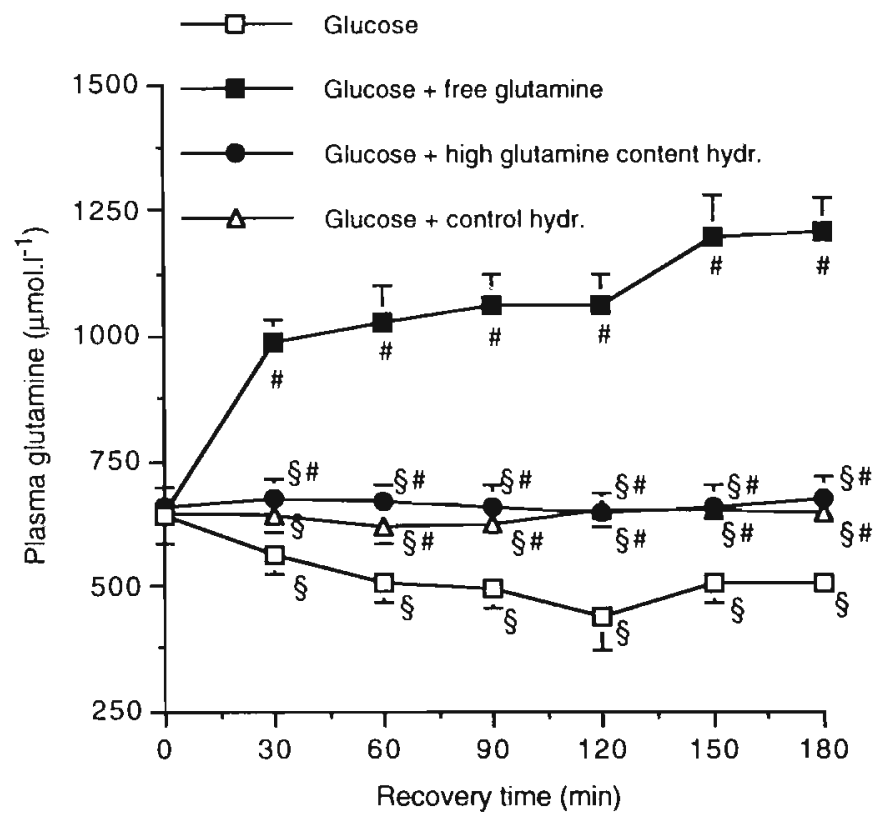

Figure 1. Plasma glutamine concentration during recovery from intense exercise with oral ingestion of glucose and glutamine or protein hydrolysates. Values are means \pm SEM from 8 subjects. \$Significant differences from glucose + free glutamine test, "significant differences from the glucose test $(P<0.05)$. 
at $37^{\circ} \mathrm{C}$ with $1 \mathrm{ml}$ of $1 \mathrm{M} \mathrm{NaOH}$. $1 \mathrm{ml}$ of ethanol was added and heated for $10 \mathrm{~min}$ at $85^{\circ} \mathrm{C}$ in sealed tubes. The solution was then kept at $4^{\circ} \mathrm{C}$ for 20 hours to precipitate glycogen and then centrifuged. $500 \mu \mathrm{l} 1 \mathrm{M} \mathrm{HCl}$ was added to the glycogen pellet and then heated for 3 hours to $100^{\circ} \mathrm{C}$ to hydrolyze the glycogen to glycosyl units. The final solution was neutralized with $1 \mathrm{M} \mathrm{NaOH} .150 \mu$ was used for enzymatic determination of glucose.

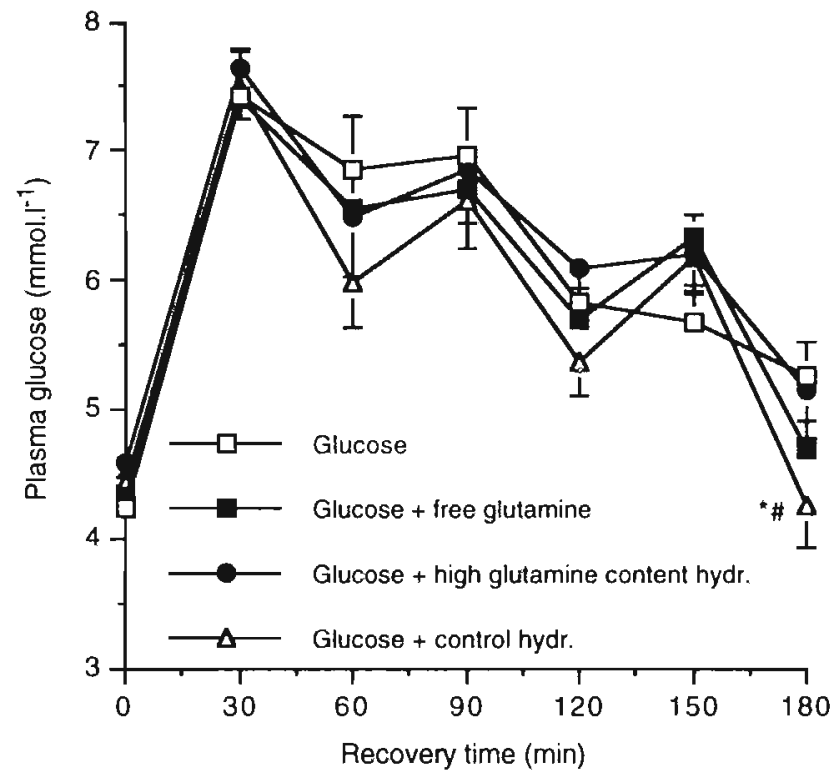

Figure 2. Plasma glucose concentration during recovery from intense exercise with oral ingestion of glucose and glutamine or protein hydrolysates.

Values are means \pm SEM from 8 subjects. "Significant differences from glucose + high glutamine content test, "significant differences from the glucose test $(P<0.05)$.

Glycogen synthase activity was measured by the method of Danforth (1965). \pm 30 $\mathrm{mg}$ of muscle tissue was homogenized in SET buffer, $250 \mathrm{mM}$ sucrose, $2 \mathrm{mM}$ EDTA and $10 \mathrm{mM}$ Tris with a pH of 7.4. The enzyme activity was assayed at $\mathrm{pH} 7.4$ and 30 ${ }^{\circ} \mathrm{C}$ in a reaction mixture containing $60 \mathrm{mM}$ Tris, $1.2 \mathrm{mM}$ EDTA, $3 \mathrm{mM}$ mercaptoethanol, $1.2 \mathrm{mM} \mathrm{NaF}, 7.5 \mathrm{mM}$ UDP-glucose and $1.2 \%$ glycogen. The assay was carried out in the presence and absence of $12 \mathrm{mM}$ glucose-6-P to measure total glycogen synthase activity $\left(G_{\text {tot }}\right)$ and active glycogen synthase activity $\left(G_{\text {act }}\right)$. The reaction was terminated by heating for $2 \mathrm{~min}$ in a boiling water bath. The denatured protein was removed by centrifugation, the supernatant solution was assayed enzymatically for UDP. UDP was measured by allowing the UDP to react with phosphoenolpyruvate in the presence of pyruvate kinase. The formed pyruvate was measured spectrofotometrically with lactate dehydrogenase. Activities are expressed as $\mu \mathrm{mol}$ of glycosyl units from UDP-glucose incorporated into glycogen. $\mathrm{min}^{-1} . \mathrm{g}^{-1}$ wet weight muscle at $30^{\circ} \mathrm{C}$. 


\section{Statistical analysis}

All data are means \pm SEM. Statistical analysis of the data was done using one way repeated measures analysis of variance (ANOVA). Differences between treatments were checked for statistical significance using the Fisher's protected least significant difference test. Statistical significance was set at $P<0.05$.

Table 1. Glycogen synthase activity after $3 \mathrm{~h}$ of recovery from intense exercise with ingestion of glucose or with the additives free glutamine, a high glutamine content protein hydrolysate and a control hydrolysate.

\begin{tabular}{|c|c|c|c|c|}
\hline $\begin{array}{l}\text { Glycogen synthase } \\
\text { activity }\left(\mu \mathrm{mol}^{-1} \cdot \mathrm{min}^{-1}\right)\end{array}$ & & $\begin{array}{l}\text { Total } \\
\text { activity }\end{array}$ & $\begin{array}{l}\text { Actual } \\
\text { activity }\end{array}$ & $\%$ active \\
\hline Glucose & post-ex & $2.4 \pm 0.2$ & $1.6 \pm 0.1$ & $\begin{array}{l}68 \pm 1 \\
72 \pm 2\end{array}$ \\
\hline Glucose + free glutamine & post-ex & $1.9 \pm 0.2$ & $1.3 \pm 0.2$ & $\begin{array}{l}68 \pm 2 \\
73+3\end{array}$ \\
\hline Glucose + gln hydrolysate & $\begin{array}{l}3 \mathrm{~h} \\
\text { post-ex } \\
3 \mathrm{~h}\end{array}$ & $\begin{array}{l}2.4 \pm 0.1 \\
2.4 \pm 0.2 \\
2.4 \pm 0.2\end{array}$ & $\begin{array}{l}1.8 \pm 0.1 \\
1.7 \pm 0.1 \\
1.8 \pm 0.2\end{array}$ & $\begin{array}{l}73 \pm 3 \\
71 \pm 2 \\
77 \pm 2\end{array}$ \\
\hline Glucose + contr hydrolysate & $\begin{array}{l}\text { post-ex } \\
3 \mathrm{~h}\end{array}$ & $\begin{array}{l}2.1 \pm 0.2 \\
2.6 \pm 0.4\end{array}$ & $\begin{array}{l}1.4 \pm 0.2 \\
1.7 \pm 0.2\end{array}$ & $\begin{array}{l}70 \pm 4 \\
72 \pm 5\end{array}$ \\
\hline
\end{tabular}

Vaiues are means \pm SEM from $\overline{8}$ subjects.

\section{RESULTS}

Three levels of plasma glutamine concentration were observed during recovery in this study (Fig 1). When the control drink with only glucose was provided, plasma glutamine concentration decreased to a level approximately $20 \%$ below the first sample point $15 \mathrm{~min}$ after cessation exercise. Both protein hydrolysates prevented the decrease in plasma glutamine observed in the control test. However, no difference was observed between the hydrolysate with a high - and low glutamine content, despite the four fold higher glutamine content in the former. Ingestion of free-glutamine caused a two-fold increase in the plasma glutamine concentration. The amount of glutamine given as the free amino acid was 4 times higher than the amount of glutamine ingested as the hydrolysate with the high glutamine content.

Plasma glucose concentration doubled after ingestion of the different drinks but gradually decreased to pre-treatment concentration (Fig. 2). Ingestion of the 2nd and $3 r d$ bolus temporarily increased plasma glucose again. Plasma insulin concentration increased after ingestion of the drinks. The highest increase was present $30 \mathrm{~min}$ after ingestion of the drinks. The increase was much higher after the 3rd bolus than after the 2 nd and 1 st bolus. The increase was higher for the protein hydrolysates than for the control and glutamine drink. A very rapid decrease occurred between 30 and 60 min after ingestion of the boluses, especially after ingestion of the 3rd bolus. No 
differences existed in plasma insulin concentration 60 min after ingestion of the 3rd bolus and the concentration at that time was not significantly different from the immediate post-exercise value. Although plasma insulin concentration was significantly higher during most of the recovery period with both protein hydrolysates compared to the control and glutamine drinks (Fig. 3) no differences were observed between drinks in plasma glucose concentration. Plasma glucose concentration gradually decreased during recovery while plasma insulin concentration gradually increased.

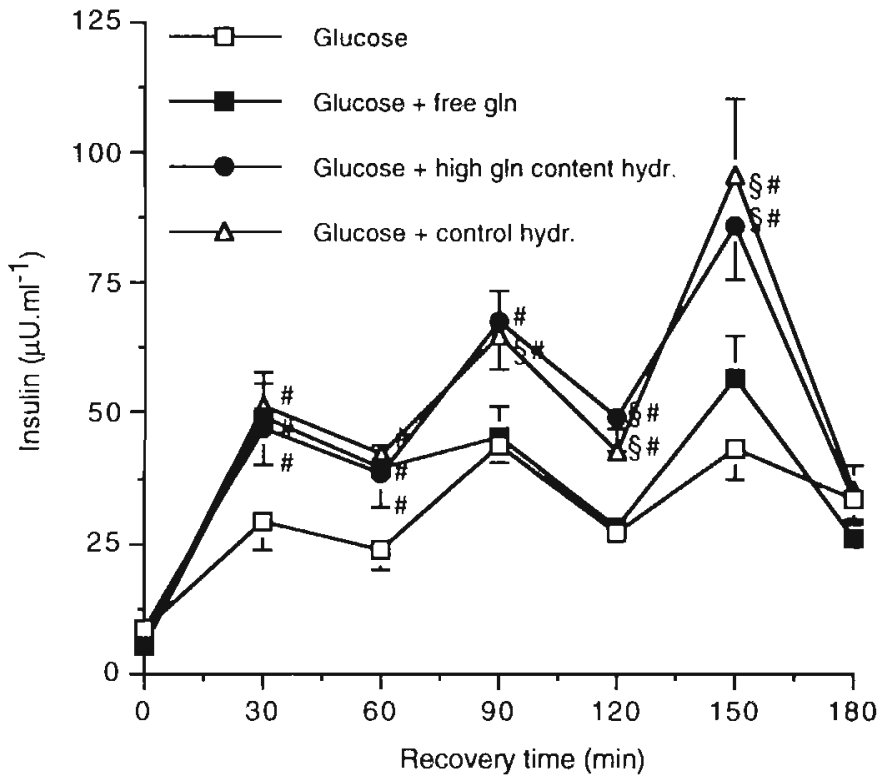

Figure 3. Plasma insulin concentration during recovery from intense exercise with oral ingestion of glucose and glutamine or protein hydrolysates.

Values are means \pm SEM from 8 subjects. \$Significant differences from glucose + free glutamine content test, "significant differences from the glucose test $(P<0.05)$.

The pre-treatment muscle glycogen concentration was $144 \pm 44,110 \pm 35,129 \pm$ 35 and $94 \pm 26 \mu \mathrm{mol}$ glycosyl units. $g^{-1}$ dry weight muscle and after three hours of recovery $228 \pm 15,181 \pm 31,245 \pm 9$ and $197 \pm 19 \mu \mathrm{mol}$ glycosyl units. $\mathrm{g}^{-1} \mathrm{dry}$ weight muscle for the control, glutamine, the hydrolysate with the high- and normal glutamine content, respectively. Muscle glycogen concentration did not differ significantly before and after $3 \mathrm{~h}$ of recovery between treatments. The rate of glycogen synthesis was similar after ingestion of the control and glutamine drinks. However, glycogen synthesis rates tended to be higher after ingestion of the protein hydrolysates, albeit not significantly $(P=0.061$ and $P=0.068$ for the hydrolysate with the high and low glutamine content, respectively) (Fig. 4). Glycogen synthase activity was the same immediately after the exercise bout and after 3 hours of recovery. No differences were observed between the drinks (Table 1). 


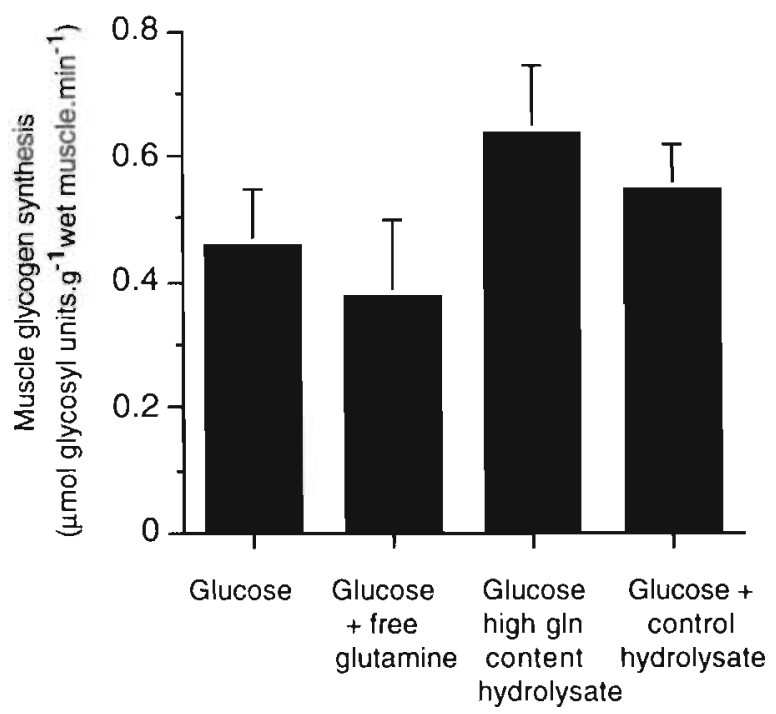

Figure 4. The rate of muscle glycogen synthesis during $3 \mathrm{~h}$ of recovery from intense exercise.

Values are means \pm SEM from 8 subjects.

\section{DISCUSSION}

The major finding of this study is that we, in contrast to previous studies (Scislowski, et al, 1989; Varnier et al, 1995), do not find an effect of glutamine on the rate of glycogen synthesis following exercise nor on glycogen synthase activity, despite a high increase in plasma glutamine concentration. A major difference is that we measured glycogen synthesis rates with ample glucose around as substrate, whereas Varnier and colleagues (1995) did not add glucose to the infusions and measured glycogen synthesis rates far from maximal. Varnier et al (1995) suggested that carbon derived from glutamine is preferentially used for glycogen resynthesis as infusion of other amino acids had no effect. From this study, however, it appears that carbon from glutamine is quantitatively not important for glycogen synthesis after intense exercise when glucose, the immediate precursor for glycogen synthesis, is available in sufficient amounts. Furthermore, we can conclude from our data that the intake of excessive amounts of glutamine does not appear to have an effect on glycogen synthase activity measured in muscle in vivo .

A striking observation in this study is that the plasma glutamine concentration was not higher after ingestion of the hydrolysate with the high glutamine content compared to the normal glutamine content hydrolysate while the glutamine content of the former was nearly 4-fold higher. A possible explanation for this observation is that glutamine is an important fuel for the gut (Souba, 1990) and the additional glutamine in the hydrolysate with the high glutamine content may all have been oxidized and 
not appeared in the main circulation. Three possible explanations may be given for the fact that free glutamine gave a much higher increase in plasma glutamine than the peptide bound glutamine 1. The amount of glutamine given was 4-fold greater and may have exceeded the maximal capacity of the splanchnic area to extract and oxidize glutamine (Déchelotte, Darmaun, Rongier, Hecketsweiller, Rigal \& Desjeux, 1991; Matthews, Marano \& Campbell, 1993); 2. Absorption of glutamine and peak glutamine concentration may be reduced in case of the hydrolysate due to limitations in the rate of digestion; 3 . The hydrolysate contains all amino acids and thus the rate of protein synthesis may have been enhanced and part of the glutamine incorporated in gut and liver protein. Glutamine provided as the free form will not be incorporated as the other amino acids were not available and, therefore, protein synthesis cannot have been enhanced.

Insulin is a strong activator of muscle glycogen synthesis because of its stimulating effect on glucose transport and glycogen synthase activity. The latter enzyme is the rate limiting enzyme in the glycogen synthesis pathway. Pancreatic insulin secretion is primarily regulated by blood glucose concentration, but protein ingestion also has been shown to stimulate insulin secretion in vivo (Rabinowitz et al, 1966; Nuttal, Mooradian, Gannon, Billington \& Krezowski, 1984). In this study ingestion of the protein hydrolysates also caused an increased insulin concentration during most of the recovery period, and although not significant, it appears that the rate of glycogen synthesis is higher after ingestion of the hydrolysates. Although it has been suggested in vitro (Sener \& Malaisse, 1980) that glutamine may enhance the insulin tropic effect of other amino acids we did not observe higher insulin concentrations following the ingestion of the peptide with the high glutamine content. After $3 \mathrm{~h}$ of recovery we did not observe differences in plasma insulin concentration and glycogen synthase activity therefore was not different between the four tests. However, since insulin concentration was higher during most of the recovery period, glycogen synthase activity may have been higher during most of the recovery period after ingestion of the protein hydrolysates and may have caused a higher glycogen synthesis rate. Zawadzki et al (1994) found a significant increase in the rate of glycogen synthesis during 4 hours of recovery when carbohydrates and protein were ingested compared to carbohydrates alone and attributed this effect to the higher insulin response with protein ingestion. Although the differences were not significant in this study we appear to confirm most of the data of Zawadzki et al (1994). Burke, Collier, Beasley, Davis, Fricker, Heeley, Walder \& Hargreaves (1995) were not able to find a positive effect on the rate of glycogen synthesis or insulin concentration after 24 hour of recovery with carbohydrate, protein and fat ingestion compared to carbohydrates alone. However, they did not sample in the early period where effects are expected to be higher. Muscle glycogen is known to regulate its own synthesis. Negative feedback may reduce the glycogen synthesis rate and lead to a similar glycogen concentration after $24 \mathrm{~h}$, despite early differences between treatments. Athletes who have to compete and train daily at high intensities and for long periods may certainly benefit from a faster early restoration of the muscle glycogen stores caused by addition of protein to carbohydrate containing drinks. 
In conclusion, ingestion of free glutamine did not increase the rate of glycogen synthesis in the $3 \mathrm{~h}$ recovery period following intermittent high intensity exercise despite a massive increase in the plasma concentration. Furthermore, glutamine did not increase glycogen synthase activity in vivo $3 \mathrm{~h}$ post-exercise. Ingestion of a hydrolysate with a high glutamine content did not increase plasma glutamine concentration compared to a hydrolysate with a normal glutamine content despite a 4-fold higher glutamine content. Both protein hydrolysates prevented the plasma glutamine decrease during recovery from intense exercise. Both protein hydrolysates tended to increase the rate of glycogen synthesis during recovery most likely via stimulating effect on insulin secretion. Our data exclude that glutamine plays a role in the enhancing effect of protein ingestion on maximal rate of glycogen resynthesis in the first hours following exercise.

\section{References}

Baquet, A. \& Hue, L. (1990). Swelling of rat hepatocyte stimulates glycogen synthesis. Journal of Biological Chemistry 265: 955-959.

Bergström, J. \& Hultman, E. (1967). Muscle glycogen synthesis after exercise: an enhancing factor localized to the muscle cells in man. Nature 201: 309-310.

Burke, L.M., Collier, G.R., Beasley, S.K., Davis, P.G., Fricker, P.A., Heeley, P., Walder, K. \& Hargreaves, M. (1995). Effect of coingestion of fat and protein with carbohydrate feedings on muscle glycogen storage. Journal of Applied Physiology 78: 2187-2192.

Danforth, W.H. (1965). Glycogen synthetase activity in skeletal muscle - Interconversion of two forms and control of glycogen synthesis. Journal of Biological Chemistry 240: 588-593.

Dechelotte, P., Darmaun, D., Rongier, M., Hecketsweiler, B. Rigal, O. \& Desjeux, J-F. (1991). Absorption and metabolic effects of enterally administered glutamine in humans. American Journal of Physiology 260: G677-G682.

Häussinger, D., Lang \& Gerok, W. (1994). Regulation of cell function by the cellular hydration state. American Joumal of Physiology 267: E343-E355.

Hutton, J.C., Sener, A. \& Malaisse, W.J. (1980). Interaction of branched chain amino acids and keto acids upon pancreatic islet metabolism and insulin secretion. Journal of Biological Chemistry 255: 7340-7346.

Ivy, J.L. \& Holloszy, J.O. (1981). Persistent increase in glucose uptake by rat skeletal muscle following exercise. American Joumal of Physiology 241: C200-C203.

Ivy, J.L., Lee, M.C., Brozinick, J.T. \& Reed, M.J. (1988). Muscle glycogen storage after different amounts of carbohydrate ingestion. Journal of Applied Physiology 65: 2018-2023.

James, D.E., Jenkins, A.B. \& Kreager, E.W. (1985). Heterogeneity of insulin action in individual muscles in vivo; euglycemic clamp studies in rats. American Joumal of Physiology 248: E567E574.

Kuipers, H., Keizer, H.A., Brouns, F. \& Saris, W.H.M. (1987). Carbohydrate feeding and glycogen synthesis in exercise in man. Plfügers Archiv 410: 62-656.

Lavoinne, A., Baquet, A. \& Hue, L. (1987). Stimulation of glycogen synthesis and lipogenesis by glutamine in isolated rat hepatocytes. Biochemical Joumal 248: 429-437.

Lund, P. (1990). In Methods of enzymatic analysis, ed Bergmeyer, H.U.; vol 8: 357-363.

Matthews, D.E., Marano, M.A. \& Campbell, R.G. (1993). Splanchnic bed utilization of glutamate and glutamic acid in humans. American Journal of Physiology 264: E848-E854.

Nuttal, F.Q., Mooradian, A.D., Gannon, M.C., Billington, C. \& Krezowski, P. (1984). Effect of protein ingestion on the glucose and insulin response to a standardized oral glucose load. Diabetes Care 7: $465-470$. 
Rabinowitz, D., Merimee, T.J., Maffezzol, R. \& Burgess, J.A. (1966). Patterns of hormonal release after glucose, protein, and glucose plus protein. Lancet 2: 454-456.

Reed, M.J., Brozinick, J.T., Lee, M.C. \& IVy, J.L. (1989). Muscle glycogen storage post exercise: effect of mode of carbohydrate administration Journal of Applied Physiology 66: 720-726.

Scislowski, , P.W.D., Niblock, A., Lindsay, Y., Weryk, B., Watt, P.W. \& Rennie, M.J. (1989). Glutamine stimulates glycogen synthesis in skeletal muscle. Clinical Nutrition (Suppl) 8: 97.

Sener, A., Hutton, J.C. \& Malaisse, W.J. (1981). The stimulus-secretion coupling of amino acidinduced insulin release synergistic effects of L-glutamine and 2-keto acids upon insulin secretion. Biochemica et Biophysica Acta 677: 32-38.

Sener, A. \& Malaisse, W.J. (1980). L-leucine and a non metabolized analogue activate pancreatic islet glutamate dehydrogenase. Nature 288: 187-189.

Souba, W.W. (1990). Glutamine a key substrate for the splanchnic bed. Annual Review of Nutrition 11: 285-308.

Varnier, M., Leese, G.P., Thompson, J. \& Rennie, M.J. (1995). Stimulatory effect of glutamine on glycogen accumulation in human skeletal muscle. American Journal of Physiology 269: E309E315.

Zawadzki, K.M., Yaspelkis III, B.B. \& IVy, J.L. (1993). Carbohydrate-protein complex increases the rate of muscle glycogen storage after exercise. Journal of Applied Physiology 72: 1854-1859. 


\title{
Chapter 8
}

\section{Muscle protein degradation rates during prolonged one leg cycle exercise in man}

\author{
G. van Hall, B. Saltin*, A.J.M. Wagenmakers \\ University of Limburg, Maastricht, The Netherlands; "CMAC, Copenhagen, Denmark.
}

Journal of Physiology submitted.

\begin{abstract}
1. The aim of this study was to investigate whether prolonged one leg knee-extensor exercise enhances net protein degradation in muscle with a normal and low glycogen content.

2. Net amino acid production as a measure for net protein degradation was estimated from the leg exchange and changes in the concentration of amino acids that are not metabolized in skeletal muscle at rest and during one leg knee-extensor exercise in six subjects having one leg with a normal and one leg with a low muscle glycogen content. Exercise was performed for 90 min at a workload of $60-65 \%$ of the maximal one leg power output starting at random first with the normal or low glycogen leg and then in the afternoon with the other leg.

3. Assuming that the increase in amino acid release originates from the active muscle during exercise then the net production of threonine, lysine and tyrosine and of the sum of nonmetabolized amino acids was about 9- to 20-fold higher during exercise of the normal glycogen leg than at rest $(P<0.05)$. The absolute muscle production rate of the sum of all amino acids was 11 -fold higher during exercise compared to rest (difference not significant).

4. The net muscle production rate of threonine, glycine, tyrosine and of the sum of the nonmetabolized amino acids was about 1.5- to 2.5 -fold higher during exercise with the low glycogen content leg than with the normal glycogen content leg $(P<0.05)$. Net production of the sum of all amino acids was 1.5 -fold higher while exercising the low glycogen leg compared to the normal glycogen leg (albeit not significant).

5. These data indicate that prolonged one leg knee-extensor exercise leads to a massive increase of net muscle protein degradation and that a reduction of the starting muscle glycogen content leads to a further increase. These data do not imply that muscle protein is broken down at a similar rate during two legged cycle exercise at $60-65 \% W_{\max }$ as the work load and oxygen consumption per $\mathrm{kg}$ muscle is 2- to 3-fold higher during one leg knee-extensor exercise.
\end{abstract}




\section{INTRODUCTION}

In the 1840 's the German physiologist Von Liebig hypothesized that muscle protein was the main fuel used to achieve muscular contraction. Fick and Wislecenus in their classic study (1866) and many others raised considerable doubts on Von Liebig's proposal as they failed to show an increase in the urinary nitrogen excretion during and after the ascent of the Faulhorn, a Swiss mountain. Since then many different methods have been used to investigate whether exercise leads to an increase of the net degradation rate of protein in muscle and/or at the whole body level. Conclusions of these studies are highly controversial due to both methodological problems and the conditions chosen under which exercise was performed.

Many recent studies performed in the laboratory at relatively low two legged cycle exercise intensities $\left(30-40 \% \mathrm{VO}_{2 \max }\right)$ for several hours did not show an effect of exercise on whole body protein synthesis and degradation (Carraro, Hartl, Stuart, Layman, Jahoor \& Wolfe, 1990), on whole body urea production (Carraro, Kimbrough \& Wolfe, 1993) and on muscle protein synthesis (Carraro, Stuart, Layman, Jahoor \& Wolfe, 1990). In a 1 hour study at $70 \% \mathrm{VO}_{2 \max }$ Carraro et al (1993) also failed to show an increase of whole body urea production, indicating that these types of exercise do not lead to net protein degradation (protein synthesis < protein degradation). However, during competitive endurance events (ultra-marathons, triathlons) athletes exercise for periods of 5 to 15 hours at moderate to high intensities $\left(50-60 \% V \mathrm{~V}_{2 \mathrm{max}}\right)$. The few field studies that have been done under extreme conditions (eg Decombaz, Reinhardt, Anantharaman, Von Glutz \& Poortmans, 1979) do show an increased urinary urea excretion during and after ultradistance running. Lemon \& Mullin (1982) also have shown that, in addition to urinary losses, substantial amounts of urea are lost in sweat, especially in endurance exercise leading to glycogen depletion. These data together suggest that ultraendurance exercise of moderate to high intensity leading to glycogen depletion (as occurs in the field during competitive ultra-endurance events) leads to net protein degradation.

During one leg knee-extensor exercise approximately $3 \mathrm{~kg}$ of skeletal muscle is involved in exercise (Andersen \& Saltin, 1985). Maximal heart rate that can be reached during one legged exercise is about 140 compared to 190 beats. min $^{-1}$ with whole body exercise. Maximal oxygen consumption of the active muscle is about 800 $\mathrm{ml}$ per min implying that maximal $\mathrm{O}_{2}$ consumption per $\mathrm{kg}$ muscle per min is 2- to 3fold higher than for whole body exercise. This also implies that the metabolic rate of the active muscle during one leg knee-extensor exercise is much higher than during whole body exercise. High metabolic rates are also reached in electrically stimulated rat muscles and in such muscles protein synthesis has been reported to decrease (Bylund-Fellenius, Ojamaa, Flaim, Li, Wassner \& Jefferson, 1984).

Good estimates of muscle protein degradation rates during exercise in man are not available in the literature due to the lack of suitable methods to measure protein degradation in vivo. Estimation of the arterio-venous balance of amino acids that are not metabolized in muscle is the most direct method to measure net protein degradation. However, during two legged cycle exercise at intensities of $>50 \%$ 
$V O_{2 \max }$ the increase in blood flow to the active muscle prevents the accurate measurement of arterio-venous differences and, therefore, this method is not suited to detect the small changes in net protein degradation between rest and low to moderate intensity whole body exercise. This situation may be different during one leg knee-extensor exercise as a fall in muscle protein synthesis may be expected in that case on the basis of the similarity in metabolic rates with electrically stimulated muscles. Therefore, the aim of this study was to estimate net muscle protein degradation with the arterio-venous amino acid balance method at rest and during prolonged one leg knee-extensor exercise at $60-65 \%$ of the one leg power output.

\section{METHODS}

\section{Subjects}

Six healthy male volunteers participated in the study. Their mean age, weight, height, and maximal one leg power output was $24 \pm 3 \mathrm{yr}, 75 \pm 4 \mathrm{~kg}, 1.88 \pm 0.03 \mathrm{~m}$ and $61 \pm$ 5 Watt. All subjects were healthy and physically active and participated regularly in leisure sport. The subjects were informed about possible risks and discomfort involved in the experiment before giving their consent to participate. The study was approved by the Ethical Committee of the Karolinska Institute, Stockholm, Sweden.

\section{Protocol}

The protocol of this study has previously been described in detail (chapter 2).

Subjects performed one leg exercise in the upright position on an ergometer that permits the exercise to be confined to the quadriceps femoralis muscle group (Andersen \& Saltin, 1985). Three days before the actual experiment subjects performed a graded exercise test to determine their maximal one leg power output $\left(W_{\text {max }}\right)$. The exercise protocol consisted of 90 min one leg knee-extensor exercise at a workload of $60-65 \% W_{\max }$. After the $90 \mathrm{~min}$ of exercise the subjects were not completely exhausted, but experienced intense exertion localized in the exercised leg. The mean heart rate was $53 \pm 6,103 \pm 7$ and $107 \pm 6$ beats. min $^{-1}$ at rest and after 30 and $90 \mathrm{~min}$, respectively. The subjects were studied under two experimental conditions, with a normal and a low glycogen content of the quadriceps femoralis muscle. The two tests were performed on one day. In the moming subjects started at random with the normal or low glycogen content leg and in the afternoon with the other leg after a resting period of $2 \mathrm{~h}$. In order to obtain one normal and one low glycogen content leg the subjects had to undergo a glycogen depletion protocol on the evening before the actual test. On the experimental day subjects reported to the laboratory in the morning. Catheters for blood sampling were placed in the femoral artery and vein in the inguinal region of the leg to be exercised and advanced with the tip placed $5-6 \mathrm{~cm}$ proximal to the inguinal ligament. The venous blood sample here drains about $9 \mathrm{~kg}$ of muscle and in addition some bone and skin. A thermistor was inserted through the venous catheter for blood flow measurements by the constant infusion thermodilution technique (Andersen \& Saltin, 1985). After placement of the catheters the subjects rested for $30 \mathrm{~min}$ in the supine position. 
During the resting period between the two tests a femoral venous catheter was placed in the leg to be exercised in the afternoon. Local anesthesia was applied to the skin and percutaneous incisions were made before exercise for subsequent muscle biopsies with the needle biopsy technique (Bergström, 1962). Muscle biopsies were taken from the lateral part of the quadriceps femoralis muscle prior to exercise and after 10 and $90 \mathrm{~min}$ of exercise. Arterial and venous blood was sampled simultaneously before exercise and after 10,30,60, and 90 min of exercise. Blood flow was measured just before the blood samples were taken in the moming exercise bout.

\section{Calculations}

Amino acid flux rates were calculated from the arterio-venous difference in the plasma concentration of the amino acid multiplied with the plasma flow. This implicates that the estimated rate of net protein degradation reflects minimal rates. As the flux rates mainly depend on the arterio-venous difference balance a very sensitive and accurate HPLC method for amino acid determination was used with variation coefficients ranging from $2 \%$ and $7 \%$ (mean CV $2.8 \%$ )(Van Eijk, Van der Heijden, Van Berlo \& Soeters, 1988). The total net exchange of amino acids between 10-90 min of exercise was determined as the area under the curve of the exchangetime relationship. The efflux rates of two consecutive time points were averaged and multiplied by the time span and summing these for the whole exercise period. Net production and consumption of amino acids at rest is equal to the flux rates of the amino acids assuming that at rest the intramuscular amino acid pool does not change. It is assumed here that the total exchange results from the $9 \mathrm{~kg}$ of muscle in the leg, ignoring the contribution of skin and bone. This assumption may result in a slight overestimation of the net protein degradation rate per $\mathrm{kg}$ muscle at rest. Net amino acid production and consumption between 10- and $90 \mathrm{~min}$ of exercise was estimated as the sum of total net exchange and the change in the intramuscular amino acid pool both expressed per $\mathrm{kg}$ of active muscle. The latter can be estimated from leg circumferences and leg skin folds (Jones \& Pearson, 1969; Bangsbo, Gollnick, Graham, Juel, Kiens, Mizuno \& Saltin, 1990) and was $2.84 \pm 0.19 \mathrm{~kg}$ in the subjects. The first $10 \mathrm{~min}$ of exercise is excluded from the estimation of net production and consumption. The large changes in muscle glutamate and alanine concentration observed in this period (chapter 2) may bias the results as they do not primarily or solely relate to changes in protein synthesis and protein breakdown (Van Hall, Saltin, Van der Vusse, Söderlund \& Wagenmakers, 1995). The net rate of protein degradation is estimated from the net production rate of amino acids that are not metabolized in rat muscle (threonine, methionine, phenylalanine, lysine, glycine and tyrosine [Chang \& Goldberg, 1978]). These amino acids are not transaminated or oxidized in muscle and, therefore, only used for protein synthesis and produced via protein degradation. The net rate of protein degradation can then be estimated from the net rate of production of a non-metabolized amino acid multiplied with its occurrence in muscle protein (Clowes, Randall \& Cha, 1980). 
Table 1. Arterial amino acid concentration at rest and arterio-venous differences at rest and during exercise with a low and normal glycogen leg.

\begin{tabular}{|c|c|c|c|c|c|c|c|}
\hline & \multicolumn{4}{|c|}{ Rest } & \multicolumn{3}{|c|}{ Exercise } \\
\hline & & arterial conc. & rest & $10 \mathrm{~min}$ & $30 \mathrm{~min}$ & $60 \mathrm{~min}$ & $90 \mathrm{~min}$ \\
\hline Threonine & $\begin{array}{l}\text { NG } \\
\text { LG }\end{array}$ & $\begin{array}{l}104 \pm 11 \\
105 \pm 8\end{array}$ & $\begin{array}{l}-34 \pm 6 \\
-32 \pm 6\end{array}$ & $\begin{array}{l}-2.4 \pm 0.6 \\
-0.2 \pm 2.5\end{array}$ & $\begin{array}{l}-2.1 \pm 0.6 \\
-2.7 \pm 2.4\end{array}$ & $\begin{array}{l}-3.9 \pm 1.8 \\
-8.6 \pm 2.6\end{array}$ & $\begin{array}{l}-2.7 \pm 1.6 \\
-5.5 \pm 1.3\end{array}$ \\
\hline Methionine & $\begin{array}{l}\text { NG } \\
\text { LG }\end{array}$ & $\begin{array}{l}26 \pm 6 \\
23 \pm 2\end{array}$ & $\begin{array}{l}-3.7 \pm 3.2 \\
-6.5 \pm 3.1\end{array}$ & $\begin{array}{r}-0.2 \pm 1.6 \\
-1.4 \pm 1.2\end{array}$ & $\begin{array}{r}-1.3 \pm 1.5 \\
1.7 \pm 0.8\end{array}$ & $\begin{array}{r}-1.1 \pm 1.4 \\
2.7 \pm 1.4\end{array}$ & $\begin{array}{l}-2.1 \pm 1.0 \\
-2.5 \pm 1.5\end{array}$ \\
\hline Phenylalanine & $\begin{array}{l}\text { NG } \\
\text { LG }\end{array}$ & $\begin{array}{l}52 \pm 4 \\
48 \pm 5\end{array}$ & $\begin{array}{l}-6.3 \pm 2.2 \\
-5.8 \pm 2.7\end{array}$ & $\begin{array}{l}-1.4 \pm 0.5 \\
-1.1 \pm 1.8\end{array}$ & $\begin{array}{r}0.4 \pm 0.5 \\
-0.3 \pm 1.4\end{array}$ & $\begin{array}{c}0.1 \pm 0.9 \\
-0.6 \pm 0.8\end{array}$ & $\begin{array}{r}1.6 \pm 0.4 \\
-1.9 \pm 0.6\end{array}$ \\
\hline Lysine & $\begin{array}{l}\text { NG } \\
\text { LG }\end{array}$ & $\begin{array}{l}146 \pm 16 \\
145 \pm 11\end{array}$ & $\begin{array}{l}-20.5 \pm 8.2 \\
-30.1 \pm 17.9\end{array}$ & $\begin{array}{r}-11.9 \pm 4.3 \\
1.3 \pm 6.4\end{array}$ & $\begin{array}{l}-7.9 \pm 2.8 \\
-3.9 \pm 3.7\end{array}$ & $\begin{array}{l}-3.9 \pm 3.7 \\
-5.5 \pm 5.7\end{array}$ & $\begin{array}{l}-2.0 \pm 1.4 \\
-3.8 \pm 1.8\end{array}$ \\
\hline Glycine & $\begin{array}{l}\text { NG } \\
\text { LG }\end{array}$ & $\begin{array}{l}181 \pm 13 \\
184 \pm 11\end{array}$ & $\begin{array}{l}-39.1 \pm 15.0 \\
-29.8 \pm 20.3\end{array}$ & $\begin{array}{l}-9.9 \pm 2.0 \\
-5.9 \pm 5.2\end{array}$ & $\begin{array}{l}-9.6 \pm 2.8 \\
-7.1 \pm 3.9\end{array}$ & $\begin{array}{r}-0.9 \pm 4.7 \\
-17.8 \pm 4.6\end{array}$ & $\begin{array}{l}-3.4 \pm 1.8 \\
-7.0 \pm 3.6\end{array}$ \\
\hline Tyrosine & $\begin{array}{l}\text { NG } \\
\text { LG }\end{array}$ & $\begin{array}{l}50 \pm 5 \\
50 \pm 6\end{array}$ & $\begin{array}{l}-6.1 \pm 2.9 \\
-4.6 \pm 1.9\end{array}$ & $\begin{array}{l}-2.2 \pm 2.3 \\
-2.9 \pm 1.3\end{array}$ & $\begin{array}{l}-4.1 \pm 2.0 \\
-2.8 \pm 3.5\end{array}$ & $\begin{array}{l}-0.2 \pm 0.9 \\
-4.5 \pm 1.6\end{array}$ & $\begin{array}{r}1.9 \pm 2.6 \\
-0.5 \pm 2.2\end{array}$ \\
\hline$n-m$ AA & $\begin{array}{l}\text { NG } \\
\text { LG }\end{array}$ & $\begin{array}{l}532 \pm 22 \\
531 \pm 19\end{array}$ & $\begin{array}{l}-94 \pm 26 \\
-80 \pm 21\end{array}$ & $\begin{array}{l}-28 \pm 4 \\
-10 \pm 16\end{array}$ & $\begin{array}{l}-25 \pm 5 \\
-15 \pm 11\end{array}$ & $\begin{array}{l}-10 \pm 11 \\
-34 \pm 12\end{array}$ & $\begin{array}{r}7 \pm 7 \\
-23 \pm 9\end{array}$ \\
\hline tot $A A$ & $\begin{array}{l}N G \\
L G\end{array}$ & $\begin{array}{l}2421 \pm 102 \\
2344 \pm 118\end{array}$ & $\begin{array}{l}351 \pm 52 \\
277 \pm 49\end{array}$ & $\begin{array}{l}-87 \pm 27 \\
-67 \pm 66\end{array}$ & $\begin{array}{l}-62 \pm 24 \\
-53 \pm 60\end{array}$ & $\begin{array}{l}-34 \pm 23 \\
-98 \pm 35\end{array}$ & $\begin{array}{l}-68 \pm 20 \\
-72 \pm 48\end{array}$ \\
\hline Arginine & $\begin{array}{l}N G \\
L G\end{array}$ & $\begin{array}{l}61 \pm 6 \\
58 \pm 6\end{array}$ & $\begin{array}{l}-10.5 \pm 1.1 \\
-12.2 \pm 2.7\end{array}$ & $\begin{array}{l}-1.1 \pm 1.0 \\
-0.7 \pm 1.1\end{array}$ & $\begin{array}{l}-2.0 \pm 0.9 \\
-1.4 \pm 1.0\end{array}$ & $\begin{array}{l}-0.8 \pm 0.5 \\
-2.0 \pm 1.2\end{array}$ & $\begin{array}{r}0.9 \pm 0.8 \\
-2.2 \pm 1.2\end{array}$ \\
\hline Asparagine & $\begin{array}{l}\text { NG } \\
\text { LG }\end{array}$ & $\begin{array}{l}42 \pm 6 \\
43 \pm 3\end{array}$ & $\begin{array}{r}-12.8 \pm 4.4 \\
-8.3 \pm 1.7\end{array}$ & $\begin{array}{r}-1.4 \pm 0.2 \\
0.4 \pm 0.9\end{array}$ & $\begin{array}{l}-0.9 \pm 0.2 \\
-0.4 \pm 0.5\end{array}$ & $\begin{array}{r}0.4 \pm 1.3 \\
-1.1 \pm 0.7\end{array}$ & $\begin{array}{l}-0.9 \pm 0.4 \\
-0.8 \pm 0.7\end{array}$ \\
\hline Serine & $\begin{array}{l}\text { NG } \\
\text { LG }\end{array}$ & $\begin{array}{l}107 \pm 14 \\
109 \pm 7\end{array}$ & $\begin{array}{l}1.1 \pm 5.5 \\
3.3 \pm 3.3\end{array}$ & $\begin{array}{l}2.7 \pm 0.7 \\
6.3 \pm 2.1\end{array}$ & $\begin{array}{l}2.1 \pm 1.6 \\
1.1 \pm 2.4\end{array}$ & $\begin{array}{r}2.5 \pm 1.8 \\
-5.3 \pm 2.0\end{array}$ & $\begin{array}{r}0.1 \pm 1.2 \\
-1.4 \pm 1.7\end{array}$ \\
\hline Histidine & $\begin{array}{l}\text { NG } \\
\text { LG }\end{array}$ & $\begin{array}{l}82 \pm 4 \\
82 \pm 3\end{array}$ & $\begin{array}{r}-16.7 \pm 2.2 \\
-7.2 \pm 2.2\end{array}$ & $\begin{array}{l}-3.1 \pm 0.5 \\
-1.7 \pm 1.4\end{array}$ & $\begin{array}{l}-1.5 \pm 0.9 \\
-1.0 \pm 1.6\end{array}$ & $\begin{array}{l}-0.5 \pm 0.8 \\
-3.8 \pm 1.8\end{array}$ & $\begin{array}{l}-0.1 \pm 0.7 \\
-0.6 \pm 1.0\end{array}$ \\
\hline Glutamine & $\begin{array}{l}N G \\
L G\end{array}$ & $\begin{array}{l}507 \pm 22 \\
517 \pm 10\end{array}$ & $\begin{array}{l}-78 \pm 13 \\
-36 \pm 25\end{array}$ & $\begin{array}{l}-23 \pm 4 \\
-16 \pm 10\end{array}$ & $\begin{array}{l}-20 \pm 6 \\
-11 \pm 7\end{array}$ & $\begin{array}{l}-13 \pm 8 \\
-19 \pm 6\end{array}$ & $\begin{array}{r}-1 \pm 5 \\
-16 \pm 7\end{array}$ \\
\hline Glutamate & $\begin{array}{l}\text { NG } \\
\text { LG }\end{array}$ & $\begin{array}{l}77 \pm 19 \\
85 \pm 19\end{array}$ & $\begin{array}{l}44 \pm 15 \\
34 \pm 2\end{array}$ & $\begin{array}{l}23 \pm 8 \\
18 \pm 9\end{array}$ & $\begin{array}{r}6 \pm 10 \\
14 \pm 10\end{array}$ & $\begin{array}{l}9 \pm 2 \\
5 \pm 5\end{array}$ & $\begin{array}{l}6 \pm 2 \\
8 \pm 7\end{array}$ \\
\hline Alanine & $\begin{array}{l}\text { NG } \\
\text { LG }\end{array}$ & $\begin{array}{l}213 \pm 18 \\
198 \pm 21\end{array}$ & $\begin{array}{l}-68 \pm 14 \\
-60 \pm 13\end{array}$ & $\begin{array}{l}-25 \pm 7 \\
-24 \pm 6\end{array}$ & $\begin{array}{l}-22 \pm 6 \\
-19 \pm 4\end{array}$ & $\begin{array}{l}-15 \pm 5 \\
-19 \pm 4\end{array}$ & $\begin{array}{r}-7 \pm 3 \\
-25 \pm 6\end{array}$ \\
\hline BCAA & $\begin{array}{l}\text { NG } \\
L G\end{array}$ & $\begin{array}{l}641 \pm 36 \\
573 \pm 48\end{array}$ & $\begin{array}{c}2.7 \pm 9.4 \\
-11.2 \pm 11.2\end{array}$ & $\begin{array}{r}-2.1 \pm 6.9 \\
3.5 \pm 6.9\end{array}$ & $\begin{array}{l}2.7 \pm 4.5 \\
5.0 \pm 7.0\end{array}$ & $\begin{array}{l}8.4 \pm 6.1 \\
0.5 \pm 2.5\end{array}$ & $\begin{array}{l}16.0 \pm 6.0 \\
14.4 \pm 4.2\end{array}$ \\
\hline
\end{tabular}

Arterial-venous difference expressed as $\mu \mathrm{mol} . \mathrm{I}^{-1}$. n-m AA, is the sum of the non-metabolized amino acids (Thr, Met, Phe, Lys, Gly, Tyr); tot AA, the sum of all amino acids. Values are means \pm SEM of 6 subjects. 


\section{Statistical analysis}

All data are means \pm SEM. Statistical analysis of the data was done using one way repeated measures analysis of variance (ANOVA). Differences between rest and exercise amino acid production/consumption were checked for statistical significance using the Fisher's protected least significant difference test. The non-parametric Wilcoxon signed-rank test was used to determine differences between data obtained in the low and normal glycogen leg and to determine whether the rate of amino acid production and consumption was different from zero. Statistical significance was set at $P<0.05$.

\section{RESULTS}

\section{Rate of exchange of non-metabolized and total amino acids}

The arterial concentration of amino acids at rest and the arterio-venous differences at rest and during exercise are presented in table 1 . The changes in arterial concentration have been published earlier (Van Hall et al, 1995). The blood flow was $0.3 \pm 0.03 \mathrm{I} \cdot \mathrm{min}^{-1}$ at rest and $3.8 \pm 0.6 \mathrm{I} \cdot \mathrm{min}^{-1}$ during exercise. The nearly 13 -fold increase in blood flow going from rest to exercise caused a considerable decrease in the arterio-venous amino acid differences.

Net production and consumption of amino acids per $\mathrm{kg}$ of dry muscle and per min are given in table 2 both at rest and during the 10-90 min period of exercise. Except for methionine all non-metabolized amino acids were produced in significant amounts at rest in the postabsorptive state (table 2). However, the net production of the sum of all amino acids was not significantly different from zero production (table 2) due to the large variation between individuals. Exercise caused a significant increase in the net muscle production of threonine, lysine, tyrosine and the sum of the nonmetabolized amino acids. The mean production of the sum of all amino acids increased 11-fold during exercise compared to rest, albeit not significantly.

At rest the low muscle glycogen stores did not influence net production rates of the non-metabolized and other amino acids (table 2). However, prolonged exercise with muscles low in glycogen appeared to lead to a further increase of net protein degradation. The production rate of threonine, glycine, tyrosine and the sum of the non-metabolized amino acids was 1.5 - to 2.5 -fold higher when exercising the low glycogen leg (table 2). The sum of all amino acids was 1.5-fold higher while exercising the low glycogen leg but the difference failed to be significant $(P<0.08)$.

The net production rate was estimated from the net amino acid exchange and their change in the intramuscular free amino acid pool. The absolute contribution of the change in the intramuscular free amino acid pool to the amino acid production rate was between $8-25 \%$ (table 3 ) and the changes in the size of the intramuscular free amino acid pool during exercise were small except for glycine (table 3 ). This implies that most of the amino acids produced by net protein degradation are directly released from muscle. 
Table 2. Net production or consumption of amino acids at rest and during one leg kneeextensor exercise .

\begin{tabular}{|c|c|c|c|c|c|c|}
\hline \multirow[b]{2}{*}{ Glycogen } & \multicolumn{3}{|c|}{ Rest } & \multicolumn{3}{|c|}{ Exercise } \\
\hline & Normal & Low & $\begin{array}{l}\text { Low/ } \\
\text { normal }\end{array}$ & Normal & Low & $\begin{array}{c}\text { Low' } \\
\text { normal }\end{array}$ \\
\hline Threonine & $-1.1 \pm 0.1^{\prime \prime}$ & $-1.0 \pm 0.2^{*}$ & 0.9 & $-11 \pm 4^{* \S}$ & $-18 \pm 3^{\star 5 n}$ & 1.7 \\
\hline Methionine & $-0.2 \pm 0.1$ & $-0.3 \pm 0.1^{*}$ & 1.5 & $-4 \pm 2$ & $3 \pm 1$ & \\
\hline Phenylalanine & $-0.3 \pm 0.05^{\circ}$ & $-0.3 \pm 0.1^{\circ}$ & 1.0 & $0.7 \pm 1$ & $-2 \pm 1^{*}$ & \\
\hline Lysine & $-1.0 \pm 0.4^{*}$ & $-1.0 \pm 0.2^{*}$ & 1.0 & $-19 \pm 4^{* \S}$ & $-19 \pm 4^{*} \S$ & 1.0 \\
\hline Glycine & $-2.0 \pm 0.4^{*}$ & $-1.7 \pm 0.3^{*}$ & 0.9 & $-11 \pm 5$ & $-29 \pm 7^{-\xi}$ & 1.5 \\
\hline Tyrosine & $-0.3 \pm 0.1^{*}$ & $-0.2 \pm 0.05^{*}$ & 0.7 & $-5 \pm 1^{* \S}$ & $-12 \pm 3^{* 5 *}$ & 2.5 \\
\hline$n-m$ AA & $-4.8 \pm 0.9^{*}$ & $-4.1 \pm 0.9^{*}$ & 0.9 & $-53 \pm 14^{-\S}$ & $-81 \pm 13^{* 5}$ & 1.6 \\
\hline tot $A A$ & $-13 \pm 3.2$ & $-12 \pm 4.1$ & 0.9 & $-149 \pm 105$ & $-213 \pm 65$ & 1.5 \\
\hline Arginine & $-0.5 \pm 0.05^{*}$ & $-0.6 \pm 0.1^{*}$ & 1.2 & $-5 \pm 2 \cdot 5$ & $-7 \pm 2^{* 65}$ & 1.4 \\
\hline Asparagine & $-0.7 \pm 0.2^{*}$ & $-0.4 \pm 0.1^{*}$ & 0.6 & $-4 \pm 2$ & $-6 \pm 1-\S$ & 1.7 \\
\hline Serine & $0.05 \pm 0.3$ & $0.3 \pm 0.2$ & 6.0 & $4 \pm 4$ & $-10 \pm 4^{* 5 n}$ & \\
\hline Histidine & $-0.6 \pm 0.1^{\circ}$ & $-0.4 \pm 0.1^{*}$ & 0.7 & $-4 \pm 2$ & $-10 \pm 3^{*}$ & 2.8 \\
\hline Glutamine & $-7.3 \pm 1.0^{\circ}$ & $-5.9 \pm 0.9^{*}$ & 0.8 & $-75 \pm 42$ & $-83 \pm 21^{*}$ & 1.2 \\
\hline Glutamate & $3.4 \pm 1.3^{\circ}$ & $3.4 \pm 1.8$ & 1.0 & $26 \pm 3^{-\S}$ & $43 \pm 4^{.6 *}$ & 0.8 \\
\hline Alanine & $-6.3 \pm 1.3^{*}$ & $-5.6 \pm 1.4^{\circ}$ & 0.9 & $-8 \pm 23$ & $-35 \pm .37$ & 2.3 \\
\hline$B C A A$ & $0.1 \pm 0.4$ & $-0.5 \pm 0.6$ & & $16 \pm 12$ & $13 \pm 13$ & 0.8 \\
\hline
\end{tabular}

$\mathrm{n}-\mathrm{m} \mathrm{AA}$, is the sum of the non-metabolized amino acids (Thr, Met, Phe, Lys, Gly, Tyr); tot AA, the sum of all amino acids. Net amino acid production or consumption at rest and during exercise.are expressed in $\mu \mathrm{mol} . \mathrm{kg}$ ${ }^{1} \mathrm{dry}$ muscle. $\mathrm{min}^{-1}$ and were calculated as indicated in the methods section A negative value significe a net production. Net production or consumption is calculated from the flux and dry muscle mass of the leg (9 kg wet weight $=2.1 \mathrm{~kg}$ dry weight) at rest and from the flux and change in muscle concentration at 10 and 90 min of exercise normalized for the estimated dry quadriceps weight involved in exercise. Values are means \pm SEM of 6

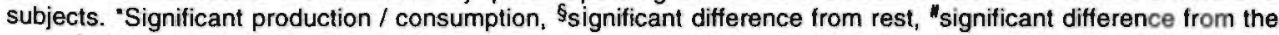
normal glycogen content leg. 
Table 3 Net amino acid exchange and the change in the muscle free amino acid pool during exercise.

\begin{tabular}{|c|c|c|c|c|c|c|}
\hline & \multicolumn{3}{|c|}{ Normal Glycogen } & \multicolumn{3}{|c|}{ Low Glycogen } \\
\hline & net exchange & a muscle & $\%$ pool & net exchange & $\partial$ muscle & $\%$ pool \\
\hline Thr & $-10 \pm 3$ & $1.3 \pm 1.4$ & 6 & $-17 \pm 2$ & $0.6 \pm 2.8$ & 3 \\
\hline Met & $-4 \pm 3$ & $0 \pm 0.1$ & 0 & $3 \pm 1$ & $0.3 \pm 0.1$ & 16 \\
\hline Phe & $-1 \pm 1$ & $0.2 \pm 0.3$ & 5 & $-3 \pm 1$ & $-0.4 \pm 0.3$ & -11 \\
\hline Lys & $-17 \pm 5$ & $1.5 \pm 2.0$ & 6 & $-17 \pm 3$ & $1.5 \pm 2.0$ & 5 \\
\hline Gly & $-18 \pm 5$ & $2.1 \pm 0.8$ & 4 & $-29 \pm 8$ & $4.8 \pm 1.4$ & 10 \\
\hline Tyr & $-4 \pm 2$ & $1.0 \pm 1.2$ & 26 & $-10 \pm 4$ & $1.3 \pm 1.1$ & 29 \\
\hline$n-m$ AA & $-48 \pm 14$ & $6.0 \pm 1.6$ & 7 & $-73 \pm 13$ & $8.5 \pm 2.3$ & 8 \\
\hline Tot AA & $-103 \pm 36$ & $12 \pm 29$ & 1 & $193 \pm 91$ & $54 \pm 26$ & 4 \\
\hline
\end{tabular}

$n-m$ AA, the sum of the non-metabolized amino acids (Thr, Met, Phe, Lys, Gly, Tyr); Tot AA, the sum of all measured amino acids. Net amino acid exhange during 10-90 min of exercise and the change in the intramuscular amino acid concentration are both given in $\mu \mathrm{mol} . \mathrm{kg}^{-1} \mathrm{dry}$ muscle.min ${ }^{-1}$. A negative value significe a net release or a decrease in the muscle free amino acid pool. \% pool is the decrease of the pool size in the 90 min biopsy in comparison to the 10 min biopsy.

\section{DISCUSSION}

The major findings of this study are that voluntary one leg knee-extensor exercise in the postabsorptive state leads to a massive increase of net protein degradation compared to rest and that low pre-exercise muscle glycogen stores augment the exercise induced increase in net protein degradation.

Net non-metabolized amino acid production was much higher during exercise than at rest indicating that net muscle protein degradation is increased. The workload and oxygen consumption per $\mathrm{kg}$ muscle is very high during one leg knee-extensor exercise (see introduction) and, therefore, the results can not be extrapolated to whole body dynamic exercise. Two legged cycle exercise at 40 and $70 \% \mathrm{VO}_{2 \max }$ did not lead to changes in protein synthesis and degradation (Carraro et al, 1990a,b) and urea production (Carraro et al, 1993) which is a measure of whole body amino acid oxidation. A high rate of oxygen consumption per $\mathrm{kg}$ muscle is also observed in electrically stimulated muscles. In such muscles protein synthesis rates are decreased during contraction (Bylund-Fellenius et al, 1984). A decrease in protein synthesis may contribute to the non-metabolized amino acid production observed here, but it also cannot be excluded that protein degradation is simultaneously increased. 
Table 4. Net rate of protein degradation caused by exercise with a normal and a low glycogen content leg.

\begin{tabular}{|c|c|c|c|c|c|c|c|}
\hline \multirow[b]{2}{*}{ Glycogen } & \multirow{2}{*}{$\begin{array}{c}\% \text { muscle } \\
\text { protein }\end{array}$} & \multicolumn{2}{|c|}{ Rest } & \multicolumn{2}{|c|}{ Exercise } & \multicolumn{2}{|c|}{ Exercise/rest } \\
\hline & & Normal & Low & Normal & Low & Normal & Low \\
\hline Threonine & 5.4 & -3.5 & -3.2 & -31 & -54 & 9 & 16 \\
\hline Methionine & 1.8 & -2.4 & -3.6 & .45 & 39 & 19 & \\
\hline Phenylalanine & 3.3 & -2.2 & -2.2 & 7 & -12 & & 5 \\
\hline Lysine & 8.1 & -2.6 & -2.6 & -47 & -47 & 18 & 18 \\
\hline Glycine & 9.7 & -2.2 & -1.9 & -20 & -30 & 9 & 16 \\
\hline Tyrosine & 2.1 & -3.7 & -2.5 & -58 & -146 & 16 & 58 \\
\hline$n-m$ AA & 30.4 & -3.2 & -2.7 & -32 & -51 & 10 & 19 \\
\hline tot $A A$ & 100 & -2.8 & -2.6 & -29 & -43 & 10 & 17 \\
\hline
\end{tabular}

One leg exercise with low pre-exercise muscle glycogen stores caused a further increase in the net production rate of 3 of 6 non-metabolized amino acids and in the sum of the non-metabolized amino acids compared to the normal glycogen content leg indicating that net protein degradation was further increased. A high rate of net protein degradation was also observed in patients with McArdle's disease during two legged cycle exercise (Wagenmakers, personal communication). These patients due to myophosphorylase deficiency, are an ideal model to study the effects of muscle glycogen availability on protein metabolism during exercise.

Conclusions on net protein degradation in first instance were primarily based on the release of threonine, methionine, phenylalanine, lysine, glycine and tyrosine as strong evidence has been presented in the literature that these amino acids are not metabolized in rat muscle (Chang \& Goldberg, 1978). However, little information is available on the metabolism of these and other amino acids in human skeletal muscle. As one leg cycle exercise appears to lead to one of the largest physiological imbalances between muscle protein synthesis and degradation observed sofar the obtained data set also is ideal to investigate whether the amino acids released by net protein degradation are totally or in part metabolized in muscle or released in proportion to their relative occurrence in human muscle protein. The latter finding indicates that little or no metabolism occurs. From table 4 and 5 we can conclude that threonine, glycine and lysine are not metabolized in human muscle as previously observed in rat muscle. Little or no metabolism also appears to occur in the case of 
Table 5. The contribution of amino acid productlon in percentage to total nel protein degradation.

\begin{tabular}{|c|c|c|c|c|c|}
\hline \multirow[b]{2}{*}{ Glycogen } & \multirow{2}{*}{$\begin{array}{l}\% \text { muscle } \\
\text { protein }\end{array}$} & \multicolumn{2}{|c|}{ Rest } & \multicolumn{2}{|c|}{ Exercise } \\
\hline & & Normal & Low & Normal & Low \\
\hline Threonine & 5.4 & 5.9 & 6.3 & 5.9 & 6.0 \\
\hline Methionine & 1.8 & 1.3 & 2.4 & 2.7 & -1.3 \\
\hline Phenylalanine & 3.3 & 2.2 & 2.6 & -0.5 & 0.9 \\
\hline Lysine & 8.1 & 6.6 & 7.8 & 12.5 & 7.8 \\
\hline Glycine & 9.7 & 6.8 & 6.8 & 3.7 & 6.1 \\
\hline Tyrosine & 2.1 & 2.4 & 1.9 & 4.1 & 6.1 \\
\hline Arginine & 4.3 & 3.9 & 5.6 & 3.9 & 3.4 \\
\hline Asparagine & \pm 5 & 4.2 & 2.8 & 2.4 & 2.2 \\
\hline serine & 5.0 & -0.2 & -1.7 & -1.9 & 3.0 \\
\hline Histidine & 2.5 & 4.2 & 3.3 & 2.8 & 4.4 \\
\hline Glutamine & \pm 8 & 48 & 46 & 49 & 34 \\
\hline Glutamate & \pm 7 & -22 & -26 & -17 & -18 \\
\hline Alanine & 8.7 & 25 & 27 & 3 & 9 \\
\hline$B C A A$ & 18.8 & -1 & 4 & -10 & -5 \\
\hline
\end{tabular}

The $\%$ of amino acids in muscle proten from Clowes, Randall \& Cha (1980). The contribution of amino acid production in percentage to total net protein degradation is estimated from the net amino acid production (table 2) and the estimated net protein degradation from the $n-m$ amino acid at rest and during exercise (table 4 ). For further details see table 2.

arginine, histidine and aspargine (table 5). Data for methionine are inconsistent, most probably due to the fact that the low occurrence in muscle potein leads to small and variable arterio-venous differences during exercise (table 1). Suggestions have also been made that methionine is metabolized in rat muscle (Lee \& Davis, 1986). Tyrosine is released in larger amounts during exercise than its relative occurrence and phenylalanine in smaller amounts. This seems to suggest that phenylalanine is converted to tyrosine in skeletal muscle. In liver and gut this conversion is catalyzed by phenylalanine hydroxylase. It is quite clear that BCAA and glutamate are metabolized in muscle as they even are taken up from the circulation during exercise despite a high occurrence in and release from skeletal muscle protein. We do not have data on aspartate as it coincides with the sulphosalicylic acid peak in the chromatograms (Van Eijk et al, 1988). In rat muscle it is rapidly transaminated to oxaloacetate (Chang and Goldberg, 1978). Alanine is released during exercise in an 
amount reflecting its relative occurrence, while glutamine is released in amounts that are much larger (table 5). This indicates that the carbon skeleton of BCAA, glutamate, aspartate and other amino acids that are partly metabolized in skeletal muscle are not used for the synthesis of alanine, but primarily for conversion to TCAcycle intermediates and glutamine. In rat muscle incubated in vitro a similar conclusion was drawn (Wagenmakers et al, 1985) as the radioactive label of [U$\left.{ }^{14} \mathrm{C}\right]$ valine was only recovered in glutamine and not in alanine, pyruvate or lactate. This also implies that the amino acids that are metabolized in muscle are not used for complete oxidation as this requires conversion to pyruvate before complete oxidation is possible. Recent tracer experiments in man in vivo (Nurhjhan, Bucci, Perriello, Stumvoll, Dailey, Bier, Toft, Jensen \& Gerich, 1995; Perriello, Jorde, Nurjhan, Stumvoll, Dailey, Jenssen, Bier \& Gerich, 1995) also suggest that the carbon atoms of glutamine are primarily derived from protein derived amino acids and the carbon atoms of alanine from glucose and glycogen. Glutamine, therefore, has been suggested to be far more important than alanine for transport of protein derived carbon from muscle to liver and kidney for gluconeogenesis.

A substantial release of alanine and glutamine was observed during the first 30 min of exercise with the normal glycogen leg, but no release was observed after 90 min of exercise (chapter 2). The initial alanine and glutamine production most likely reflects new synthesis from the muscle free glutamate pool (Van Hall et al, 1995) and is not derived from protein degradation. The intramuscular pool of alanine increased with $30 \%$ and the glutamate pool decreased with $60 \%$ within the first 10 min, most likely a consequence of a shift in the alanine aminotransferase reaction (Van Hall et al, 1995). Most of the alanine released between $10 \mathrm{~min}$ and $90 \mathrm{~min}$ of exercise was accounted for by the decrease in the muscle free alanine pool to pre-exercise concentration. The amount of alanine produced by net degradation did not exceed its relative occurrence in muscle protein (table 5). Graham, Turcotte, Kiens \& Richter (1995) reported a much higher rate of alanine production and glutamate consumption during $3 \mathrm{~h}$ of one leg knee-extensor exercise at $60 \%$ of maximal capacity as they did not correct for the initial shift in amino acid pool sizes via the alanine aminotransferase reaction.

Net protein degradation in grams of protein per $\mathrm{kg}$ of muscle per day can be calculated from the net production rate and occurrence in muscle protein of nonmetabolized amino acids. Such estimates indicate that $3 \mathrm{~g}$ protein is broken down per kg dry muscle per day at rest in the post absorptive state (table 4). From tracer studies it is known that the rate of muscle protein turnover under these conditions is about $1.5 \%$ day or 10 to $15 \mathrm{~g}$ protein. $\mathrm{kg}^{-1} \mathrm{dry}$ muscle.day-1 (Chesley, MacDougal, Tarnopolski, Atkinson \& Smith, 1982; Halliday, Pacy, Cheng, Dworzak, Gibson \& Rennie, 1988; Bennet, Connacher, Scimgeour \& Rennie, 1990). As net protein degradation is protein synthesis minus protein degradation, our data indicate that there is a slight imbalance between protein synthesis and degradation at rest in the postabsorptive state (protein synthesis < protein degradation) as previously indicated by tracer studies (Chesley et al, 19882; Halliday et al, 1988, Bennet et al, 1990). During exercise, however, the net rate of protein degradation in the normal glycogen leg is estimated at 15 to $47 \mathrm{~g}$ protein. $\mathrm{kg}^{-1}$ dry muscle.day ${ }^{-1}$ and in the low glycogen at 
30-86 g protein. $\mathrm{kg}^{-1} \mathrm{dry}$ muscle.day-1. This is a major disturbance of the balance between protein synthesis and degradation. Even if protein synthesis would fall to zero during exercise (which seems unlikely) net protein degradation would be maximally increase to $15 \mathrm{~g}$ per day, if the absolute rate of protein degradation would not change. This must imply that the absolute rate of protein degradation must increase 2-fold or more during one leg cycle exercise. Such extreme values have not been reported before in any physiological or pathophysiological condition (Rennie, 1985).

The arterio-venous balance method was used in this study to estimate the net rate of amino acid production or consumption. At rest this is a good and direct method as arterio-venous differences are large enough for accurate measurement. However, exercise at moderate to high intensity increases the blood flow several fold thereby reducing the arterio-venous difference. Even in this study with one leg kneeextensor exercise, and a substantial increase in net production or consumption of the amino acids, the arterio-venous difference became small (table 1) and accuracy of the arterio-venous difference measurement was reduced considerably. Therefore, the arterio-venous balance method to estimate net production rates can only be used for those metabolites that have a large arterio-venous difference or when exercise is causing a several fold increase in the net rate of production or consumption.

in conclusion, the data of this study clearly indicate that net muscle protein degradation is substantially increased by prolonged moderate to high intensity one leg knee-extensor exercise. Quantitative estimates suggest that both a decrease in protein synthesis and an increase in protein degradation must contribute to the large negative amino acid balance. Furthermore, a low initial muscle glycogen content augments the exercise induced increase in net muscle protein degradation. It is suggested that the functionality of the negative amino acid balance is provision of protein derived carbon for synthesis of TCA-cycle intermediates and glutamine in muscle and release of gluconeogenic precursor amino acids for liver and kidney.

\section{References}

Andersen, P. \& Saltin, B. (1985). Maximal perfusion of skeletal muscle in man. Journal of Physiology 366: 233-249.

Bangsbo, J., Gollnick, P.D., Graham, T.E., Juel, C., Kiens, B., Mizuno, M. \& Saltin, B. (1990). Anaerobic energy production and $\mathrm{O}_{2}$ deficit-debt relationship during exhaustive exercise in humans. Journal of Physiology 422: 530-559.

Bennet, W.M., Connacher, A.A. Scimgeour, C.M. \& Rennie, M.J. (1990). The effect of amino acid infusion on leg protein turnover assessed by $L-\left[{ }^{5} \mathrm{~N}\right]$ phenylalanine and $L-\left[1-{ }^{13} \mathrm{C}\right]$ leucine exchange. European Journal of Cimical Investigation 20: 41-50.

Bergstrom, J. (1962). Muscle electrolytes in man. Determination by neutron activation analysis on needle biopsy specimens. A study on normal subjects, kidney patients, and patients with chronic diarrhea. Scandinavian Journal of Clinical \& Laboratory Investigations, suppl. 68: 7-110.

Bylund-Fellenius, A.C. Ojamaa, K.M., Flaim, K.E., Li, J.B., Wassner, S.J. \& Jefferson, L.S. (1984). Protein synthesis versus energy state in contracting muscles of perfused rat hind limb. American Joumal of Physiology 246: E297-E305. 
Carraro, F., Stuart, C.A., Hartl, W.H., Rosenblatt, J. \& Wolfe, R.R. (1990a). Effect of exercise and recovery on muscle protein synthesis in human subjects. American Journal of Physiology 259: E470-E476.

Carraro, F., Hartl, W.H., Stuart, C.A., Layman, D.K., Jahoor, F. \& Wolfe, R.R. (1990). Whole body and protein synthesis in exercise and recovery in human subjects. American Journal of Physiology 258: E821-E831.

Carraro, F., Kimbrough, T.D. \& Wolfe, R.R. (1993). Urea kinetics in humans at two levels of exercise intensity. Joumal of Applied Physiology 75: 1180-1185.

Chang, T.W. \& Goldberg, A.L. (1978). The origin of alanine produced in skeletal muscle. Journal of Biological Chemistry 253: 3677-3684.

Chesley, A., MacDougal, J.D., Tarnopolski, M.A., Atkinson, S.A. \& Smith, K. (1992). Changes in human muscle protein synthesis after resistance exercise. Journal of Applied Physiology 73: 13831388.

Clowes, G.H.A., Randall, H.T. \& Cha, C.-J. (1980). Amino acid and energy metabolism in septic and traumatized patients. JPEN 4: 195-205.

Decombaz, J., Reinhardt, P, Anantharaman, K., Von Glutz, G. \& Poortmans, J.R. (1979). Biochemical changes in a 100-km run: free amino acids, urea and creatinine. European Journal of Applied Physiology 41: 61-72.

Fick, A. \& Wislecenus, J. (1886). On the origin of musular power. Philos Mag 31: 485-503.

Graham, T.E., Turcotte, L.P., Kiens, B. \& Richter, E.A. (1995). Training and muscle ammonia and amino acid metabolism in humans during prolonged exercise. Journal of Applied Physiology 78 : 725-735.

Halliday, D., Pacy, P.J., Cheng, K.N., Dworzak, F., Gibson, J.N.A. \& Rennie, M.J. (1988). Rate of protein synthesis in skeletal muscle of normal man and patients with muscular dystrophy: a reassessment. Clinical Science 74: 237-240.

Jones, P.R. \& Pearson, J. (1985). Anthropometric determination of leg fat and muscle plus bone volumes in young male and female adults. Journal of Physiology 204, 63-66P.

Lee, S-H.C., \& Davis, E.J. (1986). Amino acid catabolism by perfused rat hindquarter. Biochemical Journal 233: 621-530.

Lemon, P.W.R. \& Mullin, J.P. (1980). Effect of initial muscle glycogen levels on protein catabolism during exercise. Journal of Applied Physiology 48: 624-629.

Nurjhan, N., Bucci, A., Perriello, G., Stumvoll, M., Dailey, G., Bier, D.M., Toft, I., Jenssen, T.G. \& Gerich, J.E. (1995). Glutamine; A major gluconeogenic precursor and vehicle for interorgan carbon transport in man. Joumal of Clinical Investigation 95: 272-277.

Perriello, G., Jorde, R., Nurjhan, N., Stumvoll, M., Dailey, G., Jenssen, T., Bier, D.M. \& Gerich, J.E. (1995). Estimation of glucose-alanine-lactate-glutamine cycles in postabsorptive humans: role of skeletal muscle. American Journal of Physiology 269: E443-E450.

Rennie, M.J. (1985). Muscle protein turnover and the wasting due to injury and disease. British Medical Bulletin 41: 257-264.

Van Eijk, H.M., Van der Heijden, M.A.H., Van Berlo, C.L.H. \& Soeters, P.B. (1988). Fully automated liquid-chromatography determination of amino acids. Clinical Chemistry 34: 2510-2513.

Van Hall. G., Saltin, B., Van der Vusse, G.J., Söderlund, K. \& Wagenmakers, A.J.M. (1995). Deamination of amino acids as a source for ammonia production in human skeletal muscle: during prolonged exercise. Journal of Physiology 489: 251-261.

Wagenmakers, A.J.M., Coakley, J.H. \& Edwards, R.H.T. (1990). Metabolism of branched-chain amino acids and ammonia during exercise: clues from McArdle's disease. International Journal of Sports Medicine 11: S101-S113. 



\section{Chapter 9}

\section{General discussion}

The investigations presented in this thesis were carried out in order to gain further knowledge of muscle amino acid metabolism in man especially during exercise. Not all issues could be discussed in detail in the preceding chapters or be fully integrated in the existing literature. In this last chapter an elaboration will be given of the following topics: 1 . which reaction(s) may be involved in deamination of amino acids during prolonged exercise; 2 . what is the effect of carbohydrate availability on amino acid and ammonia metabolism during prolonged exercise and recovery; 3 . which functional interactions exist between the metabolism of amino acids and the TCAcycle during exercise and 4 . what are important issues in future research in the field of amino acid and ammonia metabolism. 


\subsection{Muscle ammonia production during prolonged exercise}

The results presented in this thesis clearly show that the rate and source of ammonia production during prolonged exercise are different from high intensity exercise. During high intensity exercise ammonia production is proportional to muscle IMP formation indicating that ammonia is primarily derived from deamination of AMP to IMP (Goodman \& Lowenstein, 1977). The maximal in vitro AMP-deaminase activity in human skeletal muscle is $110 \mathrm{mmol} . \mathrm{kg}^{-1} \cdot \mathrm{min}^{-1}\left(\mathrm{~V}_{\max }\right)$ (Tullson, Bangsbo, Hellsten \& Richter, 1995) and this is by far high enough to account for the observed rate of

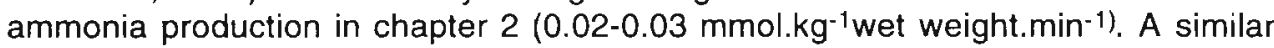
$V_{\max }$ of AMP-deaminase is observed in rat soleus muscle. However, the $K_{m}$ of AMPdeaminase for AMP has been reported to be 1-2 mM, a thousand-fold higher than the estimated levels of free AMP (Dudley \& Terjung, 1985; Rundell, Tullson \& Terjung, 1992). In rodent skeletal muscle contraction was shown to cause an increase of AMP-deaminase binding to myosin that specifically altered the enzyme kinetics such that the $K_{m}$ for AMP was reduced to 0.05-0.1 mM (Rundell et al, 1992). However, Tullson et al (1995) reported that intense dynamic exercise had no effect on AMP-deaminase binding to myosin in human skeletal muscle and they suggested that other means of regulation have to stimulate the AMP-deaminase in human skeletal muscle. Although the $\mathrm{V}_{\max }$ of AMP-deaminase is high enough to explain the rate of ammonia production it is uncertain what the actual $V$ and regulation is in vivo. In chapter 2 substantial amounts of ammonia were shown to be produced during prolonged one leg exercise without changes in muscle IMP or adenine nucleotides and ammonia production was lower during the first half hour of exercise than during the last hour of the exercise bout. Therefore, adenine nucleotide breakdown to IMP cannot be the main source of ammonia production during prolonged moderate intensity exercise. However, when the PN-cycle is active during exercise then the ammonia could still have been produced in the AMP-deaminase reaction without a net increase in muscle IMP and a net decrease in adenine nucleotides. The PN-cycle

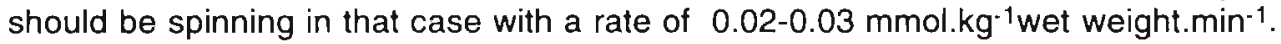
A similar rate of ammonia production as observed during one leg knee-extensor exercise in chapter 2 was also observed during prolonged two legged cycling exercise at $70 \% \mathrm{VO}_{2 \max }$ (Broberg \& Sahlin, 1989). The $\mathrm{V}_{\max }$ measured in vitro of adenylosuccinate synthase and adenyloscuccinase in rat hindlimb are about 0.7 and 0.5 mmol. $\mathrm{kg}^{-1}$ wet weight. min ${ }^{-1}$ respectively (Schulz \& Lowenstein, 1976; Goodman \& Lowenstein, 1977). Thus the rate of ammonia production and the activity of the rate limiting enzyme of the $\mathrm{PN}$-cycle are more than sufficient to account for the rate of ammonia production. However, Meyer \& Terjung (1980) concluded that PN-cycling did not take place during contraction in rat muscles as experiments with an inhibitor showed that reamination of IMP only occurred following and not during mild electrical stimulation of rat gastrocnemius muscle. Tullson, Arabadjis, Rundell \& Terjung (1996) investigated rat gastrocnemius slow twitch red fibres recovering from exercise and observed an IMP reamination rate of $0.05 \mathrm{mmol}^{\mathrm{kg}} \mathrm{kg}^{-1}$ wet weight. $\mathrm{min}^{-1}$. Reamination only started to occur when the muscle PC pool had recovered to $75 \%$ of its resting concentration. Such an IMP reamination rate would be high enough to 
explain the ammonia production during the one leg knee-extensor exercise without an increase in muscle IMP. To explain the ammonia production during exercise Tullson and colleagues (1996) suggested that individual fibres first deaminate AMP during exercise. When the fibres are fatigued, contraction failure will occur and reamination will follow. Other fibres may then be recruited to continue contraction. Such a gradual shift in fibre recruitment may lead to a continuous ammonia production without a measurable increase in whole muscle IMP concentration.

The only other likely source of ammonia is deamination of glutamate in the glutamate dehydrogenase reaction (Fig. 1). However, some observations seem to suggest that the glutamate dehydrogenase reaction is not the major source of ammonia production during prolonged exercise. The glutamate pool in muscle is decreased within a few minutes with $60 \%$ whereas ammonia production during the first min of exercise was low (chapter 2) implying that another reaction was involved in the rapid decrease of the muscle glutamate concentration. However, it cannot be excluded that the glutamate dehydrogenase reaction may produce the ammonia at the rate observed in the 30-90 min period (chapter 2). Glutamate is constantly taken up from the circulation. Furthermore, glutamate may directly be derived from protein degradation or be synthesized from other amino acids (asparagine, aspartate, $B C A A)$ via aminotransferase and TCA-cycle reactions. The activity $\left(V_{\max }\right)$ of glutamate dehydrogenase in human skeletal muscle has been reported to range from 1.03 in sedentary controls to $1.78 \mathrm{mmol}^{\mathrm{kg}}{ }^{-1}$ wet weight muscle $\mathrm{min}^{-1}$ in highly trained subjects (Wibom \& Hultman, 1990) and is much higher than the observed rate of ammonia production. It also cannot be excluded that glutamate dehydrogenase in muscle is subject to allosteric regulation as observed in other tissues (Sener \& Malaisse, 1980) and is activated during prolonged exercise. Leucine is a stimulus in pancreatic B-islets in vitro which leads to activation of glutamate dehydrogenase an increase in energy expenditure and an increase of ammonia production especially in the presence of glutamine (Sener \& Malaisse, 1980).

Indifferent whether ammonia is produced via single or multiple turns of the PNcycle or in the glutamate dehydrogenase or other deamination reactions ammonia eventually has to be derived from net deamination of amino acids. Thus during prolonged dynamic exercise a direct link seems to exist between ammonia production and amino acid metabolism. The functionality of such a link may be that deamination of amino acids may lead to net synthesis of TCA-cycle intermediates (see section 9.3).

\subsection{Carbohydrate availability and amino acid and ammonia metabolism during prolonged exercise}

Broberg \& Sahlin (1989) suggested that the reduced availability of muscle glycogen during exercise promotes net breakdown of adenine nucleotides to IMP and thus increases ammonia production. Wagenmakers et al. $(1990,1991)$ pursuing the original suggestion of Krebs (1975) hypothesized that the carbon atoms of muscle glycogen and blood born glucose are used for synthesis of tricarboxylic acid cycle 
intermediates (TCAI), glutamate and eventually glutamine (Fig. 1). In the last reaction ammonia is fixed to glutamate via the glutamine synthase reaction. Glycogen depletion may reduce the availability of carbon precursors for glutamine synthesis and, therefore, result in an increased net ammonia production. Neither of these hypotheses at first sight seem to be confirmed in this thesis. No increase in muscle ammonia production was observed when one leg exercise was performed with low compared to normal muscle glycogen stores (chapter 2). No differences were also seen in plasma ammonia concentration during two legged exercise alternating at 50 and $80 \% W_{\max }$ with and without ingestion of carbohydrates (chapter 6 ). No differences in muscle adenine nucleotides and IMP were observed between the normal and low glycogen content leg during prolonged one leg exercise (chapter 2). However, since exercise in chapter 2 was not continued until exhaustion, it cannot be excluded that IMP formation would preferentially have become apparent in the low glycogen content leg towards the moment of exhaustion as previously observed by Broberg \& Sahlin (1989) during two legged exercise first with normal and then with low glycogen content.

The high glutamine release during the first $30 \mathrm{~min}$ of exercise of the leg with the normal glycogen content (chapter 2) could have been from ammonia fixation in the glutamine synthase reaction. No significant release of glutamine was seen anymore after $90 \mathrm{~min}$ of exercise. These findings may be in support of the hypothesis of Wagenmakers et al $(1990,1991)$ that glutamine is produced when the availability of carbohydrates for synthesis of TCAI, glutamate and glutamine is high. It, however, is also possible that a small part of the large intra-muscular glutamine pool is lost in the beginning of exercise (chapter 2). A substantial glutamine release was observed after 90 min of exercise with the low glycogen leg and glutamine release was much higher in that case than in the normal glycogen leg. This finding seems in full contradiction to the hypothesis of Wagenmakers et al $(1990,1991)$. However, it might be explained by the 3-fold higher protein degradation rate in the low glycogen leg (chapter 8). The glutamine production after $90 \mathrm{~min}$ of exercise with the low glycogen leg most likely did not originate from ammonia fixation to glucose derived carbon skeletons via the glutamine synthase reaction, but from new synthesis of glutamine out of BCAA, aspartate, asparagine and glutamate derived from protein degradation and uptake of BCAA (chapter 2) and glutamate from the circulation. This suggestion is supported by observations made at rest and during two legged cycle exercise of patients with McArdle's disease (Wagenmakers et al, 1990). Patients with McArdle's disease, a glycogen breakdown defect due to myophosphorylase deficiency, showed a much larger glutamine release during exercise than healthy controls (Wagenmakers et al, 1990) and a much higher net protein degradation rate (personal communication Wagenmakers).

During recovery from exercise plasma glutamine is decreased with more than $20 \%$ from its pre-exercise concentration (chapter 6,7 ). This decrease may have been caused by a 1 . a reduced glutamine synthesis; 2 . an increased oxidative glutamine consumption (eg in gut, liver and kidney) and an increased protein synthesis rate. Since many amino acids show a decrease in plasma concentration during recovery, although not as pronounced as for glutamine, it might be that the 
process causing the decrease in plasma glutamine is common for all amino acids, most likely an increase in muscle protein synthesis rates (Carraro, Stuart, Hartl, Rosenblatt \& Wolfe, 1990). Whether this temporary decrease in plasma glutamine concentration may in vivo affect the functions attributed to glutamine such as fuel for cells of the immune system (Newsholme, Newsholme \& Curi, 1987, Newsholme \& Parry-Billings, 1990), and mucosal cells of the intestine (Souba, 1991) is unknown.

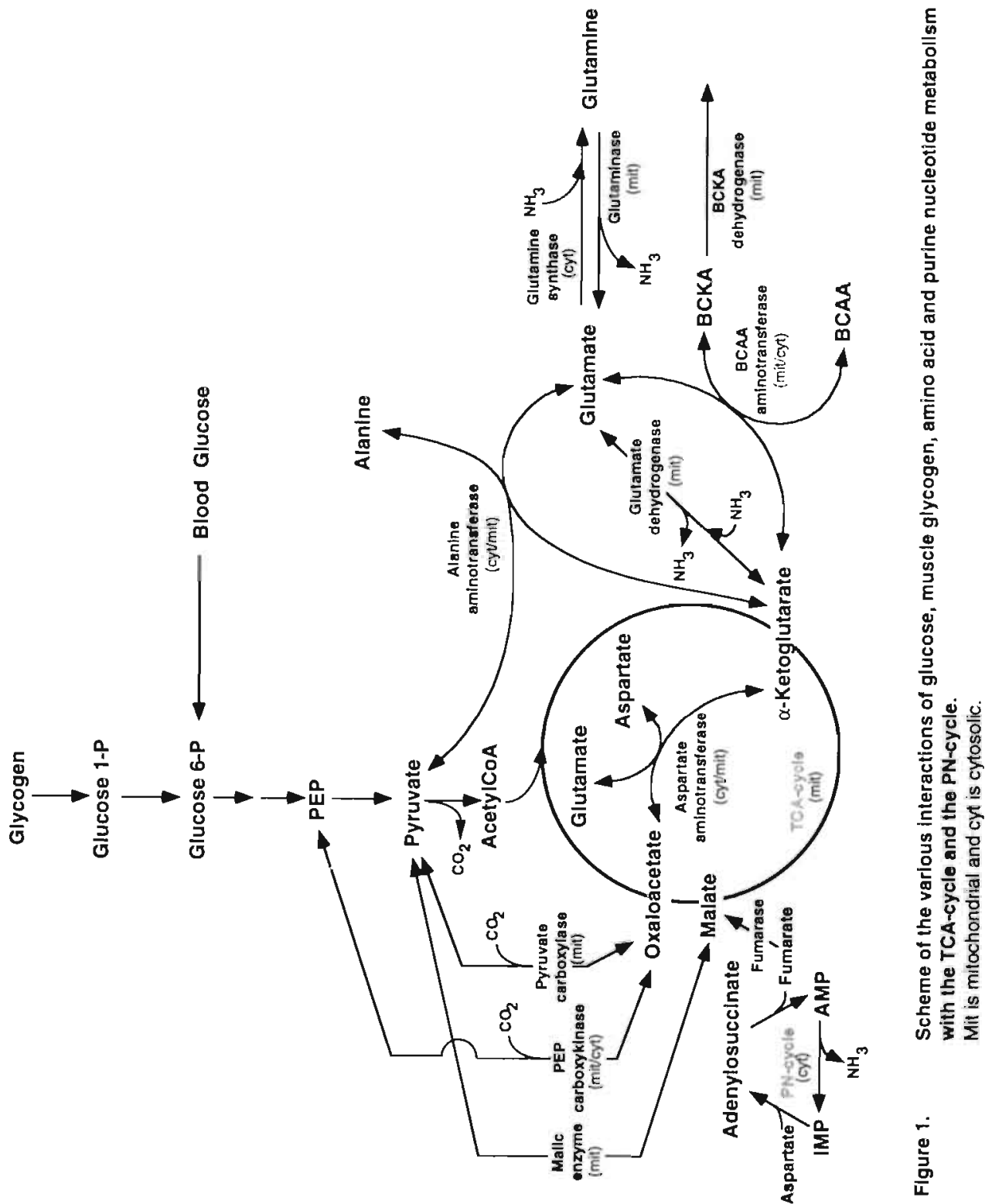


The glucose-alanine cycle has been suggested to be an important mechanism when glycogen stores become low during prolonged exercise to provide and maintain blood glucose (Felig, Pozefsky, Marliss \& Cahill, 1970). From this study it is clear that alanine production only occurs at a high rate at the initial stages of the exercise period (chapter 2) and is most likely a result from a shift in the equilibrium of the alanine aminotransferase reaction to alanine formation due to the high pyruvate formation present at the beginning of exercise. This shift, as indicated in the section about the interaction of amino acids and the TCA-cycle (see below), may function to lead to an acute increase in the concentration of TCAI when going from rest to exercise. During the latter period of prolonged one leg knee-extensor exercise no significant alanine release is observed anymore in the leg with the normal glycogen content at the start of exercise. It, therefore, appears that the glucose-alanine cycle is not an important mechanism of glucose provision during prolonged exercise as originally suggested, but that alanine production is merely caused by a functional shift of the alanine aminotransferase equilibrium towards alanine and TCAI formation. Only in the low glycogen leg substantial amounts of alanine and glutamine are released apparently in increasing amounts with exercise duration. Alanine and glutamine in that case may be used for gluconeogenesis according to the original concept of the glucose-alanine cycle, but are primarily derived from the net increase in protein degradation (chapter 8). Recent studies have been suggesting that glutamine in man is more important than alanine for transport of protein derived carbon from muscle to liver and kidney for gluconeogenesis (Nurjhan, Bucci, Perriello, Stumvoll, Dailey, Bier, Toft, Jenssen, \& Gerich, 1995; Perriello, Jorde, Nurjhan, Stumvoll, Dailey, Jenssen, Bier \& Gerich, 1995).

\subsection{Interaction of amino acids and the TCA-cycle}

The concentration TCAl in skeletal muscle has been shown to increase several fold rapidly after the start of exercise or electrical stimulation (Aragón \& Lowenstein, 1980; Essen \& Kaijser, 1978; Sahlin, Katz \& Broberg, 1990). This increase in TCAI has been suggested to be important for an optimal aerobic energy production to meet the increased energy demand for contraction (Lee \& Davis, 1979). The increased level of TCAI is maintained when exercise is continued in rat muscle (Aragón \& Lowenstein, 1980). However, Sahlin and colleagues (1990) observed a decrease in TCAI concentration in human subjects towards exhaustion of prolonged exercise. This may imply that glycogen depletion leads to a reduction of the rate of anaplerosis of the TCA-cyle (Sahlin et al, 1990) (Fig. 1). Wagenmakers, Coakley \& Edwards (1990) hypothesized that prolonged exercise may result in an increased drain on the TCA-cycle via the BCAA aminotransferase reaction. As the BCKADH was activated most in glycogen depleted muscles (Wagenmakers et al, 1990; Wagenmakers, Beckers, Brouns, Kuipers, Soeters, Van der Vusse et al, 1991; chapter 3) the suggestion was made that this drain was larger after glycogen depletion and resulted in the decrease in the concentration of TCAl observed by Sahlin et al (1990). 
Here we will reflect on the mechanisms in muscle that appear to lead to the early increase in the concentration of TCAI during exercise and on the mechanisms that may help to counteract the potential drain of the BCAA aminotransferase reaction during the late stages of prolonged exercise leading to glycogen depletion. Aragón \& Lowenstein (1980) proposed that PN-cycling is responsible for the increase in TCAI, as the net reactions of the PN-cycle is deamination of aspartate to fumarate (Fig. 1). In support of this proposal was the observation that electrical stimulation of rat muscle led to a parallel increase in the concentration of fumarate, malate and IMP. Fumarate and malate, therefore, were suggested to be generated via adenylosuccinase and fumarase. As enzymes of the PN-cycle are located in the cytosol entry of fumarate into the TCA-cycle would require its prior conversion into malate by fumarase followed by transport of malate into the mitochondria. Sahlin and coworkers (1990) on the other hand suggested that the alanine aminotransferase reaction (Fig. 1) might also be an important mechanism for de novo synthesis of TCAI. Bergström, Fürst \& Hultman (1985) had already described a $65 \%$ decrease in muscle glutamate and a $60 \%$ increase in muscle alanine after $10 \mathrm{~min}$ of exercise at $70 \% \mathrm{VO}_{2 \max }$, but did not speculate on the functionality behind these changes in muscle amino acid concentrations. Henriksson (1991) while interpreting Bergström's data and his own data on changes in muscle amino acid concentration during $3.5 \mathrm{~h}$ of exercise at $50 \% \mathrm{VO}_{2 \max }$ suggested that either the alanine aminotransferase or glutamate dehydrogenase reaction were responsible for the acute decrease in muscle glutamate and were used for de novo synthesis of TCAl. This thesis (chapter 2) provides evidence that it is not very likely that PN-cycling causes the initial increase in TCAl during moderate intensity exercise as we were unable to find a high ammonia production during the first $10-20 \mathrm{~min}$ of exercise. For the same reason glutamate dehydrogenase can be excluded as an anaplerotic reaction in that time period. The $60 \%$ decrease in muscle glutamate during the first $10 \mathrm{~min}$ of exercise (chapter 2; Bergström et al, 1985) by far exceeds the rate of ammonia production. Therefore, the alanine aminotransferase reaction appears to be the more likely candidate for de novo synthesis of TCAI and for the disappearance of glutamate. The parallel increase in muscle alanine (Bergström et al, 1985; Sahlin et al, 1990; Henriksson, 1991; chapter 2) and the high rate of alanine release from muscle during the first $30 \mathrm{~min}$ of exercise (chapter 2) support the notion that the alanine aminotransferase reaction is actively producing $\alpha$-ketoglutarate and TCAI during the first 10 min of exercise. The alanine aminotransferase reaction is a near equilibrium reaction. This implies that the formation of alanine by muscle tissue can be accounted for by spontaneous processes depending on the presence of alanine aminotransferase and the concentration of the metabolites glutamate, pyruvate, alanine and $\alpha$-ketoglutarate (Krebs, 1975). At the start of exercise the rate of glycolysis and thus of pyruvate formation is high, as indicated by an increase in muscle pyruvate concentration (Dohm, Patel \& Kasperek, 1986; Sahlin et al, 1990; Spencer, Yan, Katz, 1992) and an increased release of pyruvate and lactate from muscle (chapter 4 ). The tendency to re-establish equilibrium then automatically will lead to production of alanine and $\alpha$-ketoglutarate by the alanine aminotransferase reaction. Felig \& Wahren (1970) already had shown that the rate of release of 
alanine from muscle depended on the rate of formation of pyruvate from glycolysis, but overlooked that the main function of the alanine aminotransferase reaction could be de novo synthesis of $\alpha$-ketoglutarate and TCAl. The augmented glycolysis induced by exercise thus appears to serve a dual function. More pyruvate is generated to serve 1 . as a substrate for pyruvate dehydrogenase and subsequent oxidation and 2. to force the alanine aminotransferase reaction towards production of $\alpha$-ketoglutarate and TCAI and thus increase the TCA-cyle activity in proportion to the required energy demand. Eriksson, Broberg, Björkman \& Wahren (1985) showed that the alanine production in human skeletal muscle is proportional to the work intensity. This suggests that more pyruvate is produced by glycolysis at higher intensities in order to further shift alanine aminotransferase in the direction of $\alpha$ ketoglutarate and to match the required increase in energy demand with an increase in TCA-cyce activity.

This thesis also presents evidence suggesting that the drain on the TCA-cycle via the BCAA aminotransferase reaction (Wagenmakers et al, 1990) may increase with exercise duration and be higher when exercise is performed with a low muscle glycogen content. Muscle BCAA uptake from the blood increased with exercise duration (chapter 2) and the percentage active branched-chain $\alpha$-keto acid dehydrogenase (BCKADH), the rate limiting enzyme in BCAA degradation, was increased by exercise both in the muscle with a normal and low glycogen content (chapter 3). The BCKADH was activated more in the muscle with the low glycogen content (Chapter 3). Furthermore, net muscle protein degradation appeared to be higher during exercise of the muscle with the low glycogen content (chapter 8 ) and thus again appears to provide more BCAA for oxidation.

During prolonged exercise mechanisms most likely also will exist that may counteract the supposed carbon drain of the BCAA aminotransferase reaction on the TCA-cycle as otherwise TCAI would very rapidly be lost from muscle. The alanine aminotransferase reaction may be important to replenish TCAl as long as muscle glycogen concentrations are high enough. The rate of glycolysis and thus pyruvate formation will decrease when glycogen stores are lowered after prolonged exercise (chapter 4.) Furthermore, the muscle glutamate concentration is low (chapter 2) implying that a new equilibrium of the alanine aminotransferase has to be established causing a considerable decrease in the formation of alanine and $\alpha$-ketoglutarate. This is supported by the observation that no alanine is released from muscle anymore after 90 min of exercise in the leg with the normal glycogen content. The alanine released from muscle during exercise of the leg with the low glycogen content most likely is derived from the higher rate of muscle protein breakdown in the low glycogen content leg (chapter 2 and 8 ). Other reactions that may provide TCAI are the $\mathrm{PN}$-cycle, glutamate dehydrogenase, pyruvate carboxylase, phosphoenolpyruvate carboxykinase and malic enzyme (Fig. 1). The low muscle glycogen content and low pyruvate formation towards exhaustion also will limit the possible contribution of pyruvate carboxylase, phosphoenolpyruvate carboxykinase and the malic enzyme as all these reactions depend on high pyruvate concentrations. Therefore, glutamate dehydrogenase and $\mathrm{PN}$-cycle are the most likely candidates for TCAI formation during prolonged exercise leading to glycogen 
depletion. Increased protein degradation rates and uptake of BCAA and glutamate may, thereby, provide amino acids (BCAA, glutamate, aspartate, asparagine) for synthesis of the required substrates, glutamate and aspartate, via aminotransferase and TCA-cycle reactions. Therefore, the functionality of increased deamination of amino acids may be that it provides an alternative anaplerotic mechanism for synthesis of TCAl in conditions when glycogen stores become depleted. In agreement with this hypothesis also is the massive ammonia production in patients with McArdle's disease (Wagenmakers et al, 1990).

\subsection{Directions for future research}

This thesis shows that ammonia produced during prolonged exercise has to be derived from net deamination of amino acids. However, it would be very important to know which enzymatic reaction(s) is responsible for the ammonia production. Additional information is needed concerning the enzyme activities in muscle of the most important reactions such as the activity and metabolic regulation of enzymes of the PN-cycle, glutamate dehydrogenase, glutaminase, alanine- and aspartate aminotransferase. However, the activities of these enzymes most times are measured in vitro and as such these measurements provide limited information about in vivo fluxes. Therefore, a better approach appears to be the in vivo use of $15 \mathrm{~N}$-labeled amino acids and measurements in time of the appearance of the ${ }^{15} \mathrm{~N}$ label in ammonia, ATP and in other amino acids. This may help to gain decisive information about the reactions involved in ammonia production during prolonged exercise and their activities in vivo.

A fascinating part of research that has to be done is on the regulation of the carbon flux through the TCA-cycle and the source of that carbon. The TCA-cycle plays an important role in the tremendous increase in energy production to meet the energy demands of exercise. The TCA-cycle is able to generate that energy but the exact mechanism which leads to increased spinning is not known. Critical measurements will be the concentration in muscle of $\alpha$-ketoglutarate and oxaloacetate, as they are regarded as the intermediates determining the rate of carbon flux through the TCA-cycle. However, solid measurements are not easy as they are present in very low concentrations in muscle. However, even when we are able to measure these intermediates it would give us only information of a momentum of this very dynamic process. Measuring TCA-cycle flux rates in skeletal muscle with carbon tracers, therefore, is going to be a very important issue for a complete understanding of the regulation of TCA-cycle flux.

Glutamine has several metabolic key functions (chapter 6) and is considered as a conditional essential amino acid (Lacey \& Wilmore, 1990) which should be added to the nutrition of patients with trauma and sepsis and with a reduced endogenous capacity to synthesize glutamine. Skeletal muscle plays a key role in whole body glutamine metabolism since it contains the main pool of free glutamine and is the main tissue of glutamine production. Two main processes appear to contribute to glutamine production in skeletal muscle. One is the synthesis from protein and blood 
(glutamate and BCAA) derived amino acids and the other is synthesis from blood glucose and muscle glycogen via pyruvate, TCA-cycle and glutamate into glutamine (Krebs, 1975). The capacity of both of these processes depends on the size of the skeletal muscle compartment. Process number 2 involves many mitochondrial reactions. The possibility should, therefore, be considered that invalidity diseases and the aging process which are known to lead to muscle wasting and a decrease of the mitochondrial content lead to a decreased endogenous production of glutamine. Such a decrease in glutamine production could have health consequences when not enough glutamine would be available to provide optimal in vivo support to the immune system and the gut (chapter 6 ). Future research, therefore, should focus on the relation between muscle size and mitochondrial content and whole body glutamine production rates and should aim to investigate whether potential functional consequences occur in vivo when glutamine production rates fall below a certain initial level. Regular physical exercise by this mechanism in fact may be the most important means to maintain endogenous glutamine production and optimal health. Addition of glutamine to the nutrition may also be considered in those conditions where physical exercise is not possible.

\subsection{Main conclusions}

- During prolonged moderate intensity exercise ammonia is mainly derived from deamination of amino acids and not from the net breakdown of ATP to IMP.

- The alanine aminotransferase reaction functions to provide TCAI especially during the first 10 minutes of prolonged exercise.

- A low muscle glycogen content increases the exercise induced activation of the BCKADH.

- Oral ingestion of BCAA activates the BCKADH at rest and during exercise and the activation of the BCKADH caused by exercise and BCAA ingestion are additive.

- Ammonia and adrenaline do not seem to be implicated in the regulation of the rate of glycogen breakdown during prolonged moderate intensity exercise.

- The muscle glycogen content is a main regulator of the rate of glycogen breakdown during prolonged exercise.

- Lowered muscle glycogen stores and reduced carbohydrate availability during prolonged exercise in healthy trained subjects do not influence ammonia production. 
- Lowered muscle glycogen stores tend to increase muscle amino acid release, most likely due to a higher net protein degradation rate (protein degradationprotein synthesis).

- Oral ingestion of BCAA and tryptophan does not affect endurance performance.

- Glucose ingestion does not prevent the decrease in plasma glutamine during recovery from intense prolonged exercise.

- Glutamine ingestion does not affect the rate of glycogen resynthesis in vivo during recovery from intense exercise nor affect glycogen synthase activity when an adequate amount of carbohydrates is available.

- Ingestion of protein hydrolysates prevents the plasma glutamine decrease during recovery from intense exercise.

- Ingestion of protein hydrolysates tends to increase the rate of glycogen synthesis during recovery.

- The glucose-alanine cycle is not as important as a mechanism to maintain blood glucose during exercise as previously suggested

\section{References}

Aragón, J.J. \& Lowenstein, J.M. (1980). The purine nucleotide cycle. Comparison of the levels of citric acid cycle intermediates with the operation of the purine nucleotide cycle in rat skeletal muscle during exercise and recovery from exercise. European Journal of Biochemistry 110: 371-377.

Bergström, J., Fürst, P. \& Hultman, E. (1985). Free amino acids in muscle tissue and plasma during exercise in man. Clinical Physiology 5: 155-160.

Broberg, S. \& Sahlin, K. (1989). Adenine nucleotide degradation in human skeletal muscle during prolonged exercise. Journal of Applied Physiology 67: 116-122.

Carraro, F., Stuart, C.A., Hartl, W.H., Rosenblatt, J. \& Wolfe, R.R. (1990). Effect of exercise and recovery on muscle protein synthesis in human subjects. American Journal of Applied Physiology 259: E470-E476.

Dohm, G.L., Patel, V. \& Kasperek, G.J. (1986). Regulation of muscle pyruvate metabolism during exercise. Biochemical Medicine and Metabolic Biology 35: 260-266.

Dudley, G.A. \& Turjung, R.L. (1985). Influence of acidosis on AMP deaminase activity in contracting fast-twitch muscle. American Journal of Physiology 248: C43-C50.

Eriksson, L.S., Broberg, S., Björkman, O. \& Wahren, J. (1985). Ammonia metabolism during exercise in man. Clinical Physiology 5: 325-336.

Essen, B. \& Kaijser, L. (1978). Regulation of glycolysis in intermittent exercise in man. Journal of Physiology 281: 499-511.

Felig, P., Pozefsky, T., Marliss, E. \& Cahill, G.F. (1970). Alanine: key role in gluconeogenesis. Science 167:1003-1004.

Goodman, T.E. \& Lowenstein, J.M. (1977). The purine nucleotide cycle. Studies of ammonia production by skeletal muscle in situ and in perfused preparations. Journal of Biological Chemistry 252: 5054-5060. 
Henriksson, J. (1991). Effect of exercise on amino acid concentrations in skeletal muscle and plasma. Journal of Experimental Biology 160: 149-165.

Krebs, H.A. (1975). The role of chemical equilibria in organ function. Advances in Enzyme Regulation 15: $449-472$.

Lacey, J.M. \& Wilmore, D.W. (1990). Is glutamine a conditionally essential amino acid? Nutritional Reviews 48: 297-309.

Lee, S.-H. \& Davis, E.J. (1979). Carboxylation and decarboxylation reactions. Anaplerotic flux and removal of citrate cycle intermediates in skeletal muscle. Journal of Biological Chemistry 254: 420430.

Meyer, R.A. \& Terjung, R.L. (1980). AMP deamination and IMP reamination in working muscle. American Journal of Physiology 239: C32-C38.

Nurjhan, N., Bucci, A., Perriello, G., Stumvoll, M., Dailey, G., Bier, D.M., Toft, I., Jenssen, T.G. \& Gerich, J.E. (1995). Glutamine: A major gluconeogenic precursor and vehicle for interorgan carbon transport in man. Journal of Clinical Investigation 95: 272-277.

Perriello, G., Jorde, R., Nurjhan, N., Stumvoll, M., Dailey, G., Jenssen, T., Bier, D.M. \& Gerich, J.E. (1995). Estimation of glucose-alanine-lactate-glutamine cycles in postabsorptive humans: role of skeletal muscle. American Journal of Physiology 269: E443-E450.

Rundell, K.W., Tullson, P.C. \& Terjung, R.L. (1992). AMP deaminase binding in contracting rat skeletal muscle. American Journal of Physiology 263: C287-C293.

Sahlin, K., Katz, A. \& Broberg, S. (1990). Tricarboxylic acid cycle intermediates in human muscle during prolonged exercise. American Journal of Physiology 259: C834-C841.

Schulz, V. \& Lowenstein, J.M. (1976). Purine nuclotide cycle - evidence for the occurrence of the cycle in brain. Journal of Biological Chemistry 251: 485-492.

Sener, A. \& Malaisse, W.J. (1980). L-Leucine and nonmetablized analogue activate pancreatic islet glutamate dehydrogenase. Nature 288: 187-189.

Spencer, M.K., Yan, Z. \& Katz, A. (1992). Effect of glycogen on carbohydrate and energy metabolism in human muscle during exercise. American Journal of Physiology 262: C975-C979.

Tullson, P.C., Bangsbo, J., Hellsten, Y. \& Richter, E.A. (1995). IMP metabolism in human skeletal muscle after exhaustive exercise. Journal of Applied Physiology 78: 146-152.

Tullson, P.C., Arabadjis, P.G., Rundell, K.W. \& Terjung, T.L. (1996). IMP reamination to AMP in rat skeletal muscle fiber types. American Journal of Physiology 270: C1067-C1074.

Wagenmakers, A.J.M., Coakley, J.H. \& Edwards, R.H.T. (1990). Metabolism of branched-chain amino acids and ammonia during exercise: clues from McArdle's disease. International Joumal of Sports Medicine 11: S101-S113.

Wagenmakers, A.J.M., Beckers, E.J., Brouns, F., Kuipers, H., Soeters, P.B., Van der Vusse, G.J. \& Saris, W.H.M. (1991). Carbohydrate supplementation, glycogen depletion, and amino acid metabolism during exercise. American Journal of Physiology 260: E883-E890.

Wibom, R. \& Hultman, E. (1990). ATP production rate in mitochondria isolated from microsamples of human muscle. Americian Journal of Physiology 259: E204-E209. 


\section{SUMMARY}

It is generally accepted that amino acids are not very important as a fuel during exercise. However, they deserve attention as they might have an important regulatory role in skeletal muscle metabolism both at rest and during exercise. Therefore, in this thesis amino acid metabolism in general and its regulatory roles in muscle and whole body metabolism have been studied during prolonged exercise in man.

Ammonia is continuously released from the active muscle during exercise. The ammonia can either originate from net adenine nucleotide breakdown to IMP, as during very high intensity exercise, or from net deamination of amino acids. In chapter 2 it was clearly shown that during prolonged one leg knee-extensor exercise ammonia production exceeded by far the breakdown of adenine nucleotides to IMP. This implies that during this type of exercise ammonia has to be derived from net deamination of amino acids. A low pre-exercise muscle glycogen content had no effect on ammonia production nor on plasma and muscle amino acids as suggested in previous studies during two legged exercise first with a normal and then with a reduced muscle glycogen content. Further research is needed to identify the reaction(s) responsible for ammonia production and deamination of amino acids. The TCA-cycle plays an important role in the tremendous increase in energy production to meet the energy demands of exercise. It is suggested that an increase in the carbon flux through the TCA-cycle is important to increase ATP production going from rest to exercise. This increase can mechanistically be achieved by an increase in de activity of $\alpha$-ketoglutarate dehydrogenase regulation or an increase in the concentration of the TCA-cycle intermediates A large glutamate consumption and alanine production was observed during the early phase of exercise indicating that the alanine aminotransferase reaction was very active. This reaction leads to the formation of $\alpha$-ketoglutarate, a TCA-cycle intermediate. It is concluded that this reaction is very important for the acute increase in TCA-cycle intermediates going from rest to exercise.

The branched-chain amino acids (BCAA) - leucine, valine and isoleucine - are three of the nine essential amino acids in mammals and primarily degraded in skeletal muscle. Exercise increases the branched-chain $\alpha$-keto acid dehydrogenase (BCKADH) activity. This enzyme catalyses the rate limiting step in BCAA degradation. An increase in BCAA degradation during exercise has been suggested to play a role in mechanisms of muscle fatigue. We, therefore, studied the activity of this enzyme during exercise with a normal and low muscle glycogen content and BCAA supplementation (chapter 3 ). At rest muscle glycogen content did not affect BCKADH activity but BCAA ingestion, causing an increased muscle BCAA uptake and intra-muscular concentration, resulted in a 3-fold increase in BCKADH activity. Prolonged exercise with a low pre-exercise muscle glycogen content increased the exercise induced activation of BCKADH, whereas BCKADH activity was higher with $B C A A$ ingestion. However, BCAA ingestion appeared not to augment the exercise 
induced BCKADH activation. Therefore, it is concluded that the mechanism of activation caused by low pre-exercise muscle glycogen content and BCAA ingestion is different. An increase in the concentration of muscle free ADP and branched-chain $\alpha$-keto acids appear to be the most important mechanism of BCKADH activation.

The two most important enzymes determining the rate of glycogenolysis are glycogen phosphorylase and phosphofructokinase. Glycogen phosphorylase activity depends on the concentration of muscle AMP, IMP, $\mathrm{P}_{\mathrm{i}}$ and glycogen. Whereas phosphofructokinase activity is thought to be influenced by the muscle energy charge, and the concentrations of AMP, fructose-biphosphate, adrenaline, ammonia and $\mathrm{pH}$. Most of our knowledge on these factors originate from studies using high intensity exercise. In chapter $\mathbf{4}$ we investigated whether some of these factors are also involved in the regulation of glycogen breakdown during prolonged moderate intensity one legged exercise. In contrast to observation made during high intensity exercise adrenaline and ammonia do not appear to be involved in the regulation of the rate of glycogen breakdown during prolonged moderate intensity exercise. Muscle glycogen, as a substrate enhanced its own utilization, and muscle $P_{i}$ appeared to play a role in the control of the rate of muscle glycogen breakdown both at high and moderate exercise intensity.

Prolonged exercise inevitably leads to fatigue. Traditionally fatigue mechanisms have focused on events in skeletal muscle. However, more recently it is suggested that fatigue during prolonged exercise may be caused by increased serotoninergic activity in the brain, referred to as central fatigue. An increased oxidation of BCAA and displacement of tryptophan from albumin during prolonged exercise leads to an increased tryptophan/BCAA ratio. This increased ratio would lead to an enhanced transport of tryptophan across the blood-brain barrier, since tryptophan and BCAA compete for entry to the brain by the same amino acid transporter. An increased tryptophan concentration in the brain would lead to an increase in the neurotransmitter serotonin. According to this hypothesis BCAA ingestion during prolonged exercise may delay central fatigue and tryptophan ingestion would lead to premature central fatigue. In chapter 5 we clearly showed that BCAA nor tryptophan ingestion, which would lead to early central fatigue according to the hypothesis, had an effect on the time to exhaustion during sustained high intensity exercise. Furthermore, estimation of the rate of tryptophan uptake to the brain showed that BCAA ingestion had only a marginal effect on the rate of tryptophan transport to the brain compared to the exercise induced changes in tryptophan concentration. From these results we conclude that manipulation of tryptophan supply to the brain either has no additional effect upon serotoninergic activity during prolonged exhaustive exercise or that manipulation of serotoninergic activity functionally does not contribute to mechanisms of fatigue.

Glutamine is produced in skeletal muscle in considerable amounts at rest and during exercise. The biochemical pathways that contribute to glutamine production are only partly known. Sir Hans Krebs suggested that muscle glycogen and glucose are carbon-chain precursors for glutamine production. We, therefore, investigated whether carbohydrate supplementation during intense exercise leading to glycogen depletion influences plasma glutamine concentration. The data of chapter 6 showed 
that carbohydrate ingestion had neither an effect on the plasma glutamine concentration nor on the plasma concentration of other amino acids. After 2 to 3 hours of recovery the plasma glutamine concentration decreased with $22 \%$ compared to the concentration at the moment of fatigue. Glutamine is an important fuel for cells of the immune system and the gut mucosa. Such decrease in plasma glutamine, therefore, could potentially impair immune function. A decrease of $10-25 \%$ is also observed for most of the other amino acids. The reason for this decrease is not clear but might be a result of an increased protein synthesis or an increase in amino acid clearance by other organs such as the gut and liver. Carbohydrate ingestion during exercise did not prevent the fall in the plasma concentration of glutamine and the other amino acids during recovery and, therefore, is not a useful tool to maintain the plasma glutamine and other amino acid concentration.

The maintenance of a post-exercise glutamine concentration might also be important for an optimal glycogen resynthesis rate, as it has been suggested that glutamine stimulates glycogen resynthesis potentially via activation of glycogen phosphorylase. However, in chapter 7 we clearly showed that glutamine ingestion, causing a 2-fold increase of the plasma glutamine concentration, did not affect the rate of muscle glycogen resynthesis nor glycogen synthase activity during recovery from exercise leading to glycogen depletion when ample carbohydrates were available. On the other hand glycogen resynthesis rates tended to be higher after ingestion of a mixture of carbohydrates and protein hydrolysate. This increase was probably mediated by an increased plasma insulin concentration.

In chapter 8 we estimated net muscle protein degradation during prolonged one leg knee-extensor exercise with the arterio-venous amino acid balance method at rest and during exercise with a normal and low muscle glycogen content leg. The data indicated that prolonged one leg knee-extensor exercise lead to a massive increase in net muscle protein degradation and that a low pre-exercise muscle glycogen content leads to a further increase. The functionality of this protein breakdown might be provision of protein derived carbon for the synthesis of TCAcycle intermediates and glutamine and release of gluconeogenic precursor amino acids for kidney and liver. The results obtained in this study, however, cannot directly be extrapolated to whole body dynamic exercise as workload and oxygen consumption per $\mathrm{kg}$ of muscle is much higher during one leg knee-extensor exercise. 


\section{SAMENVATIING}

Er wordt in het algemeen aangenomen dat aminozuren geen belangrijke bijdrage leveren aan de energiebehoefte van de actieve spier tijdens inspanning. De aminozuren verdienen echter onze aandacht omdat ze mogelijk een belangrijke rol spelen in de regulatie van spiermetabolisme zowel in rust als tijdens inspanning. In dit proefschrift wordt dan ook gekeken naar het aminozuurmetabolisme in het algemeen en naar de rol die aminozuren spelen in de regulatie van spier- en heel lichaamsmetabolisme tijdens duurinspanning in de mens.

Ammoniak wordt voortdurend vrijgemaakt door de actieve spier tijdens inspanning. De ammoniak kan afkomstig zijn van de netto afbraak van adenine nucleotiden tot IMP. Dit is het geval tijdens inspanning van zeer hoge intensiteit. Daarnaast kan ammoniak ook afkomstig zijn van netto deaminering van aminozuren. In hoofdstuk 2 is gevonden dat de ammoniakproduktie tijdens eenbeens duurinspanning vele malen hoger is dan de adenine nucleotide afbraak tot IMP. Dit betekent dat tijdens deze vorm van duurinspanning, waarbij met het onderbeen een schoppende voorwaartse beweging wordt gemaakt en voornamelijk de $\mathrm{m}$. quadriceps wordt gebruikt, netto deaminering van aminozuren de belangrijkste bron van ammoniakproduktie moet zijn. De reacties die betrokken zijn bij deaminering van aminozuren tijdens duurinspanning zijn nog niet geïdentificeerd. Een lage spierglycogeenconcentratie voor het begin van de inspanning beïnvloedde de ammoniakproduktie niet, dit in tegenstelling tot eerdere suggesties gedaan in de literatuur. Spiercontractie leidt tot een sterk verhoogde energiebehoefte van de spiercel. Dit impliceert dat gaande van rust naar inspanning de energiegeneratie via de citroenzuurcyclus sterk moet toenemen. Een toename van de koolstof-flux in de citroenzuurcyclus is nodig om de ATP produktie te doen toenemen. Deze toename wordt mechanistisch bereikt oa door een toename van de activitiet van $\alpha$ ketoglutaraat dehydrogenase via allosterische regulatie. Een andere mogelijkheid is een toename van de substraatconcentratie ( $d w z$ de concentratie van de citroenzuurcyclus-intermediairen. Aan het begin van de inspanningsperiode werd een aanzienlijke glutamaatconsumptie en alanineproduktie waargenomen hetgeen duidt op een zeer actieve alanine aminotransferase reactie. Deze reactie leidt tot de formatie van $\alpha$-ketoglutarate, een citroenzuurcyclus-intermediair. Geconcludeerd wordt dat de alanine aminotransferase reactie van groot belang is voor een acute toename van citroenzuurcyclus-intermediairen concentratie.

De vertakte keten aminozuren (BCAA) - leucine, valine en isoleucine - zijn drie van de negen essentiële aminozuren in zoogdieren en worden voornamelijk afgebroken in de skeletspier. Inspanning verhoogt de activiteit van het vertakte keten $\alpha$-ketozuur dehydrogenase (BCKADH), het enzym dat de snelheidsbepalende stap katalyseert in de afbraak van de BCAA. Er is gesuggereerd dat de toename in de BCAA afbraak tijdens inspanning een rol speelt in mechanismen van spiervermoeidheid. Vandaar dat we de activiteit van het BCKADH hebben bestudeerd in rust en tijdens inspanning met een normale en een lage 
spierglycogeenconcentratie en orale BCAA inneming (hoofdstuk 3 ). De spierglycogeenconcentratie had geen invloed op de BCKADH activiteit in rust maar $B C A A$ inneming resulteerde in een drievoudige toename van de BCKADH activiteit. Een verlaagde spierglycogeenconcentratie tijdens duurinspanning leidde tot een verhoging van de door inspanning veroorzaakte toename in de BCKADH activiteit. $B C A A$ inneming lijkt niet te leiden tot een verhoging van de door inspanning geïnduceerde toename in de BCKADH activiteit. De effecten van inspanning en BCAA inneming waren additief. Vandaar dat we kunnen concluderen dat het mechanisme van activatie veroorzaakt door de spierglycogeenconcentratie en BCAA inneming waarschijnlijk verschillend is. Een toename van de mitochondriale vrije ADP of vertakte keten $\alpha$-ketozuur concentratie wordt als het meest waarschijnlijke activeringsmechanisme beschouwd.

De twee belangrijkste enzymen die betrokken zijn bij de regulatie van de afbraaksnelheid van spierglycogeen zijn glycogeenfosforylase en fosfofructokinase. Glycogeenfosforylase activiteit wordt ondermeer gereguleerd door de spierconcentratie van AMP, IMP, anorganisch fosfaat en glycogeen. De regulatie van fosfofructokinase is complex en lijkt te worden beïnvloed door de energy charge van de spiercel en de concentratie van AMP, fructose-bifosfaat, ammoniak, adrenaline en de zuurgraad in de spiercel. Onze kennis van deze factoren, betrokken bij de regulatie van de afbraaksnelheid van spierglycogeen, is voornamelijk gebaseerd op waarnemingen gedaan tijdens onderzoek met inspanning van hoge intensiteit. In hoofdstuk 4 onderzoeken we of dezelfde factoren ook betrokken zijn bij spierglycogeenafbraak tijdens duurinspanning van gemiddelde intensiteit. Adrenaline en ammoniak blijken niet betrokken te zijn bij de regulatie van de glycogeenafbraak tijdens eenbeensinspanning van gemiddelde intensiteit. Echter spierglycogeen, als substraat versnelt het eigen gebruik, en spier anorganisch fosfaat lijkt tijdens zowel hoog als gemiddelde inspanningsintensiteit een rol te spelen bij de regulatie van de afbraaksnelheid van spierglycogeen.

Duurinspanning leidt onvermijdelijk tot vermoeidheid. Traditioneel worden de mechanismen van spiervermoeidheid toegeschreven aan processen die zich afspelen in de skeletspier. Meer recent is echter gesuggereerd dat duurinspanning leidt tot een toename van de serotoninerge activiteit in de hersenen en dat dit leidt tot het ontstaan van centrale vermoeidheid. Een toename in de verbranding van de $B C A A$ en verdringing van tryptofaan van albumine ten gevolge van inspanning leidt tot een toename in de tryptofaan/BCAA ratio in het bloed. Het primaire mechanisme voor een toename van de serotoninerge activiteit is dat de vrije vetzuurconcentratie bij inspanning stijgt en tryptofaan verdringt van binding aan albumine. Dit leidt tot een stijging van de vrije tryptofaan concentratie tijdens inspanning. Daarnaast zou een toename in de verbranding van BCAA tot een daling van de BCAA concentratie leiden en de tryptofaan/BCAA ratio nog verder doen toenemen. Deze toename zou leiden tot een verhoogd vervoer van tryptofaan over de bloed-hersen barrière omdat tryptofaan en de BCAA in competitie zijn met elkaar om vervoerd te worden met dezelfde aminozuurtransporter. Verhoging van de tryptofaan concentratie in de hersenen zou leiden tot een toename in de concentratie van de neurotransmitter serotonine. Volgens deze hypothese zal BCAA inneming tijdens duurinspanning 
leiden tot een vertraging van de centrale vermoeidheid en tryptofaan inneming tot een versnelde centrale vermoeidheid. In hoofdstuk 5 hebben we duidelijk aangetoond dat tijdens zware duurinspanning BCAA noch tryptofaan inneming enig effect hebben op de tijd tot uitputting. Uit de berekende snelheid van tryptofaan vervoer over de bloed-hersen barrière blijkt dat BCAA inneming slechts een geringe invloed heeft op de tryptofaan opname door de hersenen vergeleken bij de inspanning gerelateerde verhoging van de tryptofaan concentratie. Deze resultaten leiden tot de conclusies dat ingestie van BCAA of tryptofaan geen extra effect heeft op de serotoninerge activiteit tijdens duurinspanning of dat de manipulatie van de serotoninerge activiteit niet bijdraagt tot de mechanismen van vermoeidheid.

De skeletspier produceert glutamine in aanzienlijke hoeveelheden in rust en tijdens inspanning. De biochemische routes die een bijdrage leveren tot de glutamine productie zijn slechts ten dele bekend. Sir Hans Krebs suggereerde dat spierglycogeen en glucose koolstofvoorlopers zijn van glutamine. Daarom hebben we onderzocht of koolhydraat inneming tijdens zware inspanning, leidend tot glycogeen lediging, de plasma glutamine concentratie beïnvloedt. De resultaten uit hoofdstuk 6 laten zien dat koolhydraat inneming tijdens inspanning geen effect heeft op de plasma glutamine- en overige aminozuurconcentraties tijdens inspanning en herstel. Na 2 tot 3 uren van herstel daalde de glutamine concentratie met $22 \%$ ten opzichte van de concentratie op het moment van uitputting. Glutamine is een belangrijke brandstof voor cellen van het immuunsysteem en de mucosa van het maagdarmkanaal. Een dergelijke daling zou derhalve kunnen leiden tot een verlaagde immuunrespons. Een daling van $10-25 \%$ in de herstelfase werd ook waargenomen in de plasma concentratie van de meeste andere aminozuren. De reden voor deze daling is niet duidelijk maar het zou veroorzaakt kunnen worden door een tijdelijke toename van de spiereiwitsynthese. Een andere mogelijkheid is een toename in de opname van aminozuren door andere organen zoals de maag en de lever. Koolhydraat inneming tijdens inspanning kan echter de daling in de plasma concentratie van glutamine en de andere aminozuren tijdens de herstelfase niet voorkomen en is dus geen goed middel om de aminozuurconcentratie op peil te houden.

Het handhaven van de glutamine concentratie na inspanning kan ook van belang zijn voor een optimale glycogeenhersynthese omdat er suggesties zijn dat glutamine de glycogeenhersynthese stimuleert mogelijk via activatie van glycogeensynthase. In hoofdstuk 7 hebben we echter duidelijk aangetoond dat glutamine inneming niet leidt tot een toename in de snelheid van glycogeenhersynthese noch tot een hogere glycogeensynthase activiteit als er voldoende koolhydraten ter beschikking zijn. De snelheid van glycogeenhersynthese lijkt echter wel versneld te worden door inneming van een koolhydraten / eiwithydrolysaat mengsel. Deze versnelling wordt waarschijnlijk veroorzaakt door een toename in de plasma insuline concentratie.

In hoofdstuk 8 is de netto spiereiwitafbraak berekend met behulp van de zogenaamde arterio-veneuze aminozuur balans methode in rust en tijdens langdurige eenbeensinspanning met een normale en lage spierglycogeenconcentratie. De berekeningen duiden op een aanzienlijke toename van de netto spiereiwitafbraak. Een lage spierglycogeenconcentratie leidt tot een 
verdere toename van de netto spiereiwitafbraak. De functionaliteit van de toename in spiereiwitafbraak tijdens inspanning zou kunnen zijn het voorzien van koolstof afkomstig van eiwit voor de synthese van citroenzuurcyclus-intermediairen en glutamine in de spier en het vrijmaken van aminozuren voor glucoseproduktie in de lever en de nier. De berekende netto spiereiwitafbraak tijdens eenbeensinspanning geldt niet zondermeer voor inspanning in de praktijk, zoals fietsen en hardlopen, daar de belasting en het zuurstofverbruik per kilogram spier veel hoger is tijdens eenbeensinspanning. 


\section{Abbreviations}

\begin{tabular}{|c|c|}
\hline ADP & adenosine diphosphate \\
\hline Ala & alanine \\
\hline$\alpha-K G$ & $\alpha$-ketoglutarate \\
\hline AMP & adenosine monophosphate \\
\hline AMP-deaminase & adenosine monophosphate deaminase \\
\hline ANOVA & analysis of variance \\
\hline ATP & adenosine triphosphate \\
\hline$a-f v$ & arterio-femoral venous \\
\hline A-V difference & arterio-venous difference \\
\hline $\mathrm{BCAA}$ & branched-chain amino acids \\
\hline BCKA & branched-chain $\alpha$-keto acids \\
\hline BCFA & branched-chain fatty acids \\
\hline $\mathrm{BCKADH}$ & branched-chain $\alpha$-keto acid dehydrogenase \\
\hline $\mathrm{CO}_{2}$ & carbon dioxide \\
\hline $\mathrm{dm}$ & dry mass \\
\hline EMG & electromyogram \\
\hline FFA & free fatty acids \\
\hline GDP & guanosine diphosphate \\
\hline Gin & glutamine \\
\hline GS & glycogen synthase \\
\hline $\mathrm{GS}_{\text {tol }}$ & total glycogen synthase activity \\
\hline $\mathrm{GS}_{\mathrm{act}}$ & actual glycogen synthase activity \\
\hline Glu & glutamate \\
\hline h & hour \\
\hline $\mathrm{H}^{+}$ & hydrogen ion \\
\hline H-BCFA & hydroxylated branched-chain fatty acids \\
\hline $\mathrm{HCl}$ & hydrochloric acid \\
\hline HPLC & high performance liquid chromatography \\
\hline IMP & inosine monophosphate \\
\hline $\mathrm{K}^{+}$ & potassium ion \\
\hline $\mathrm{KHCO}_{3}$ & potassiumbicarbonate \\
\hline $\mathrm{K}_{\mathrm{m}}$ & Michaelis-Menten constant \\
\hline$K_{m, a p p}$ & apparent Michaelis-Menten constant \\
\hline $\min$ & minutes \\
\hline $\mathrm{NAD}^{+}$ & nicotinamide adenine dinucleotide (oxidized form) \\
\hline $\mathrm{NH}_{3}$ & ammonia \\
\hline $\mathrm{O}_{2}$ & oxygen \\
\hline $\mathrm{PC}$ & creatine phosphate \\
\hline PCA & perchloric acid \\
\hline PEP & phosphoenolpyruvate \\
\hline $\mathrm{pH}$ & concentration of hydrogen ions (acidity) \\
\hline$P_{i}$ & inorganic ortophosphate \\
\hline PN-cycle & purine nucleotide cycle \\
\hline $\mathrm{PO}_{2}$ & partial blood oxygen pressure \\
\hline Pyr & pyruvate \\
\hline s & seconds \\
\hline SD & standard deviation \\
\hline SEM & standard error of the mean \\
\hline
\end{tabular}


TCA-cycle

TCAI

tot AA

Trp

UDP

UDP-glucose

$\checkmark$

$\mathrm{V}_{\max }$

$\mathrm{VO}_{2 \text { max }}$

$W_{\max }$

ww

yr tricarboxylic acid cycle (Krebs cycle)

tricarboxylic acid cycle intermediates

total amino acids

tryptophan

uridine diphosphate

uridine diphosphate-glucose

velocity

maximal velocity

maximal oxygen uptake

peak mechanical power

wet weight

year 


\section{Dankwoord}

De aftiteling van een film en het dankwoord in een proefschrift geven beide duidelijk aan dat een mens zelden iets geheel alleen tot een goed einde kan brengen en dit geldt zeer zeker voor de experimenten beschreven in dit proefschrift. Een bijdrage in meer of mindere mate is geleverd door velen maar een aantal zou ik met name willen noemen. Allereerst Ton Wagenmakers die als enthousiaste en meelevende begeleider altijd een zeer stimulerende rol heeft vervult ook in tijden dat het wat moeilijker ging. Wim Saris die de mogelijkheden bood om al onze ideeën te kunnen toetsen. Bas Raaijmakers en Pedro van der Schoor die als stagiair een grote bijdrage aan twee studies hebben geleverd. Verder Joan Senden die niet alleen met mij koude tijden in Stockholm heeft doorstaan maar ook geweldig assisteerde bij de experimenten aldaar. Mijn kamergenoten Olav Rooyackers, Patrick Schrauwen en Annemie Gijsen voor de vele stimulerende discussies over het werk en héél soms over iets héél anders. Jos Stegen die klaarstond om een hand toe te steken bij mijn eerste schreden op het wetenschapspad. Hans van Eijck, Dennis Rooyakkers en Mick Deutz voor de aminozuur bepalingen, Will Coumans en Ger van der Vusse voor de glycogeen- en nucleotide-bepalingen. Verder alle mensen van de vakgroep Humane Biologie voor de geweldige werksfeer en het doorstaan van mijn humor. De experimenten in dit proefschrift konden uiteraard alleen worden uitgevoerd door de geweldige medewerking van de vele proefpersonen uit Nederland en Scandinavië.

I especially would like to thank Bengt Saltin who gave me the opportunity to perform the invasive human exercise studies and that I will be able to extend my knowledge at the Copenhagen Musle Research Centre for the next two years. Furthermore, I would like to thank all the people in Stockholm and Copenhagen that helped a tall stranger in the lab. I would like to mention on that point Karen, Dave, Gunilla and Linda in Stockholm and Karin, Charlotte and again Dave MacLean in Copenhagen.

Een wielercoach heeft eens gezegd dat het goed was voor de prestaties van een wielrenner als deze getrouwd is zodat hij zijn gedachten beter bij het fietsen kan houden. Welnu hij heeft daarbij voor de eenvoud, het was tenslotte een wielercoach, vergeten dat er nog enige tijdrovende bezigheden aan het trouwen voorafgaan. Maar al de gedachten en tijd besteed aan jou Jacqueline, in plaats van aan het proefschrift, zijn de beste geweest die ik mij kan voorstellen. Als laatste zou ik mijn ouders willen bedanken die al 32 jaar mijn steun en toeverlaat zijn. Jullie aanmoedigingen en ondersteuning tijdens al die jaren van studie hebben uiteindelijk geleid tot dit proefschrift. 


\section{Curriculum vitea}

Gerrit van Hall werd geboren op 3 maart 1964 te Doetinchem. In 1982 behaalde hij het HAVO diploma aan het Menso Alting College te Hoogeveen. $\mathrm{Na}$ anderhalf jaar studie elektrotechniek aan de HTS te Zwolle begon hij in 1984 aan de Hoge School Emmen met de hogere laboratorium opleiding (HLO, chemie). Tijdens deze studie heeft hij zich gespecialiseerd in de richting biochemie. Dit kwam tot stand dmv stages bij Dr Tal en Prof Karlish (Department of Biochemistry, The Weizmann Institute of Science te Rehovot, Isreal) en bij Prof de Pont (Vakgroep Biochemie, Katholieke Universiteit Nijmegen). $\mathrm{Na}$ in 1988 het ingenieurs diploma te hebben behaald begon hij aan de Rijksuniversiteit Groningen met de studie scheikunde met als hoofdvak biochemie. Tijdens zijn stage bij de Vakgroep Milieu Biotechnologie onder leiding van Dr van de Ploeg en Prof Janssen heeft hij onderzoek gedaan naar de genetische aanpassingen van bacteria aan gehalogeneerde koolwaterstoffen. In mei 1991 heeft hij deze studie met goed gevolg afgerond. Datzelfde najaar is hij begonnen als AIO aan de Rijksuniversiteit Limburg bij de Vakgroep Humane Biologie. Hij deed onderzoek naar aminozuur- en ammoniak-metabolisme tijdens duurinspanning bij de mens onder leiding van Dr Wagenmakers, Prof Saltin en Prof Saris. Een deel van zijn onderzoek heeft hij verricht aan het Karolinska Institute te Stockholm en aan het Copenhagen Muscle Research Centre te Kopenhagen. Hij is momenteel werkzaam als post-doc aan het Copenhagen Muscle Research Centre. 
